\title{
The antiphospholipid syndrome
}

Citation for published version (APA):

Chayoua, W. (2021). The antiphospholipid syndrome: The clinical importance of detecting antiphospholipid antibodies by immunoassays. [Doctoral Thesis, Maastricht University]. Maastricht University. https://doi.org/10.26481/dis.20210518wc

Document status and date:

Published: 01/01/2021

DOI:

10.26481/dis.20210518wc

Document Version:

Publisher's PDF, also known as Version of record

\section{Please check the document version of this publication:}

- A submitted manuscript is the version of the article upon submission and before peer-review. There can be important differences between the submitted version and the official published version of record.

People interested in the research are advised to contact the author for the final version of the publication, or visit the DOI to the publisher's website.

- The final author version and the galley proof are versions of the publication after peer review.

- The final published version features the final layout of the paper including the volume, issue and page numbers.

Link to publication

\footnotetext{
General rights rights.

- You may freely distribute the URL identifying the publication in the public portal. please follow below link for the End User Agreement:

www.umlib.nl/taverne-license

Take down policy

If you believe that this document breaches copyright please contact us at:

repository@maastrichtuniversity.nl

providing details and we will investigate your claim.
}

Copyright and moral rights for the publications made accessible in the public portal are retained by the authors and/or other copyright owners and it is a condition of accessing publications that users recognise and abide by the legal requirements associated with these

- Users may download and print one copy of any publication from the public portal for the purpose of private study or research.

- You may not further distribute the material or use it for any profit-making activity or commercial gain

If the publication is distributed under the terms of Article $25 \mathrm{fa}$ of the Dutch Copyright Act, indicated by the "Taverne" license above, 


\section{THE ANTIPHOSPHOLIPID SYNDROME}

The clinical importance of detecting antiphospholipid antibodies by immunoassays

Walid Chayouâ 


\section{COLOPHON}

Cover design: James Jardine | Jww.jamesjardine.nl

Layout:

James Jardine | www.jamesjardine.nl

Print:

Ridderprint | www.ridderprint.nl

ISBN:

978-94-93108-18-9

C Copyright 2021, Walid Chayouâ 


\section{The Antiphospholipid Syndrome \\ The clinical importance of detecting antiphospholipid antibodies by immunoassays}

\section{PROEFSCHRIFT}

Ter verkrijging van de graad van doctor aan de Universiteit Maastricht, op gezag van de Rector Magnificus, Prof. Dr. R.M. Letschert, volgens het besluit van het College van Decanen, in het openbaar te verdedigen op

dinsdag 18 mei 2021 om 10.00 uur

door

Walid Chayouâ

Geboren op 14 juli 1993 te Heerlen 


\section{Promotores}

Prof. Dr. H. ten Cate

Prof. Dr. K.M.J. Devreese (Universitair Ziekenhuis Gent, Gent, België)

\section{Copromotor}

Dr. B. de Laat

\section{Beoordelingscommissie}

Prof. Dr. Y.M.C. Henskens (voorzitter)

Prof. Dr. C.P.M. Reutelingsperger

Prof. Dr. E. Beckers

Prof. Dr. S. Zuily (University of Lorraine, Nancy, Frankrijk)

Dr. D. Erkan (Weill Cornell Medicine, New York, USA)

The research in this thesis was supported by an unrestricted grant from Synapse Research Institute. Additional support by a grant of CARIM is gratefully acknowledged (HS-BAFTA fellowship).

Financial support by Stichting Hart Onderzoek Nederland, an initiative of the Heart Research Institute (www.hartonderzoek.nl) is gratefully acknowledged.

Financial support by Stichting NVLE Fonds is gratefully acknowledged.

Financial support by Synapse Research Institute and Diagnostica Stago is gratefully acknowledged. 


voor papa \& mama 


\section{CONTENTS}

\section{Chapter 1}

General introduction and outline

\section{Chapter 2}

Detection of anti-cardiolipin and anti- $\beta 2$ glycoprotein I antibodies

differs between platforms without influence on association with clinical symptoms

\section{Chapter 3}

Identification of high thrombotic risk triple-positive antiphospholipid

syndrome patients is dependent on anti-cardiolipin and anti-

$\beta 2$ glycoprotein I antibody detection assays

\section{Chapter 4}

The (non-)sense of detecting anti-cardiolipin and anti- $\beta 2$ glycoprotein I

IgM antibodies in the antiphospholipid syndrome

\section{Chapter 5}

Is there an additional value in detecting anti-cardiolipin and

aß2glycoprotein I IgA antibodies in the antiphospholipid syndrome?

\section{Chapter 6}

The significance of antibodies against domain I of beta-2 glycoprotein I in antiphospholipid syndrome 


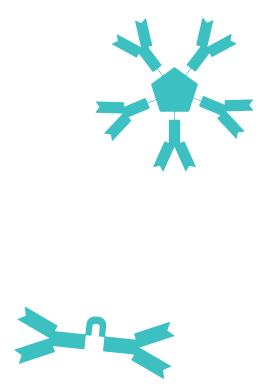

\section{Chapter 7}

Detection of anti-domain I antibodies by chemiluminescence enables

the identification of high-risk antiphospholipid syndrome patients: A

multicenter multiplatform study

\section{Chapter 8}

Antiprothrombin antibodies induce platelet activation: a possible

explanation for anti-FXa therapy failure in patients with antiphospholipid syndrome?

\section{Chapter 9}

General discussion, summary and future perspectives

\section{Appendices}

Nederlandse samenvatting

Impact

Dankwoord

Curriculum Vitae

Publications

List of abbreviations 

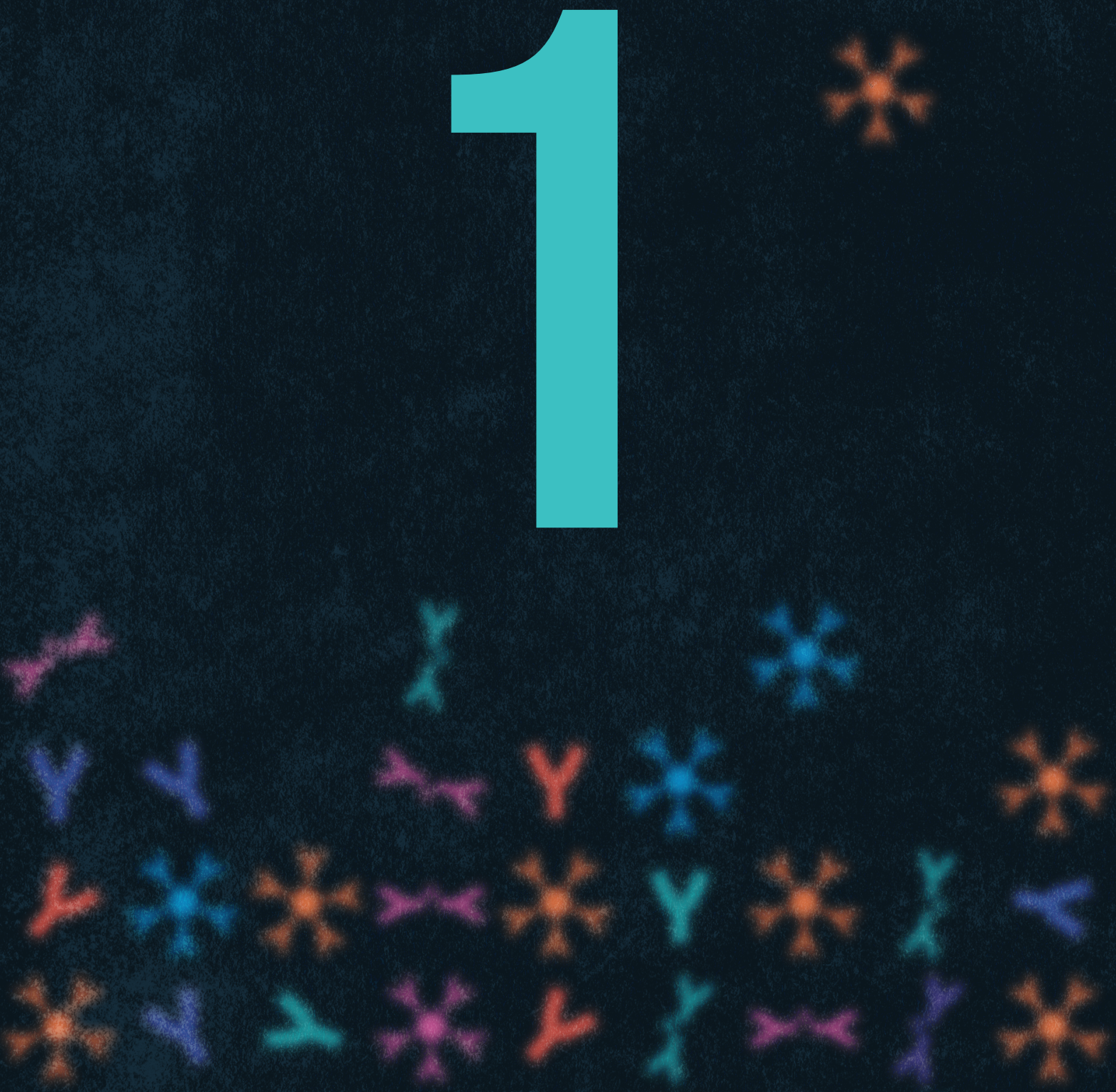


\section{General introduction and outline}





\section{INTRODUCTION}

\section{History of the antiphospholipid syndrome}

The antiphospholipid syndrome (APS) is an autoimmune disease characterized by the persistent presence of antiphospholipid ( $\mathrm{aPL}$ ) antibodies and thrombosis or pregnancy morbidity (1). The first classification criteria for definite APS were published in 1999 (2). However, the APS story started in 1906 with the development of a diagnostic test for syphilis (Figure 1) (3). The Wassermann (reagin) test is a serological assay based on complement fixation (3). The'Wassermann reagent' contained a liver extract of newborns who had died from congenital syphilis (3-5). In the following years, research showed that tissue extracts of animals never exposed to the causative organism of syphilis (Treponema pallidum), for example an ethanolic extract of beef heart could also be used $(4,5)$. In 1941 a breakthrough occurred as Pangborn identified the antigenic component of the reagin test extracted from beef heart, cardiolipin (6). This breakthrough resulted in the development and standardization of new tests, including the Venereal Disease Research Laboratory (VDRL) test $(4,5,7,8)$. The VDRL test was a screening tool for syphilis based upon microflocculation $(7,8)$. Heated serum is mixed with reagin containing cardiolipin, lecithin and cholesterol $(7,8)$. In case of positivity, flocculation or clumping can be observed using a microscope $(7,8)$. Population screening using the VDRL test showed a group of patients that were biologically false positive. The lack of specificity to the antigen was already seen with the Wassermann test, which was confirmed by the T. pallidum immobilization test $(4,5,9)$. In 1947, Lubinski listed diseases and conditions with biological false positive syphilis reactions (10). The list included diseases and conditions like malaria, lupus erythematosus and pregnancy (10). In 1952, Mohr and Moore found a high incidence of biological false positives due to infections (e.g. leprosy and malaria) (11). However, non-infectious diseases like systemic lupus erythematosus (SLE) and rheumatoid arthritis had also a high approximate incidence of biological false positives of $20 \%$ and $5 \%$, respectively.

In the same year Conley and Hartman described two patients with lupus erythematosus who both had a biological false positive serological test for syphilis and a prolonged prothrombin time (12). This was one of the first descriptions of lupus anticoagulant (LAC), a phospholipid dependent prolongation of the clotting time. In 1954, Beaumont et al. published a report of a patient with LAC and seven previous abortions (13). More than two decades later, Firkin et al. suggested a possible relationship between LAC and recurrent abortion, which was later confirmed by Bowie et al. $(14,15)$. In the 1950's it became apparent that some patients with SLE also had a circulating anticoagulant (12,16-18). In the 1960's the association between LAC and thrombosis 


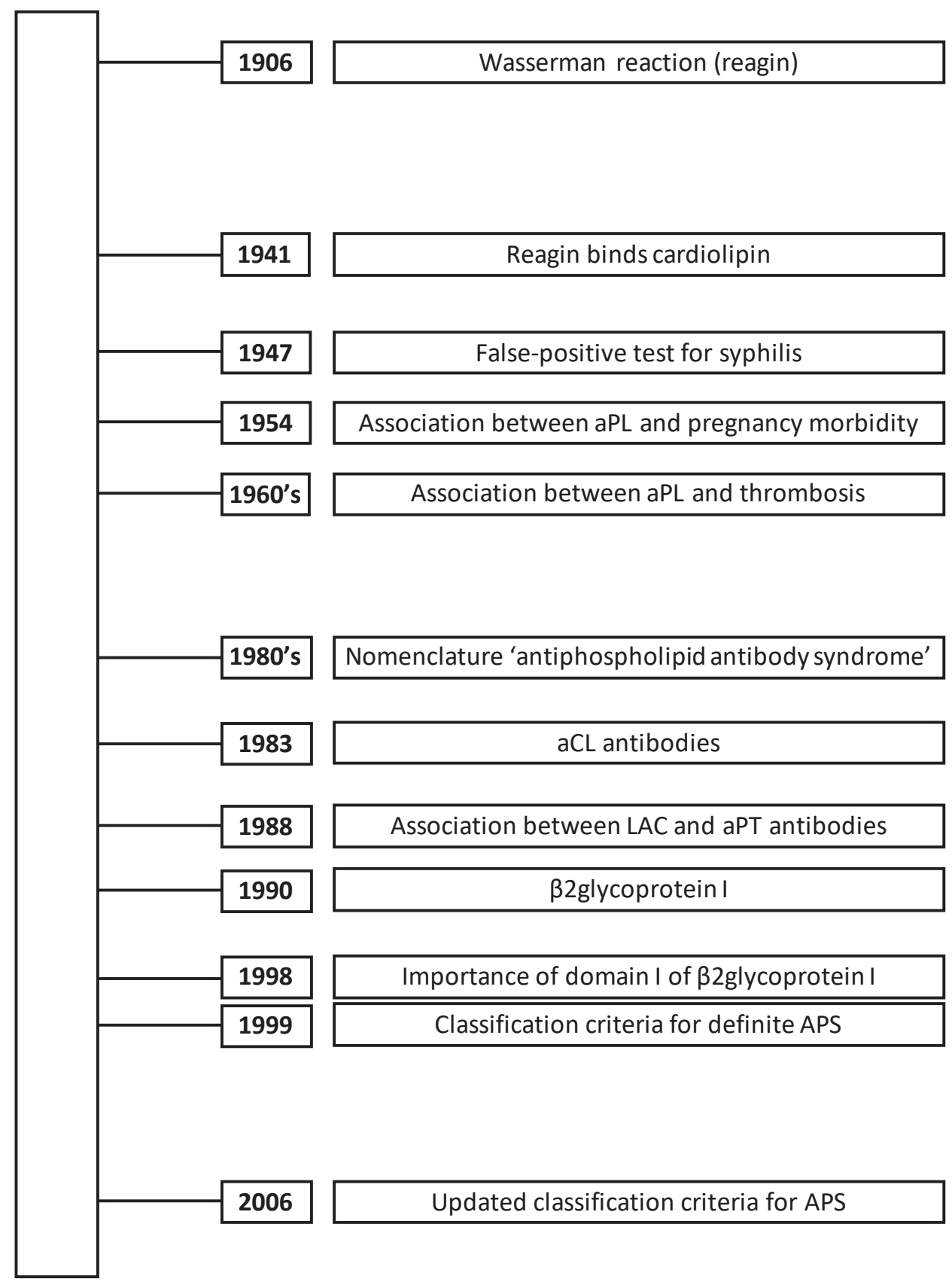

Figure 1. Timeline of key events and discoveries in APS. 
was established (19). Bowie et al. demonstrated that the prolonged clotting time in patients could be corrected using soybean phosphatide (inosithin, a platelet substitute) and that this correction was related to thrombosis (19). In 1983, Harris et al. described a radioimmunoassay for the detection of anti-cardiolipin ( $\mathrm{aCL}$ ) antibodies (20). This milestone, resulted in the correlation between $\mathrm{aCL}$ antibodies and thrombosis within SLE patients. aCL antibodies were also found to correlate with LAC (20). Two years later, an enzyme-linked immunosorbent assay (ELISA) for the detection of aCL antibodies was described (21). In the 1980's, the nomenclature 'antiphospholipid antibody syndrome' (APS) was starting to be widely used (4). However, it was not until 1987 that the first article using this terminology was published by Bingley and Hoffbrand (22). In 1988, Fleck et al. established a correlation between anti-prothrombin antibodies (aPT) and LAC (23). LAC was hypothesized to have immunological specificity for several anionic phospholipids including phosphatidylserine, cardiolipin, phosphatidylinositol and phosphatidic acid (24). However, Fleck et al. demonstrated that aPT immunoglobulin (Ig)G antibodies possessed LAC activity (23). In 1990, it became apparent that $\beta 2$ glycoprotein I ( $\beta 2 \mathrm{GPI}$ ) was the main target for antibody binding instead of cardiolipin itself. These publications already suggest that the term antiphospholipid antibody is a misnomer, as the antibodies are not directed against phospholipids per se, but rather to phospholipid binding proteins like $\beta 2 \mathrm{GPI}$ and prothrombin. In 1998, Iverson et al. suggested that antibodies directed against the first domain of $\beta 2 \mathrm{GPI}$ are clinically important (25). Seven years later, de Laat et al. confirmed the importance of anti-domain I $\beta 2 \mathrm{GPI}$ antibodies and suggested that these antibodies might be pathogenic as they cause LAC activity and strongly correlate with thrombosis (26). In 1999, an international consensus was reached for the classification of definite APS and updated in $2006(1,2)$. First-line treatment for a first or recurrent APS-related venous thrombotic event is treatment with vitamin K-antagonists (VKA) (27). According to international guidelines, treatment with VKAs is recommended in APS patients with a first arterial thrombosis (28). In a recent consensus paper published in The Netherlands Journal of Medicine, either treatment with clopidogrel (anti-platelet therapy) or VKAs is recommended in APS patients with a first arterial thrombosis (27). Still, both papers discourage the use of direct oral anticoagulants (DOACs) like rivaroxaban (direct Xa inhibitor) (27-29). DOACs have shown to be non-inferior to VKAs for treatment and secondary prevention of venous thromboembolic events and prevention of stroke and systemic embolism in patients with non-valvular atrial fibrillation $(27,30)$. The use of DOACs over VKAs has many advantageous, including no need for frequent laboratory monitoring, which is very much desired in patients with APS who are mostly young women of fertile age (31). It was until 2018 that an article was published evaluating the use of DOACs in triple positive (combined positivity for LAC, aCL and a 2 GPI antibodies) APS patients (32). 
Pengo et al. showed that rivaroxaban therapy was associated with an increased rate of arterial events, compared to warfarin treatment (32). However, an explanation for the observed increased rate of arterial events in patients treated with DOACs is unknown and should be further explored. Overall, the efficacy of DOAC use in APS patients should be further studied.

\section{Pathophysiology of the antiphospholipid syndrome}

Multiple studies have reported an association between aPL antibodies and thrombosis or pregnancy morbidity (1). However, the underlying mechanisms are poorly understood $(33,34)$. Patients with the persistent presence of aPL antibodies do not constantly develop thrombosis, suggesting that other factors play a role in the development of thrombotic APS (35). A "two hit" theory is suggested, in which aPL antibodies induce a thrombophilic state (first hit), and the second hit is another thrombophilic stimulus $(36,37)$. In agreement, antibodies from APS patients only induce thrombosis in mice upon induction of vessel wall injury $(38,39)$. However, the "two hit" theory seems not to apply for obstetric complications as antibodies with aPL activity induce fetal loss in naive pregnant mice (36).

B cells produce $a \beta 2 \mathrm{GPI}$ antibodies which can form $\beta 2 \mathrm{GPI}$ immune complexes on cellular surfaces (33). Binding of $\beta 2 \mathrm{GPI}$ immune complexes to endothelial cells requires priming with pro-inflammatory factors (40). $\beta 2 \mathrm{GPI}$ immune complexes have also shown to bind to monocytes and platelets, inducing their proinflammatory and procoagulant state $(41,42)$. Activation of inflammatory and endothelial cells by $\beta 2 \mathrm{GPI}$ immune complexes results in the activation of the complement pathway, upregulation of adhesion molecules (E-selectin), upregulation of TF, increased level of vascular endothelial growth factor and the release of neutrophil extracellular traps $(33,34)$. Prothrombotic changes by aPL antibodies may be caused by increased expression of the platelet fibrinogen receptor glycoprotein IIb/IIla, suppressing the activity of tissue factor pathway inhibitor, protein $\mathrm{C}$ activity and fibrinolysis $(33,34)$. aPL antibodies have also an effect on the placenta, non-thrombotic mechanisms include activation of the complement system, increased trophoblast apoptosis, decreased human chorionic gonadotropin, proliferation and syncytia formation $(33,34)$. Activation of coagulation, inflammatory and endothelial cells and interference with trophoblasts and decidual cells can lead to clinical manifestations of APS like thrombosis and pregnancy complications $(33,34)$. However, aPL antibodies are also correlated with non-criteria manifestations like inflammation and vasculopathy $(33,34)$. Despite all the efforts made, our understanding of the molecular mechanisms causing the development of aPL antibodies and APS related clinical manifestations is poorly understood. 


\section{Antiphospholipid antibodies}

For the classification of APS, a patient has to meet at least one clinical and one laboratory criterion (Table 1). Laboratory criteria include positivity for $L A C, a C L \lg G / M$ or a $32 \mathrm{GPI}$ $\mathrm{lgG} / \mathrm{M}$ antibodies on two occasions at least 12 weeks apart $(1,43)$. The prevalence of APS is estimated to be around 50 per 100,000 of the population (44). Frequency of aPL is estimated at $9.5 \%$ in deep vein thrombosis, $11 \%$ in myocardial infarction, $13.5 \%$ in stroke and $6 \%$ in pregnancy morbidity (45). As clinical features of APS occur frequently and independent of APS, reliable aPL detecting assays are of utmost importance.

TABLE 1. Classification criteria of APS.

APS is present if a patient meets at least one of the following clinical criteria and one of the laboratory criteria (1)

\begin{tabular}{|c|c|}
\hline Clinical criteria & Laboratory criteria \\
\hline $\begin{array}{l}\text { 1. Vascular thrombosis } \\
\text { One or more clinical episodes of confirmed arterial, } \\
\text { venous, or small vessel thrombosis, in any tissue or } \\
\text { organ. } \\
\text { 2. Pregnancy morbidity } \\
\text { (a) One or more unexplained deaths of a } \\
\text { morphologically normal fetus at or beyond the 10th } \\
\text { week of gestation, or } \\
\text { (b) One or more premature births of a } \\
\text { morphologically normal neonate before the 34th } \\
\text { week of gestation, or } \\
\text { (c) Three or more unexplained consecutive } \\
\text { spontaneous abortions before the 10th week of } \\
\text { gestation. }\end{array}$ & $\begin{array}{l}\text { 1. Lupus anticoagulant present in plasma, on } \\
\text { two or more occasions at least } 12 \text { weeks apart, } \\
\text { detected according to the guidelines of the ISTH- } \\
\text { SSC ( } 46 \text { ). } \\
\text { 2. Anticardiolipin antibody of IgG and/or IgM } \\
\text { isotype present in serum or plasma on two or } \\
\text { more occasions, at least } 12 \text { weeks apart ( } 47 \text { ). } \\
\text { 3. Anti- } \beta 2 \text { glycoprotein-I antibody of IgG and/ } \\
\text { or IgM isotype present in serum or plasma on } \\
\text { two or more occasions, at least } 12 \text { weeks apart } \\
\text { (47). }\end{array}$ \\
\hline
\end{tabular}

\section{Lupus anticoagulant}

LAC is detected by a phospholipid dependent prolongation of the clotting time (1). The detection of LAC is a three-step procedure including a screening, mixing and confirmatory test. Citrated blood is collected and platelet free plasma is made by double centrifugation (46). LAC should be detected based on two different principles, preferably using a dilute Russell's viper venom time (dRVVT) and a LAC sensitive activated partial thromboplastin time (aPTT) (46). Patients referred for LAC testing are tested for prolongation of the clotting time (screening). Next, patient plasma is diluted with pooled normal plasma (1:1) to exclude clotting factor deficiencies (mixing). Lastly, LAC is confirmed using an excess of hexagonal phase II phospholipids (46). LAC is the only functional assay within the aPL-panel and considered the strongest predictor of 
thrombosis and pregnancy morbidity $(48,49)$. LAC has been shown to be dependent on aPT or aß2GPI antibodies (23,50-52). However, it has also been demonstrated that LAC can occur in the absence of these antibodies (53). Isolated LAC positivity is considered to be less correlated with thrombosis than triple positivity (54). Still, the risk of a first thrombotic event in isolated LAC positives is higher than controls without aPL antibodies of the same age $(54,55)$. Many efforts have been made in standardization of aPL antibody testing. In 2009, the International Society on Thrombosis and Haemostasis-Scientific and Standardization Committee (ISTH-SSC) subcommittee on lupus anticoagulant/anti-phospholipid antibodies published detailed guidelines for LAC detection (46). Laboratory testing for LAC remains complicated with many pitfalls in the implemented procedure as well as in the interpretation (56). LAC detection has many drawbacks, including sensitivity to anticoagulant therapy, difficulties in the interpretation of mixing studies, the use of normal pooled plasma and lack of consensus on the calculation of cut-off values (46,57-62).

\section{Anti-cardiolipin antibodies}

Traditionally, aCL antibodies are measured by an ELISA. Typically, the ELISA plate is coated with cardiolipin and incubated overnight (63). Plates are blocked with the use of adult bovine serum (ABS) or fetal bovine serum (FBS). The use of phosphate buffered saline (PBS), bovine serum albumin (BSA) or casein to block non-specific binding are not recommended as they do not contain $\beta 2 \mathrm{GPI}$. ABS and FBS do contain $\beta 2 \mathrm{GPI}$, which is crucial for binding of pathogenic 'aCL' antibodies $(63,64)$. After blocking the plate, samples are diluted and incubated. A secondary conjugated antibody (anti-lgG, anti$\lg M$ or anti-lgA) is incubated for the detection of aCL antibodies (63). Quality control is important for the detection of $\mathrm{aCL}$ antibodies and inter-assay variation should not exceed $20 \%$ for ELISAs detecting aCL antibodies (47). Nowadays, automated immunoassays have become available for the detection of $\mathrm{aCL}$ and $\mathrm{a} \beta 2 \mathrm{GPI}$ antibodies using different solid phases (magnetic particles, microbeads, coated polystyrene cups or membranes) with various detection systems like chemiluminescence, flow cytometry and multiplex systems (65-67). These automated systems have shown to have less inter-assay variation and inter-laboratory variation compared to traditional ELISAs $(47,65,68)$. Automated systems are also less labor intensive, more rapid and can detect several aPL antibodies simultaneously in one sample (65). Cut-off values are recommended calculated from at least 120 plasmas or sera of which the $99^{\text {th }}$ percentile is calculated (47). However, it is not always possible to collect samples from 120 healthy donors. Alternatively, manufacturer's recommended cut-off values can be validated on 
a limited number of at least 20 healthy donors and transferred (47). Similar to LAC and aß2GPI, aCL positivity should be confirmed after at least 12 weeks to rule out transient positivity induced by infections or drugs (1).

\section{Anti- $\beta 2$ glycoprotein I antibodies}

a $32 \mathrm{GPI}$ antibodies are traditionally detected by ELISA, but equally as for aCL automated systems are available (65-67). For the detection of aß2GPI antibodies, (high-binding) ELISA plates are coated with $\beta 2 \mathrm{GPI}$ overnight (69). Wells are then blocked with a blocking agent and samples are diluted and incubated (69). A secondary conjugated antibody (anti-lgG, anti-lgM or anti-lgA) is then incubated for the detecting of a $32 \mathrm{GPI}$ antibodies (69). The absence of cardiolipin is theorized to increase the detection of clinically relevant antibodies (70). However, not all aß2GPI antibodies are correlated with thrombosis (26).

\section{Cofactors for anti-phospholipid antibodies}

$\beta 2 \mathrm{GPI}$ and prothrombin are considered the most important cofactors for aPL antibodies.

\section{B2glycoprotein I}

$\beta 2 \mathrm{GPI}$ is an abundant plasma protein (approximately $200 \mu \mathrm{g} / \mathrm{ml}$ ) which is produced in the liver and placenta (26,71-73). $\beta 2 \mathrm{GPI}$ is an anionic $50-\mathrm{kDa}$ protein, is evolutionary conserved and has shown to regulate haemostasis as well as the complement system $(38,39,72,74-77)$. Also, $\beta 2 \mathrm{GPI}$ is considered the main antigenic target for aPL antibodies (78). Still, $\beta 2 \mathrm{GPI}$-deficient humans and mice do not express a clear phenotype of thrombosis or bleeding, indicating it is not essential for life $(71,72,79,80)$. Notably, breeding of $\beta 2 \mathrm{GPI}$ null mice results in reduced percentage of offspring, suggesting that the lack of $\beta 2 \mathrm{GPI}$ is a selective disadvantage for survival $(72,75,80)$. $\beta 2 \mathrm{GPI}$ is a highly glycosylated phospholipid-binding protein, consisting of four complement control protein (CCP) domains of 60 amino acids each. Domain $V$ is different as it consists of 82 amino acids and a phospholipid-binding site $(26,72,81-86)$. The CCP domain functions as a module for protein-protein interactions in many different proteins (72). Domain $V$ of $\beta 2$ GPI contains a large positively charged patch that determines the affinity for anionic phospholipids. $\beta 2 \mathrm{GPI}$ can be found in two distinct conformations: a 'circular' (native) conformation in plasma and an 'activated' (open) conformation (87). Upon binding of $\beta 2$ GPI to an anionic phospholipid surface, circular $\beta 2$ GPI unfolds to an open conformation, exposing cryptic epitopes. One of these cryptic epitopes is Gly40-Arg43, located in the first domain of $\beta 2 \mathrm{GPI}$. Antibodies against the cryptic epitope Gly40-Arg43 are associated with LAC and strongly correlate with thrombosis $(26,88)$. 


\section{Prothrombin}

Prothrombin, also known as coagulation factor (F)II, is a $72-\mathrm{kDa}$, vitamin $\mathrm{K}$-dependent zymogen produced in the liver. Prothrombin has a plasma concentration of approximately $100 \mu \mathrm{g} / \mathrm{mL}$. Prothrombin is converted to thrombin upon vessel wall injury. Coagulation factor Xa cleaves prothrombin at Arg271-Thr272 and Arg320-Ile321 generating the enzyme thrombin and fragment $1.2(89,90)$. Thrombin is a central coagulation factor that cleaves fibrinogen to fibrin to produce a firm clot.

Genetic depletion of prothrombin in adult mice is not compatible with survival $(91,92)$. To date, no living patient has been reported with undetectable plasma prothrombin, suggesting that prothrombin is essential for life. Like $\beta 2 \mathrm{GPI}$, prothrombin can be found in an open and closed conformation. aPT antibodies are a heterogenous group of antibodies of which it has become more apparent that the conformation of prothrombin and the target epitope is of clinical importance, similar to $\beta 2$ GPI (93-96).

\section{Non-Criteria anti-phospholipid antibodies}

The first international consensus statement on the classification criteria for definite APS included the detection of LAC, aCL IgG and aCL IgM (2). In 2006, classification criteria were revised and the detection of a 2 GPI IgG and aß2GPI IgM was added to the $\mathrm{PPL}$ panel (1). Inclusion of other aPL antibodies like aCL IgA, aß2GPI IgA, aPT and antiphosphatidylserine/prothrombin (aPS/PT) antibodies needed further investigation (1).

\section{Domain I antibodies}

aß2GPI antibodies may be directed to any epitope or part of the molecule. However, antibodies directed to the first domain of $\beta 2 \mathrm{GPI}$ have shown to be pathogenic by both in vivo and in vitro studies. In vitro, anti-domain I antibodies have shown to display LAC activity, increase resistance to the anticoagulant properties of annexin A5 and activated protein $C$ (APC) and neutralize the inhibitory function of $\beta 2 \mathrm{GPI}$ on von Willebrand factor induced platelet aggregation (26,97-102). In vivo, domain I antibodies have shown to be pathogenic by inducing thrombosis and/or fetal loss in mice and rats (103-105). Antibodies against domain $V$ failed to exert a thrombogenic effect in rats (105). However, APS patients could have both anti-domain I and anti-domain V antibodies. Antibodies against domain $\mathrm{V}$ bind circulating $\beta 2 \mathrm{GPI}$, blocking interaction of $\beta 2 \mathrm{GPI}$ with anionic phospholipid surfaces and therefore hindering the conformational change of $\beta 2 \mathrm{GPI}$ to an open conformation and exposing cryptic epitopes. It is hypothesized that patients with anti-domain I $\beta 2$ GPI IgG antibodies and anti-domain $V$ antibodies have a lower thrombotic risk if the anti-domain $V$ level exceeds the level of anti-domain I $(105,106)$. Anti-domain $\mathrm{V}$ antibodies might therefore be protective as these antagonize the 
procoagulant activity of domain I antibodies. Calculating a ratio of anti-domain I to antidomain 4/5 might be useful for risk stratification (106). Although domain I antibodies are not part of the current classification aPL-panel, commercial assays for the detection of anti-domain I antibodies have become available (107). Unfortunately, a commercial chemiluminescence immunoassay (CIA) detecting anti-domain I antibodies failed to expose the cryptic epitope Gly40-Arg43, hampering the use of anti-domain I antibodies in APS patients (107). These results highlight the importance of standardization of solid phase assays detecting aPL antibodies $(59,107)$.

\section{Anti-cardiolipin and anti- $\boldsymbol{\beta} 2$ glycoprotein I IgA antibodies}

$\mathrm{aCL}$ and $\mathrm{a} \beta 2 \mathrm{GPI} \lg \mathrm{A}$ antibodies are not included in the current classification criteria for APS (1). Nevertheless, multiple studies have demonstrated an association between $\operatorname{IgA}$ aPL antibodies and thrombosis or pregnancy morbidity (108-118). The ISTH-SSC committee concluded in 2008 that aCL IgA does not add diagnostic power to the current aPL-panel. Data supporting the inclusion of aß2GPI IgA antibody testing was found to be inadequate (1). Another point of discussion raised by the committee, is the lack of uniform guidelines on how to perform the assay, unavailability of control material and lack of consensus on units of measurement (1). Since 2006, new data on the association between IgA aPL antibodies and clinical manifestations of APS became available $(108,111-116,118)$. A systematic review was published concerning the clinical relevance of $\mathrm{aCL}$ and $\mathrm{a} \beta 2 \mathrm{GPI} \lg \mathrm{A}$ antibodies and concluded that there is not enough evidence to recommend $\mathrm{aCL}$ and/or a $\beta 2 \mathrm{GPI} \lg \mathrm{A}$ antibody testing as diagnostic accuracy is not improved (119). However, new assays for the detection of $\mathrm{aCL}$ and aß2GPI IgA antibodies have become commercially available, but their value in the current aPL panel remains to be investigated (117).

\section{Anti-prothrombin antibodies and anti-phosphatidylserine/prothrombin antibodies}

For the detection of aPT antibodies, prothrombin is directly coated on irradiated ELISA plates (120). Detection of anti-phosphatidylserine/prothrombin (aPS/PT) antibodies is performed by coating phosphatidylserine/prothrombin complex on non-irradiated ELISA plates $(120,121)$. Although a correlation has been shown between aPS/PT and aPT antibodies, it is hypothesized that these aPL antibodies belong to a different population of antibodies $(120,122,123)$. In a systematic review, aPT antibodies correlated less with thrombosis than aPS/PT antibodies. Already in 1988, an association was established between aPT antibodies and LAC, which is considered the strongest predictor of thrombosis and pregnancy morbidity in APS, making aPS/PT antibodies an interesting group of aPL antibodies to further investigate $(23,48,49)$. aPS/PT antibodies 
are frequently found in patients with APS and suggested to be included in the current aPL-criteria $(1,121,124)$. They may have a potential role in risk stratification and are strongly correlated with isolated LAC in APS patients, as well as in asymptomatic carriers $(94,95,125-127)$.

\section{Antiphospholipid profile}

Although every aPL antibody in the current panel ( $L A C, a C L \lg , a C L \lg M, a \beta 2 G P I \lg G$, a 32 GPI IgM) for the classification of APS has the same diagnostic value, it is more apparent to evaluate the complete aPL-profile $(1,128,129)$. Evaluation of an aPL profile can be important for risk stratification of thrombosis or pregnancy morbidity and "reliability" of diagnosis. Single positivity or isolated positivity, is positivity for one of the five consensus aPL antibodies but negative results for the other four aPL antibodies. Double positivity is referred as aCL and a $32 \mathrm{GPI}$ positivity, but negative for LAC. Triple positivity is referred as combined positivity for $L A C, a C L$ and $a \beta 2 G P I$ from the same isotype. $L A C$ is considered the main predictor of thrombosis and pregnancy morbidity in APS $(49,130)$. However, single LAC positivity is not considered a high risk profile for thrombosis or pregnancy morbidity in comparison to triple positivity (131-133). A strong correlation with thrombosis is found when aß2GPI antibodies are present with LAC (134). Single LAC positivity in patients receiving anticoagulation must be interpreted carefully as anticoagulation therapy can induce a false positive LAC result (62). Antibodies against other cardiolipin binding proteins (complement factor 4 or Factor $\mathrm{H}$ ) and $\beta 2 \mathrm{GPI}$ independent $\mathrm{aCL}$ antibodies are also detected $(135,136)$. $\mathrm{aCL}$ and $\mathrm{a} \beta 2 \mathrm{GPI}$ assays contain the same antigen $(\beta 2 \mathrm{GPI})$, an overlap is therefore expected. A positive aCL result with the absence of $\mathrm{a} \beta 2 \mathrm{GPI}$ antibodies and LAC should therefore be interpreted with care as no association is found for isolated $\mathrm{aCL}$ positivity (131). Also, isolated $\mathrm{a} \beta 2 \mathrm{GPI}$ antibodies are not correlated with thrombosis and hypothesized to be of no importance as these antibodies do not induce LAC activity $(131,136)$. For example, aß2GPI antibodies might occur in patients with leprosy in which thrombosis is uncommon (137). However, these a 32 GPI antibodies are not directed against the first epitope of $\beta 2$ GPI (137). It became apparent that positivity for multiple aPL is highly associated with clinical manifestations of APS (138-140). Triple positivity is more strongly associated with thrombosis than single and double positivity $(129,141)$. Not only for recurrent thrombosis, but also for a first thrombotic event in asymptomatic carriers, triple positivity is a risk factor $(141,142)$. Double positive patients are at lower risk to develop APS related clinical manifestations than triple positive patients, and single positive patients are even less likely to develop thrombosis $(43,67,136)$. 


\section{Anti-cardiolipin and anti- $\beta 2$ glycoprotein I isotype}

The isotype of $\mathrm{aCL}$ and $\mathrm{a} \beta 2 \mathrm{GPI}$ antibodies should be taken into consideration for diagnosis of APS and correct interpretation of the assays (136). A laboratory test result with positivity for aCL IgG and aß2GPI IgM, but not for $\mathrm{aCL} \lg M$ and $a \beta 2 \mathrm{GPI} \lg \mathrm{aPL}$ should be classified as "inappropriate" (136). Concordance of isotype in aCL and aß2GPI detection is essential, but not required according to the updated classification criteria $(1,136)$. The isotype of $\mathrm{aCL}$ and $\mathrm{a} \beta 2 \mathrm{GPI}$ is not only a valuable tool for the interpretation of the aPL assays, but may also help in evaluating the risk for thrombosis or pregnancy morbidity. A meta-analysis found more significant correlations with thrombosis for the IgG isotype compared to the IgM isotype (143). aCL IgM antibodies have shown to be important in obstetric APS $(130,144)$. However, the relevance of $\mathrm{aCL}$ and aß2GPI IgM antibodies in thrombosis is debated (143).

\section{OUTLINE}

Classification of APS is dependent on the detection of aPL antibodies by laboratory tests. This includes the detection of $\mathrm{LAC}, \mathrm{aCL} \operatorname{lgG} / \mathrm{M}$ antibodies and $\mathrm{a} \beta 2 \mathrm{GPI} \mathrm{lgG} / \mathrm{M}$ antibodies. Multiple studies have concluded that aPL antibody detecting assays show a large inter-assay variability. It is hypothesized that the inter-assay variation for $\mathrm{aCL}$ and aß2GPI detected automated systems is lower compared to traditional ELISAs. Chapter2 assesses the agreement between four commercially available and fully automated assays detecting $\mathrm{aCL}$ and $\mathrm{a} \beta 2 \mathrm{GPI} \mathrm{lgG} / \mathrm{M}$ antibodies in patients with APS and controls. In addition, the association of aPL antibodies with clinical manifestations is investigated. Patients with triple positive aPL antibodies have a high risk for a first thrombotic event and recurrence. Subsequently, clinicians may adapt their treatment strategy. Altogether, reliable detection is of utmost importance in triple positive patients. Triple positivity is often associated with high aCL and aß2GPI titers and therefore hypothesized to be less affected by variations between solid phase assays. In chapter3, agreement between four $\mathrm{aCL}$ and $\mathrm{a} \beta 2 \mathrm{GPI}$ assays in the detection of triple positive APS patients is investigated. In the current classification criteria, positivity for aCL or a $32 \mathrm{GPI}$, independent of the isotype ( $\mathrm{lgG} / \mathrm{M})$ is sufficient to fulfill the laboratory criteria of APS. However, the relevance of IgM antibodies in the classification of thrombotic APS is debated. We therefore investigated in chapter 4 the relevance of $\mathrm{aCL}$ and $\mathrm{a} \beta 2 \mathrm{GPI}$ IgM antibodies in thrombosis and pregnancy morbidity. Chapter $\mathbf{5}$ studies the added value of $\mathrm{aCL} \lg \mathrm{A}$ and $\mathrm{a} \beta 2 \mathrm{GPI} \lg \mathrm{A}$ antibodies in APS. $\mathrm{aCL} \lg \mathrm{A}$ and $\mathrm{a} \beta 2 \mathrm{GPI} \lg \mathrm{A}$ antibodies have shown to correlate with thrombosis and induce thrombosis in mice. However, IgA is still not included in the current aPL-panel for the classification of APS. Antibodies against domain I of $\beta 2 \mathrm{GPI}$ are considered pathogenic and correlate well with LAC. The 
significance of anti-domain I antibodies in APS is reviewed in chapter 6. In chapter 7, we investigate whether anti-domain I antibodies can be used as a tool to identify highrisk APS patients. The role of aPT antibodies in platelet activation is investigated in chapter $\mathbf{8}$. Finally, chapter $\mathbf{9}$ summarizes key findings of this thesis and discusses these findings in relation to the literature. 


\section{REFERENCES}

1. Miyakis S, Lockshin MD, Atsumi T, et al. International consensus statement on an update of the classification criteria for definite antiphospholipid syndrome (APS). J Thromb Haemost 2006; 4: 295-306.

2. Wilson $W A$, Gharavi $A E$, Koike $T$, et al. International consensus statement on preliminary classification criteria for definite antiphospholipid syndrome: report of an international workshop. Arthritis Rheum 1999; 42: 1309-11.

3. Wassermann A. Eine serodiagnostiche Reaction bei Syphilis. Deutsch Med Wöchenschr 1906; 32: 747.

4. Jayakody Arachchillage $D$, Greaves $M$. The chequered history of the antiphospholipid syndrome. Br J Haematol 2014; 165: 609-17.

5. Hanly JG. Antiphospholipid syndrome: an overview. Can Med Assoc J 2003; 168: 1675-82.

6. Pangborn MC. A New Serologically Active Phospholipid from Beef Heart. Proc Soc Exp Biol Med 1941; 48: 484-6.

7. Harris A, Portnoy J. J vener Dis Inform 1944; 23: 353.

8. Vogelsang TM. The Harris Slide Test: A Microflocculation Test for Syphilis with Cardiolipin Antigen. Br J Vener Dis 1947; 23: 109-15.

9. Nelson RA, Mayer MM. Immobilization of Treponema pallidum in vitro by antibody produced in syphilitic infection. J Exp Med 1949; 89: 369-93.

10. Lubinski HH. Interpretation and significance of false positive serologic reactions for syphilis. Can Med Assoc J 1947; 57: 33-5.

11. Moore JE, Mohr CF. Biologically false positive serologic tests for syphilis; type, incidence, and cause. J Am Med Assoc 1952; 150: 467-73.

12. Conley $\mathrm{CL}$, Hartman RC. A hemorrhagic disorder caused by circulating anticoagulant in patients with disseminated lupus erythematosus. J Clin Invest 1952; 621-2.

13. Beaumont JL. Acquired hemorrhagic syndrome caused by a circulating anticoagulant; inhibition of the thromboplastic function of the blood platelets; description of a specific test. Sang 1954; 25: 1-15.

14. Firkin BG, Howard MA, Radford N. Possible relationship between lupus inhibitor and recurrent abortion in young women. Lancet 1980; 2: 366.

15. Boey ML, Colaco CB, Gharavi $A E$, et al. Thrombosis in systemic lupus erythematosus: striking association with the presence of circulating lupus anticoagulant. Br Med J (Clin Res Ed) 1983; 287: 1021-3.

16. Frick PG. Acquired circulating anticoagulants in systemic collagen disease; auto-immune thromboplastin deficiency. Blood 1955; 10: 691-706.

17. Laurell $A B$, Nilsson IM. Hypergammaglobulinemia, circulating anticoagulant, and biologic false positive Wassermann reaction; a study in two cases. J Lab Clin Med 1957; 49: 694-707.

18. Lee SL, Sanders M. A disorder of blood coagulation in systemic lupus erythematosus. J Clin Invest 1955; 34: 1814-22. 
19. Bowie EJ, Thompson JH, Pascuzzi CA, et al. Thrombosis in systemiclupus erythematosus despite circulating anticoagulants. J Lab Clin Med 1963; 62: 416-30.

20. Harris $E N$, Gharavi $A E$, Boey $M L$, et al. Anticardiolipin antibodies: detection by radioimmunoassay and association with thrombosis in systemic lupus erythematosus. Lancet 1983; 2: 1211-4.

21. Loizou S, McCrea JD, Rudge AC, et al. Measurement of anti-cardiolipin antibodies by an enzyme-linked immunosorbent assay (ELISA): standardization and quantitation of results. Clin Exp Immunol 1985; 62: 738-45.

22. Bingley PJ, Hoffbrand BI. Antiphospholipid antibody syndrome: a review. J R Soc Med 1987; 80: 445-8.

23. Fleck RA, Rapaport SI, Rao LV. Anti-prothrombin antibodies and the lupus anticoagulant. Blood 1988; 72: 512-9.

24. Pengo V, Thiagarajan P, Shapiro SS, et al. Immunological specificity and mechanism of action of IgG lupus anticoagulants. Blood 1987; 70: 69-76.

25. Iverson GM, Victoria EJ, Marquis DM. Anti- 2 glycoprotein I (beta2GPI) autoantibodies recognize an epitope on the first domain of 2GPI. Proc Natl Acad Sci USA 1998; 95: 15542-6.

26. de Laat B, Derksen RHWM, Urbanus RT, et al. IgG antibodies that recognize epitope Gly40Arg43 in domain I of $\beta 2$-glycoprotein I cause LAC, and their presence correlates strongly with thrombosis. Blood 2005; 105: 1540-5.

27. Limper M, de Leeuw K, Lely AT, et al. Diagnosing and treating antiphospholipid syndrome: a consensus paper. Neth J Med 2019; 77: 98-108.

28. Tektonidou MG, Andreoli L, Limper M, et al. EULAR recommendations for the management of antiphospholipid syndrome in adults. Ann Rheum Dis 2019; 78: 1296-304.

29. Arachchillage DRJ, Gomez K, Alikhan R, et al. Addendum to British Society for Haematology Guidelines on Investigation and Management of Antiphospholipid syndrome, 2012 (Br. J. Haematol. 2012; 157: 47-58): use of direct acting oral anticoagulants. Br J Haematol 2020; 189: 212-5.

30. Hulle T van der, Kooiman J, Exter PL den, et al. Effectiveness and safety of novel oral anticoagulants as compared with vitamin $\mathrm{K}$ antagonists in the treatment of acute symptomatic venous thromboembolism: a systematic review and meta-analysis. J Thromb Haemost 2014; 12: 320-8.

31. Cohen D, Berger SP, Steup-Beekman GM, et al. Diagnosis and management of the antiphospholipid syndrome. Br J Haematol (clinical research ed.) 2010; 340: [c2541].

32. Pengo V, Denas G, Zoppellaro G, et al. Rivaroxaban vs warfarin in high-risk patients with antiphospholipid syndrome. Blood; 2018; 132: 1365-71.

33. Garcia D, Erkan D. Diagnosis and Management of the Antiphospholipid Syndrome. N Engl J Med 2018; 378: 2010-21.

34. Giannakopoulos B, Krilis SA. The Pathogenesis of the Antiphospholipid Syndrome. N Engl J Med 2013; 368: 1033-44.

35. Arachchillage DRJ, Laffan M. Pathogenesis and management of antiphospholipid syndrome. Br J Haematol 2017; 178: 181-95. 
36. Meroni PL, Borghi MO, Raschi E, et al. Pathogenesis of antiphospholipid syndrome: understanding the antibodies. Nat Rev Rheumatol 2011; 7: 330-9.

37. Meroni PL, Raschi E, Grossi C, et al. Obstetric and vascular APS: same autoantibodies but different diseases? Lupus 2012; 21: 708-10.

38. Fischetti F, Durigutto P, Pellis V, et al. Thrombus formation induced by antibodies to beta2glycoprotein I is complement dependent and requires a priming factor. Blood 2005; 106: 2340-6.

39. Arad A, Proulle V, Furie RA, et al. $\beta_{2}$-Glycoprotein-1 autoantibodies from patients with antiphospholipid syndrome are sufficient to potentiate arterial thrombus formation in a mouse model. Blood 2011; 117: 3453-9.

40. Agostinis C, Biffi S, Garrovo C, et al. In vivo distribution of $\beta 2$ glycoprotein I under various pathophysiologic conditions. Blood 2011; 118: 4231-8.

41. Meroni PL, Ronda N, De Angelis V, et al. Role of anti-beta2 glycoprotein I antibodies in antiphospholipid syndrome: in vitro and in vivo studies. Clin Rev Allergy Immunol 2007; 32: 67-74.

42. Brusch A. The Significance of Anti-Beta-2-Glycoprotein I Antibodies in Antiphospholipid Syndrome. Antibodies (Basel) 2016; 5: 16.

43. Devreese KMJ, Ortel TL, Pengo V, et al. Laboratory criteria for antiphospholipid syndrome: communication from the SSC of the ISTH. J Thromb Haemost 2018; 16: 809-13.

44. Duarte-García A, Pham MM, Crowson CS, et al. The Epidemiology of Antiphospholipid Syndrome: A Population-Based Study. Arthritis Rheum 2019; 71: 1545-52.

45. Andreoli L, Chighizola CB, Banzato A, et al. Estimated Frequency of Antiphospholipid Antibodies in Patients With Pregnancy Morbidity, Stroke, Myocardial Infarction, and Deep Vein Thrombosis: A Critical Review of the Literature. Arthritis Care Res (Hoboken) 2013; 65: 1869-73.

46. Pengo V, Tripodi A, Reber G, et al. Update of the guidelines for lupus anticoagulant detection. J Thromb Haemost 2009; 7: 1737-40.

47. Devreese KMJ, Pierangeli SS, de Laat B, et al. Testing for Antiphospholipid antibodies with Solid Phase Assays: guidance from the SSC of the ISTH. J Thromb Haemost 2014; 12: 792-5.

48. Galli M. Lupus anticoagulants are stronger risk factors for thrombosis than anticardiolipin antibodies in the antiphospholipid syndrome: a systematic review of the literature. Blood 2003; 101: 1827-32.

49. Lockshin MD, Kim M, Laskin CA, et al. Prediction of adverse pregnancy outcome by the presence of lupus anticoagulant, but not anticardiolipin antibody, in patients with antiphospholipid antibodies. Arthritis Rheum 2012; 64: 2311-8.

50. Loeliger A, Alsbach EJJ, Miss W the TAO. Prothrombin as Co-Factor of the Circulating Anticoagulant in Systemic Lupus Erythematosus? Thromb Haemost 1959; 03: 237-56.

51. Oosting JD, Derksen RH, Entjes HT, et al. Lupus anticoagulant activity is frequently dependent on the presence of beta 2-glycoprotein I. Thromb Haemost 1992; 67: 499-502. 
52. Roubey RA, Pratt CW, Buyon JP, et al. Lupus anticoagulant activity of autoimmune antiphospholipid antibodies is dependent upon beta 2-glycoprotein I. J Clin Invest 1992; 90: 1100-4.

53. Fabris M, Giacomello R, Poz A, et al. The introduction of anti-phosphatidylserine/ prothrombin autoantibodies in the laboratory diagnostic process of anti-phospholipid antibody syndrome: 6 months of observation. Auto Immun Highlights; 2014; 5: 63-7.

54. Pengo V, Testa $S$, Martinelli I, et al. Incidence of a first thromboembolic event in carriers of isolated lupus anticoagulant. Thromb Res 2015; 135: 46-9.

55. Ruffatti A, Del Ross T, Ciprian M, et al. Risk factors for a first thrombotic event in antiphospholipid antibody carriers: a prospective multicentre follow-up study. Ann Rheum Dis 2011; 70: 1083-6.

56. Devreese KMJ. Antiphospholipid antibody testing and standardization. Int J Lab Hematol 2014; 36: 352-63.

57. Devreese KMJ. Interpretation of normal plasma mixing studies in the laboratory diagnosis of lupus anticoagulants. Thromb Res 2007; 119: 369-76.

58. Devreese K, Hoylaerts MF. Challenges in the diagnosis of the antiphospholipid syndrome. Clin Chem 2010; 56: 930-40.

59. Devreese KMJ. Standardization of antiphospholipid antibody assays. Where do we stand? Lupus 2012; 21: 718-21.

60. Tripodi A, Chantarangkul V, Cini M, et al. Variability of cut-off values for the detection of lupus anticoagulants: results of an international multicenter multiplatform study. J Thromb Haemost 2017; 15: 1180-90.

61. Devreese KMJ. No more mixing tests required for integrated assay systems in the laboratory diagnosis of lupus anticoagulants? J Thromb Haemost 2010; 8: 1120-2.

62. Tripodi A, Cohen H, Devreese KMJ. Lupus anticoagulant detection in anticoagulated patients. Guidance from the Scientific and Standardization Committee for lupus anticoagulant/ antiphospholipid antibodies of the International Society on Thrombosis and Haemostasis. J Thromb Haemost 2020; 18: 1569-75.

63. Pierangeli SS, Harris EN. A protocol for determination of anticardiolipin antibodies by ELISA. Nat Protoc 2008; 3: 840-8.

64. Devreese KMJ, Ortel TL, Pengo V, et al. Laboratory criteria for antiphospholipid syndrome: reply. J Thromb Haemost 2018; 16: 2117-9.

65. Devreese KM, Poncet A, Lindhoff-Last E, et al. A multicenter study to assess the reproducibility of antiphospholipid antibody results produced by an automated system. J Thromb Haemost 2017; 15: 91-5.

66. Vanoverschelde L, Kelchtermans $H$, Musial J, et al. Influence of anticardiolipin and anti- $\beta 2$ glycoprotein I antibody cutoff values on antiphospholipid syndrome classification. Res Pract Thromb Haemost 2019; 3: 515-27.

67. Devreese KMJ. How to Interpret Antiphospholipid Laboratory Tests. Curr Rheumatol Rep 2020; 22: 38. 
68. Pengo V, Biasiolo A, Bison E, et al. Antiphospholipid antibody ELISAs: survey on the performance of clinical laboratories assessed by using lyophilized affinity-purified IgG with anticardiolipin and anti-beta2-Glycoprotein I activity. Thromb Res 2007; 120: 127-33.

69. Cucnik S, Ambrozic A, Bozic B, et al. Anti-beta2-glycoprotein I ELISA: methodology, determination of cut-off values in 434 healthy Caucasians and evaluation of monoclonal antibodies as possible international standards. Clin Chem Lab Med 2000; 38: 777-83.

70. Giannakopoulos B, Passam F, loannou Y, et al. How we diagnose the antiphospholipid syndrome. Blood 2009; 113: 985-94.

71. H.E. Schultze, K. Heide, H. Haput. Uber ein bisher ubekanntes niedermolekulars $\beta 2$-Globulin des Humanserums. Naturwissenschften 1961; 48: 719.

72. de Groot PG, Meijers JCM. $\beta(2)$-Glycoproteinl: evolution, structure and function. J Thromb Haemost 2011; 9: 1275-84.

73. Steinkasserer A, Estaller C, Weiss EH, et al. Complete nucleotide and deduced amino acid sequence of human beta 2-glycoprotein I. Biochem J 1991; 277: 387-91.

74. Gropp K, Weber N, Reuter M, et al. $\beta_{2}$-glycoprotein I, the major target in antiphospholipid syndrome, is a special human complement regulator. Blood 2011; 118: 2774-83.

75. Miyakis S, Giannakopoulos B, Krilis SA. Beta 2 glycoprotein l--function in health and disease. Thromb Res 2004; 114: 335-46.

76. Amara U, Rittirsch D, Flierl M, et al. Interaction between the coagulation and complement system. Adv Exp Med Biol 2008; 632: 71-9.

77. Jankowski M, Vreys I, Wittevrongel C, et al. Thrombogenicity of beta 2-glycoprotein I-dependent antiphospholipid antibodies in a photochemically induced thrombosis model in the hamster. Blood 2003; 101: 157-62.

78. Yang Y-H, Chang C-J, Chuang Y-H, et al. Identification of anti-prothrombin antibodies in the anti-phospholipid syndrome that display the prothrombinase activity. Rheumatology 2010; 49: 34-42.

79. Haupt H, Schwick HG, Störiko K. On a hereditary beta-2-glycoprotein I deficiency. Humangenetik 1968; 5: 291-3.

80. Sheng Y, Reddel SW, Herzog H, et al. Impaired thrombin generation in beta 2-glycoprotein I null mice. J Biol Chem 2001; 276: 13817-21.

81. Gröger H, Hummel W. Combining the "two worlds" of chemocatalysis and biocatalysis towards multi-step one-pot processes in aqueous media. Curr Opin Chem Biol 2014; 19: 171-9.

82. McDonnell T, Wincup C, Buchholz I, et al. The role of beta-2-glycoprotein I in health and disease associating structure with function: More than just APS. Blood Rev 2020; 39: 100610.

83. Steinkasserer A, Barlow PN, Willis AC, et al. Activity, disulphide mapping and structural modelling of the fifth domain of human beta 2-glycoprotein I. FEBS Lett 1992; 313: 193-7.

84. Hunt J, Krilis S. The fifth domain of beta 2-glycoprotein I contains a phospholipid binding site (Cys281-Cys288) and a region recognized by anticardiolipin antibodies. J Immunol 1994; 152: 653-9. 
85. Mehdi H, Naqvi A, Kamboh MI. A hydrophobic sequence at position 313-316 (Leu-Ala-PheTrp) in the fifth domain of apolipoprotein $\mathrm{H}$ (beta2-glycoprotein I) is crucial for cardiolipin binding. Eur J Biochem 2000; 267: 1770-6.

86. Sheng $Y$, Sali A, Herzog $H$, et al. Site-directed mutagenesis of recombinant human beta 2-glycoprotein I identifies a cluster of lysine residues that are critical for phospholipid binding and anti-cardiolipin antibody activity. J Immunol 1996; 157: 3744-51.

87. Agar C, van Os GMA, Mörgelin M, et al. Beta2-glycoprotein I can exist in 2 conformations: implications for our understanding of the antiphospholipid syndrome. Blood 2010; 116: 1336-43.

88. de Laat B, Derksen RHWM, van Lummel M, et al. Pathogenic anti-beta2-glycoprotein I antibodies recognize domain I of beta2-glycoprotein I only after a conformational change. Blood 2006; 107: 1916-24.

89. Mann KG, Elion J, Butkowski RJ, et al. Prothrombin. Methods Enzymol 1981; 80 Pt C: 286302.

90. Krishnaswamy S, Field KA, Edgington TS, et al. Role of the membrane surface in the activation of human coagulation factor X. J Biol Chem 1992; 267: 26110-20.

91. Mullins ES, Kombrinck KW, Talmage KE, et al. Genetic elimination of prothrombin in adult mice is not compatible with survival and results in spontaneous hemorrhagic events in both heart and brain. Blood 2009; 113: 696-704.

92. Sun WY, Witte DP, Degen JL, et al. Prothrombin deficiency results in embryonic and neonatal lethality in mice. Proc Natl Acad Sci USA 1998; 95: 7597-602.

93. Chinnaraj M, Planer W, Pengo $V$, et al. Discovery and characterization of 2 novel subpopulations of aPS/PT antibodies in patients at high risk of thrombosis. Blood Adv 2019; 3: 1738-49.

94. Le A, Dasgupta $S$, Planque $S$, et al. Lupus-derived antiprothrombin autoantibodies from a $\mathrm{V}$ gene phage display library are specific for the kringle 2 domain of prothrombin. Biochemistry 2004; 43: 4047-54.

95. Côté HC, Huntsman DG, Wu J, et al. A new method for characterization and epitope determination of a lupus anticoagulant-associated neutralizing antiprothrombin antibody. Am J Clin Pathol 1997; 107: 197-205.

96. Rao LV, Hoang AD, Rapaport SI. Mechanism and effects of the binding of lupus anticoagulant IgG and prothrombin to surface phospholipid. Blood 1996; 88: 4173-82.

97. de Laat $\mathrm{B}, \mathrm{Wu} \mathrm{X}-\mathrm{X}$, van Lummel $\mathrm{M}$, et al. Correlation between antiphospholipid antibodies that recognize domain I of beta2-glycoprotein I and a reduction in the anticoagulant activity of annexin A5. Blood 2007; 109: 1490-4.

98. de Laat B, Mertens K, de Groot PG. Mechanisms of disease: antiphospholipid antibodiesfrom clinical association to pathologic mechanism. Nat Clin Pract Rheumatol 2008; 4: 192-9.

99. Wahezi DM, llowite NT, Wu XX, et al. Annexin A5 anticoagulant activity in children with systemic lupus erythematosus and the association with antibodies to domain I of $\beta 2$ glycoprotein I. Lupus 2013; 22: 702-11. 
100. de Laat B, Pengo V, Pabinger I, et al. The association between circulating antibodies against domain I of beta2-glycoprotein I and thrombosis: an international multicenter study. J Thromb Haemost 2009; 7: 1767-73.

101. Hunt BJ, Wu X-X, de Laat B, et al. Resistance to annexin A5 anticoagulant activity in women with histories for obstetric antiphospholipid syndrome. Am J Obstet Gynecol 2011; 205: 485. e17-23.

102. Hulstein JJ, Lenting PJ, de Laat B, et al. beta2-Glycoprotein I inhibits von Willebrand factor dependent platelet adhesion and aggregation. Blood 2007; 110: 1483-91.

103. Pierangeli SS, Liu X, Espinola R, et al. Functional analyses of patient-derived IgG monoclonal anticardiolipin antibodies using in vivo thrombosis and in vivo microcirculation models. Thromb Haemost 2000; 84: 388-95.

104. Agostinis C, Durigutto $P$, Sblattero $D$, et al. A non-complement-fixing antibody to $\beta 2$ glycoprotein I as a novel therapy for antiphospholipid syndrome. Blood 2014; 123: 3478-87.

105. Durigutto $\mathrm{P}$, Grossi $\mathrm{C}$, Borghi MO, et al. New insight into antiphospholipid syndrome: antibodies to $\beta 2$ glycoprotein I-domain 5 fail to induce thrombi in rats. Haematologica 2019; 104: 819-26.

106. Andreoli L, Chighizola CB, Nalli C, et al. Clinical characterization of antiphospholipid syndrome by detection of $\mathrm{lgG}$ antibodies against $\beta 2$-glycoprotein i domain 1 and domain 4/5: ratio of anti-domain 1 to anti-domain $4 / 5$ as a useful new biomarker for antiphospholipid syndrome. Arthritis Rheum 2015; 67: 2196-204.

107. Yin $D$, de Laat $B$, Devreese KMJ, et al. The clinical value of assays detecting antibodies against domain I of $\beta 2$-glycoprotein I in the antiphospholipid syndrome. Autoimmun Rev 2018; 17 : 1210-8.

108. Despierres L, Beziane A, Kaplanski G, et al. Contribution of anti- $\beta 2$ glycoprotein I IgA antibodies to the diagnosis of anti-phospholipid syndrome: potential interest of target domains to discriminate thrombotic and non-thrombotic patients. Rheumatology 2014; 53: 1215-8.

109. Carmo-Pereira S, Bertolaccini M, Escudero-Contrera... A, et al. Value of IgA anticardiolipin and anti-ß2-glycoprotein I antibody testing in patients with pregnancy morbidity. Ann Rheum Dis 2003; 62: 540-3.

110. Lakos G, Kiss E, Czy NR, et al. Isotype distribution and clinical relevance of anti-b2glycoprotein I (b2-GPI) antibodies: importance of IgA isotype. Clin Exp Immunol 1999; 117: 574-9.

111. Mattia E, Ruffatti A, Tonello $M$, et al. IgA anticardiolipin and IgA anti- $\beta 2$ glycoprotein I antibody positivity determined by fluorescence enzyme immunoassay in primary antiphospholipid syndrome. Clin Chem Lab Med 2014; 52:1329-33

112. Ruiz-García R, Serrano M, Ángel Martínez-Flores J, et al. Isolated IgA Anti- $\beta 2$ Glycoprotein I Antibodies in Patients with Clinical Criteria for Antiphospholipid Syndrome. J Immunol Res 2014; 2014: 704395 
113. Samarkos M, Davies KA, Gordon C, et al. Clinical significance of IgA anticardiolipin and anti- $\beta 2-G P 1$ antibodies in patients with systemic lupus erythematosus and primary antiphospholipid syndrome. Clin Rheumatol 2006; 25: 199-204.

114. Shen $Y$, Lee R, Frenkel E, et al. IgA antiphospholipid antibodies are an independent risk factor for thromboses. Lupus 2008; 17: 996-1003.

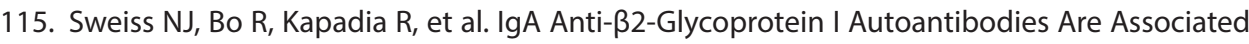
with an Increased Risk of Thromboembolic Events in Patients with Systemic Lupus Erythematosus. PLoS ONE 2010; 5: e12280.

116. Tortosa C, Cabrera-Marante O, Serrano M, et al. Incidence of thromboembolic events in asymptomatic carriers of IgA anti B2 glycoprotein-I antibodies. PLOS ONE 2017; 12: e0178889.

117. Bertolaccini $M$, Amengual $\mathrm{O}$, Atsumi T, et al. 'Non-criteria' aPL tests: report of a task force and preconference workshop at the 13th International Congress on Antiphospholipid Antibodies, Galveston, TX, USA, April 2010. Lupus 2011; 20: 191-205.

118. Mehrani T, Petri M. Association of IgA Anti-ß2 Glycoprotein I with Clinical and Laboratory Manifestations of Systemic Lupus Erythematosus. J Rheumatol 2011; 38: 64-8.

119. Meijide H, Sciascia S, Sanna G, et al. The clinical relevance of $\lg A$ anticardiolipin and IgA anti- $\beta 2$ glycoprotein I antiphospholipid antibodies: A systematic review. Autoimmun Rev 2013; 12: 421-5.

120. Sciascia S, Sanna G, Murru V, et al. Anti-prothrombin (aPT) and anti-phosphatidylserine/ prothrombin (aPS/PT) antibodies and the risk of thrombosis in the antiphospholipid syndrome: A systematic review. Thromb Haemost 2014; 111: 354-64.

121. Sciascia S, Khamashta MA, Bertolaccini ML. New tests to detect antiphospholipid antibodies: antiprothrombin (aPT) and anti-phosphatidylserine/prothrombin (aPS/PT) antibodies. Curr Rheumatol Rep 2014; 16: 415.

122. Bertolaccini ML, Atsumi T, Koike T, et al. Antiprothrombin antibodies detected in two different assay systems. Prevalence and clinical significance in systemic lupus erythematosus. Thromb Haemost 2005; 93: 289-97.

123. Bertolaccini ML, Gomez S, Pareja JFP, et al. Antiphospholipid antibody tests: spreading the net. Ann Rheum Dis 2005; 64: 1639-43.

124. Galli M, Barbui T. Antiprothrombin Antibodies: Detection and Clinical Significance in the Antiphospholipid Syndrome. Blood American Society of Hematology; 1999; 93: 2149-57.

125. Litvinova E, Darnige L, Kirilovsky A, et al. Prevalence and Significance of Non-conventional Antiphospholipid Antibodies in Patients With Clinical APS Criteria. Front Immunol 2018; 9: 2971

126. Sciascia S, Sanna G, Murru V, et al. GAPSS: the Global Anti-Phospholipid Syndrome Score. Rheumatology (Oxford) 2013; 52: 1397-403.

127. Tonello M, Mattia E, Favaro M, et al. IgG phosphatidylserine/prothrombin antibodies as a risk factor of thrombosis in antiphospholipid antibody carriers. Thromb Res 2019; 177: 157-60.

128. Pengo V, Ruffatti $A$, Legnani $C$, et al. Clinical course of high-risk patients diagnosed with antiphospholipid syndrome. J Thromb Haemost 2010; 8: 237-42. 
129. Sciascia S, Murru V, Sanna G, et al. Clinical accuracy for diagnosis of antiphospholipid syndrome in systemic lupus erythematosus: evaluation of 23 possible combinations of antiphospholipid antibody specificities. J Thromb Haemost 2012; 10: 2512-8.

130. Gris J-C, Bouvier S, Molinari N, et al. Comparative incidence of a first thrombotic event in purely obstetric antiphospholipid syndrome with pregnancy loss: the NOH-APS observational study. Blood 2012; 119: 2624-32.

131. Pengo V, Biasiolo A, Pegoraro C, et al. Antibody profiles for the diagnosis of antiphospholipid syndrome. Thromb Haemost 2005; 93: 1147-52.

132. Pengo V, Biasiolo A, Gresele $P$, et al. A comparison of lupus anticoagulant-positive patients with clinical picture of antiphospholipid syndrome and those without. Arterioscler Thromb Vasc Biol 2007; 27: e309-310.

133. de Groot PG, Lutters B, Derksen RHWM, et al. Lupus anticoagulants and the risk of a first episode of deep venous thrombosis. J Thromb Haemost 2005; 3: 1993-7.

134. de Laat HB, Derksen RHWM, Urbanus RT, et al. beta2-glycoprotein I-dependent lupus anticoagulant highly correlates with thrombosis in the antiphospholipid syndrome. Blood 2004; 104: 3598-602.

135. Rampazzo P, Biasiolo A, Garin J, et al. Some Patients with Antiphospholipid Syndrome Express hitherto Undescribed Antibodies to Cardiolipin-binding Proteins. Thromb Haemost 2001; 85: 57-62.

136. Pengo V, Bison E, Denas G, et al. Laboratory Diagnostics of Antiphospholipid Syndrome. Semin Thromb Hemost 2018; 44: 439-44.

137. Arvieux J, Renaudineau Y, Mane I, et al. Distinguishing features of anti-beta2 glycoprotein I antibodies between patients with leprosy and the antiphospholipid syndrome. Thromb Haemost 2002; 87: 599-605.

138. Kearon C, Parpia S, Spencer FA, et al. Antiphospholipid antibodies and recurrent thrombosis after a first unprovoked venous thromboembolism. Blood 2018; 131: 2151-60.

139. Wahl D. "Antiphospholipids": the more, the worse? Blood 2018; 131: 2092-4.

140. Lazzaroni M-G, Fredi M, Andreoli L, et al. Triple Antiphospholipid (aPL) Antibodies Positivity Is Associated With Pregnancy Complications in aPL Carriers: A Multicenter Study on 62 Pregnancies. Front Immunol 2019; 10: 1948.

141. Mustonen P, Lehtonen KV, Javela K, et al. Persistent antiphospholipid antibody (aPL) in asymptomatic carriers as a risk factor for future thrombotic events: a nationwide prospective study. Lupus 2014; 23: 1468-76.

142. Pengo V, Ruffatti A, Legnani C, et al. Incidence of a first thromboembolic event in asymptomatic carriers of high-risk antiphospholipid antibody profile: a multicenter prospective study. Blood 2011; 118: 4714-8.

143. Kelchtermans $H$, Pelkmans L, Laat B de, et al. lgG/lgM antiphospholipid antibodies present in the classification criteria for the antiphospholipid syndrome: a critical review of their association with thrombosis. J Thromb Haemost 2016; 14: 1530-48.

144. Boffa M-C, Boinot C, De Carolis S, et al. Laboratory criteria of the obstetrical antiphospholipid syndrome. Data from a multicentric prospective European women cohort. Thromb Haemost 2009; 102: 25-8. 

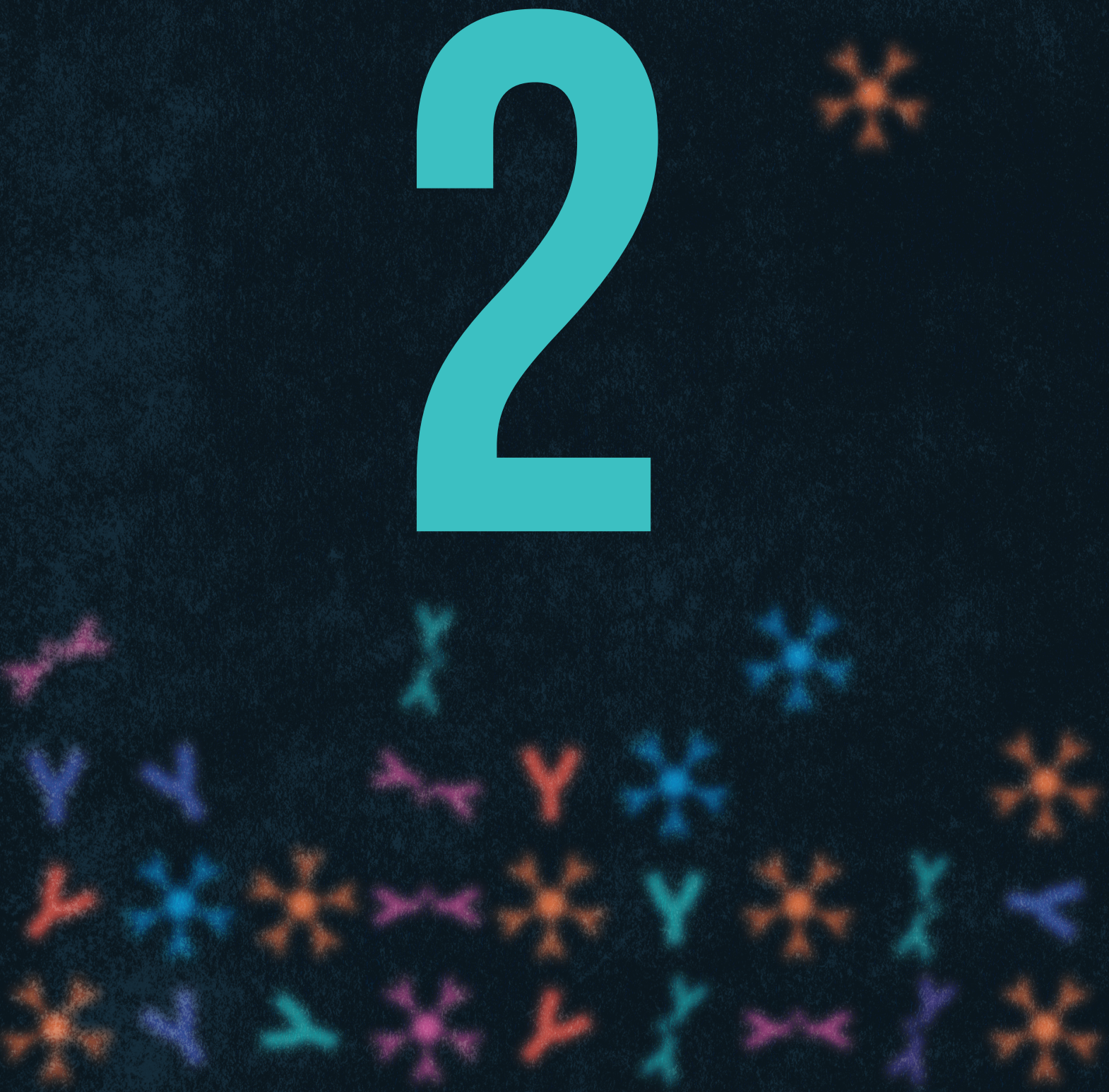


\section{Detection of anti-cardiolipin and anti- $\beta 2$ glycoprotein I antibodies differs between platforms without influence on association with clinical symptoms}

Walid Chayoua, Hilde Kelchtermans, Gary W. Moore, Jean-Christophe Gris, Jacek Musial, Denis Wahl, Stéphane Zuily, Francesca Gianniello, Pierre Fontana, Jasper Remijn, Rolf T. Urbanus, Bas de Laat, Katrien M. J. Devreese

Thromb Haemost. 2019; 119: 797-806 


\section{ABSTRACT}

Background: The antiphospholipid syndrome (APS) is characterized by thrombosis and/or pregnancy morbidity with persistent presence of antiphospholipid antibodies (aPL). Laboratory criteria include aPL detection by coagulation tests for lupus anticoagulant (LAC) or solid phase assays measuring anti- $\beta 2$ glycoprotein I (aß2GPI) or anti-cardiolipin (aCL) immunoglobulin (lg) $\mathrm{G} / \mathrm{lgM}$ antibodies. External quality control programs illustrate that commercially available aPL assays produce variable results.

Objective: We aimed to investigate the agreement and diagnostic accuracy of solid phase assays.

Materials and Methods: In this multi-centre study, 1,168 patient samples were tested on one site for $\mathrm{aCL}$ and $\mathrm{a} \beta 2 \mathrm{GPI} \mathrm{lgG} / \mathrm{lgM}$ antibodies by four solid phase test systems. Samples included APS patients, controls and monoclonal antibodies (MoAB) against different epitopes of $\beta 2$ GPI. LAC was determined by the local centre.

Results: aCL IgM assays resulted in the most discrepancies (60\%), while aCL IgG and aß2GPI IgM assays resulted in lower discrepancies (36\%), suggesting better agreement. Discrepant samples displayed lower median aPL titers. Dependent on the solid phase test system, odds ratios ORs for thrombosis and pregnancy morbidity ranged from 1.98 to 2.56 and 3.42 to 4.78 , respectively. Three platforms showed lower sensitivity for MoAB directed against the glycine (Gly) 40-arginine (Arg) 43 epitope of domain I of $\beta 2 \mathrm{GPI}$.

Conclusion: Poor agreement was observed between different commercially available $\mathrm{aCL}$ and aß2GPI IgG/lgM assays, hampering uniformity in the identification of aPLpositive patients. Clinical association was globally concordant between solid phase test systems considering results of the four aPL together. An assay sensitive in detecting the MoAB against Gly40-Arg43 of domain I of $\beta 2$ GPI reached the highest OR for thrombosis. 


\section{INTRODUCTION}

The anti-phospholipid syndrome (APS) is characterized by thrombosis and/or pregnancy morbidity with the persistent presence of anti-phospholipid antibodies (aPL) (1). Laboratory criteria include $\mathrm{aPL}$ detection by phospholipid-dependent prolongation of coagulation tests referred to as lupus anticoagulant (LAC) or by solid phase assays measuring anti- $\beta 2$ glycoprotein I (a $\beta 2 \mathrm{GPI})$ and anti-cardiolipin $(\mathrm{aCL})$ immunoglobulin (lg) G/lgM antibodies (1). For the classification of APS at least one clinical and one persistent positive laboratory criterion is required (1). Given the high frequency of clinical manifestations (thrombosis and pregnancy morbidity) associated with APS in the general population, laboratory tests are of utmost importance for the classification of patients with APS. Although LAC positivity is considered the strongest predictor of clinical manifestations of APS, $\mathrm{aCL}$ and $\mathrm{a} \beta 2 \mathrm{GPI} \operatorname{lgG} / \mathrm{lgM}$ antibodies have the same value in the current classification criteria (1-5)

Anti- $\beta 2$ GPI antibodies are detected using $\beta 2 \mathrm{GPI}$ as antigen, while both cardiolipin and $\beta 2 \mathrm{GPI}$ are used as antigens in aCL immunoassays. The use of antigens from human sources is preferred above antigens from animal origin (e.g. bovine) to avoid falsepositives (6). In contrast to a $32 \mathrm{GPI}$ immunoassays, antigens used in $\mathrm{aCL}$ immunoassays are not exclusively from human origin (Supplemental Table 1). Traditionally, aCL and aß2GPI antibodies are detected with an enzyme-linked immunosorbent assay (ELISA). Nowadays, more advanced and automated systems have become available for the detection of $\mathrm{aCL}$ and $\mathrm{a} \beta 2 \mathrm{GPI}$ aPL (7-10). Automated systems make use of an alternative solid phase (e.g. magnetic beads) and use alternative detection methods, such as chemiluminescence or (enzyme linked) fluorescence. A large variety of assays are used in clinical laboratories as there is no consensus on a 'gold standard' for the detection of $\mathrm{aCL}$ and $\mathrm{a} \beta 2 \mathrm{GPI}$ aPL (6). Reports from external quality control programs illustrate that $\mathrm{aPL}$ assays produce variable results $(11,12)$. Detection of a $32 \mathrm{GPI}$ antibodies is challenging as some antibodies may be directed against a cryptic epitope that is only exposed after conformational shape change $(13,14)$. Exposure of this cryptic epitope, spanning glycine (Gly) 40-arginine (Arg) 43 in the first domain of $\beta 2 \mathrm{GPI}$, has been shown to vary across commercial a $32 \mathrm{GPI}$ IgG assays $(7,15)$. In addition, variability between assays might be due to the heterogeneous origin of $\mathrm{aPL}$, differences in local working conditions, differences in assay design and a lack of standardization (6). As classification of APS heavily depends on the detection of aPL, variation within these tests will affect the treatment strategy.

Therefore, we aimed to investigate the agreement and diagnostic accuracy of commonly used commercially available solid phase assays measuring $\lg G$ and $\lg M a C L$ and aß2GPI 
aPL. Samples and normal pooled plasma supplemented with monoclonal antibodies (MoAB) against different domains of $\beta 2 \mathrm{GPI}$ were tested with four assays at one location by a single technician to exclude inter-laboratory and inter-operator variation.

\section{MATERIALS AND METHODS}

\section{Patient cohort}

We obtained 1,168 samples from 8 European centers. Classification of APS was based on the Sydney criteria (1). Patients were classified by the corresponding centre resulting in 259 thrombotic APS patients (APS thrombosis), 204 patients with a history of thrombosis and negative for laboratory criteria of APS (non-APS thrombosis), 122 obstetric APS patients (APS obstetric), 33 patients with pregnancy complications and negative for laboratory criteria of APS (non-APS obstetric), 196 patients with an autoimmune disease other than APS (autoimmune diseases), 100 individuals with a normal pregnancy (normal pregnancy), 194 controls that were referred for aPL testing for other reasons than the clinical criteria of APS, like subfertility and prolonged activated partial thromboplastin time (controls) and 60 women that were diagnosed with APS without information on the specification of the clinical manifestations (unspecified APS). Centers with the indicated number of samples included Ghent (469), London (196), Nîmes (164), Nancy (114), Kraków (101), Milan (52), Geneva (50) and Apeldoorn (22). The study was approved by the central and the local ethical committees.

\section{Assays}

$\mathrm{aCL} \operatorname{lgG}, \mathrm{aCL} \lg \mathrm{M}, \mathrm{a} \beta 2 \mathrm{GPI} \lg \mathrm{G}$ and $\mathrm{a} \beta 2 \mathrm{GPI} \operatorname{lgM}$ aPL were measured in the Ghent University Hospital (Ghent, Belgium) by four commercially available immunoassays: BioPlex2200 (Bio-Rad, Bio-Rad Laboratories, Hercules, USA), ImmunoCapEliA (Thermo Fisher Scientific/Phadia, Uppsala, Sweden), ACL AcuStar (Werfen/Instrumentation Laboratories, Bedford, USA) and QUANTA Lite ELISA (Inova Diagnostics, San Diego, USA) (Supplemental Table 1). Assays were selected based on frequently used assays in the External quality Control of diagnostic Assays and Tests program and the willingness of manufacturers for collaboration. Due to shortage of patient sample, three and two patients were excluded for aCL IgG and aß2GPI IgG detection by BioPlex2200, respectively. Manufacturers' recommended cut-off values were used upon confirmation in 20 healthy volunteers, in accordance with the Scientific and Standardization committee (SSC) guidelines of the International Society on Thrombosis and Haemostasis (16). Assays were performed according to the manufacturer's instructions. All four methods were performed in parallel in runs of 40 samples. According to the 
guidelines, single measurement was used on the automated systems (BioPlex2200, ImmunoCapEliA and ACL AcuStar) as the intra- and inter-run imprecision coefficient of variation was $<10 \%$ and duplicate measurement for the ELISA (QUANTA Lite ELISA) (16). aPL titers were expressed in arbitrary units (GPL, MPL, U/ml, SGU and SMU). All samples were measured by the same technician and values below the calculated limit of detection (LOD) were replaced by the calculated LOD.

\section{Monoclonal antibodies}

Two human-derived MoAB P2-6 and P1-117 were used to test the specificity and sensitivity of the four commercially available $\mathrm{aCL}$ and $\mathrm{a} \beta 2 \mathrm{GPI}$ lgG assays. P2-6 recognizes $\beta 2 \mathrm{GPI}$ independently of its conformation and $\mathrm{P} 1-117$ recognizes $\beta 2 \mathrm{GPI}$ in its open conformation binding to the Gly40-Arg43 epitope of the domain I $(15,17)$. Serial dilutions of antibodies $(0-250 \mu \mathrm{g} / \mathrm{ml})$ in normal pooled plasma were tested in duplicate for all platforms included in the study. Platforms were used according to the manufacturer's recommendations and these spiked samples were handled as patient samples and tested in the same conditions. The threshold for positivity corresponding to a positive titer of $\mathrm{aCL}$ or $\mathrm{a} \beta 2 \mathrm{GPI}$ was determined.

\section{Statistical analysis}

Solid phase assays were compared pairwise as no 'gold standard' for aPL detection exists. Agreement between assays in positivity was assessed by $2 \times 2$ contingency tables in all measured samples. Comparison of discrepancies between aCL lgG, aCL IgM and $a \beta 2$ GPI IgG and a 32 GPIgM positivity was calculated: positivity discrepancy $(\%)=$ (only positive for method A + only positive for method B) / (all positives) x 100. Median $\mathrm{aPL}$ titers within one platform were calculated with titers above the cut-off value. Correlation between solid phase assays was performed by a Spearman's rank correlation coefficient. Diagnostic accuracy was assessed by calculating odds ratios, sensitivity, specificity, negative predictive value (NPV), positive predictive value (PPV) and the receiver operator curve (ROC). The area under the ROC curve between solid phase assays was compared using DeLong et al.'s method (18). Significance of differences was determined with the Mann-Whitney $U$ test, as appropriate using the statistical package for social sciences (SPSS 23.0; SPSS, Chicago, Illinois, United States) and MedCalc Statistical Software version 17.7.2 (MedCalc Software bvba, Ostend, Belgium). 


\section{RESULTS}

We measured $\mathrm{aCL} \operatorname{lgG} / \operatorname{lgM}$ and $\mathrm{a} \beta 2 \mathrm{GPI} \lg \mathrm{g} / \mathrm{lgM}$ aPL in 1,168 individuals with a mean age of 43 years ranging from 16 to 87 years old (Table 1 ) with four commercially available assays (Supplemental Table 1).

TABLE 1. Demographic and clinical characteristics of the study population

\begin{tabular}{|c|c|c|c|c|c|c|c|c|c|}
\hline & \multirow[b]{2}{*}{ 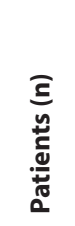 } & \multirow[b]{2}{*}{$\begin{array}{l}\frac{0}{\pi} \\
\text { हैं } \\
\text { है }\end{array}$} & \multirow[b]{2}{*}{ 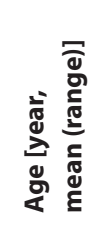 } & \multirow[b]{2}{*}{ 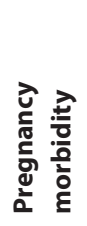 } & \multicolumn{5}{|c|}{ Thrombosis } \\
\hline & & & & & $\begin{array}{l}\frac{n}{0} \\
\stackrel{0}{0} \\
\stackrel{0}{J}\end{array}$ & 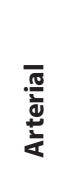 & 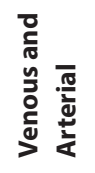 & $\begin{array}{l}\overline{\bar{\Xi}} \overline{\tilde{\nu}} \\
\overline{\tilde{y}} \\
\bar{\nu}\end{array}$ & 훌 \\
\hline $\begin{array}{l}\text { APS } \\
\text { thrombosis }\end{array}$ & 259 & $\begin{array}{c}164 \\
(63 \%)\end{array}$ & $\begin{array}{c}50 \\
(17-87)\end{array}$ & 22 & 160 & 55 & 26 & 4 & 14 \\
\hline $\begin{array}{l}\text { Non-APS } \\
\text { thrombosis }\end{array}$ & 204 & $\begin{array}{c}116 \\
(57 \%)\end{array}$ & $\begin{array}{c}46 \\
(19-85)\end{array}$ & 0 & 149 & 47 & 5 & 0 & 3 \\
\hline $\begin{array}{l}\text { APS } \\
\text { obstetric }\end{array}$ & 122 & $\begin{array}{c}122 \\
(100 \%)\end{array}$ & $\begin{array}{c}35 \\
(19-61)\end{array}$ & 122 & 4 & 2 & 0 & 0 & 4 \\
\hline $\begin{array}{l}\text { Non-APS } \\
\text { obstetric }\end{array}$ & 33 & $\begin{array}{c}33 \\
(100 \%)\end{array}$ & $\begin{array}{c}33 \\
(20-52)\end{array}$ & 33 & NA & NA & NA & NA & NA \\
\hline $\begin{array}{l}\text { Autoimmune } \\
\text { diseases }\end{array}$ & 196 & $\begin{array}{c}158 \\
(81 \%)\end{array}$ & $\begin{array}{c}46 \\
(16-83)\end{array}$ & NA & NA & NA & NA & NA & NA \\
\hline $\begin{array}{l}\text { Normal } \\
\text { pregnancy }\end{array}$ & 100 & $\begin{array}{c}100 \\
(100 \%)\end{array}$ & $\begin{array}{c}31 \\
(27-36)\end{array}$ & 0 & NA & NA & NA & NA & NA \\
\hline Controls & 194 & $\begin{array}{c}170 \\
(88 \%)\end{array}$ & $\begin{array}{c}39 \\
(18-82)\end{array}$ & NA & NA & NA & NA & NA & NA \\
\hline $\begin{array}{l}\text { Unspecified } \\
\text { APS }\end{array}$ & 60 & $\begin{array}{c}60 \\
(100 \%)\end{array}$ & $\begin{array}{c}48 \\
(24-70)\end{array}$ & NS & NS & NS & NS & NS & NS \\
\hline $\begin{array}{l}\text { Total } \\
\text { population }\end{array}$ & 1168 & $\begin{array}{c}923 \\
(79 \%)\end{array}$ & $\begin{array}{c}43 \\
(16-87)\end{array}$ & 177 & 313 & 104 & 31 & 4 & 21 \\
\hline
\end{tabular}

Abbreviations: APS, anti-phospholipid syndrome; $N A=$ not applicable; $N S=$ not specified.

Laboratory criteria for the classification of APS require at least one positive aPL. We therefore compared positivity for at least one aPL between platforms using $2 \mathrm{x}$ 2 contingency tables (Table 2). Discrepancies varied between 79 (ACL AcuStar vs. BioPlex2200) and 164 (ACL AcuStar vs. ImmunoCapEliA) samples. aCL IgM and aß2GPI IgG positivity resulted in the most discrepancies, varying from 69 to 162 and 44 to 153 samples, respectively (Table 3 ). On the other hand, aCL IgG and aß2GPI IgM positivity 
resulted in less discrepancies between assays, varying from 49 to 98 and 34 to 58 samples, respectively. Comparison of discrepancies between aCL $\operatorname{lgG} / \operatorname{lgM}$ and aß2GPI $\mathrm{lgG/IgM} \mathrm{positivity} \mathrm{was} \mathrm{calculated} \mathrm{by} \mathrm{the} \mathrm{percentage} \mathrm{of} \mathrm{discrepancies} \mathrm{from} \mathrm{all} \mathrm{positives,}$ resulting in a maximum discrepancy of $36,60,53$ and $36 \%$ for aCL IgG, aCL IgM, aß2GPI IgG and aß2GPI IgM positivity, respectively. In accordance, aCL IgM titers were less correlated between the solid phase assays compared to aCL IgG and aß2GPI IgM with Spearman's rank correlation coefficients.

TABLE 2. Number of samples positive for aCL IgG, aCL IgM, aß2GPI IgG or a $32 \mathrm{GPI} \lg M$ by BioPlex2200, ImmunoCapEliA, ACL AcuStar and QUANTA Lite ELISA are compared pairwise

\begin{tabular}{|c|c|c|c|c|c|c|c|}
\hline & & \multicolumn{2}{|c|}{ BioPlex 2200} & \multicolumn{2}{|c|}{ ImmunoCap EliA } & \multicolumn{2}{|c|}{ ACL AcuStar } \\
\hline & & - & + & - & + & - & + \\
\hline \multirow[t]{2}{*}{ BioPlex 2200} & - & & & & & & \\
\hline & + & & & & & & \\
\hline \multirow[t]{2}{*}{ ImmunoCap EliA } & - & 755 & 37 & & & & \\
\hline & + & 108 & 268 & & & & \\
\hline \multirow[t]{2}{*}{ ACL AcuStar } & - & 795 & 11 & 717 & 89 & & \\
\hline & + & 68 & 294 & 75 & 287 & & \\
\hline \multirow[t]{2}{*}{ QUANTA Lite ELISA } & - & 792 & 64 & 751 & 105 & 753 & 103 \\
\hline & + & 71 & 241 & 41 & 271 & 53 & 259 \\
\hline
\end{tabular}

Abbreviations: $a C L$, anti-cardiolipin; a $\beta 2$ GPI anti- $\beta 2$ glycoprotein l; lg, immunoglobulin.

In accordance, aCL IgM titers were less correlated between the solid phase assays compared to aCL IgG and aß2GPI IgM with Spearman's rank correlation coefficients of $\geq 0.514$ (95\% confidence interval [Cl], 0.471-0.555), $\geq 0.635(95 \% \mathrm{Cl}, 0.599-0.668)$ and $\geq 0.738(95 \% \mathrm{Cl}, 0.711-0.763)$ respectively (Table 4$)$.

aPL positive samples not in agreement across the platforms were characterized by lower median aPL titers than positives in agreement (Figure 1). However, for the majority of discrepancies observed, respective individuals suffered from clinical manifestations of APS (thrombosis and/or pregnancy morbidity) (Figure 1). Clinical implications of the observed (dis)agreements were assessed by calculating the sensitivity, specificity, NPV, PPV and OR for thrombosis, pregnancy morbidity or both clinical criteria (Table 5). Positivity was defined when at least one aPL was positive. Clinically affected and non-clinically affected patients were set as outcome variable rather than APS/non-APS in order to be independent of aPL presence previously detected by the medical centers 
TABLE 3. Discrepancies in aPL positivity detection between platforms

\begin{tabular}{|c|c|c|c|c|c|c|c|c|}
\hline & & & \multicolumn{2}{|c|}{ BioPlex $® 2200$} & \multicolumn{2}{|c|}{ ImmunoCap $®$ EliA } & \multicolumn{2}{|c|}{ ACL AcuStar ${ }^{\circledR}$} \\
\hline & & & - & + & - & + & - & + \\
\hline \multirow[t]{8}{*}{ A } & BioPlex@ 2200 & - & & & & & & \\
\hline & & + & & & & & & \\
\hline & ImmunoCap $®$ EliA & - & 892 & 59 & & & & \\
\hline & & + & 25 & 190 & & & & \\
\hline & ACL AcuStar ${ }^{\circledast}$ & - & 905 & 37 & 913 & 30 & & \\
\hline & & + & 12 & 212 & 40 & 185 & & \\
\hline & QUANTA Lite ELISA ${ }^{\circledR}$ & - & 897 & 78 & 913 & 46 & 919 & 58 \\
\hline & & + & 20 & 171 & 22 & 169 & 24 & 167 \\
\hline
\end{tabular}

B BioPlex® 2200

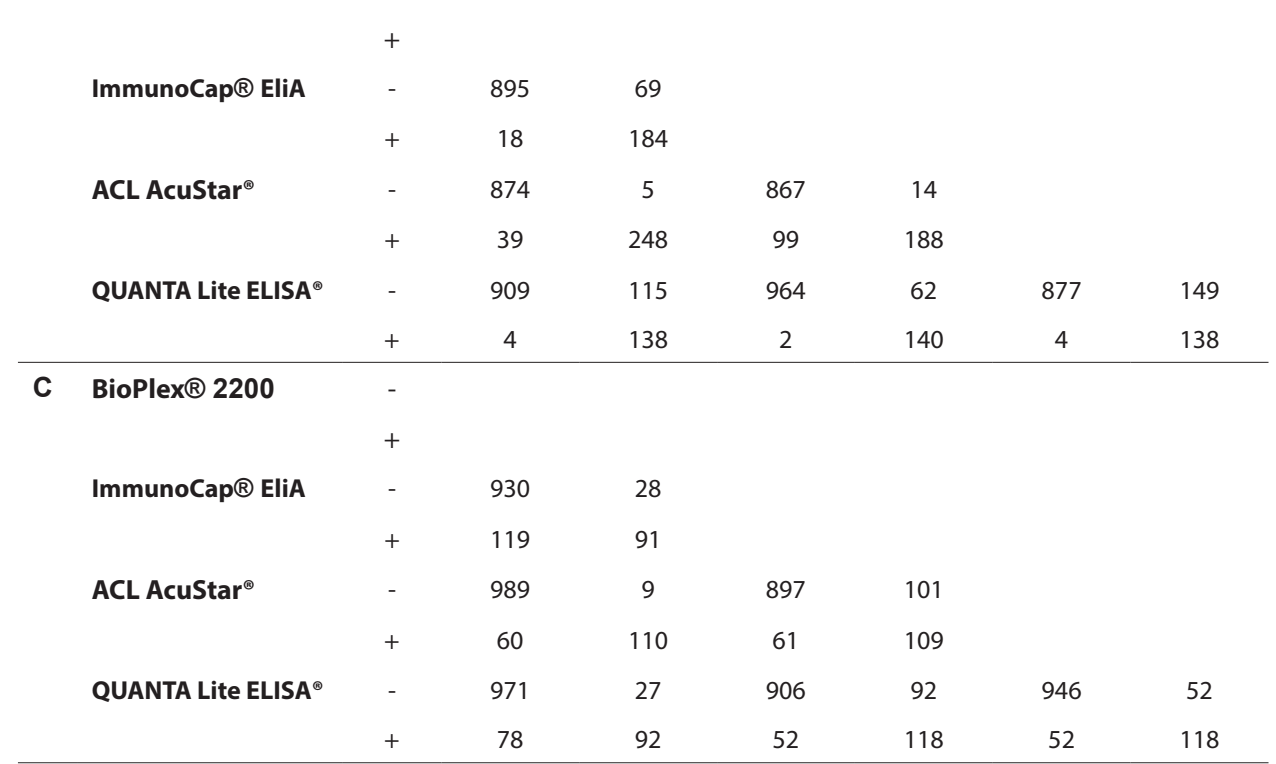

\section{BioPlex® 2200}

\begin{tabular}{|c|c|c|c|c|c|c|c|}
\hline \multirow[t]{2}{*}{ ImmunoCap $®$ EliA } & - & 1007 & 23 & & & & \\
\hline & + & 29 & 109 & & & & \\
\hline \multirow[t]{2}{*}{ ACL AcuStar ${ }^{\circledast}$} & - & 1028 & 26 & 1024 & 30 & & \\
\hline & + & 8 & 106 & 6 & 108 & & \\
\hline \multirow[t]{2}{*}{ QUANTA Lite ELISA ${ }^{\circledR}$} & - & 997 & 19 & 996 & 20 & 1006 & 10 \\
\hline & + & 39 & 113 & 34 & 118 & 48 & 104 \\
\hline
\end{tabular}


A

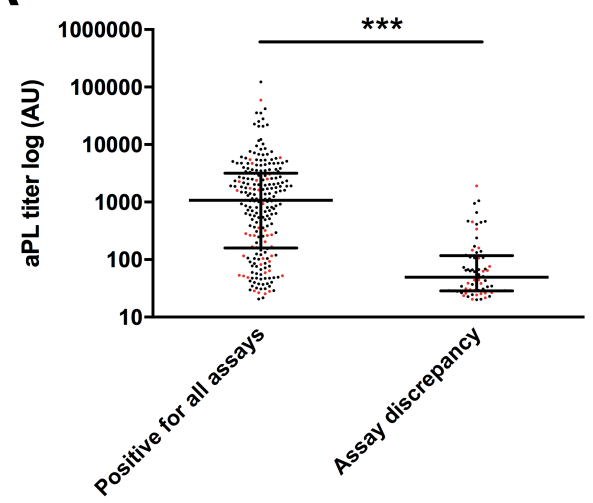

B

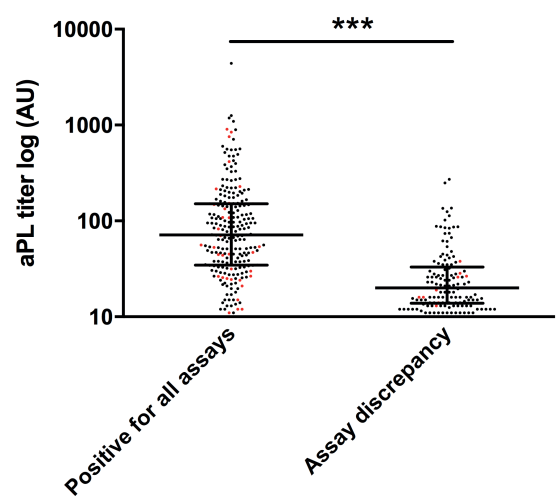

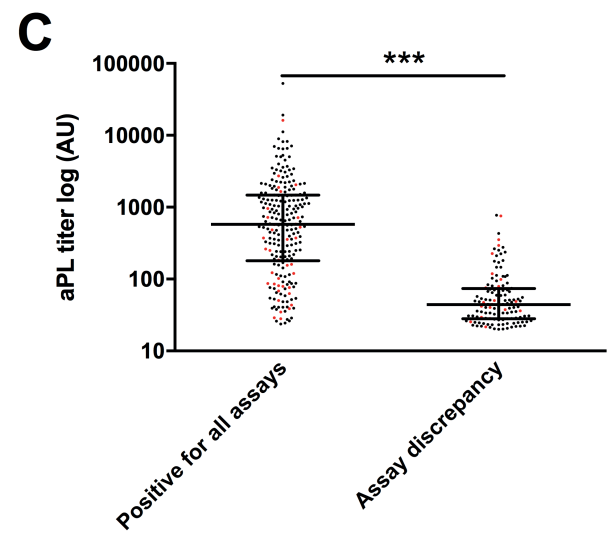

D

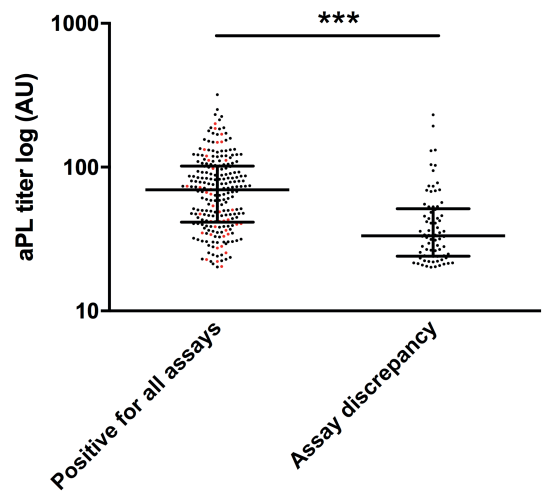

FIGURE 1. Anti-phospholipid antibodies (aPL) titers of samples in (dis)agreement. Titers of samples positive for all assays and assay discrepancies are shown as detected with (A) BioPlex2200, (B) ImmunoCapEliA, (C) ACL AcuStar and (D) QUANTA Lite ELISA. Patients with thrombosis and/or pregnancy morbidity are indicated in black and without in red. Titers are expressed as the median value of positive aPL titers with interquartile ranges. ${ }^{* * *} \mathrm{p}<0.001 . \mathrm{AU}$, arbitrary units.

that collected the samples, minimizing selection bias. Independent from the assay used, a statistically significant association with thrombosis and/or pregnancy morbidity was found. ORs for thrombosis varied between $1.98(95 \% \mathrm{Cl}, 1.46-2.69)$ and $2.56(95 \%$ $\mathrm{Cl}, 1.82-3.59)$ detected by ImmunoCapEliA and BioPlex2200, respectively. ORs for pregnancy morbidity ranged between $3.42(95 \% \mathrm{Cl}, 2.32-5.05)$ and $4.78(95 \% \mathrm{Cl}, 3.14-$ 7.27) detected by ImmunoCapEliA and QUANTA Lite ELISA, respectively. Although not the most sensitive aPL detection platform for thrombosis and/or pregnancy morbidity, the QUANTA Lite ELISA resulted in the highest specificity $(87.76 \%[95 \% \mathrm{Cl}, 84.52-90.52 \%]$ ) 
and OR (4.24 [95\% Cl, 3.10-5.79]). PPVs for thrombosis and/or pregnancy morbidity ranged from $74.73 \%(95 \% \mathrm{Cl}, 70.74-78.35 \%)$ to $80.77 \%(95 \% \mathrm{Cl}, 76.47-84.44 \%)$ and NPVs ranged from $49.71 \%(95 \% \mathrm{Cl}, 48.07-51.35 \%)$ to $50.23 \%(95 \% \mathrm{Cl}, 48.57-51.90 \%)$ as shown in Table 5. The area under the ROC curve of the solid phase assays for thrombosis and/ or pregnancy morbidity was low as expected and was not significantly different among the tested solid phase assays.

BioPlex2200 aCL and a $32 \mathrm{GPI}$ IgG showed the highest and equal sensitivity for both MoAB P2-6, that recognizes $\beta 2 \mathrm{GPI}$ independently of its conformation, and P1-117, which only recognizes $\beta 2$ GPI upon exposure of the Gly40-Arg43 epitope in domain I (Table 6). ACL AcuStar aCL and a 32 GPI IgG sensitivity was slightly lower for P1-117, in the same extent for $\mathrm{aCL}$ and $\mathrm{a} \beta 2 \mathrm{GPI}$. QUANTA Lite ELISA and ImmunoCapEliA showed much lower sensitivity for P2-6 and P1-117, with large difference in sensitivity for P2-6 and P1-117. Both aCL assays did not detect P1-117 at all. OR for thrombosis and/or pregnancy morbidity for aCL and aß2GPI (Table 5) ranged from 4.24 to 6.12 and 3.49 to 6.56 , respectively. The platform (BioPlex2200) with the highest sensitivity in detecting the $\mathrm{P} 1-117$ MoAB also reached the highest OR for thrombosis, but not for pregnancy morbidity.

TABLE 4. Correlation between $\mathrm{aCL} \lg G, \mathrm{aCL} \lg \mathrm{M}, \mathrm{a} \beta 2 \mathrm{GPI} \lg \mathrm{G}$ and $\mathrm{a} \beta 2 \mathrm{GPI}$ lgM titers of solid phase assays

\begin{tabular}{|c|c|c|c|c|}
\hline & $\begin{array}{l}\text { aCL IgG } \\
(95 \% \mathrm{CI})\end{array}$ & $\begin{array}{l}\text { aCL IgM } \\
(95 \% \mathrm{CI})\end{array}$ & $\begin{array}{c}\text { aß2GPI lgG } \\
(95 \% \mathrm{Cl})\end{array}$ & $\begin{array}{c}\text { aß2GPI lgM } \\
(95 \% \mathrm{Cl})\end{array}$ \\
\hline BioPlex2200 vs & 0.712 & 0.514 & 0.784 & 0.739 \\
\hline ImmunoCapEliA & $(0.682-0.739)$ & $(0.471-0.555)$ & $(0.716-0.806)$ & $(0.712-0.764)$ \\
\hline BioPlex2200 vs & 0.767 & 0.803 & 0.900 & 0.813 \\
\hline ACL AcuStar & $(0.742-0.789)$ & $(0.781-0.822)$ & $(0.889-0.911)$ & $(0.792-0.831)$ \\
\hline BioPlex2200 vs QUANTA Lite & 0.744 & 0.586 & 0.676 & 0.701 \\
\hline ELISA & $(0.717-0.768)$ & $(0.547-0.622)$ & $(0.644-0.706)$ & $(0.671-0.729)$ \\
\hline ImmunoCapEliA vs ACL & 0.635 & 0.521 & 0.758 & 0.775 \\
\hline AcuStar & $(0.599-0.668)$ & $(0.478-0.562)$ & $(0.732-0.781)$ & $(0.752-0.797)$ \\
\hline ImmunoCapEliA vs QUANTA & 0.716 & 0.562 & 0.686 & 0.764 \\
\hline Lite ELISA & $(0.687-0.743)$ & $(0.521-0.600)$ & $(0.655-0.716)$ & $(0.739-0.787)$ \\
\hline ACL AcuSta vs QUANTA Lite & 0.673 & 0.580 & 0.632 & 0.738 \\
\hline ELISA & $(0.640-0.703)$ & $(0.541-0.617)$ & $(0.596-0.665)$ & $(0.711-0.763)$ \\
\hline
\end{tabular}

Abbreviations: aCL, anti-cardiolipin; a $32 \mathrm{GPI}$, anti- $\beta 2$ glycoprotein I; Cl, Confidence interval; Ig, immunoglobulin. Note: Spearman Rank Correlation rho coefficients with their respective $95 \%$ confidence intervals are shown. 
TABLE 5. Diagnostic accuracy of aPL detection by BioPlex2200, ImmunoCapEliA, ACL AcuStar and QUANTA Lite ELISA. Samples were defined as positive if at least one aPL was positive, excluding LAC.

\begin{tabular}{|c|c|c|c|c|c|c|}
\hline & $\begin{array}{l}\text { Sensitivity } \\
(\%, 95 \% \mathrm{CI})\end{array}$ & $\begin{array}{l}\text { Specificity } \\
(\%, 95 \% \mathrm{CI})\end{array}$ & $\begin{array}{c}\text { PPV } \\
(\%, 95 \% \mathrm{CI})\end{array}$ & $\begin{array}{c}\text { NPV } \\
(\%, 95 \% \mathrm{CI})\end{array}$ & $\begin{array}{l}\text { Odds ratio } \\
(95 \% \mathrm{Cl})\end{array}$ & $\begin{array}{c}\text { AUC }^{a} \\
(95 \% \mathrm{Cl})\end{array}$ \\
\hline \multicolumn{7}{|c|}{ Thrombosis $\mathrm{N}=853^{\mathrm{b}}$} \\
\hline $\begin{array}{l}\text { BioPlex }^{\circledast} \\
2200\end{array}$ & $\begin{array}{c}31.32 \\
(27.12-35.76)\end{array}$ & $\begin{array}{c}84.87 \\
(80.92-88.28)\end{array}$ & $\begin{array}{c}71.08 \\
(65.21-76.32)\end{array}$ & $\begin{array}{c}51.00 \\
(49.14-52.86)\end{array}$ & $\begin{array}{c}2.56 \\
(1.82-3.59)\end{array}$ & $\begin{array}{c}0.58 \\
(0.55-0.61)\end{array}$ \\
\hline $\begin{array}{l}\text { ImmunoCap } \\
{ }^{\circledR} \text { EliA }\end{array}$ & $\begin{array}{c}36.29 \\
(31.90-40.85)\end{array}$ & $\begin{array}{c}77.69 \\
(73.23-81.73)\end{array}$ & $\begin{array}{c}65.88 \\
(60.75-70.66)\end{array}$ & $\begin{array}{c}50.67 \\
(48.5-52.84)\end{array}$ & $\begin{array}{c}1.98 \\
(1.46-2.69)\end{array}$ & $\begin{array}{c}0.57 \\
(0.54-0.60)\end{array}$ \\
\hline $\begin{array}{l}\text { ACL } \\
\text { AcuStar }^{\circledast}\end{array}$ & $\begin{array}{c}35.85 \\
(31.48-40.41)\end{array}$ & $\begin{array}{c}79.74 \\
(75.41-83.62)\end{array}$ & $\begin{array}{c}67.76 \\
(62.50-72.59)\end{array}$ & $\begin{array}{c}51.15 \\
(49.04-53.26)\end{array}$ & $\begin{array}{c}2.20 \\
(1.61-3.00)\end{array}$ & $\begin{array}{c}0.58 \\
(0.54-0.61)\end{array}$ \\
\hline $\begin{array}{l}\text { QUANTA } \\
\text { Lite ELISA }^{\oplus}\end{array}$ & $\begin{array}{c}31.10 \\
(26.91-35.54)\end{array}$ & $\begin{array}{c}84.62 \\
(80.65-88.05)\end{array}$ & $\begin{array}{c}70.59 \\
(64.71-75.86)\end{array}$ & $\begin{array}{c}50.85 \\
(48.99-52.71)\end{array}$ & $\begin{array}{c}2.48 \\
(1.77-3.48)\end{array}$ & $\begin{array}{c}0.58 \\
(0.55-0.61)\end{array}$ \\
\hline \multicolumn{7}{|c|}{ Pregnancy morbidity $\mathrm{N}=645^{c}$} \\
\hline $\begin{array}{l}\text { BioPlex }^{\circledast} \\
2200\end{array}$ & $\begin{array}{c}38.06 \\
(30.39-46.20)\end{array}$ & $\begin{array}{c}87.55 \\
(84.30-90.34)\end{array}$ & $\begin{array}{c}49.17 \\
(41.52-56.85)\end{array}$ & $\begin{array}{c}81.71 \\
(79.73-83.55)\end{array}$ & $\begin{array}{c}4.32 \\
(2.84-6.58)\end{array}$ & $\begin{array}{c}0.63 \\
(0.59-0.67)\end{array}$ \\
\hline $\begin{array}{l}\text { ImmunoCap } \\
{ }^{\circledR} \text { EliA }\end{array}$ & $\begin{array}{c}45.16 \\
(37.17-53.35)\end{array}$ & $\begin{array}{c}80.61 \\
(76.83-84.02)\end{array}$ & $\begin{array}{c}42.42 \\
(36.45-48.63)\end{array}$ & $\begin{array}{c}82.29 \\
(80.01-84.36)\end{array}$ & $\begin{array}{c}3.42 \\
(2.32-5.05)\end{array}$ & $\begin{array}{c}0.63 \\
(0.59-0.67)\end{array}$ \\
\hline $\begin{array}{l}\text { ACL } \\
\text { AcuStar }^{\circledast}\end{array}$ & $\begin{array}{c}42.58 \\
(34.68-50.77)\end{array}$ & $\begin{array}{c}82.45 \\
(78.79-85.71)\end{array}$ & $\begin{array}{c}43.42 \\
(37.06-50.01)\end{array}$ & $\begin{array}{c}81.95 \\
(79.76-83.95)\end{array}$ & $\begin{array}{c}3.48 \\
(2.35-5.17)\end{array}$ & $\begin{array}{c}0.63 \\
(0.59-0.66)\end{array}$ \\
\hline $\begin{array}{l}\text { QUANTA } \\
\text { Lite ELISA }{ }^{\oplus}\end{array}$ & $\begin{array}{c}40.00 \\
(32.22-48.17)\end{array}$ & $\begin{array}{c}87.76 \\
(84.52-90.52)\end{array}$ & $\begin{array}{c}50.82 \\
(43.22-58.38)\end{array}$ & $\begin{array}{c}82.22 \\
(80.19-84.08)\end{array}$ & $\begin{array}{c}4.78 \\
(3.14-7.27)\end{array}$ & $\begin{array}{c}0.64 \\
(0.60-0.68)\end{array}$ \\
\hline \multicolumn{7}{|c|}{ Clinical criteria $\mathrm{N}=1,168$} \\
\hline $\begin{array}{l}\text { BioPlex }^{\circledR} \\
2200\end{array}$ & $\begin{array}{c}35.99 \\
(32.37-39.73)\end{array}$ & $\begin{array}{c}87.55 \\
(84.30-90.34)\end{array}$ & $\begin{array}{c}80.00 \\
(75.60-83.78)\end{array}$ & $\begin{array}{c}49.71 \\
(48.07-51.35)\end{array}$ & $\begin{array}{c}3.95 \\
(2.90-5.39)\end{array}$ & $\begin{array}{c}0.62 \\
(0.59-0.65)\end{array}$ \\
\hline $\begin{array}{l}\text { ImmunoCap } \\
{ }^{\circledR} \text { EliA }\end{array}$ & $\begin{array}{c}41.45 \\
(37.71-45.26)\end{array}$ & $\begin{array}{c}80.61 \\
(76.83-84.02)\end{array}$ & $\begin{array}{c}74.73 \\
(70.74-78.35)\end{array}$ & $\begin{array}{c}49.87 \\
(47.96-51.79)\end{array}$ & $\begin{array}{c}2.94 \\
(2.24-3.86)\end{array}$ & $\begin{array}{c}0.61 \\
(0.59-0.65)\end{array}$ \\
\hline $\begin{array}{l}\mathrm{ACL} \\
\text { AcuStar }^{\circledast}\end{array}$ & $\begin{array}{c}40.71 \\
(36.98-44.51)\end{array}$ & $\begin{array}{c}82.45 \\
(78.79-85.71)\end{array}$ & $\begin{array}{c}76.24 \\
(72.19-79.87)\end{array}$ & $\begin{array}{c}50.12 \\
(48.26-51.99)\end{array}$ & $\begin{array}{c}3.23 \\
(2.44-4.26)\end{array}$ & $\begin{array}{c}0.62 \\
(0.59-0.64)\end{array}$ \\
\hline $\begin{array}{l}\text { QUANTA } \\
\text { Lite ELISA }{ }^{\circledR}\end{array}$ & $\begin{array}{c}37.17 \\
(33.52-40.93)\end{array}$ & $\begin{array}{c}87.76 \\
(84.52-90.52)\end{array}$ & $\begin{array}{c}80.77 \\
(76.47-84.44)\end{array}$ & $\begin{array}{c}50.23 \\
(48.57-51.90)\end{array}$ & $\begin{array}{c}4.24 \\
(3.10-5.79)\end{array}$ & $\begin{array}{c}0.63 \\
(0.60-0.65)\end{array}$ \\
\hline
\end{tabular}

Abbreviations: $A P L$, anti-phospholipid antibodies; APS, anti-phospholipid syndrome; $A U C$, area under the curve; $C l$, confidence interval; LAC, lupus anticoagulant; NPV, negative predictive value; PPV, positive predictive value.

Note: Samples were defined as positive if at least one aPL was positive, excluding LAC.

${ }^{a} A U C$ from the receiver operator curve (ROC) were not significantly different between solid phase assays.

${ }^{b}$ APS thrombosis + non-APS thrombosis + AID + controls.

${ }^{C} A P S$ obstetric + non-APS obstetric + AID + normal pregnancy + controls. 


\section{DISCUSSION}

APS classification strongly depends on the laboratory criteria. Besides the clinical criteria, thrombosis or pregnancy morbidity, often due to other causes than aPL, APS is defined by the persistent presence of aPL (1). aPLs are detected by LAC assays or by semi-quantitative solid phase assays measuring aCL IgG, aCL IgM, a 2 GPI IgG or aß2GPI IgM antibodies (1). Many studies on head-to-head comparisons of solid phase assays with different study designs, already have shown that solid phase assays differ in performance and agreement. In our study we analyzed a large cohort of APS and non-APS patients simultaneously with four different platforms, allowing comparison of different methods on the same patient population. LAC was determined by the local center but excluded from the comparative analysis investigate the variation solely introduced by solid phase assays. aPLs have a low prevalence (1-5\%) in the general population, and APS is even more infrequent (40-50/100,000 persons) $(19,20)$. As a consequence, studies comparing aPL detection methods are often based on a small patient group and/or lack diagnostic accuracy. We investigated the (dis)agreement and diagnostic accuracy of four commercially available solid phase assays for the detection of aCL IgG, aCL IgM, a 32 GPI IgG and a 32 GPI IgM antibodies in 1,168 samples from eight European centers. As in the Sydney criteria, all individual aPL are part of the laboratory criteria for APS, diagnostic accuracy was assessed for positivity for at least one aPL detected by a solid phase assay ( $\mathrm{aCL} \lg \mathrm{G}, \mathrm{aCL} \operatorname{lgM}$, a $32 \mathrm{GPI} \lg \mathrm{G}$ or a $2 \mathrm{GPI} \operatorname{lgM}$ ) (1). Positivity for at least one aPL detected by a solid phase assay was significantly correlated with thrombosis and/or pregnancy morbidity, independent from the solid phase assay used. The highest OR for thrombosis was obtained by detection of aPL by BioPlex2200 $(2.56[95 \% \mathrm{Cl}, 1.82-3.59])$. Detection of aPL by ImmunoCapEliA resulted in the lowest OR (1.98 [95\%Cl, 1.46-2.69]), mainly because of lower specificity. aPL detection by BioPlex2200 and QUANTA Lite ELISA resulted in similar OR for thrombosis and/or pregnancy morbidity, higher than OR obtained by detection with ImmunoCapEliA and ACL AcuStar. Calculated sensitivity, NPV and AUC for thrombosis and/or pregnancy morbidity were low as expected, since we included patients with thrombosis and/or pregnancy morbidity without APS (negative for aPL). Inclusion of only APS patients would lead to a selection bias as diagnosis of APS is dependent on the aPL detection assays used by the local centre.

In our study, a maximum discrepancy of $36,60,53$ and $36 \%$ for aCL IgG, aCL IgM, a $32 \mathrm{GPI}$ IgG and a 32 GPI IgM positivity was found, respectively. Detection of aCL IgG and a $\beta 2$ GPI IgM resulted in the best agreement. However, still a substantial number of samples were in disagreement. Conversely, a study comparing different kits detecting $\mathrm{CCL}$ and a $32 \mathrm{GPI}$ IgG/IgM found better agreement between aß2GPI ELISAs than aCL ELISAs (21). This might be a consequence of the small number of a $32 \mathrm{GPI}$ positive samples in this study 
(21). Another study compared the performance of aCL IgG and IgM antibody detection of the ImmunoCapEliA with their in-house aCL ELISA in 1,143 routine samples (22). The authors reached a good agreement $(>90 \%)$ between the automated systems and their in-house ELISA assay (22). As expected, positivity for aPL proved to be relatively rare, because of which the majority of

TABLE 6. Threshold for positivity: titer of MoAB corresponding to a positive titer of aCL or a $32 \mathrm{GPI}$ lgG

\begin{tabular}{|c|c|c|c|c|c|c|c|c|}
\hline & \multicolumn{4}{|c|}{ aCL IgG } & \multicolumn{4}{|c|}{$\mathrm{a} \beta 2 \mathrm{GPI}$ IgG } \\
\hline & 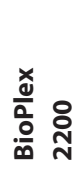 & 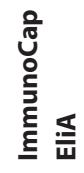 & 岁莣 & 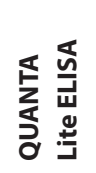 & 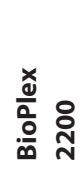 & 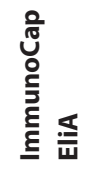 & 这 & 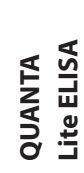 \\
\hline P2-6 ( $\mu \mathrm{g} / \mathrm{ml})$ & 1.95 & 125 & 15.63 & 62.5 & 1.95 & 31.25 & 1.95 & 62.5 \\
\hline P1-117 ( $\mu \mathrm{g} / \mathrm{ml})$ & 1.95 & $\mathrm{Neg}^{\mathrm{a}}$ & 31.25 & $\mathrm{Neg}^{\mathrm{a}}$ & 1.95 & 125 & 7.81 & 125 \\
\hline
\end{tabular}

Abbreviations: aCL, anti-cardiolipin; aß2GPI, anti- $\beta 2$ glycoprotein l; lg, immunoglobulin; MoAB, monoclonal antibodies. ${ }^{a}$ Negative results for all concentrations.

routine samples were classified as negative independent of the method used, resulting in a high agreement. Importantly, more samples were classified positive by only ImmunoCapEliA or only the in-house ELISA than by both methods (116/179 and 72/90 for $\mathrm{aCL} \lg \mathrm{G}$ and $\mathrm{aCL} \operatorname{lgM}$, respectively), suggesting a poor agreement comparable to our findings (22). We observed large differences in positivity across platforms, even between automated systems sharing the same solid phase (BioPlex2200 vs ACL AcuStar). In a collaborative study the inter-laboratory variability of a $32 \mathrm{GPI} \lg$ and a $32 \mathrm{GPI} \operatorname{lgM}$ antibodies was assessed in 30 serum samples from 22 centres (22). Poor agreement was found between centers as positivity ranged from 50 to $93 \%$ and 13 to $70 \%$ for a $32 \mathrm{GPI}$ IgG and a $32 \mathrm{GPI}$ IgM detection, respectively (23). We excluded inter-laboratory variability and found the best agreement between BioPlex2200 and ACL AcuStar. However, OR for clinical features of APS obtained by BioPlex2200 were more comparable with an ELISA assay (QUANTA Lite ELISA) than an assay sharing the same solid phase (ACL AcuStar). BioPlex2200 and QUANTA Lite ELISA were in poor agreement but characterized by a comparable diagnostic accuracy. Our results highlight the importance of measuring both the agreement between assays as well as their diagnostic accuracy. It seems also important that in daily practice the four aPLs are measured with a same platform. Although some small differences exist in the diagnostic performance of the tested platforms, the values of sensitivity and specificity for APS related clinical symptoms and OR for clinical events are essentially comparable. This may be explained by the higher 
agreement that was observed in samples with higher levels of aPL (Figure 1). That newer generation ELISA and automated systems show low agreement but comparable diagnostic accuracy was also illustrated in other studies $(9,10,24-26)$.

In our study, guidelines from the SSC were followed by confirming manufacturer's cutoff values in at least 20 healthy volunteers (16). In practice, most laboratories transfer their cut-off values similarly, predominately due to practical difficulties to calculate the 99th percentiles in a population of at least 120 healthy volunteers. Positivity for aPL not in agreement across the assays were characterized by lower median aPL titers. The majority of samples positive for aCL and/or a 2 GPI lgG/lgM detected by one assay, but not for all solid phase assays fulfilled the clinical criteria of APS, suggesting that higher cut-off values result in reduced sensitivity for APS. The clinical relevance of aPL levels below the 99th percentile, needs to be further studied (27). Lower levels of antibodies are observed especially in obstetric APS $(28,29)$.

Variability between aPL detecting assays is hypothesized to result from pre-analytical, analytical, and post-analytical conditions, calibration and assay-specific issues $(30,31)$. In our study, detection of aPL and analysis was performed by a single operator, eliminating inter-laboratory and inter-operator variation. Traditionally, $\mathrm{aCL}$ and $\mathrm{a} \beta 2 \mathrm{GPI}$ antibodies are detected by ELISAs. Nowadays, automated systems become available which are hypothesized to improve agreement (8). Automation of assays indeed improved intralaboratory and inter-laboratory reproducibility compared with non-automated ELISA. In general, ELISAs have shown large inter-laboratory variation and limited consensus in external quality control programs $(11,12)$. The lack of international calibration standards makes the comparison between assays challenging. Efforts have been made for standardization by international reference materials, such as the Harris standards (pool of patient material and thus limited in production) and Koike standards (directed against a single epitope, thus decreasing the sensitivity of the assay in which it is used as aPL), although not reflecting the real life since aPL of patients are a heterogeneous group of antibodies [31]. Variation in aPL detection might be introduced by the heterogeneous origin of $\mathrm{aPL}$, differences in assay design and a lack of standardization. All four tested aß2GPI antibody detection assays make use of an antigen of human origin. However, for detection of aCL antibodies only BioPlex2200 uses human $\beta 2 \mathrm{GPI}$ and non-animal derived cardiolipin. Human antigen source is considered more specific than animal $C L$ and/or $\beta 2$ GPI (6). Different preparations of human $\beta 2 \mathrm{GPI}$ have shown not to influence agreement in aß2GPI IgG and IgM detection (32). Indeed, BioPlex2200 and QUANTA Lite ELISA showed high specificity for thrombosis and/or pregnancy morbidity. However, 
our results show that the QUANTA Lite ELISA using purified cardiolipin and bovine $\beta 2 \mathrm{GPI}$ as antigen source resulted in the highest specificity for thrombosis and/or pregnancy morbidity.

Anti- $\beta 2$ GPI immunoassays detect antibodies against all five domains of $\beta 2 \mathrm{GPI}$, including non-pathogenic antibodies, phospholipid-independent and low affinity aß2GPI $(6,33)$. The use of negative surface charge of the solid phase in a 32 GPI ELISAs have shown to increase the antigen density and exposure of cryptic epitopes of $\beta 2 \mathrm{GPI}$ such as Gly40Arg43 in domain I, mimicking the binding between negatively charged phospholipids and $\beta 2 G P I(6,13,14)$. Variation in solid phase may lead to variability in exposure of the epitope Gly40-Arg43 (15). Hence, antibodies against the Gly40-Arg43 epitope are considered pathogenic and have shown to highly correlate with thrombosis $(13,14,34)$. We used patient derived MoAB P1-117 and P2-6 to verify and assess variability in exposure of epitopes of $\beta 2 \mathrm{GPI}(7,15,17)$. We confirmed that the platform most sensitive in detecting $\mathrm{P} 1-117$ (the MoAB reactive against Gly40-Arg43 in domain I) by both the $\mathrm{aCL}$ and $\mathrm{a} \beta 2 \mathrm{GPI}$ IgG assay has the highest OR for thrombosis. Other platforms are less sensitive in detecting P1-117 compared to P2-6 (the MoAB recognizing $32 \mathrm{GPI}$ irrespective of its conformation), resulting in lower OR for thrombosis.

In conclusion, we found poor agreement between commercially available immunoassays detecting $\mathrm{aCL}$ and aß2GPI lgG/lgM antibodies, which may hamper uniformity in the classification of aPL positive samples. However, computed OR for thrombosis and/or pregnancy morbidity in our study, considering results of the four aPL together, were globally concordant among solid phase test systems. Since our comparison between systems is based considering measurement of the four aPL within one test system, classification and follow-up of patients for aPL is preferable when performed with the same system.

\section{ACKNOWLEDGEMENTS}

The authors thank Michael Luypaert for his technical assistance, Bio-Rad Laboratories, ThermoFisher/Phadia, Werfen/Instrumentation Laboratory and Inova Diagnostics for providing the test kits for the detection of a $32 \mathrm{GPI}$ and $\mathrm{aCL} \lg \mathrm{G}$ and $\lg \mathrm{M}$ antibodies. 


\section{REFERENCES}

1. Miyakis S, Lockshin MD, Atsumi T, et al. International consensus statement on an update of the classification criteria for definite antiphospholipid syndrome (APS). J Thromb Haemost 2006; 4: 295-306.

2. Ruiz-Irastorza G, Crowther M, Branch W, et al. Antiphospholipid syndrome. Lancet 2010; 376: 1498-509.

3. Gris J-C, Bouvier S, Molinari N, et al. Comparative incidence of a first thrombotic event in purely obstetric antiphospholipid syndrome with pregnancy loss: the NOH-APS observational study. Blood 2012; 119: 2624-32.

4. Male $\mathrm{C}$, Foulon $\mathrm{D}$, Hoogendoorn $\mathrm{H}$, et al. Predictive value of persistent versus transient antiphospholipid antibody subtypes for the risk of thrombotic events in pediatric patients with systemic lupus erythematosus. Blood 2005; 106: 4152-8.

5. Galli M, Luciani D, Bertolini G, et al. Lupus anticoagulants are stronger risk factors for thrombosis than anticardiolipin antibodies in the antiphospholipid syndrome: a systematic review of the literature. Blood 2003; 101: 1827-32.

6. Devreese KMJ. Antiphospholipid antibody testing and standardization. Int J Lab Hematol 2014; 36: 352-63.

7. Devreese K, Kelchtermans H. De laat B. Differences in sensitivity of two automated assay panels for anticardiolipin and anti beta2- glycoprotein I antibodies in the laboratory diagnosis of antiphospholipid syndrome due to the exposure of the domain I epitope of beta2glycoprotein I on the solid phase. ISTH SSC 2014 meeting abstracts [Internet]; 2014. Available at: http://hdl.handle.net/ 1854/LU-8043838. Accessed April 26, 2018

8. Devreese KM, Poncet A, Lindhoff-Last E, et al. A multicenter study to assess the reproducibility of antiphospholipid antibody results produced by an automated system. J Thromb Haemost 2017; 15: 91-5.

9. De Moerloose P, Reber G, Musial J, et al. Analytical and clinical performance of a new, automated assay panel for the diagnosis of antiphospholipid syndrome. J Thromb Haemost 2010; 8: 1540-6.

10. Hoecke FV, Persijn L, Decavele A-S, et al. Performance of two new, automated chemiluminescence assay panels for anticardiolipin and anti-beta2-glycoprotein I antibodies in the laboratory diagnosis of the antiphospholipid syndrome. Int J Lab Hematol 2012; 34: 630-40.

11. Favaloro EJ, Silvestrini R, Mohammed A. Clinical Utility of Anticardiolipin Antibody Assays: High Inter-Laboratory Variation and Limited Consensus by Participants of External Quality Assurance Programs Signals a Cautious Approach. Pathology 1999; 31: 142-7.

12. Favaloro $E J$, Wheatland $L$, Jovanovich $S$, et al. Internal quality control and external quality assurance in testing for antiphospholipid antibodies: Part I--Anticardiolipin and anti- $\beta 2$ glycoprotein I antibodies. Semin Thromb Hemost 2012; 38: 390-403. 
13. de Laat B, Derksen RHWM, Urbanus RT, et al. IgG antibodies that recognize epitope Gly40Arg43 in domain I of beta 2-glycoprotein I cause LAC, and their presence correlates strongly with thrombosis. Blood 2005; 105: 1540-5.

14. de Laat B, Derksen RHWM, van Lummel M, et al. Pathogenic anti-beta2-glycoprotein I antibodies recognize domain I of beta2-glycoprotein I only after a conformational change. Blood 2006; 107: 1916-24.

15. Pelkmans L, Kelchtermans $\mathrm{H}$, de Groot PG, et al. Variability in exposure of epitope G40-R43 of domain I in commercial anti-beta2-glycoprotein I lgG ELISAs. PLoS ONE 2013; 8: e71402.

16. Devreese KMJ, Pierangeli SS, de Laat B, et al. Testing for antiphospholipid antibodies with solid phase assays: guidance from the SSC of the ISTH. J Thromb Haemost 2014; 12: 792-5.

17. Dienava-Verdoold I, Boon-Spijker MG, de Groot PG, et al. Patient-derived monoclonal antibodies directed towards beta2 glycoprotein-1 display lupus anticoagulant activity. J Thromb Haemost 2011; 9: 738-47.

18. DeLong ER, DeLong DM, Clarke-Pearson DL. Comparing the Areas under Two or More Correlated Receiver Operating Characteristic Curves: A Nonparametric Approach. Biometrics 1988; 44: 837-45.

19. Mehrani T, Petri M. Chapter 2 Epidemiology of the Antiphospholipid Syndrome. In: Cervera R, Reverter JC, Khamashta M, eds. Antiphospholipid Syndrome in Systemic Autoimmune Diseases [Internet]. Elsevier; 2009:13-34. Available at: http://www. sciencedirect.com/ science/article/pii/S1571507808004029. Accessed February 5, 2019

20. Cervera R, Espinosa G, Reverter JC. Chapter 8Systemic Manifestations of the Antiphospholipid Syndrome. In: Cervera R, Reverter JC, Khamashta M, editors. Antiphospholipid Syndrome in Systemic Autoimmune Diseases Elsevier; 2009. p. 105-16.

21. Audrain MAP, Colonna F, Morio F, et al. Comparison of different kits in the detection of autoantibodies to cardiolipin and beta2glycoprotein 1. Rheumatology (Oxford) 2004; 43: 181-5.

22. Andreoli L, Rizzini S, Allegri F, et al. Are the current attempts at standardization of antiphospholipid antibodies still useful? Emerging technologies signal a shift in direction. Semin Thromb Hemost 2008; 34: 356-60.

23. Reber G, Schousboe I, Tincani A, et al. Inter-laboratory variability of anti-beta2-glycoprotein I measurement. A collaborative study in the frame of the European Forum on Antiphospholipid Antibodies Standardization Group. Thromb Haemost 2002; 88: 66-73.

24. Decavele AS, Schouwers S, Devreese KMJ. Evaluation of three commercial ELISA kits for anticardiolipin and anti-beta2-glycoprotein I antibodies in the laboratory diagnosis of the antiphospholipid syndrome. Int J Lab Hematol 2011; 33: 97-108.

25. Persijn L, Decavele A-S, Schouwers S, et al. Evaluation of a new set of automated chemiluminescense assays for anticardiolipin and anti-beta2-glycoprotein I antibodies in the laboratory diagnosis of the antiphospholipid syndrome. Thromb Res 2011; 128: 565-9.

26. Martins TB, Heikal N, Miller J, et al. Assessment of diagnostic methods for the detection of anticardiolipin and anti- $\beta$ eta 2 glycoprotein I antibodies in patients under routine evaluation for antiphospholipid syndrome. Clin. Chim. Acta 2018; 485: 7-13. 
27. Devreese KMJ, Ortel TL, Pengo V, et al. Laboratory criteria for antiphospholipid syndrome: communication from the SSC of the ISTH. J Thromb Haemost 2018; 16: 809-13.

28. Arachchillage DRJ, Machin SJ, Mackie IJ, et al. Diagnosis and management of non-criteria obstetric antiphospholipid syndrome. Thromb Haemost 2015; 113: 13-9.

29. Ruffatti A, Olivieri S, Tonello $M$, et al. Influence of different IgG anticardiolipin antibody cutoff values on antiphospholipid syndrome classification. J Thromb Haemost 2008; 6: 1693-6.

30. Devreese K, Hoylaerts MF. Laboratory diagnosis of the antiphospholipid syndrome: a plethora of obstacles to overcome. Eur J Haematol 2009; 83: 1-16.

31. Devreese KMJ. Standardization of antiphospholipid antibody assays. Where do we stand? Lupus 2012; 21: 718-21.

32. Cavazzana A, Pengo V, Tonello M, et al. Anti-beta(2)-glycoprotein I ELISA assay: the influence of different antigen preparations. Thromb Haemost 2009; 101: 789-91.

33. Devreese K, Hoylaerts MF. Challenges in the diagnosis of the antiphospholipid syndrome. Clin Chem 2010; 56: 930-40.

34. de Laat B, Pengo V, Pabinger I, et al. The association between circulating antibodies against domain I of beta2-glycoprotein I and thrombosis: an international multicenter study. J Thromb Haemost 2009; 7: 1767-73. 


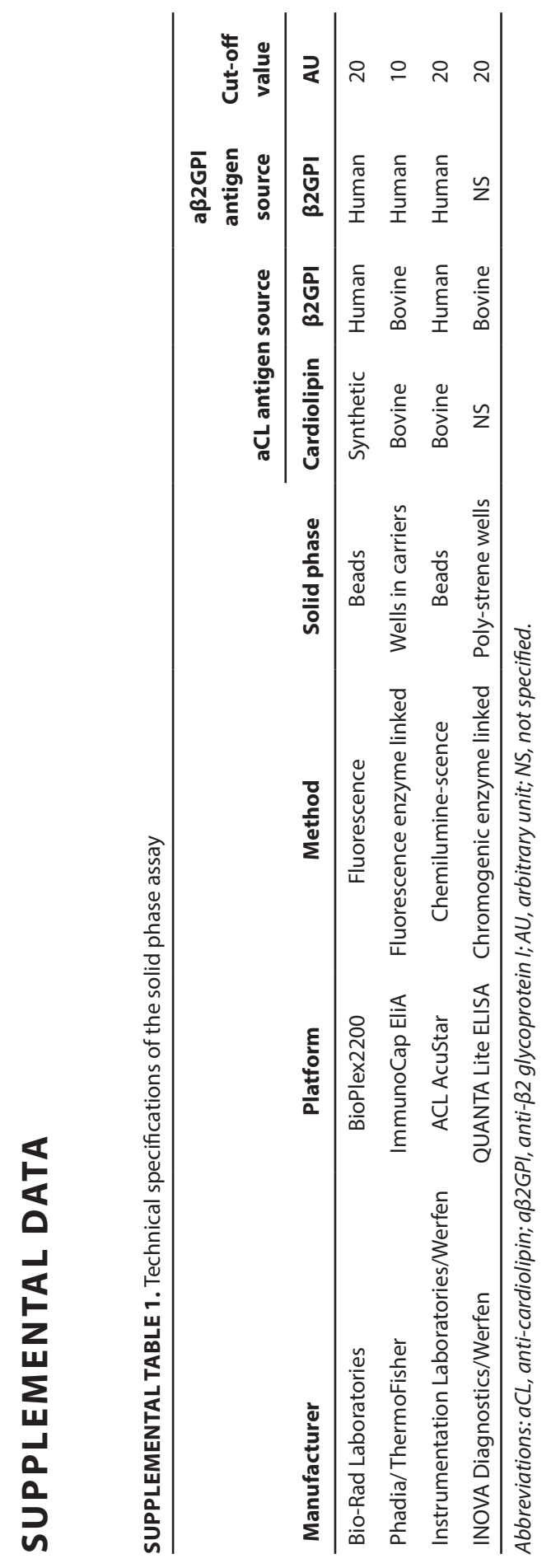



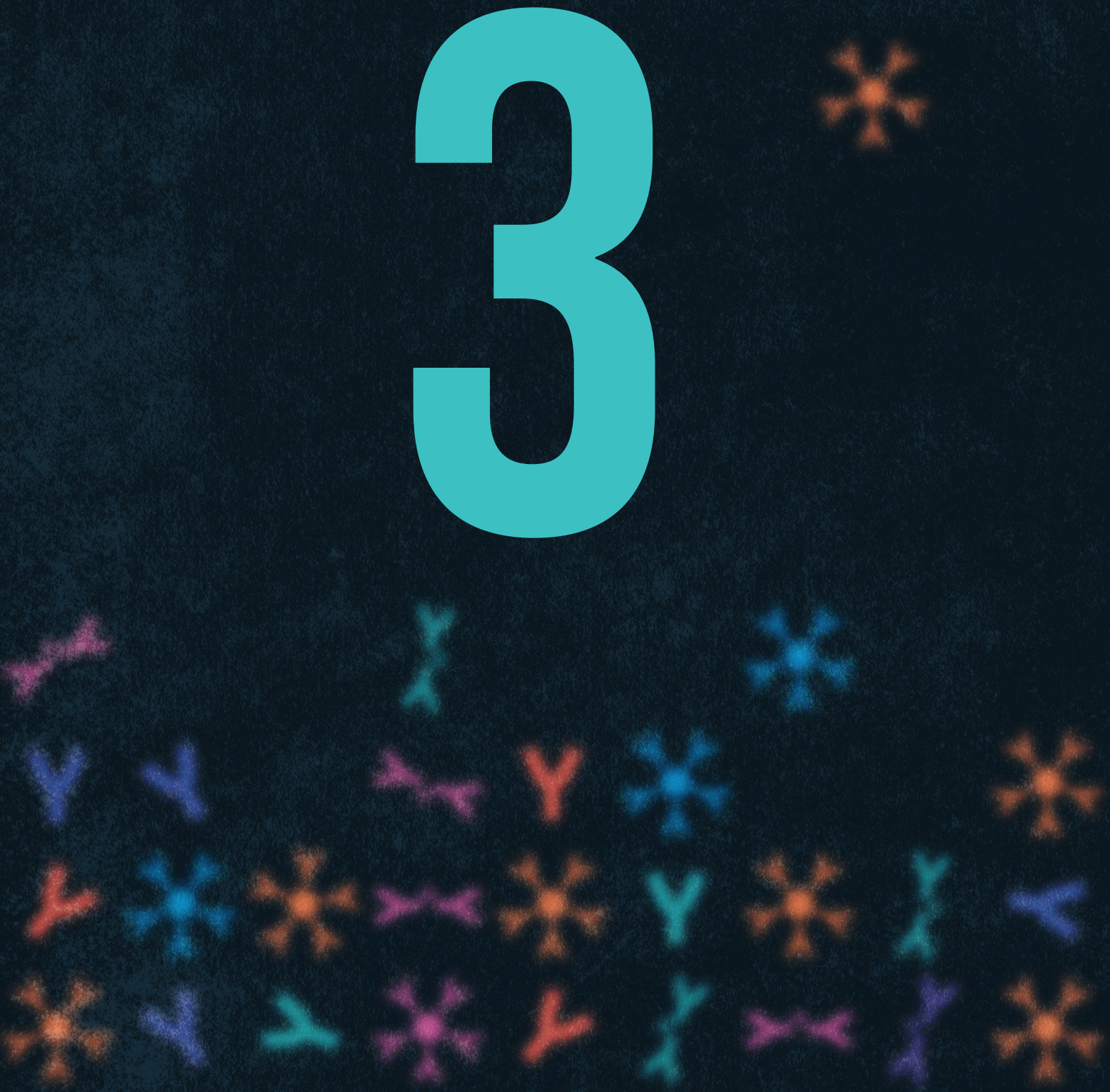


\section{Identification of high thrombotic risk triple-positive antiphospholipid syndrome patients is dependent on anti-cardiolipin and anti- $\beta 2$ glycoprotein I antibody detection assays}

Walid Chayoua, Hilde Kelchtermans, Gary W. Moore, Jacek Musiał,

Denis Wahl, Bas de Laat, Katrien M. J. Devreese

J Thromb Haemost. 2018; 16: 2016-23 


\section{ABSTRACT}

Background:The antiphospholipid syndrome (APS) is characterized by thrombosis and/ or pregnancy morbidity with the persistent presence of antiphospholipid antibodies (aPL). Triple-positivity, (i.e. positivity for lupus anticoagulant [LAC], anti-cardiolipin [aCL] and anti- $\beta 2$ glycoprotein I [aß2GPI] antibodies) is associated with a high thrombotic risk.

Objectives: We investigated the variability in triple-positivity detection by measuring the same samples with four commercially available solid phase assays. In addition, the added clinical value of aPL in LAC positive patients was investigated, as well as the association of IgM triple-positivity and thrombosis.

Patients/Methods: We included 851 patients from seven European medical centers. Anti-CL and a $32 \mathrm{GPI} \operatorname{lgG} / \mathrm{lgM}$ antibodies were determined by four platforms: BioPlex ${ }^{\oplus} 2200$, ImmunoCap ${ }^{\oplus}$ EliA, ACL AcuStar $^{\oplus}$ and QUANTA Lite ELISA ${ }^{\oplus}$.

Results: Triple-positivity detection by solid phase assays varied, ranging from 89 up to 118 in thrombotic APS patients $(n=258$ ) of which 86 were detected independent of the platform. Lupus anticoagulant positivity resulted in an odds ratio (OR) for thrombosis of 3.4; triple-positivity (irrespective of the isotype) increased the OR from 4.3 up to 5.2, dependent on the platform. Triple-positivity solely for the lgM isotype did not increase the OR for thrombosis compared with LAC positivity. The highest OR for thrombosis was reached for positivity for $\lg G$ and $\lg M$ a $\beta 2 \mathrm{GPI}$ and $\mathrm{aCL}$ (8.6 up to 28.9).

Conclusions: Triple-positivity proved to be highly associated with thrombosis, but identification is assay dependent. Within triple-positivity, IgM antibodies only have an added clinical value in patients positive for lg $\mathrm{G}$ antibodies. 


\section{INTRODUCTION}

The antiphospholipid syndrome (APS) is characterized by thrombosis and/or pregnancy morbidity with the persistent presence of antiphospholipid antibodies (aPL) [1]. Laboratory criteria include aPL detection by phospholipid-dependent coagulation tests referred to as lupus anticoagulant (LAC) or by quantitative solid phase assays measuring anti- $\beta_{2}$ glycoprotein I (aß2GPI) and anti-cardiolipin $(\mathrm{aCL}) \mathrm{IgG} / \mathrm{lgM}$ antibodies [1]. Given the high-frequency of thrombosis irrespective of the syndrome, laboratory tests are of utmost importance for the classification of APS. Detection of aPL by solid phase assays is associated with high inter-laboratory and inter-method variation $[2,3]$. Reports from external quality control programs illustrate that commercially available aPL assays produce variable results [4-6].

In order to improve the identification of patients at risk, it was suggested that APS patients should be evaluated according to their aPL profile $[1,7]$. Combined positivity for LAC, aCL and a $\beta 2 \mathrm{GPI}$ antibodies (i.e. triple-positivity) has shown to be associated with a high risk for both a first thrombotic event and recurrence [8-10]. In the NOH-APS study, a large observational study, triple-positivity was a predictor for thrombosis in purely obstetric APS patients [11]. However, computed risks for thrombosis of LAC positivity and triple-positivity were globally concordant, with the exception of pulmonary embolism [11]. Despite the high correlation of triple-positives with thrombosis, the predictive value is argued to originate from LAC positivity [12]. Recently, the detection of triple-positivity (i.e. positivity for $\mathrm{LAC}, \mathrm{aCL}$ and a $\beta 2 \mathrm{GPI}$ antibodies) was suggested to be method and platform independent [13].

Looking at the isotype of aPL, both $\lg G$ and $\lg M$ antibodies directed against cardiolipin and $\beta 2 \mathrm{GPI}$ are included in the Sydney criteria [1]. However, the clinical value of IgM antibodies in thrombotic APS is debated [14]. To date, the thrombotic association of IgM antibodies in aPL profiles like triple-positivity is not known. In this study we included 851 patients from seven European medical centers. Four solid-phase assay platforms were selected based on frequency of use and the willingness of manufacturers to provide their assays. The samples were tested with all assays at one location by a single technician.

In a retrospective multicenter study we aimed to investigate the variability in triplepositivity detection between different aPL detection platforms and the impact of the platform on the association of triple-positivity with thrombosis. In addition, we aimed to assess the added value of aPL detection in LAC positive patients and the impact of the isotype with respect to the association with thrombosis. 


\section{MATERIALS AND METHODS}

\section{Study population}

We included 851 patients from seven European medical centers. Classification of APS was based on the Sydney criteria [1]. Patients were classified by the local centers resulting in 258 thrombotic APS patients (APS thrombosis), 204 patients with a history of thrombosis and negative for laboratory criteria of APS (non-APS thrombosis), 196 patients with an autoimmune disease other than APS, like systemic lupus erythematosus (52\%) and systemic sclerosis (27\%), without thrombotic complications (AID controls) and 193 controls that were referred for aPL testing for other reasons than the clinical criteria of APS, including subfertility and prolonged activated partial thromboplastin time (controls). Patients were enrolled within a timespan of 1 year, with patient samples stored less than 5 years. Thrombosis was objectively confirmed according the Sydney criteria [1]. The majority of thrombotic APS patients received anticoagulant therapy including vitamin $\mathrm{K}$ antagonists (VKA) (46\%), low molecular weight heparins (LMWHs) (5\%) and direct oral anticoagulants (DOACs) (4\%). Twenty-seven patients (10\%) received anti-platelet therapy and only $2 \%$ of patients with thrombotic APS received both anticoagulant and anti-platelet therapy. Details on anti-coagulant and anti-platelet therapy of the remaining 84 patients are not available. Women classified with obstetrical APS were excluded. The study was approved by the local ethical committees. Lupus anticoagulant positivity was determined by the local center, according to the ISTHSSC (International Society of Thrombosis and Haemostasis-Scientific Standardisation Subcommittee) guideline [15]

\section{Solid phase assays}

Commercially available solid phase assays (Supplemental Table 1) were selected based on frequently used assays in the external quality control program of the ECAT (External quality Control of diagnostic Assays and Tests, Leiden, The Netherlands) and the willingness of manufacturers for collaboration. Anti-CL IgG, aCL IgM, aß2GPI IgG and aß2GPI IgM antiphospholipid antibodies were detected by BioPlex ${ }^{\oplus} 200$ (Bio-Rad, BioRad Laboratories, Hercules, USA), ImmunoCap ${ }^{\oplus}$ EliA (Thermo Fisher Scientific/Phadia, Uppsala, Sweden), ACL AcuStar ${ }^{\circledast}$ (Werfen/Instrumentation Laboratories, Bedford, USA) and QUANTA Lite ELISA ${ }^{\oplus}$ (Inova Diagnostics, San Diego, USA) in the Ghent University Hospital (Ghent, Belgium). Reagents used for the detection of aCL and aß2GPI IgG/ $\lg M$ antibodies were measured with their corresponding instruments according to the manufacturer's instructions. All four methods were performed in parallel runs of 40 samples. Anti-phospholipid antibody titers were expressed in arbitrary units (GPL, MPL, $\mathrm{U} \mathrm{ml}^{-1}, \mathrm{SGU}$ or SMU). All samples were measured by the same technician and values 
below the calculated limit of detection (LOD) were replaced by the LOD. Manufacturer's recommended cut-off values were used upon confirmation in 20 healthy volunteers, in accordance with the ISTH-SSC guideline [16].

\section{Statistics}

Significance of differences between aPL titers was determined with the Mann-Whitney $U$ test. Diagnostic efficacy was assessed within the total population by sensitivity, specificity and odds ratios (ORs) using the statistical package for social sciences (SPSS 23.0; SPSS, Chicago, IL) and MedCalc Statistical Software version 17.7.2 (MedCalc Software bvba, Ostend, Belgium). Statistical significance was set at $P$ value less than 0.05 .

\section{RESULTS}

We measured $\mathrm{aCL} \operatorname{lgG} / \lg M$ and $\mathrm{a} \beta 2 \mathrm{GPI} \operatorname{lgG} / \lg \mathrm{M}$ aPL in 833 individuals with a mean age of 46 years ranging from 16 to 87 years old (Table 1) with four commercially available assays (Supplemental Table 1). In our study population, venous thrombosis (VT), was more common than arterial thrombosis (AT), both in the APS and control group. In addition, primary APS (PAPS) was more prevalent than APS secondary to an underlying connective tissue disorder (SAPS).

From the 851 samples tested, 274 were LAC positive, and for these triple-positivity ranged from 106 (39\%) up to 146 (53\%) detected by QUANTA Lite ELISA ${ }^{\circledR}$ and BioPlex $^{\circledR} 2200$, respectively (Table 2$)$. In patients diagnosed with thrombotic APS $(n=258)$, 202 were positive for LAC. From these 202 LAC positive samples 118, 101, 111 and 89 were defined as triple-positive (positivity for LAC, aCL IgG or IgM aß2GPI IgG or IgM) detected with the solid phase assays: BioPlex ${ }^{\circledast} 2200$, ImmunoCap ${ }^{\circledR}$ EliA, ACL AcuStar ${ }^{\circledast}$ and QUANTA Lite ELISA ${ }^{\circledR}$, respectively (Table 2 ). By a comparison of two proportions, triple-positivity detection was found to be statistically different between BioPlex ${ }^{\circledR} 2200$ and QUANTA Lite ELISA ${ }^{\circledR}(P=0.0122)$. Other combinations proved not to be statistically different, although the comparison of ACL AcuStar ${ }^{\circledast}$ and QUANTA Lite ELISA ${ }^{\circledast}$ almost reached statistical significance $(P=0.0586)$. Of the $L A C$ positive patients not defined as triple-positive, the majority was isolated LAC positive (Supplemental Table 2). 


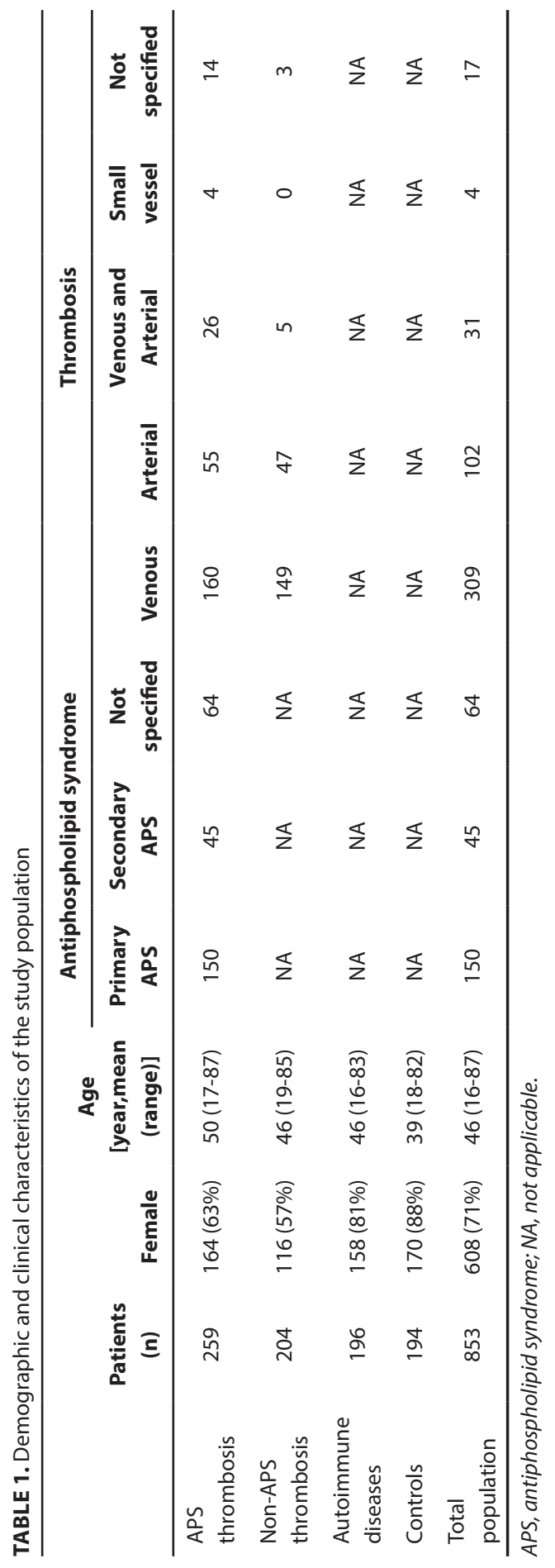


TABLE 2. Triple-positive patients detected with BioPlex ${ }^{\circledR} 2200$, ImmunoCap ${ }^{\oplus}$ EliA, ACL AcuStar ${ }^{\oplus}$ and QUANTA Lite ELISA ${ }^{\oplus}$ in patients with thrombotic antiphospholipid syndrome (APS), patients with non-APS thrombosis, autoimmune disease (AID) controls and controls

\begin{tabular}{|c|c|c|c|c|c|}
\hline & \multirow{2}{*}{$\begin{array}{c}\text { Lupus } \\
\text { anticoagulant } \\
\text { positive }\end{array}$} & \multicolumn{4}{|c|}{ Triple positives } \\
\hline & & $\begin{array}{c}\text { BioPlex }^{\circledast} \\
2200\end{array}$ & $\begin{array}{l}\text { Immuno } \\
\text { Cap }^{\circledR} \text { EliA }\end{array}$ & $\begin{array}{c}\text { ACL } \\
\text { AcuStar }\end{array}$ & $\begin{array}{c}\text { QUANTA } \\
\text { Lite ELISA }\end{array}$ \\
\hline $\begin{array}{l}\text { APS Thrombosis ( } \\
=258)\end{array}$ & 202 & 118 & 101 & 111 & 89 \\
\hline $\begin{array}{l}\text { Non-APS Thrombosis } \\
(n=204)\end{array}$ & 0 & 0 & 0 & 0 & 0 \\
\hline $\begin{array}{l}\text { AID controls }(n= \\
\text { 196) }\end{array}$ & 56 & 22 & 18 & 19 & 14 \\
\hline $\begin{array}{l}\text { Controls } \\
(n=193)\end{array}$ & 16 & 6 & 6 & 4 & 3 \\
\hline $\begin{array}{l}\text { Total patient } \\
\text { population }(n=851)\end{array}$ & 274 & 146 & 125 & 134 & 106 \\
\hline
\end{tabular}

TABLE 3. Discrepancies in triple-positivity detection with pairwise comparison. Number of LAC-positive samples and those positive for $\mathrm{aCL}$ and a $32 \mathrm{GPI}$ antibodies (irrespective of the isotype) detected by BioPlex ${ }^{\oplus} 2200$, ImmunoCap ${ }^{\oplus}$ EliA, ACL AcuStar ${ }^{\oplus}$ and QUANTA Lite ELISA ${ }^{\oplus}$.

\begin{tabular}{|c|c|c|c|c|c|c|c|}
\hline & & \multicolumn{2}{|c|}{ BioPlex $^{\otimes} 2200$} & \multicolumn{2}{|c|}{ ImmunoCap ${ }^{\oplus}$ EliA } & \multicolumn{2}{|c|}{ ACL AcuStar ${ }^{\circledast}$} \\
\hline & & - & + & - & + & - & + \\
\hline \multirow[t]{2}{*}{ BioPlex 2200} & - & & & & & & \\
\hline & + & & & & & & \\
\hline \multirow[t]{2}{*}{ ImmunoCap ${ }^{\circledast}$ EliA } & - & 696 & 30 & & & & \\
\hline & + & 9 & 116 & & & & \\
\hline \multirow[t]{2}{*}{ ACL AcuStar ${ }^{\circledast}$} & - & 704 & 13 & 706 & 11 & & \\
\hline & + & 1 & 133 & 20 & 114 & & \\
\hline \multirow[t]{2}{*}{ Quanta Lite ELISA ${ }^{\oplus}$} & - & 701 & 44 & 722 & 23 & 713 & 32 \\
\hline & + & 4 & 102 & 4 & 102 & 4 & 102 \\
\hline
\end{tabular}

Agreement of triple-positivity detection by solid phase assays was assessed by a $2 \times 2$ contingency table within the total population (Table 3). Discrepancies varied between 14 (BioPlex $^{\oplus} 2200$ vs ACL AcuStar ${ }^{\circledast}$ ) and 48 (BioPlex ${ }^{\circledR} 2200$ vs QUANTA Lite ELISA ${ }^{\oplus}$ ) individuals. In patients diagnosed with thrombotic APS $(n=258) 118$ triple-positives were detected by BioPlex ${ }^{\circledast} 2200$ of which 86 patients were defined triple-positive, 
independent of the solid phase assay used (Table 4). On the other hand, 32 patients were defined as triple-positive by BioPlex ${ }^{\circledR} 2200$ but negative by all the other tested solid phase assays (Table 4). However, the majority of patients with discrepant results by the tested solid phase platforms have a history of thrombosis, illustrating clinical relevance (Table 4). Median aPL titers were calculated by aCL and aß2GPI antibody titers above the cut-off. Triple-positives in agreement across all platforms displayed higher median aPL titers than triple-positive samples not positive for all tested platforms (Figure 1). Statistical difference was reached for BioPlex ${ }^{\circledast 2} 200(P<0.001)$, ACL AcuStar $^{\circledast}$ $(P<0.001)$ and QUANTA Lite ELISA $^{\oplus}(P=0.0029)$, but not for ImmunoCap ${ }^{\oplus}$ EliA $(P=$ $0.5851)$, as shown in Figure 1.

The sensitivity of triple-positivity for thrombosis was low compared to LAC alone and varied from $19 \%$ (95\% confidence interval [95\% Cl], 16-23\%) up to $26 \%$ (95\% Cl, $22-30 \%)$ between the tested assays (Figure 2A). However, higher specificity for thrombosis was obtained, ranging from $93 \%(95 \% \mathrm{Cl}, 90-95 \%)$ up to $96 \%(95 \% \mathrm{Cl}, 93-97 \%)$, as shown in Figure 2(B). Lupus anticoagulant positivity resulted in an OR of 3.63 (95\% Cl, 2.76-4.76). Triple-positivity was statistically correlated with thrombosis, independent of the solid phase assay used to detect $\mathrm{aCL}$ and $\mathrm{a} \beta 2 \mathrm{GPI} \operatorname{lgG} / \mathrm{lgM}$ antibodies (Figure $2 \mathrm{~B}$ ). Odds ratios for thrombosis ranged from $4.3(95 \% \mathrm{Cl}, 2.7-6.8)$ up to $5.2(95 \% \mathrm{Cl}, 3.0-8.9)$ among the platforms (Table 5).

TABLE 4. Discrepancies in triple-positivity detection between BioPlex ${ }^{\oplus} 2200$, ImmunoCap ${ }^{\oplus}$ EliA, ACL AcuStar ${ }^{\circledast}$ and QUANTA Lite ELISA ${ }^{\oplus}$. Number of triple-positives in (dis)agreement among all four solid phase assays in patients with thrombotic APS, patients with non-APS thrombosis, autoimmune disease (AID) controls and controls

\begin{tabular}{lccccc}
\hline & $\begin{array}{c}\text { BioPlex } \\
\mathbf{2 2 0 0}\end{array}$ & $\begin{array}{c}\text { ImmunoCap } \\
\text { EliA }\end{array}$ & $\begin{array}{c}\text { ACL } \\
\text { AcuStar }\end{array}$ & $\begin{array}{c}\text { QUANTA Lite } \\
\text { ELISA }^{\circledR}\end{array}$ & $\begin{array}{c}\text { In agreement } \\
\text { among all solid } \\
\text { phase assays }\end{array}$ \\
\hline APS-thrombosis & 32 & 15 & 25 & 3 & 86 \\
AID & 10 & 6 & 7 & 2 & 12 \\
Controls & 3 & 3 & 1 & 0 & 3 \\
Total & 45 & 24 & 33 & 5 & 101 \\
\hline
\end{tabular}




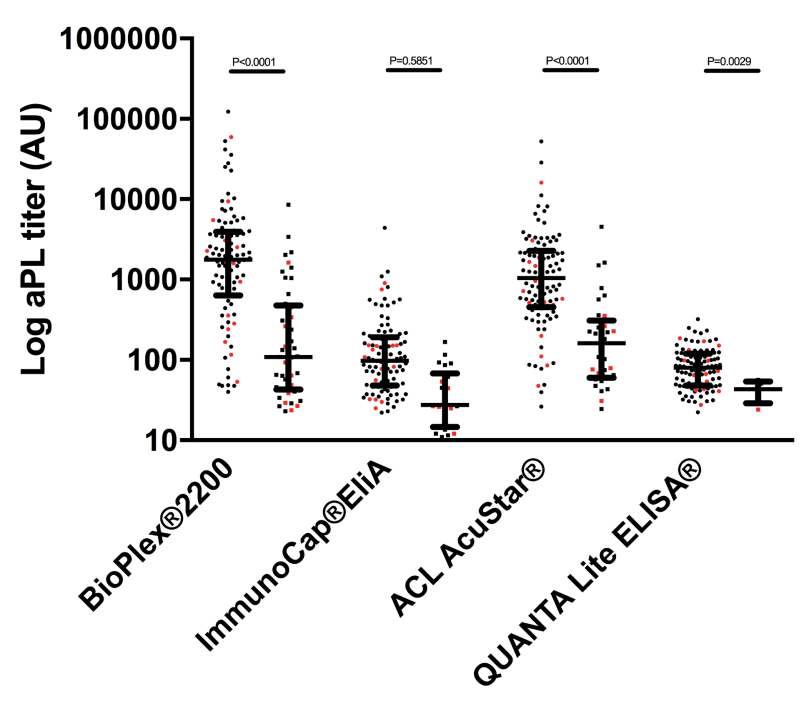

FIGURE 1. Antiphospholipid antibody (aPL) titers of triple-positives in (dis)agreement. Log transformed aPL titers in agreement for all platforms tested are indicated by solid dots, disagreements are indicated by solid squares. Patients without the clinical criteria for the anti-phospholipid syndrome (APS) are indicated in red and patients with a history of thrombosis are indicated in black. Titers are expressed as the median value of positive aPL titers with interquartile ranges. $\mathrm{AU}$, arbitrary units.

A

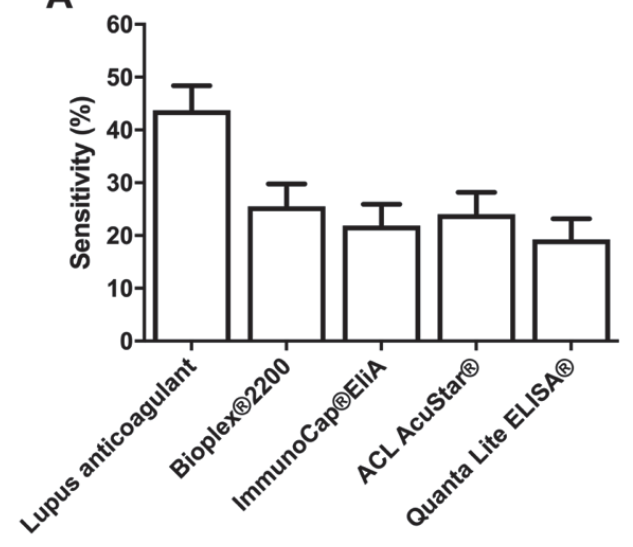

B

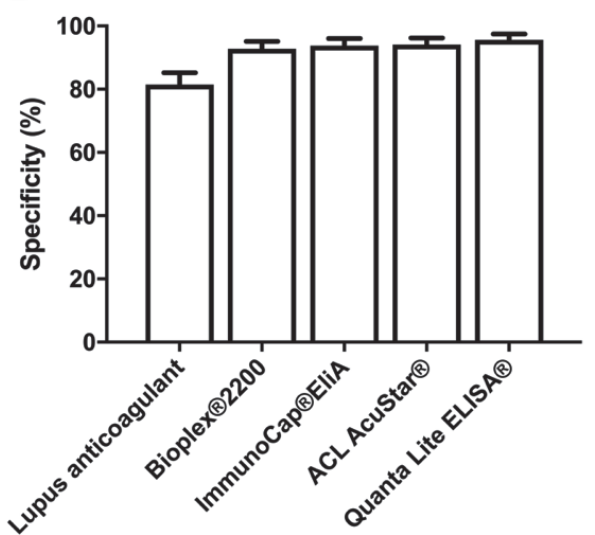

FIGURE 2. Diagnostic efficacy of lupus anticoagulant (LAC) and triple-positive patients detected by BioPlex ${ }^{\circledR} 2200$, ImmunoCap ${ }^{\circledR}$ EliA, ACL AcuStar $^{\circledR}$ and QUANTA Lite ELISA ${ }^{\circledast}$. (A) Sensitivity and (B) specificity for thrombosis (mean $\pm 95 \%$ confidence interval $[95 \% \mathrm{CI}]$ ). 
Triple-positivity for aCL IgG and aß2GPI IgG or aCL IgM and aß2GPI IgG IgM was significantly correlated with thrombosis, independent of the solid phase assay used. However, positivity for the $\operatorname{lgM}$ isotype (aCL $\lg M$ and aß2GPI $\operatorname{lgM}$ ) was more correlated with thrombosis than triple-positivity for the $\lg G$ isotype ( $\mathrm{aCL} \lg G$ and a $32 \mathrm{GPI} \lg G$ )

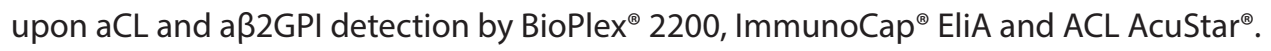
On the other hand, triple-positivity for the $\lg G$ isotype was stronger correlated with thrombosis than for the IgM isotype upon detection of aPL by QUANTA Lite ELISA ${ }^{\oplus}$. However, the majority of triple-positives for the IgM isotype were also positive for the IgG isotype (data not shown). Isolated triple-positivity for the lgG isotype increased the OR for thrombosis compared to LAC positivity only in two out of the four tested aPL solid phase assays (ACL AcuStar ${ }^{\circledast}$ and QUANTA Lite ELISA ${ }^{\oplus}$ ), as shown in Table 5 . In triplepositivity, isolated IgM positivity did not increase OR compared with LAC. Moreover, isolated triple-positivity for the IgM isotype did not reach statistical difference when aPL were detected with BioPlex ${ }^{\circledR} 2200$ and ACL AcuStar ${ }^{\circledast}(1.9[95 \% \mathrm{Cl}, 0.6-5.4]$ and 2.0 [95\% $\mathrm{Cl}$, 0.7-5.9], respectively). Positivity for all tested aPL (LAC, aCL IgG, aCL IgM, aß2GPI lgG and $\mathrm{a} \beta 2 \mathrm{GPI} \operatorname{lgM})$ resulted in the highest $\mathrm{OR}$ for thrombosis ranging from $8.6(95 \% \mathrm{Cl} 3.1$ 24.4) up to 28.9 (3.9-212.4) detected by BioPlex ${ }^{\circledast} 2200$ and ACL AcuStar ${ }^{\circledast}$ respectively.

TABLE 5. Correlation of aPL profiles with thrombosis. Odds ratios (ORs) with $95 \%$ confidence intervals (Cls) are shown (significant ORs in bold).

\begin{tabular}{|c|c|c|c|c|c|}
\hline Positive & Negative & $\begin{array}{c}\text { BioPlex }^{\circledR} 2200 \\
(95 \% \mathrm{Cl})\end{array}$ & $\begin{array}{l}\text { ImmunoCap }{ }^{\oplus} \\
\text { EliA }(95 \% \mathrm{Cl})\end{array}$ & $\begin{array}{c}\text { ACL AcuStar }^{\circledast} \\
(95 \% \mathrm{Cl})\end{array}$ & $\begin{array}{c}\text { QUANTA Lite } \\
\text { ELISA }^{\circledast}(95 \% \mathrm{CI})\end{array}$ \\
\hline LAC & - & $\begin{array}{c}3.4 \\
(2.5-4.7)\end{array}$ & $\begin{array}{c}3.4 \\
(2.5-4.7)\end{array}$ & $\begin{array}{c}3.4 \\
(2.5-4.7)\end{array}$ & $\begin{array}{c}3.4 \\
(2.5-4.7)\end{array}$ \\
\hline $\begin{array}{l}\mathrm{LAC}+\mathrm{aCL}+\mathrm{a} \beta 2 \mathrm{GPI} \\
\text { (irrespective of } \\
\text { isotype) }\end{array}$ & - & $\begin{array}{c}4.4 \\
(2.9-6.9)\end{array}$ & $\begin{array}{c}4.3 \\
(2.7-6.8)\end{array}$ & $\begin{array}{c}5.0 \\
(3.1-8.1)\end{array}$ & $\begin{array}{c}5.2 \\
(3.0-8.9)\end{array}$ \\
\hline $\begin{array}{l}\mathrm{LAC}+\mathrm{aCL} \lg \mathrm{g}+ \\
\mathrm{a} \beta 2 \mathrm{GPI} \lg G\end{array}$ & - & $\begin{array}{c}4.8 \\
(3.0-7.7)\end{array}$ & $\begin{array}{c}4.8 \\
(2.8-8.4)\end{array}$ & $\begin{array}{c}6.0 \\
(3.5-10.2)\end{array}$ & $\begin{array}{c}6.2 \\
(3.1-12.3)\end{array}$ \\
\hline $\begin{array}{l}\mathrm{LAC}+\mathrm{aCL} \lg M+ \\
\mathrm{a} \beta 2 \mathrm{GPI} \lg \mathrm{M}\end{array}$ & - & $\begin{array}{c}5.0 \\
(2.4-10.3)\end{array}$ & $\begin{array}{c}5.0 \\
(2.4-10.3)\end{array}$ & $\begin{array}{c}6.7 \\
(2.8-15.9)\end{array}$ & $\begin{array}{c}4.6 \\
(2.2-9.4)\end{array}$ \\
\hline $\begin{array}{l}\mathrm{LAC}+\mathrm{aCL} \lg \mathrm{G}+ \\
\mathrm{a} \beta 2 \mathrm{GPI} \lg \mathrm{G}\end{array}$ & $\begin{array}{c}\mathrm{aCL} \lg \mathrm{M}+ \\
\mathrm{a} \beta 2 \mathrm{GPI} \lg M\end{array}$ & $\begin{array}{c}3.4 \\
(2.0-5.8)\end{array}$ & $\begin{array}{c}3.4 \\
(1.9-6.2)\end{array}$ & $\begin{array}{c}4.0 \\
(2.3-6.9)\end{array}$ & $\begin{array}{c}4.8 \\
(2.2-10.3)\end{array}$ \\
\hline $\begin{array}{l}\text { LAC+ aCL IgM+ } \\
\text { aß2GPI IgM }\end{array}$ & $\begin{array}{c}\mathrm{aCL} \operatorname{lgG}+ \\
\mathrm{a} \beta 2 \mathrm{GPI} \lg G\end{array}$ & $\begin{array}{c}1.9 \\
(0.6-5.4)\end{array}$ & $\begin{array}{c}2.7 \\
(1.2-6.5)\end{array}$ & $\begin{array}{c}2.0 \\
(0.7-5.9)\end{array}$ & $\begin{array}{c}2.7 \\
(1.2-6.5)\end{array}$ \\
\hline $\begin{array}{l}\mathrm{LAC}+\mathrm{aCL} \lg \mathrm{G}+ \\
\mathrm{a} \beta 2 \mathrm{GPI} \operatorname{lgG}+\mathrm{aCL} \\
\lg \mathrm{M}+\mathrm{a} \beta 2 \mathrm{GPI} \lg M\end{array}$ & - & $\begin{array}{c}8.6 \\
(3.1-24.4)\end{array}$ & $\begin{array}{c}12.0 \\
(2.8-50.8)\end{array}$ & $\begin{array}{c}28.9 \\
(3.9-212.4)\end{array}$ & $\begin{array}{c}10.1 \\
(2.4-43.3)\end{array}$ \\
\hline
\end{tabular}




\section{DISCUSSION}

Detection of aPL antibodies is accompanied by large inter-method and inter-laboratory variation $[2,4,5,17,18]$. Traditionally, aCL and a $\beta 2 \mathrm{GPI}$ antibodies are detected by ELISA. Nowadays, more advanced (automated) systems are available, which are suggested to reduce inter-laboratory variation $[4,17,19-21]$. We excluded inter-laboratory variation, by detecting $\mathrm{aCL}$ and $\mathrm{a} \beta 2 \mathrm{GPI}$ antibodies in the same samples at one laboratory (Ghent, Belgium), carried out by a single technician. Despite many efforts, standardization of antiphospholipid antibody (aPL) assays is far from reached as poor consensus is obtained between assays when measuring the same sample $[2,20]$. The identification of triple-positive patients was recently suggested to be less affected by inter-method variation, thereby better classifying APS patients at risk [13]. In a retrospective crosssectional study, the authors suggested that identification of patients with triple aPL positivity is platform and method independent, having compared two methods with a different solid phase from the same manufacturer [13]. However, they found a disparity of 6 or 9 triple-positives out of 220 patients (121 with APS and 99 with systemic lupus erythematosus), depending on the cut-off value used, already suggesting the presence of patients with low levels of $a \beta 2 \mathrm{GPI}$ and $\mathrm{aCL}$ aPL titers and difficulties in reaching consensus in the classification of these patients [13, 22]. In our cohort, the highest discrepancy in number of triple-positive samples was found between BioPlex ${ }^{\circledR} 2200$ and QUANTA Lite ELISA ${ }^{\oplus}$ with a discrepancy of 29 triple-positives out of 202 LACpositive samples (14\%). Similar to single positivity, identification of triple-positives was found to be assay dependent. In addition, we did not assess the variation of triplepositivity detection introduced by LAC assays. Indeed, an external quality control program concluded that inter-method and inter-laboratory variation is higher in solid phase assays than LAC detection by dilute Russell's Viper Venom Time (dRVVT) assay [3]. However, still difficulties persist in reaching consensus among weak-positive samples [2-4, 23]. The presented variation in triple-positivity detection may therefore be underestimated. A possible limitation of our study is that thrombotic patients under treatment during the time of blood collection, could result in an increased risk of false positive LAC tests.

Samples positive for $\mathrm{LAC}, \mathrm{aCL}$ and a $\beta 2 \mathrm{GPI}$ antibodies by one solid phase platform but not by all four tested platforms have lower median aPL titers, suggesting difficulties in consensus on positivity among low aPL titers (Figure 1) [24]. We accept that the cut-off calculated by the 99th percentile of a normal population is the best consensus between sensitivity and specificity, and the clinical relevance of aCL and/or a $32 \mathrm{GPI}$ results that are below the 99th percentile needs to be further studied [25]. Few studies showed that low titers of aCL also were predictive for thrombotic recurrence [26]. In this study, we 
transferred the manufacturer's cut-off after confirmation, as recommend by the ISTHSSC guidelines [16]. In terms of clinical practice, a recent questionnaire raised by the SSC showed that the majority of laboratories use the same approach, because only a minority of laboratories have the resources to calculate a cut-off value from at least 120 normals. With this cut-off choice applied for all platforms, the majority of discrepant samples in our study were from patients that experienced a thrombotic event (Table 4).

A minority of non-thrombotic patients ( $n=582$, auto-immune disease and controls) in our study population showed triple-positivity $(n=17-28 / 583$ or $2.9 \%-4.8 \%$, depending on the platform). These should be regarded as asymptomatic carriers, what is in line with the findings of Mustonen et al. who found that $5 \%$ of asymptomatic triple-positives were carriers [27].

The association of thrombosis and single aPL positivity is debated because results are contrary. Recent studies showed that the risk of thrombotic events increases with the number of positive tests in APS patients and the creation of antibody profiles and test combinations increases the association with thrombosis [7, 8, 28-30]. On the other hand, another study showed a strong association between single aPL positivity and thrombosis in paediatric APS patients [31]. Although single positivity is not always significantly correlated with thrombosis, within the current guidelines all aPL have the same diagnostic value [1]. In our cohort, we confirmed the strong correlation between triple-positivity and thrombosis, as triple-positivity was significantly correlated with thrombosis independent of the platform used. A large observational study investigated the incidence of thrombosis in obstetric APS patients. Frequencies of thrombotic events were assessed in 517 APS patients, 279 women carrying a genetic thrombophilia polymorphism and 796 women with negative thrombophilia polymorphism results [11]. Computed risks for thrombosis of LAC positivity and triple-positivity were globally concordant [11]. However, triple-positivity was a predictor for pulmonary embolism, whereas LAC positivity alone was not [11]. In an Italian cohort, 618 patients were referred to aPL testing, of which 55\% met the clinical criteria consistent with the Sapporo criteria [7]. A statistically significant correlation between LAC and thrombosis was found (OR 4.4, 95\% Cl 1.5-13.3) [7]. In triple-positive patients the association with thrombosis increased even further (OR 33.3, 95\% Cl 7.0-157.6), suggesting an additional value of triple-positivity detection in thrombotic risk stratification [7]. Patient population and aPL detection method may impact the correlation of thrombosis with triple-positivity and the role of $\mathrm{aCL}$ and $\mathrm{a} \beta 2 \mathrm{GPI}$ antibodies in addition to $\mathrm{LAC}$. It has already been shown that the presence of $\mathrm{aCL}$ and $\mathrm{a} \beta 2 \mathrm{GPI}$ of the same isotype reinforces the clinical probability of APS [32]. We confirmed that ORs for all platforms are higher for triple-positivity with concordance of isotype compared to triple-positivity including combinations of $\mathrm{aCL}$ 
and aß2GPI irrespective of isotype, except for one platform (QUANTA Lite ELISA ${ }^{\oplus}$ ) with lower OR for IgM triple-positivity compared with the OR for triple-positivity irrespective of the isotype.

Our results clearly illustrate the wide variation in thrombotic association introduced by aPL detection methods. In LAC positives, "isolated" IgM or "isolated" IgG aPL was less correlated with thrombosis than triple-positivity irrespective of the isotype. Interestingly, positivity for $\mathrm{LAC}, \mathrm{aCL}$ and a $\beta 2 \mathrm{GPI}$ antibodies for both isotypes resulted in the strongest correlation with thrombosis. Therefore, both IgG and IgM antibodies are of added value in stratification of risk of thrombosis in APS. However, IgM did not add any value in thrombotic association to $L A C$ positives in the absence of $\operatorname{lgG}$ aPL.

In conclusion, detection of triple-positivity varied among commercially available solid phase assays detecting $\mathrm{aCL}$ and aß2GPI antibodies. However, triple-positivity (irrespective of the isotype) was statistically correlated with thrombosis, independent of the solid phase assay used. Except for one platform, concordance of isotype resulted in the highest OR. Detection of IgM antibodies in triple-positivity was only of added clinical value in combination with $L A C, a C L \lg G$ and a $32 \mathrm{GPI}$ IgG positivity. These data confirm the high association of triple-positivity with thrombosis and show that the isotype and solid phase assay used to detect aPL affect the association with thrombosis. As triplepositive APS patients have an increased risk of thrombotic recurrence, standardization in triple-positivity detection is urgently warranted. 


\section{ADDENDUM}

K. M. J. Devreese, B. de Laat and H. Kelchtermans designed the study. K. M. J. Devreese organized the sample collection at the different centers. K. M. J. Devreese, D. Wahl, G. W. Moore and J. Musiał collected samples and identified sample characteristics. Samples were analyzed under supervison of K. M. J. Devreese. W. Chayoua, K. M. J. Devreese, B. de Laat and $\mathrm{H}$. Kelchtermans interpreted data, performed statistical analyses and wrote the manuscript. D. Wahl, G. W. Moore and J. Musiał critically reviewed the manuscript.

\section{ACKNOWLEDGEMENTS}

The authors thank M. Luypaert for his technical assistance, Bio-Rad Laboratories, ThermoFisher/Phadia, Werfen/Instrumentation Laboratory and Inova Diagnostics for providing the test kits for the detection of a $32 \mathrm{GPI}$ and $\mathrm{aCL} \lg \mathrm{G}$ and IgM antibodies and S. Zuily, A. Tripodi, P. Fontana and J. Remijn for providing patient samples.

\section{DISCLOSURE OF CONFLICT OF INTERESTS}

G. W. Moore reports personal fees from DSM Pentapharm, outside the submitted work, and has been a member of the Coagulation Advisory Board for Roche Diagnostics. The other authors state that they have no conflict of interest. 


\section{REFERENCES}

1 Miyakis S, Lockshin MD, Atsumi T, Branch DW, Brey RL, Cervera R, Derksen RHWM, de Groot PG, Koike T, Meroni PL, Reber G, Shoenfeld Y, Tincani A, Vlachoyiannopoulos PG, Krilis SA. International consensus statement on an update of the classification criteria for definite antiphospholipid syndrome (APS). J Thromb Haemost. 2006; 4: 295-306.

2 Devreese KM. Antiphospholipid antibody testing and standardization. Int J Lab Hematol. 2014; 36: 352-63.

3 Favaloro EJ. Variability and diagnostic utility of antiphospholipid antibodies including lupus anticoagulants. Int J Lab Hematol. 2013; 35: 269-74.

4 Favaloro EJ, Franchini M, Lippi G. Biological therapies for von Willebrand disease. Expert Opin Biol Ther. 2012; 12: 551-64.

5 Favaloro EJ, McVicker W, Zhang Y, Hamdam S, Huynh M, Peris P, O'Neal M, Hocker N. Improving the inter-laboratory harmonization of the international normalized ratio (INR): utilizing the concept of transference to estimate and/or validate international sensitivity index (ISI) and mean normal prothrombin time (MNPT) values and/or to eliminate measurement bias. Clin Lab Sci. 2012; 25: 13-25.

6 Wong R, Wilson R, Pollock W, Steele R, Gillis D. Anti-cardiolipin antibody testing and reporting practices among laboratories participating in a large external Quality Assurance Program. Pathology. 2004; 36: 174-81.

7 Pengo V, Biasiolo A, Pegoraro C, Cucchini U, Noventa F, Iliceto S. Antibody profiles for the diagnosis of antiphospholipid syndrome. Thromb Haemost. 2005; 93: 1147-52.

8 Pengo V, Ruffatti A, Legnani C, Gresele P, Barcellona D, Erba N, Testa S, Marongiu F, Bison E, Denas G, Banzato A, Padayattil Jose S, Iliceto S. Clinical course of high-risk patients diagnosed with antiphospholipid syndrome. J Thromb Haemost. 2010; 8: 237-42.

9 Sciascia S, Murru V, Sanna G, Roccatello D, Khamashta MA, Bertolaccini ML. Clinical accuracy for diagnosis of antiphospholipid syndrome in systemic lupus erythematosus: evaluation of 23 possible combinations of antiphospholipid antibody specificities. J Thromb Haemost. 2012; 10: 2512-8.

10 Sciascia S, Cosseddu D, Montaruli B, Kuzenko A, Bertero MT. Risk Scale for the diagnosis of antiphospholipid syndrome. Ann Rheum Dis. 2011; 70: 1517-8.

11 Gris JC, Bouvier S, Molinari N, Galanaud JP, Cochery-Nouvellon E, Mercier E, Fabbro-Peray P, Balducchi JP, Mares P, Quere I, Dauzat M. Comparative incidence of a first thrombotic event in purely obstetric antiphospholipid syndrome with pregnancy loss: the NOH-APS observational study. Blood. 2012; 119: 2624-32.

12 Krilis SA, Giannakopoulos B. Laboratory methods to detect antiphospholipid antibodies. Hematology Am Soc Hematol Educ Program. 2014; 2014: 321-8.

13 Iwaniec T, Kaczor MP, Celinska-Lowenhoff M, Polanski S, Musial J. Identification of patients with triple antiphospholipid antibody positivity is platform and method independent. Pol Arch Med Wewn. 2016; 126: 19-24. 
14 Kelchtermans H, Pelkmans L, de Laat B, Devreese KM. IgG/IgM antiphospholipid antibodies present in the classification criteria for the antiphospholipid syndrome: a critical review of their association with thrombosis. J Thromb Haemost. 2016; 14: 1530-48.

15 Pengo V, Tripodi A, Reber G, Rand JH, Ortel TL, Galli M, De Groot PG. Update of the guidelines for lupus anticoagulant detection. J Thromb Haemost. 2009; 7: 1737-40.

16 Devreese KM, Pierangeli SS, de Laat B, Tripodi A, Atsumi T, Ortel TL. Testing for antiphospholipid antibodies with solid phase assays: guidance from the SSC of the ISTH. J Thromb Haemost. 2014; 12: 792-5.

17 Devreese K, Hoylaerts MF. Laboratory diagnosis of the antiphospholipid syndrome: a plethora of obstacles to overcome. Eur J Haematol. 2009; 83: 1-16.

18 Urbanus RT, de Groot PG. Antiphospholipid antibodies--we are not quite there yet. Blood Rev. 2011; 25: 97-106.

19 Tincani A, Allegri F, Sanmarco M, Cinquini M, Taglietti M, Balestrieri G, Koike T, Ichikawa K, Meroni P, Boffa MC. Anticardiolipin antibody assay: a methodological analysis for a better consensus in routine determinations--a cooperative project of the European Antiphospholipid Forum. Thromb Haemost. 2001; 86: 575-83.

20 Favaloro EJ, Wong RC, Jovanovich S, Roberts-Thomson P. A Review of beta2 -glycoprotein-I antibody testing results from a peer-driven multilaboratory quality assurance program. Am J Clin Pathol. 2007; 127: 441-8.

21 Devreese KM, Poncet A, Lindhoff-Last E, Musial J, de Moerloose P, Fontana P. A multicenter study to assess the reproducibility of antiphospholipid antibody results produced by an automated system. J Thromb Haemost. 2017; 15: 91-5.

22 Iwaniec T, Kaczor MP, Celinska-Lowenhoff M, Polanski S, Musial J. Clinical utility of automated chemiluminescent antiphospholipid antibody assay. Thromb Res. 2015; 136: 1033-9.

23 Reber G, Meijer P. In ECAT veritas? Lupus. 2012; 21: 722-4.

24 Ruffatti A, Olivieri S, Tonello M, Bortolati M, Bison E, Salvan E, Facchinetti M, Pengo V. Influence of different IgG anticardiolipin antibody cut-off values on antiphospholipid syndrome classification. J Thromb Haemost. 2008; 6: 1693-6.

25 Devreese KMJ, Ortel TL, Pengo V, de Laat B, Subcommittee on Lupus Anticoagulant/ Antiphospholipid A. Laboratory criteria for antiphospholipid syndrome: communication from the SSC of the ISTH. J Thromb Haemost. 2018; 16:809-13.

26 Schulman S, Svenungsson E, Granqvist S. Anticardiolipin antibodies predict early recurrence of thromboembolism and death among patients with venous thromboembolism following anticoagulant therapy. Duration of Anticoagulation Study Group. Am J Med. 1998; 104: 3328.

27 Mustonen P, Lehtonen KV, Javela K, Puurunen M. Persistent antiphospholipid antibody (aPL) in asymptomatic carriers as a risk factor for future thrombotic events: a nationwide prospective study. Lupus. 2014; 23: 1468-76.

28 Bergrem A, Jacobsen EM, Skjeldestad FE, Jacobsen AF, Skogstad M, Sandset PM. The association of antiphospholipid antibodies with pregnancy-related first time venous thrombosis--a population-based case-control study. Thromb Res. 2010; 125: e222-7. 
29 Devreese KM. Antiphospholipid antibodies: evaluation of the thrombotic risk. Thromb Res. 2012; 130 Suppl 1: S37-40.

30 Devreese K, Peerlinck K, Hoylaerts MF. Diagnostic test combinations associated with thrombosis in lupus anticoagulant positive patients. Thromb Haemost. 2011; 105: 736-8.

31 Ma J, Song H, Wei M, He Y. Clinical characteristics and thrombosis outcomes of paediatric antiphospholipid syndrome: analysis of 58 patients. Clin Rheumatol. 2017. In press, DOI 10.1007/s10067-017-3776-5

32 Pengo V, Banzato A, Bison E, Bracco A, Denas G, Ruffatti A. What have we learned about antiphospholipid syndrome from patients and antiphospholipid carrier cohorts? Semin Thromb Hemost. 2012; 38: 322-7. 


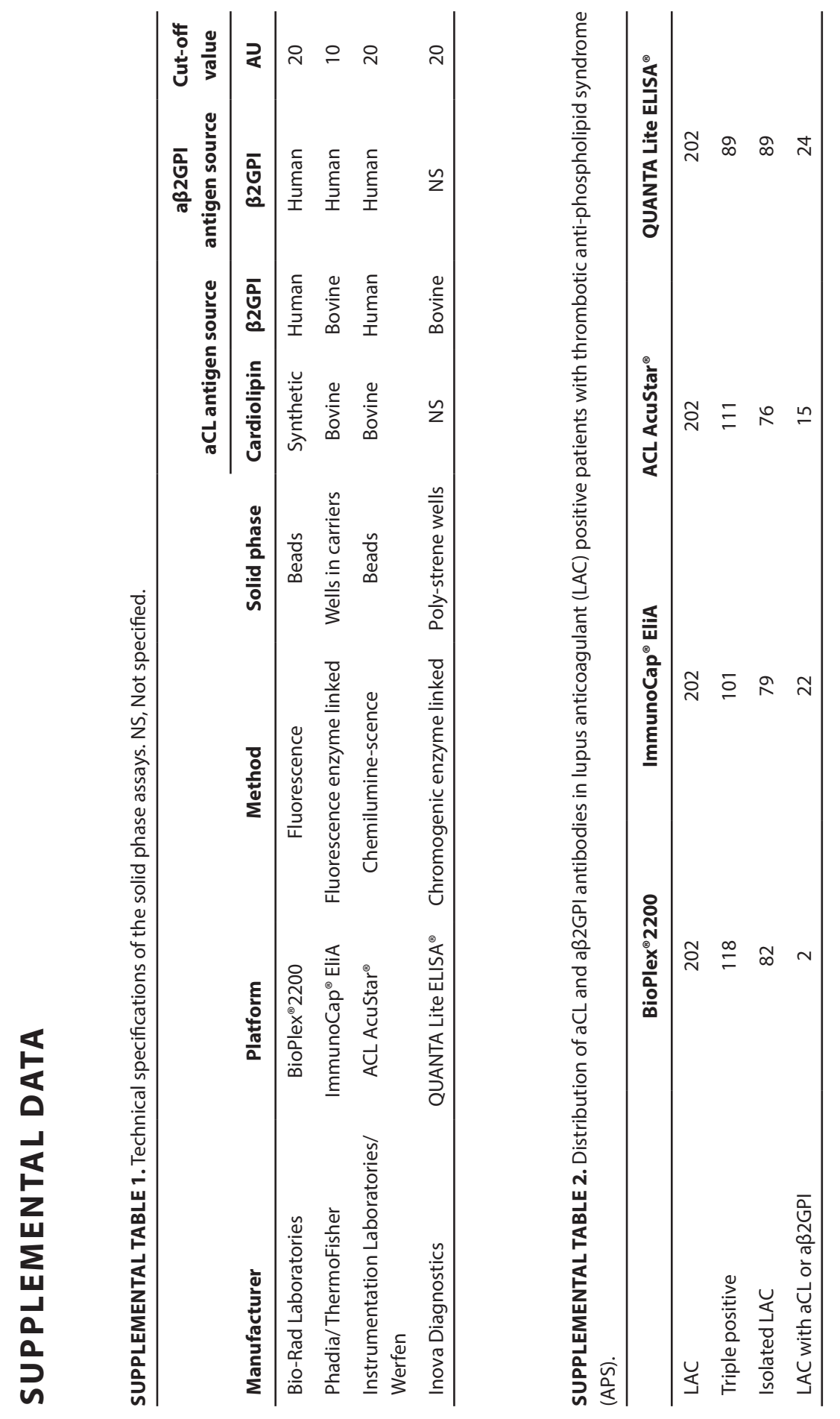




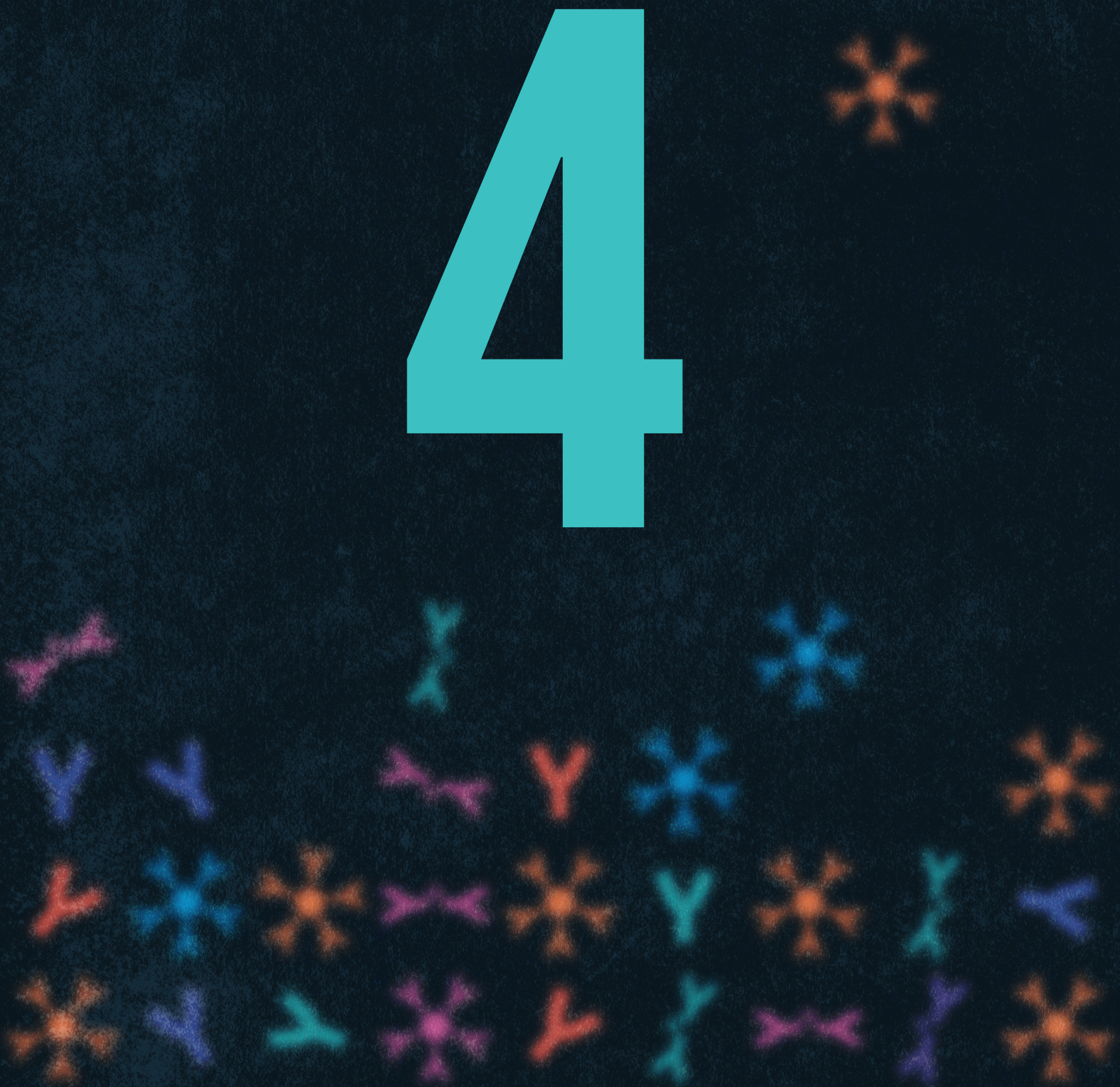


\section{The (non-)sense of detecting anti-cardiolipin and anti- B2glycoprotein I IgM antibodies in the antiphospholipid syndrome}

Walid Chayoua*, Hilde Kelchtermans*, Jean-Christophe Gris, Gary W. Moore, Jacek Musiał, Denis Wahl, Philip G. de Groot, Bas de Laat, Katrien M. J. Devreese

*Equal contribution

J Thromb Haemost. 2020; 18: 169-79 


\section{ABSTRACT}

Background: The antiphospholipid syndrome (APS) is characterized by thrombosis and/or pregnancy morbidity with the persistent presence of lupus anticoagulant (LAC), anti-cardiolipin (aCL) and/or anti-b2glycoprotein I (aß2GPI) antibodies of the immunoglobulin $\mathrm{G} /$ immunoglobulin $\mathrm{M}$ ( $\mathrm{lgG} / \mathrm{lgM}$ ) isotype. However, the role of $\mathrm{aCL}$ and $\mathrm{a} \beta 2 \mathrm{GPI}$ IgM as a serologic marker in APS is debated.

Objectives: We aimed to assess the diagnostic and clinical value of IgM antiphospholipid antibodies (aPL) in APS within the classification criteria.

Patients/Methods: Our multicenter study comprised of 1008 patients, including APS patients and controls. Anti-CL and aß2GPI IgG and IgM antibodies were detected with four commercially available solid phase assays.

Results: Positivity for aCL and/or aß2GPI antibodies was significantly correlated with thrombosis and pregnancy morbidity, independent of the isotype and solid phase assay. Higher odds ratios were obtained for IgG compared to IgM positivity. Isolated IgM was rare in thrombotic APS, but more frequent in obstetric APS, ranging from $3.5 \%$ to $5.4 \%$ and $5.7 \%$ to $12.3 \%$, respectively, dependent on the solid phase assay. In a multivariate logistic regression analysis of aPL, IgM positivity was found to be associated with pregnancy morbidity. However, detection of IgM was not independently associated with thrombosis. Combined positivity for LAC, IgG and IgM was highly associated with thrombosis and pregnancy morbidity.

Conclusions: Our data support testing for $\mathrm{aCL}$ and a $32 \mathrm{GPI}$ IgM in women suspected of obstetric APS. However, no added value was found for testing IgM in patients suspected of thrombotic APS. Still, IgM aPL might be useful as a second-line test to improve thrombotic risk stratification. 


\section{INTRODUCTION}

The antiphospholipid syndrome (APS) is characterized by thrombosis and/or pregnancy morbidity with the persistent presence of antiphospholipid antibodies (aPL) [1]. Obstetrical complications include fetal loss after the 10th week of gestation, recurrent early miscarriages and premature birth due to severe preeclampsia or intrauterine growth restriction [1]. Thrombotic APS is characterized by venous, arterial and/or small vessel thrombosis [1]. Diagnosis of APS predominantly relies on aPL assays detecting lupus anticoagulant (LAC) by a functional assay or detection of anti-cardiolipin ( $\mathrm{aCL}$ ) immunoglobulin $\mathrm{G}$ / immunoglobulin $\mathrm{M}(\mathrm{lgG} / \mathrm{lgM})$ antibodies and anti- $\beta 2$ glycoprotein I (aß2GPI) IgG/lgM antibodies by solid phase assays [1-3]. Within the current criteria, persistent presence of either $\operatorname{lgG}$ or $\operatorname{lgM}$ aPL with associated thrombosis and/or pregnancy morbidity is sufficient for the classification of APS [1]. However, the value of $\operatorname{lgM~aCL}$ and aß2GPI antibodies in APS classification is debated [4-10].

Recently a meta-analysis aimed to assess the clinical value of $\operatorname{lgM} \mathrm{aCL}$ and $\mathrm{a} \beta 2 \mathrm{GPI}$ antibodies in thrombotic APS and found a stronger thrombotic correlation for IgG than for IgM antibodies [4]. Studies that found a statistical association for $\mathrm{aCL}$ and aß2GPI IgM antibodies with thrombosis mostly also found a significant association for the IgG isotype, suggesting a limited role of IgM in thrombotic APS [4]. In the metaanalysis, two studies were included that found a protective role of $\lg M$ antibodies in thrombosis $[4,11,12]$. In 2006, another meta-analysis assessed the association between $\mathrm{aCL}$ antibodies and recurrent fetal loss in women without an autoimmune disease and found a statistical association for both isotypes ( $\lg M$ and $\lg G$ ) [6]. However, in both meta-analyses authors were unable to evaluate $\operatorname{lgM}$ antibodies as a single serologic marker, because of unavailability of separate IgG and IgM results [4,6]. In addition, comparison of clinical studies is difficult as multiple study designs are used with a wide variety of aPL assays. Solid phase assays are poorly standardized and external quality control programs have shown that aPL assays produce variable results $[13,14]$.

More evidence has become available that hints towards evaluation of the complete aPL profile to improve risk stratification of APS patients [2,15-17]. In an observational study among purely obstetric APS patients, aCL and aß2GPI positivity together with LAC (triple positivity) was a predictor of pulmonary embolism while single LAC positivity was not [18]. Another study found that the presence of any aPL at any time did not result in a significant increase in the risk of thrombotic recurrence, while the persistent presence of the same type increased the risk of thrombotic recurrence significantly [15]. Multiple aPL positivity at the same time or at different time points even further increased the risk of recurrence [15]. We have previously shown that the thrombotic association of IgM 
antibodies within triple positive (positivity for $\mathrm{LAC}, \mathrm{aCL}$ and $\mathrm{a} \beta 2 \mathrm{GPI}$ ) patients is limited [19]. Here, we aimed to assess the value of IgM antibodies as a single serologic marker in APS and its clinical value in aPL profiles within the current classification criteria. Four commercially available solid phase assays were used, reducing assay dependency on the association of IgM antibodies and thrombosis or obstetric complications.

\section{METHODS}

\section{Study population}

Patient samples were collected from eight medical European centers within a timespan of one year, with patient samples stored less than five years at or below $-80^{\circ} \mathrm{C}$. The Sydney classification criteria were followed for the diagnosis of thrombotic and obstetric APS [1]. Thrombosis was defined as one or more clinical episodes of arterial, venous, or small vessel thrombosis, in any tissue or organ, confirmed by objective validated criteria (e.g. unequivocal findings of appropriate imaging studies or histopathology) [1]. Pregnancy morbidity was defined as: (1) one or more unexplained deaths of a morphologically normal fetus at or beyond the 10th week of gestation, with normal fetal morphology documented by ultrasound or by direct examination of the fetus; (2) one or more premature births of a morphologically normal neonate before the 34th week of gestation because of: eclampsia or severe pre-eclampsia defined according to standard definitions, recognized features of placental insufficiency; (3) three or more unexplained consecutive spontaneous abortions before the 10th week of gestation, with maternal anatomic or hormonal abnormalities and paternal and maternal chromosomal causes excluded [1]. Patients were classified as thrombotic or obstetric APS by the local center. Control populations consisted of patients with an autoimmune disease other than APS (e.g. systemic lupus erythematosus and systemic sclerosis) without thrombotic complications (autoimmune disease [AID] controls); patients that were referred for aPL testing for other reasons than the clinical criteria of APS (e.g. subfertility and prolonged activated partial thromboplastin time [aPTT], controls); patients with a previous thrombotic event negatively tested for aPL (non-APS thrombosis); and patients that experienced obstetric complications in the absence of aPL (non-APS obstetric). The study was approved by the local ethical committees. 


\section{LABORATORY ASSAYS}

\section{Lupus anticoagulant}

Lupus anticoagulant assays were performed by the local center, according to the International Society of Thrombosis and Haemostasis-Scientific Standardisation Subcommittee (ISTH-SSC) guideline [20]. Briefly, citrated blood was double centrifugated for 15 minutes at $2000 \mathrm{~g}$ (room temperature) [20]. After transferring the plasma in a non-activating plastic centrifuge tube, the plasma was centrifugated for an additional 10 minutes at $>2500 \mathrm{~g}$ (room temperature) [20]. The obtained platelet poor plasma was tested for a prolonged clotting time with two tests based on different principles (e.g. aPTT and dilute Russell viper venom time). Lupus anticoagulant testing was performed by a three-step procedure including screening, mixing, and confirmation.

\section{Solid phase assays}

Commercially available solid phase assays were selected based on frequently used assays in the external quality control program of the ECAT (External quality Control of diagnostic Assays and Tests, Voorschoten, The Netherlands) and the willingness of manufacturers for collaboration. Anti-CL IgG, aCL IgM, aß2GPI lgG and a $32 \mathrm{GPI} \operatorname{lgM}$ aPL were detected by four solid phase assays: BioPlex ${ }^{\oplus 2} 200$ (Bio-Rad, Bio-Rad Laboratories, Hercules, USA), Phadia ${ }^{\circledR}$ (Thermo Fisher Scientific/Phadia, Uppsala, Sweden), ACL AcuStar $^{\circledR}$ (Instrumentation Laboratories, Bedford, USA) and QUANTA Lite ${ }^{\oplus}$ ELISA (Inova Diagnostics, San Diego, USA) in the Ghent University Hospital (Ghent, Belgium). Detection of $\mathrm{aCL}$ and a $32 \mathrm{GPI}$ antibodies was performed according manufacturer's instructions. Manufacturer's recommended cut-off values were used upon confirmation in 20 healthy volunteers, in accordance with the ISTH-SSC guideline [21].

\section{Statistical analyses}

Crude odds ratios for thrombosis were calculated within patients with thrombotic APS, non-APS thrombosis, AID controls and controls. Crude odds ratios for pregnancy morbidity were calculated within women with obstetric APS, non-APS obstetric APS, normal pregnancy, AID controls and controls. Differences in IgM titers above the threshold were assessed with the Mann-Whitney $U$ test. In a multivariate logistic regression analysis, a backward variable selection was performed with variables having a $P$-value $<0.2$. In order to evaluate independent variables for thrombosis, analysis was performed on the total population with a model including age, sex, pregnancy morbidity, LAC, IgG and IgM. Within women, age, thrombosis, LAC, IgG and IgM were included in the multivariate model to evaluate independent variables for pregnancy 
morbidity. Odds ratios with their respective $95 \%$ confidence interval was determined for each variable in the final model. A $P$-value $<0.05$ was regarded as statistically significant. Statistical analyses were performed using the statistical package for social sciences (SPSS 23.0; SPSS, New York, USA) and MedCalc Statistical Software version 17.7.2 (MedCalc Software bvba, Ostend, Belgium).

\section{RESULTS}

\section{Patient characteristics}

We included 1008 patients of whom $75.7 \%$ were female with a mean age of 44 years (Table 1). Venous thrombosis was more prevalent compared to arterial thrombosis in thrombotic APS and non-APS thrombosis patients, $62 \%$ and $73 \%$ respectively (Table 1). The majority of thrombotic APS patients received anticoagulant therapy including vitamin $\mathrm{K}$ antagonists (46\%), low molecular weight heparins (5\%) and direct oral anticoagulants (4\%). Twenty-seven patients (10\%) received antiplatelet therapy and $2 \%$ of patients with thrombotic APS received both anticoagulant and antiplatelet therapy. Details on anticoagulant and anti-platelet therapy of the remaining 84 patients were not available.

\section{Diagnostic role of aCL and aß2GPI IgG/IgM antibodies in thrombosis}

Lupus anticoagulant positivity resulted in an odds ratio (OR) for thrombosis of 3.4 (95\% confidence interval [95\% Cl], 2.5-4.7) (Table 2). Positivity for aCL or a $32 \mathrm{GPI}$ antibodies was significantly associated with thrombosis, independent of the isotype or solid phase assay used (Table 2). Positivity for IgG aCL or aß2GPI antibodies was more strongly correlated with thrombosis than IgM aCL or aß2GPI antibodies (Table 2). Lupus anticoagulant, IgG aCL or a $32 \mathrm{GPI}$ and $\operatorname{lgM} \mathrm{aCL}$ or $\mathrm{a} \beta 2 \mathrm{GPI}$ were analyzed in a multivariate model in which IgM aCL or a $2 \mathrm{GPI}$ antibodies resulted not to be an independent variable for thrombosis, independent of the solid phase assay used. In addition, we performed a subanalysis separately on patients with venous or arterial thrombosis in which $\operatorname{lgM} \mathrm{aCL}$ or aß2GPI antibodies were not an independent variable for both types of thrombosis (data not shown for the separate subpopulations). Within the multivariate model, lupus anticoagulant and IgG aCL or a $22 \mathrm{GPI}$ antibodies were independent variables with $\mathrm{OR}$ between $2.3(95 \% \mathrm{Cl}, 1.6-3.3)$ and $2.4(95 \% \mathrm{Cl}, 1.7-3.4)$ and $2.3(95 \% \mathrm{Cl}, 1.6-3.5)$ and 3.2 (95\%Cl, 2.0-5.0), respectively (Table 2 ). 


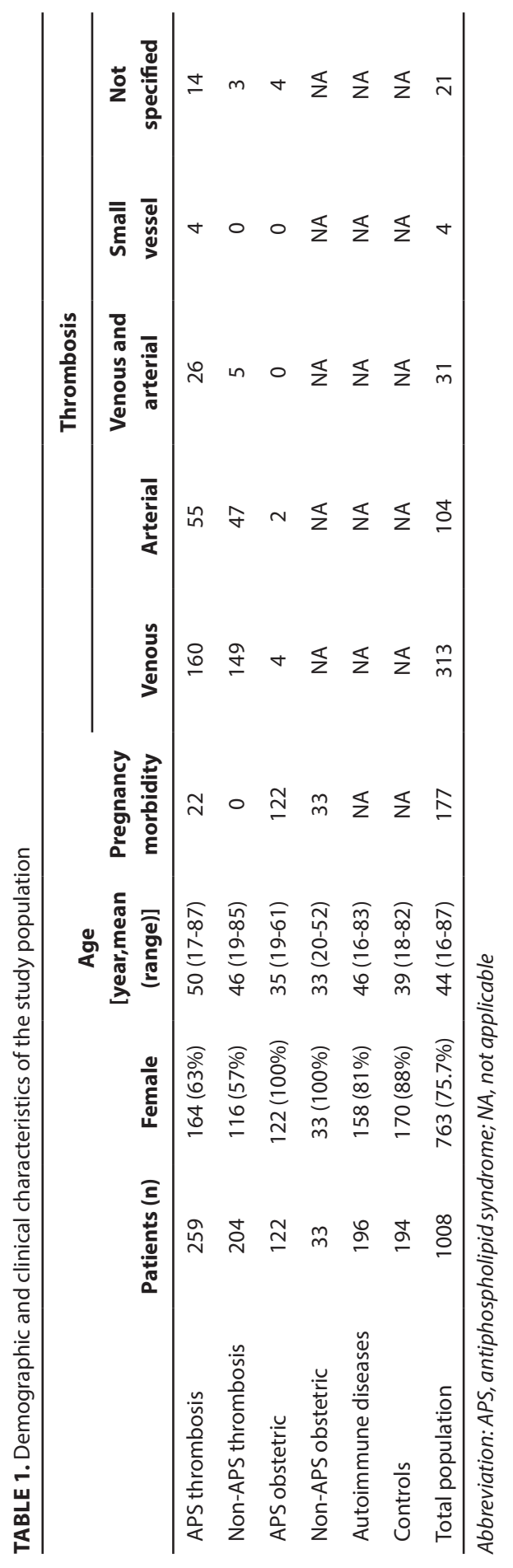




\section{Diagnostic role of aCL and a $32 \mathrm{GPI} \lg \mathrm{G} / \mathrm{lgM}$ antibodies in pregnancy morbidity}

Similar to thrombosis, positivity for $\mathrm{aCL}$ or $\mathrm{a} \beta 2 \mathrm{GPI}$ antibodies was significantly associated with pregnancy morbidity, independent of the isotype or solid phase assay used (Table3). Positivity for IgG aCL or aß2GPI antibodies clearly resulted in higher crude OR for obstetric complications than positivity for $\operatorname{lgM} \mathrm{aCL}$ or a $32 \mathrm{GPI}$ antibodies (Table 3). In contrast to thrombosis, IgM aCL or aß2GPI antibodies was an independent variable for pregnancy morbidity with OR ranging between $1.7(95 \% \mathrm{Cl}, 1.1-2.8)$ and 2.0 (95\% Cl, 1.1-3.5). The OR of LAC positivity varied between $3.6(95 \% \mathrm{Cl}, 2.3-5.7)$ and 3.9 (95\% Cl, 2.5-6.1) (Table 3). IgG aCL or aß2GPI antibodies was an independent variable with three out of the four tested solid phase assays, resulting in OR between $1.9(95 \% \mathrm{Cl}$, 1.1-3.2) and $2.5(95 \% \mathrm{Cl}, 1.5-4.4)$.

\section{Additional diagnostic value of aCL and aß2GPI IgM antibodies in thrombotic patients}

Positivity for IgM aCL or a 32 GPI antibodies ranged from $26 \%$ to $36 \%$ among thrombotic APS patients, $0 \%$ to $3.4 \%$ among non-APS thrombosis patients and $6.4 \%$ to $16 \%$ among patients with an autoimmune disease and controls (Table 4). Thrombotic APS patients with isolated IgM aCL or aß2GPI positivity ranged from $3.5 \%$ to $5.4 \%$ (Table 4). In addition, up to $2.5 \%$ patients classified as non-APS thrombosis were found to be isolated positive for IgM aCL or aß2GPI antibodies (Table 4). The prevalence of isolated $\operatorname{lgM} \mathrm{aCL}$ or a $32 \mathrm{GPI}$ antibodies in controls and AID patients was $1.8 \%$ to $10 \%$ as detected by BioPlex ${ }^{\circledR} 2200$ and Phadia $^{\circledR}$, respectively (Table 4 ). 
TABLE 2. Correlation of lupus anticoagulant, $\lg G$ and $\operatorname{lgM} \mathrm{aCL}$, or a $\mathrm{\beta} 2 \mathrm{GPI}$ antibodies with thrombosis

\begin{tabular}{|c|c|c|c|c|c|c|c|c|}
\hline & \multicolumn{2}{|c|}{ BioPlex $^{\circledR} 2200$} & \multicolumn{2}{|c|}{ Phadia ${ }^{\circledR}$} & \multicolumn{2}{|c|}{ AcuStar ${ }^{\circledast}$} & \multicolumn{2}{|c|}{$\begin{array}{c}\text { QUANTA } \\
\text { Lite }{ }^{\circledR} \text { ELISA }\end{array}$} \\
\hline & 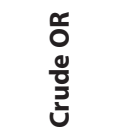 & 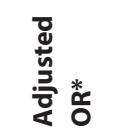 & 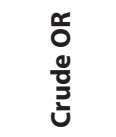 & 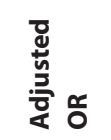 & 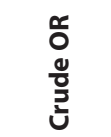 & 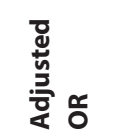 & 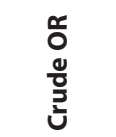 & 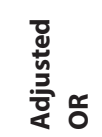 \\
\hline $\begin{array}{l}\text { Lupus } \\
\text { anticoagulant }\end{array}$ & $\begin{array}{c}3.4 \\
(2.5-4.7)\end{array}$ & $\begin{array}{c}2.4 \\
(1.7-3.4)\end{array}$ & $\begin{array}{c}3.4 \\
(2.5-4.7)\end{array}$ & $\begin{array}{c}2.4 \\
(1.7-3.4)\end{array}$ & $\begin{array}{c}3.4 \\
(2.5-4.7)\end{array}$ & $\begin{array}{c}2.3 \\
(1.6-3.3)\end{array}$ & $\begin{array}{c}3.4 \\
(2.5-4.7)\end{array}$ & $\begin{array}{c}2.4 \\
(1.7-3.4)\end{array}$ \\
\hline $\begin{array}{l}\lg G \\
\text { antibodies }\end{array}$ & $\begin{array}{c}2.7 \\
(1.9-3.9)\end{array}$ & $\begin{array}{c}2.3 \\
(1.6-3.5)\end{array}$ & $\begin{array}{c}3.7 \\
(2.5-5.5)\end{array}$ & $\begin{array}{c}2.9 \\
(1.9-4.4)\end{array}$ & $\begin{array}{c}2.7 \\
(1.9-3.8)\end{array}$ & $\begin{array}{c}2.4 \\
(1.6-3.3)\end{array}$ & $\begin{array}{c}4.7 \\
(2.9-7.5)\end{array}$ & $\begin{array}{c}3.2 \\
(2.0-5.0)\end{array}$ \\
\hline $\begin{array}{l}\text { IgM } \\
\text { antibodies }\end{array}$ & $\begin{array}{c}2.5 \\
(1.5-4.0)\end{array}$ & NS & $\begin{array}{c}1.5 \\
(1.1-2.1)\end{array}$ & NS & $\begin{array}{c}1.7 \\
(1.1-2.5)\end{array}$ & NS & $\begin{array}{c}1.8 \\
(1.2-2.7)\end{array}$ & NS \\
\hline
\end{tabular}

Odds ratios (ORs) are shown with their respective 95\% confidence interval. IgG antibodies, aCL, or a $32 G P I \lg G$ antibodies; IgM antibodies, aCL, or aß2GPI IgM antibodies; NS, nonsignificant

Multivariate analysis, adjusted for age, sex, and pregnancy morbidity.

TABLE 3. Correlation of lupus anticoagulant, lgG and IgM aCL or a $32 \mathrm{GPI}$ antibodies with pregnancy morbidity.

\begin{tabular}{|c|c|c|c|c|c|c|c|c|}
\hline & \multicolumn{2}{|c|}{ BioPlex ${ }^{\circledR} 2200$} & \multicolumn{2}{|c|}{ Phadia ${ }^{\circledR}$} & \multicolumn{2}{|c|}{ AcuStar $^{\circledast}$} & \multicolumn{2}{|c|}{$\begin{array}{c}\text { QUANTA } \\
\text { Lite }^{\circledR} \text { ELISA }\end{array}$} \\
\hline & $\begin{array}{l}\text { ơ } \\
\frac{0}{0} \\
\text { ํํㄴ }\end{array}$ & 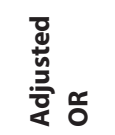 & 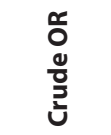 & 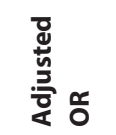 & $\begin{array}{l}\text { Oั } \\
\text { ou } \\
\text { ํํㄴ }\end{array}$ & 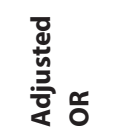 & 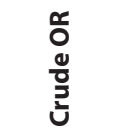 & 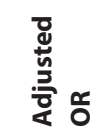 \\
\hline Lupus & 4.2 & 3.6 & 4.2 & 3.7 & 4.2 & 3.9 & 4.2 & 3.6 \\
\hline anticoagulant & $(2.8-6.4)$ & $(2.3-5.7)$ & $(2.8-6.4)$ & $(2.4-5.7)$ & $(2.8-6.4)$ & $(2.5-6.1)$ & $(2.8-6.4)$ & $(2.4-5.6)$ \\
\hline $\lg G$ & 3.2 & 1.9 & 4.1 & 2.2 & 2.8 & 1.5 & 5.5 & 2.5 \\
\hline antibodies & $(2.0-5.0)$ & $(1.1-3.2)$ & $(2.5-6.8)$ & $(1.3-3.6)$ & $(1.8-4.4)$ & $(0.9-2.5)$ & $(3.1-9.9)$ & $(1.5-4.4)$ \\
\hline $\lg M$ & 2.9 & 2.0 & 2.2 & 1.7 & 2.1 & 2.0 & 2.8 & 2.0 \\
\hline antibodies & $(1.6-5.4)$ & $(1.1-3.5)$ & $(1.4-3.5)$ & $(1.1-2.8)$ & $(1.3-3.5)$ & $(1.2-3.4)$ & $(1.7-4.6)$ & $(1.2-3.3)$ \\
\hline
\end{tabular}

Odds ratios (ORs) are shown with their respective 95\% confidence interval. IgG antibodies, aCL, or a $32 G P I \lg G$ antibodies; IgM antibodies, aCL, or aß2GPI IgM antibodies; NS, nonsignificant

Multivariate analysis, adjusted for age and thrombosis. 
A

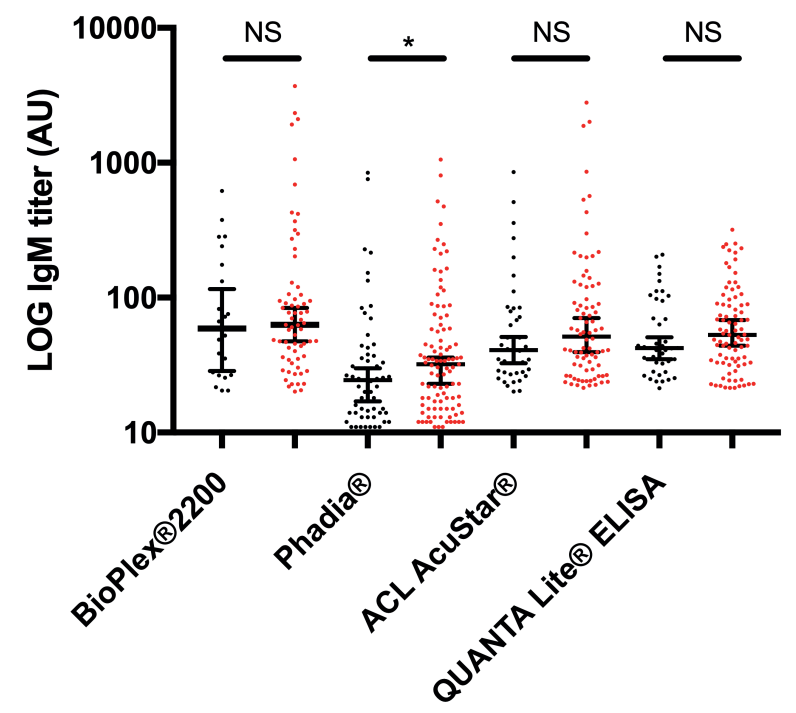

B

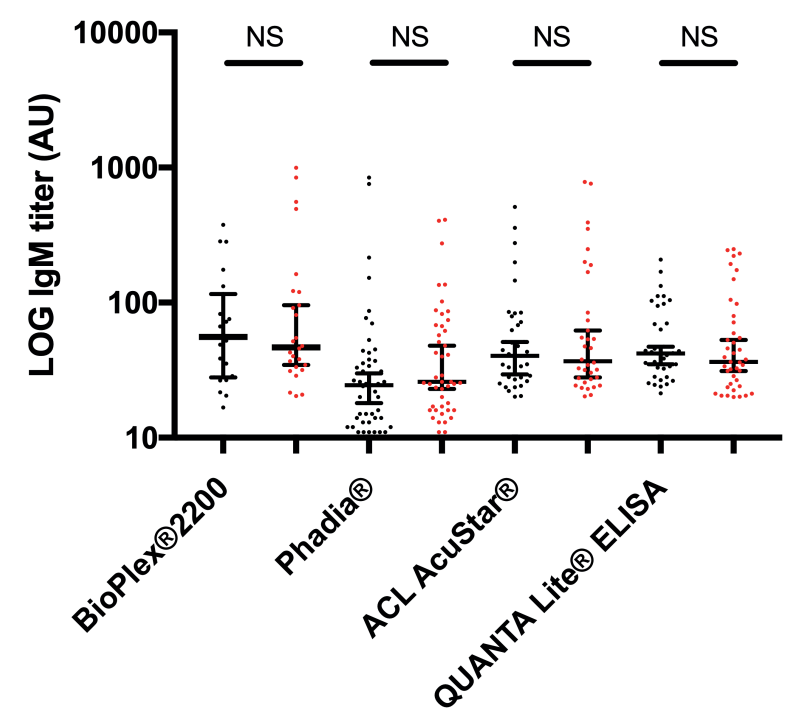

FIGURE 1. Titers of patients with thrombosis or pregnancy morbidity positive for IgM antibodies versus controls (autoimmune disease and controls) positive for IgM antibodies. Log transformed IgM titers of patients with (A) thrombosis or (B) pregnancy morbidity are indicated in red and patients without the clinical criteria for APS are indicated in black. Titers are expressed as the median value of positive IgM titers with their $95 \%$ confidence interval. ${ }^{*} P$-value $<.05$. NS, not significant; AU, arbitrary units 
TABLE 4. Additional diagnostic value of $\mathrm{aCL}$ and $\mathrm{a} \beta 2 \mathrm{GPI} \operatorname{lgM}$ antibodies

\begin{tabular}{|c|c|c|c|c|c|c|c|c|c|c|c|c|c|c|c|}
\hline \multirow[t]{3}{*}{ A } & & \multicolumn{2}{|c|}{$\begin{array}{c}\text { Overall } \\
\text { population } \\
(\mathrm{n}=1008)\end{array}$} & \multicolumn{2}{|c|}{$\begin{array}{l}\text { Non-APS } \\
\text { thrombosis } \\
(n=204)\end{array}$} & \multicolumn{2}{|c|}{$\begin{array}{c}\text { APS- } \\
\text { thrombosis } \\
(n=259)\end{array}$} & \multicolumn{2}{|c|}{$\begin{array}{c}\text { Non-APS } \\
\text { obstetric } \\
(n=33)\end{array}$} & \multicolumn{2}{|c|}{$\begin{array}{c}\text { APS- } \\
\text { obstetric } \\
(n=122)\end{array}$} & \multicolumn{2}{|c|}{$\begin{array}{c}\text { AID } \\
(n=196)\end{array}$} & \multicolumn{2}{|c|}{$\begin{array}{l}\text { Controls } \\
(n=194)\end{array}$} \\
\hline & & \multicolumn{2}{|c|}{ LAC/IgG } & \multicolumn{2}{|c|}{$\mathrm{LAC} / \mathrm{IgG}$} & \multicolumn{2}{|c|}{ LAC/IgG } & \multicolumn{2}{|c|}{ LAC/IgG } & \multicolumn{2}{|c|}{ LAC/IgG } & \multicolumn{2}{|c|}{ LAC/IgG } & \multicolumn{2}{|c|}{$\mathrm{LAC} / \mathrm{IgG}$} \\
\hline & & + & - & + & - & + & - & + & - & + & - & + & - & + & - \\
\hline $\operatorname{IgM}$ & + & 95 & 23 & 0 & 0 & 58 & 9 & 0 & 0 & 19 & 7 & 12 & 6 & 6 & 1 \\
\hline & - & 304 & 586 & 3 & 201 & 157 & 35 & 0 & 33 & 72 & 24 & 56 & 122 & 16 & 171 \\
\hline Total & & 399 & 609 & 3 & 201 & 215 & 44 & 0 & 33 & 91 & 31 & 68 & 128 & 22 & 172 \\
\hline
\end{tabular}

\begin{tabular}{|c|c|c|c|c|c|c|c|c|c|c|c|c|c|c|c|}
\hline \multirow[t]{3}{*}{ B } & & \multicolumn{2}{|c|}{$\begin{array}{c}\text { Overall } \\
\text { population } \\
(\mathrm{n}=1008)\end{array}$} & \multicolumn{2}{|c|}{$\begin{array}{c}\text { Non-APS } \\
\text { thrombosis } \\
(n=204)\end{array}$} & \multirow{2}{*}{\multicolumn{2}{|c|}{$\begin{array}{c}\text { APS- } \\
\text { thrombosis } \\
(n=259)\end{array}$}} & \multicolumn{2}{|c|}{$\begin{array}{c}\text { Non-APS } \\
\text { obstetric } \\
(n=33)\end{array}$} & \multicolumn{2}{|c|}{$\begin{array}{c}\text { APS- } \\
\text { obstetric } \\
(n=122)\end{array}$} & \multicolumn{2}{|c|}{$\begin{array}{c}\text { AID } \\
(n=196)\end{array}$} & \multicolumn{2}{|c|}{$\begin{array}{l}\text { Controls } \\
(n=194)\end{array}$} \\
\hline & & \multicolumn{2}{|c|}{$\mathrm{LAC} / \operatorname{IgG}$} & \multicolumn{2}{|c|}{$\mathrm{LAC} / \operatorname{lgG}$} & & & \multicolumn{2}{|c|}{$\mathrm{LAC} / \lg \mathrm{g}$} & \multicolumn{2}{|c|}{ LAC/IgG } & \multicolumn{2}{|c|}{ LAC/IgG } & \multicolumn{2}{|c|}{ LAC/IgG } \\
\hline & & + & - & + & - & + & - & + & - & + & - & + & - & + & - \\
\hline IgM & + & 135 & 72 & 2 & 5 & 80 & 14 & 1 & 2 & 30 & 12 & 15 & 25 & 7 & 14 \\
\hline & - & 273 & 528 & 10 & 187 & 136 & 29 & 1 & 29 & 62 & 18 & 51 & 105 & 13 & 160 \\
\hline Total & & 408 & 600 & 12 & 192 & 216 & 43 & 2 & 31 & 92 & 30 & 66 & 130 & 20 & 174 \\
\hline
\end{tabular}

\begin{tabular}{|c|c|c|c|c|c|c|c|c|c|c|c|c|c|c|c|}
\hline \multirow[t]{3}{*}{ C } & & \multirow{2}{*}{\multicolumn{2}{|c|}{$\begin{array}{c}\begin{array}{c}\text { Overall } \\
\text { population } \\
(\mathrm{n}=1008)\end{array} \\
\text { LAC/IgG }\end{array}$}} & \multirow{2}{*}{\multicolumn{2}{|c|}{$\begin{array}{c}\text { Non-APS } \\
\text { thrombosis } \\
(\mathrm{n}=204) \\
\text { LAC/IgG }\end{array}$}} & \multirow{2}{*}{\multicolumn{2}{|c|}{$\begin{array}{c}\text { APS- } \\
\text { thrombosis } \\
(n=259) \\
\text { LAC/IgG }\end{array}$}} & \multirow{2}{*}{\multicolumn{2}{|c|}{$\begin{array}{c}\begin{array}{c}\text { Non-APS } \\
\text { obstetric } \\
(n=33)\end{array} \\
\text { LAC/IgG }\end{array}$}} & \multirow{2}{*}{\multicolumn{2}{|c|}{$\begin{array}{c}\text { APS- } \\
\text { obstetric } \\
(n=122)\end{array}$}} & \multirow{2}{*}{\multicolumn{2}{|c|}{$\begin{array}{c}\text { AID } \\
(n=196)\end{array}$}} & \multirow{2}{*}{\multicolumn{2}{|c|}{$\begin{array}{l}\text { Controls } \\
(n=194)\end{array}$}} \\
\hline & & & & & & & & & & & & & & & \\
\hline & & + & - & + & - & + & - & + & - & + & - & + & - & + & - \\
\hline $\operatorname{lgM}$ & + & 123 & 37 & $\overline{0}$ & 1 & 71 & 10 & 0 & 1 & 24 & 9 & 21 & 10 & 7 & 6 \\
\hline & - & 294 & 554 & 7 & 196 & 153 & 25 & 0 & 32 & 70 & 19 & 50 & 115 & 14 & 167 \\
\hline Total & & 417 & 591 & 7 & 197 & 224 & 35 & 0 & 33 & 94 & 28 & 71 & 125 & 21 & 173 \\
\hline
\end{tabular}

\begin{tabular}{|c|c|c|c|c|c|c|c|c|c|c|c|c|c|c|c|}
\hline \multirow[t]{3}{*}{ D } & & \multicolumn{2}{|c|}{$\begin{array}{c}\text { Overall } \\
\text { population } \\
(\mathrm{n}=1008)\end{array}$} & \multicolumn{2}{|c|}{$\begin{array}{l}\text { Non-APS } \\
\text { thrombosis } \\
(n=204)\end{array}$} & \multicolumn{2}{|c|}{$\begin{array}{c}\text { APS- } \\
\text { thrombosis } \\
(n=259)\end{array}$} & \multicolumn{2}{|c|}{$\begin{array}{c}\text { Non-APS } \\
\text { obstetric } \\
(n=33)\end{array}$} & \multicolumn{2}{|c|}{$\begin{array}{c}\text { APS- } \\
\text { obstetric } \\
(n=122)\end{array}$} & \multicolumn{2}{|c|}{$\begin{array}{c}\text { AID } \\
(n=196)\end{array}$} & \multicolumn{2}{|c|}{$\begin{array}{l}\text { Controls } \\
(n=194)\end{array}$} \\
\hline & & \multicolumn{2}{|c|}{$\mathrm{LAC} / \mathrm{IgG}$} & \multicolumn{2}{|c|}{ LAC/IgG } & \multicolumn{2}{|c|}{ LAC/IgG } & \multicolumn{2}{|c|}{ LAC/IgG } & \multicolumn{2}{|c|}{ LAC/IgG } & \multicolumn{2}{|c|}{ LAC/IgG } & \multicolumn{2}{|c|}{ LAC/IgG } \\
\hline & & + & - & + & - & + & - & + & - & + & - & + & - & + & - \\
\hline IgM & + & 113 & 56 & 0 & 1 & 70 & 14 & 0 & 2 & 24 & 15 & 15 & 19 & 4 & 5 \\
\hline & - & 276 & 563 & 5 & 198 & 143 & 32 & 1 & 30 & 66 & 17 & 47 & 115 & 14 & 171 \\
\hline Total & & 389 & 619 & 5 & 199 & 213 & 46 & 1 & 32 & 90 & 32 & 62 & 134 & 18 & 176 \\
\hline
\end{tabular}

Note: figures indicate the number of patients testing positive or negative for IgM antibodies or $L A C / \lg$. A BioPlex ${ }^{\circledast 2} 200$ B, Phadia ${ }^{\circledast}$ C, ACL AcuStar ${ }^{\circledast}$ and D, QUANTA Lite ${ }^{\circledast}$ ELISA. AID, autoimmune disease; APS antiphospholipid syndrome; IgG antibodies, aCL, or aß2GPI IgG antibodies; IgM antibodies, aCL, or aß2GPI IgM antibodies; LAC, lupus anticoagulant.

\section{Additional diagnostic value of $\mathrm{aCL}$ and a $\beta 2 \mathrm{GPI}$ I IgM antibodies in patients with pregnancy morbidity}

Positivity for $\operatorname{lgM}$ aCL or a $32 \mathrm{GPI}$ antibodies ranged from $21 \%$ to $34 \%$ among obstetric APS patients, $0 \%$ to $9.1 \%$ among non-APS obstetric patients (Table 2), and $6.4 \%$ to $16 \%$ among female patients with an autoimmune disease and controls. Isolated IgM aCL or aß2GPI positivity ranged from $5.7 \%$ to $12.3 \%$ in APS-obstetric patients (Table 2 ). Up to $6 \%$ of the patients classified as non-APS obstetric were found to be isolated positive for $\operatorname{lgM~aCL}$ or a $32 \mathrm{GPI}$ and up to $10 \%$ of female patients with an autoimmune disease and controls were only positive for $\operatorname{lgM} \mathrm{aCL}$ or a $32 \mathrm{GPI}$ antibodies but not $\mathrm{LAC}$ or $\mathrm{lgG} \mathrm{aCL}$ or aß2GPI antibodies. 


\section{IgM antibody titers in thrombotic patients and controls}

Positive IgM aCL or a $32 \mathrm{GPI}$ antibody titers were compared between patients with thrombosis and controls (AID and control) within one solid phase assay. No significant difference in $\operatorname{lgM} \mathrm{aCL}$ or $\mathrm{a} \beta 2 \mathrm{GPI}$ antibody titers was found between patients with thrombosis and our control population with the exception of one solid phase assay (Phadia $^{\circledR}$ ) (Figure 1A).

\section{IgM antibody titers in obstetric patients and controls}

$\operatorname{lgM} \mathrm{aCL}$ or a $32 \mathrm{GPI}$ antibody titers were not significantly different between patients with pregnancy morbidity and the control population with all solid phase assays tested (Figure 1B). Of note, maximum IgM aCL or a $32 \mathrm{GPI}$ antibody titers measured were higher in thrombotic patients versus obstetric patients: 3708 versus 995 (BioPlex ${ }^{\circledR 2200), ~} 1056$ versus 410 (Phadia ${ }^{\circledR}$ ), 2798 versus 785 (ACL AcuStar ${ }^{\circledR}$ ) and 320 versus 250 (QUANTA Lite ${ }^{\circledR}$ ELISA) of the respective units.

\section{Additional clinical value of aCL and a $\beta 2 \mathrm{GPI}$ I IgM antibodies in thrombotic patients}

Within the current criteria positivity for either LAC, IgG aCL/aß2GPI or IgM aCL/a $32 \mathrm{GPI}$ is sufficient for classification of APS. In our cohort, these classification criteria resulted in OR between $2.4(95 \% \mathrm{Cl}, 1.8-3.2)$ and $2.9(95 \% \mathrm{Cl}, 2.2-3.9)$ (Table 5). Combined positivity for LAC and IgG aCL or a $32 \mathrm{GPI}$ antibodies resulted in higher OR than combined positivity for LAC and IgM aCL or aß2GPI antibodies with two out of the four tested solid phase assays. With the other solid phase assays, combined positivity for $L A C$ and $\operatorname{IgM} \mathrm{aCL}$ or a 32 GPI reached higher OR than positivity for $L A C$ and IgG aCL or a 2 GPI. The variation in OR for thrombosis among solid phase assays increased in combined positivity for IgG aCL or a $32 \mathrm{GPI}$ and IgM aCL or a 2 GPI antibodies from $2.6(95 \% \mathrm{Cl}, 1.6-4.5)$ up to 7.1 (95\% Cl, 3.0-16.7) (Table 5). The combination of positive LAC, IgG aCL or a $32 \mathrm{GPI}$ and IgM $\mathrm{aCL}$ or aß2GPI results is highly associated with thrombosis with OR between $5.5(95 \% \mathrm{Cl}$, 2.6-11.8) and 9.6 (95\% Cl, 3.4-27.1) (Table 5). 
TABLE 5. Additional value of $\mathrm{aCL}$ and $\mathrm{a} \beta 2 \mathrm{GPI}$ IgM antibodies in thrombosis

\begin{tabular}{|c|c|c|c|c|}
\hline & BioPlex ${ }^{\circledast} 2200$ & Phadia ${ }^{\circledR}$ & AcuStar ${ }^{\circledast}$ & $\begin{array}{c}\text { QUANTA } \\
\text { Lite }^{\circledR} \text { ELISA }\end{array}$ \\
\hline \multirow[t]{3}{*}{ LAC and/or lgG and/or IgM } & 2.9 & 2.4 & 2.9 & 2.8 \\
\hline & $(2.2-3.9)$ & $(1.8-3.2)$ & $(2.1-3.8)$ & $(2.1-3.7)$ \\
\hline & $n=324$ & $n=372$ & $n=350$ & $n=337$ \\
\hline \multirow[t]{3}{*}{ LAC and IgG } & 3.8 & 4.7 & 3.3 & 5.9 \\
\hline & $(2.5-5.9)$ & $(2.8-7.6)$ & $(2.2-4.9)$ & $(3.4-10.5)$ \\
\hline & $n=138$ & $n=118$ & $n=148$ & $\mathrm{n}=104$ \\
\hline \multirow[t]{3}{*}{ LAC and IgM } & 4.5 & 3.5 & 3.5 & 3.6 \\
\hline & $(2.3-8.7)$ & $(2.1-5.8)$ & $(2.0-6.3)$ & $(2.1-6.3)$ \\
\hline & $n=64$ & $n=93$ & $\mathrm{n}=77$ & $n=83$ \\
\hline \multirow[t]{3}{*}{$\lg G$ and $\lg M$} & 3.3 & 5.8 & 2.6 & 7.1 \\
\hline & $(1.7-6.2)$ & $(2.8-11.9)$ & $(1.6-4.5)$ & $(3.0-16.7)$ \\
\hline & $\mathrm{n}=60$ & $\mathrm{n}=65$ & $\mathrm{n}=78$ & $\mathrm{n}=52$ \\
\hline \multirow[t]{3}{*}{ LAC and IgG and IgM } & 6.4 & 6.2 & 5.5 & 9.6 \\
\hline & $(2.7-15.2)$ & $(2.8-13.8)$ & $(2.6-11.8)$ & $(3.4-27.1)$ \\
\hline & $\mathrm{n}=48$ & $n=54$ & $n=56$ & $n=46$ \\
\hline
\end{tabular}

Note: Odds ratios (ORs) were calculated in a subpopulation of 853 patients consisting of thrombotic APS ( $n=259)$, non-APS thrombosis $(n=204)$, AID controls $(n=196)$ and controls $(n=194)$. ORs are shown with their respective $95 \%$ confidence interval. IgG antibodies, aCL, and/or aß2GPI IgG antibodies; IgM antibodies, aCL and/or aß2GPI IgM antibodies; LAC, lupus anticoagulant

TABLE 6. Additional value of $\mathrm{aCL}$ and $\mathrm{a} \beta 2 \mathrm{GPI}$ IgM antibodies in pregnancy morbidity

\begin{tabular}{|c|c|c|c|c|}
\hline & BioPlex ${ }^{\circledast} 2200$ & Phadia ${ }^{\circledR}$ & AcuStar ${ }^{\circledast}$ & $\begin{array}{c}\text { QUANTA } \\
\text { Lite }^{\circledR} \text { ELISA }\end{array}$ \\
\hline $\begin{array}{l}\text { LAC and/or lgG } \\
\text { and/or IgM }\end{array}$ & $\begin{array}{c}5.1(3.4-7.7) \\
n=181\end{array}$ & $\begin{array}{c}4.9(3.2-7.4) \\
n=213\end{array}$ & $\begin{array}{c}5.3(3.5-8.0) \\
n=195\end{array}$ & $\begin{array}{c}6.6(4.3-10.0) \\
n=193\end{array}$ \\
\hline LAC and IgG & $\begin{array}{c}3.3(1.9-5.6) \\
n=62\end{array}$ & $\begin{array}{c}3.7(2.0-6.8) \\
n=50\end{array}$ & $\begin{array}{c}2.5(1.5-4.2) \\
n=67\end{array}$ & $\begin{array}{c}4.3(2.2-8.6) \\
n=39\end{array}$ \\
\hline LAC and IgM & $\begin{array}{c}3.5(1.5-8.3) \\
n=23\end{array}$ & $\begin{array}{c}3.4(1.7-6.4) \\
n=41\end{array}$ & $\begin{array}{c}2.7(1.3-5.6) \\
n=33\end{array}$ & $\begin{array}{c}2.7(1.4-5.5) \\
n=35\end{array}$ \\
\hline $\lg G$ and $\lg M$ & $\begin{array}{c}3.8(1.7-8.2) \\
n=29\end{array}$ & $\begin{array}{c}6.5(2.9-14.3) \\
n=33\end{array}$ & $\begin{array}{c}2.7(1.4-5.2) \\
n=39\end{array}$ & $\begin{array}{c}8.0(3.1-20.2) \\
n=26\end{array}$ \\
\hline $\begin{array}{l}\text { LAC and } \lg G \text { and } \\
\lg M\end{array}$ & $\begin{array}{c}5.9(2.1-16.9) \\
n=18\end{array}$ & $\begin{array}{c}5.6\left(\begin{array}{c}(2.3-13.9) \\
\mathrm{n}=24\end{array}\right.\end{array}$ & $\begin{array}{c}4.9(2.0-12.3) \\
n=22\end{array}$ & $\begin{array}{c}8.7(2.8-26.6) \\
n=19\end{array}$ \\
\hline
\end{tabular}

Note: Odds ratios (ORs) were calculated in a subpopulation of 483 patients consisting of, obstetric APS ( $n=122)$, non-APS obstetric $(n=33)$, female AID controls $(n=158)$ and female controls $(n=170)$. ORs are shown with their respective $95 \%$ confidence interval. IgG antibodies, aCL, and/or aß2GPI lgG antibodies; IgM antibodies, aCL and/or aß2GPI IgM antibodies; LAC, lupus anticoagulant 


\section{Additional clinical value of aCL and a $32 \mathrm{GPI}$ IgM antibodies in patients with pregnancy morbidity}

Positivity for either LAC, IgG and/or IgM antibodies resulted in OR between 4.9 (95\% $\mathrm{Cl}, 3.2-7.4)$ and $6.6(95 \% \mathrm{Cl}, 4.3-10.0)$ (Table 6). In contrast to thrombosis, combined positivity for $L A C$ and IgG aCL or $\mathrm{a} \beta 2 \mathrm{GPI}$ or $\mathrm{LAC}$ and $\operatorname{IgM} \mathrm{aCL}$ or a $32 \mathrm{GPI}$ antibodies did not increase the association with pregnancy morbidity compared to the classification criteria (Table 6). Positivity for LAC and IgG aCL or aß2GPI antibodies resulted in OR between 2.5 (95\% Cl, 1.5-4.2) and $4.3(95 \% \mathrm{Cl}, 2.2-8.6)$ (Table 6). Positivity for LAC and $\operatorname{lgM} \mathrm{aCL}$ or aß2GPI antibodies resulted in OR between $2.7(95 \% \mathrm{Cl}, 1.3-5.6)$ and 3.5 (95\% Cl, 1.5-8.3) (Table 6). The association between pregnancy morbidity and LAC, IgG and/or IgM aCL or aß2GPI positivity were similar (Table 6). However, positivity for IgG aCL or a $32 \mathrm{GPI}$ and IgM aCL or a $32 \mathrm{GPI}$ antibodies resulted in a large variation of OR for pregnancy morbidity among solid phase assays. Combined positivity for IgG aCL or a $32 \mathrm{GPI}$ and IgM aCL or a $\beta 2 \mathrm{GPI}$ antibodies resulted in OR between $2.7(95 \% \mathrm{Cl}$. 1.45.2) and 8.0 (95\% Cl, 3.1-20.2). IgM aCL or aß2GPI positivity in combination with LAC and IgG aCL or a $32 \mathrm{GPI}$ positivity is highly associated with pregnancy morbidity with OR between $4.9(95 \% \mathrm{Cl}, 2.0-12.3)$ and 8.7 (95\% Cl, 2.8-26.6).

\section{DISCUSSION}

The role of IgM aCL or a $32 \mathrm{GPI}$ antibodies as a serologic marker in APS is debated $[1,4,7,8,22]$. Although most studies were unable to demonstrate an association between IgM aCL or aß2GPI antibodies and thrombosis, a questionnaire by the SSC of the ISTH indicated that most of the respondents found it too early to eliminate $\operatorname{lgM~aCL}$ or aß2GPI antibodies from the criteria [8]. We demonstrated a significant correlation for both IgG and IgM aCL and a $32 \mathrm{GPI}$ antibodies with thrombosis as well as pregnancy morbidity. However, IgM positivity was mostly associated with positivity for LAC and/ or IgG aPL. The presence of isolated IgM antibodies in thrombotic APS patients was rare (3.5\%-5.4\%, Table 4), and not an independent variable for thrombosis. In addition, $\operatorname{lgM} \mathrm{aCL}$ or $\mathrm{a} \beta 2 \mathrm{GPI}$ was not found to be an independent variable for arterial nor venous thrombosis. These results are in line with prospectively collected data from patients referred to Italian thrombosis centers in which only a minority of APS patients was found to be positive for predominantly aCL or a 2 GPI IgM antibodies (>40 MPL units and < 40 GPL units) [16]. A thrombotic association of true isolated IgM has not been reported in literature. One study concluded that "isolated" IgG antibodies are more prevalent in deep venous thrombosis and pulmonary embolism while "isolated" aCL IgM antibodies were frequently found in patients with a cerebrovascular infarction [23]. However, patients were only tested for $\mathrm{aCL}$ and $\mathrm{a} \beta 2 \mathrm{GPI} \operatorname{lgG} / \mathrm{lgM}$ antibodies and not for 
$L A C$, rendering the identification of true isolated IgG or IgM antibodies impossible [23]. While we showed that IgM was not an independent variable of thrombosis along with LAC and IgG, another study even found that in SLE patients a 32 GPI IgM antibodies were protective against lupus nephritis and renal damage [24].

Within the current aPL-panel, LAC is considered the strongest predictor of thrombosis and pregnancy morbidity $[25,26]$. In 2003, a meta-analysis assessed the role of LAC and $\mathrm{aCL}$ antibodies in thrombosis. Computed ORs for both $\mathrm{LAC}$ and $\mathrm{aCL}$ positivity were only available in five studies of which none was able to illustrate a significant association between thrombosis and $\operatorname{lgG}$ or $\operatorname{lgM} \mathrm{aCL}$ antibodies [26]. We found an association between LAC as well as aCL antibodies and thrombosis, independent of the isotype and solid phase assay used. As argued by de Groot et al most of the studies included in the meta-analysis did not follow the ISTH-SSC guidelines, in which it is stated that $\mathrm{aCL}$ antibodies should bind to cardiolipin in a b2GPI-dependent manner [1,3,27-29]. A more recent meta-analysis included studies between 2001 and 2014 and showed that $\mathrm{aCL}$ antibodies are associated with thrombosis, especially aCL IgG antibodies [4]. In our cohort, LAC was an independent variable for thrombosis, illustrating its importance in thrombotic APS. In addition, LAC showed the highest association with pregnancy morbidity within the current aPL panel.

Thrombotic and obstetric APS are hypothesized to have a distinct aPL profile with more frequent IgM positivity in obstetrical APS [30]. Our results suggest comparable IgM positivity in obstetrical APS to thrombotic APS, 21\%-34\% and 26\%-36\%, respectively (dependent on the solid phase assay). However, LAC, aCL, and aß2GPI lgG/lgM antibodies were found to be independently associated with pregnancy morbidity. In contrast, IgM was not independently associated with thrombosis. In agreement, a systematic review and meta-analysis found a significant association of $L A C, a C L$ lgG/ $\lg \mathrm{M}$, and aß2GPI lgG/lgM antibodies with pre-eclampsia and fetal death [31]. Another study found that positivity for $\mathrm{LAC}, \mathrm{aCL} \lg \mathrm{G}$, and $\mathrm{aCL} \lg M$ were associated with recurrent fetal loss in women without autoimmune disease [6]. In the same study, no significant association was found between a $32 \mathrm{GPI}$ positivity and recurrent loss, presumably due to the small study population [6]. In a population-based, case-control study, aPL were measured in 582 stillbirth deliveries and 1547 live birth deliveries [32]. Women with a stillbirth were found to be more likely to have elevated $\mathrm{aCL}$ and $\mathrm{a} \beta 2 \mathrm{GPI}$ lgG levels, but not $\mathrm{aCL}$ and aß2GPI IgM levels compared to those with term live births [32]. We found a significant association between $\mathrm{aCL} \lg \mathrm{M}$ or aß2GPI IgM antibodies and pregnancy morbidity, but were not able to differentiate in subgroups due to unavailability of detailed description of obstetric complications. The PROMISSE (Predictors of pRegnancy Outcome: bioMarkers In antiphospholipid antibody Syndrome and 
Systemic lupus Erythematosus) study has shown that LAC is the primary predictor of obstetric complications after 12 weeks of gestation in aPL associated pregnancies [25]. Positivity for $\mathrm{aCL}$ and $\mathrm{a} \beta 2 \mathrm{GPI}$ antibodies did not predict adverse pregnancy outcomes if LAC was absent [25]. In contrast, we found that positivity for aCL and aß2GPI IgG and $\lg \mathrm{M}$ were independently associated with a history of pregnancy morbidity. However, LAC showed the highest association with pregnancy morbidity within the current aPLpanel. In addition, the presence of isolated IgM antibodies in obstetric APS patients was rare (5.7\%-12.3\%, Table 4), dependent on the solid phase assay.

Some studies found a strong correlation of high aPL titers with clinical manifestations of APS [9,33-35]. However, previous reports on the association between aPL titers and pregnancy morbidity are conflicting $[32,36,37]$. In a retrospective study a higher cut-off value did not result in a stronger association with stillbirth [32]. Another study assessed whether there is a relationship between low aPL levels and obstetrical complications [36]. The authors found that patients with low aPL titers have similar obstetrical outcomes compared to confirmed APS patients [36]. In contrast, the risk of adverse fetal/neonatal outcome was found to be higher in APS-obstetrical patients with high aPL titers ( $\geq 4$ times upper limit of normal) compared to APS-obstetrical patients with aPL titers $<4$ times the upper limit of normal [37]. Our results showed that IgM titers were not significantly different between obstetrical patients and our control population. Of note, the maximum lgM titer measured in obstetric patients was lower than the maximum titers measured in thrombotic patients. In addition, patients with a history of thrombosis did not have significant differently lgM titers than patients without thrombosis. Future studies are needed to investigate the relationship between aPL titers and clinical manifestation of APS in more detail. Categorizing aPL titers into low, medium and high positivity might help to study the correlation between aPL titers and thrombosis or pregnancy morbidity.

In APS, multiple aPL positivity (aPL profiles) have shown to be of added value in thrombotic risk stratification $[15,17,38]$. In agreement we found that OR for thrombosis were highest in patients positive for LAC, IgG, and IgM. One study assessed the role of a 2 GPI and $\mathrm{aCL}$ antibodies in $87 \mathrm{LAC}$ positive patients and found that the presence of IgG but not IgM antibodies in LAC-positives predicts an increased risk of thrombosis [39]. We found that combined positivity for LAC and IgG as well as combined positivity for LAC and IgM were significantly associated with thrombosis. However, in two out of four solid phase assays OR of combined LAC and IgG aCL or aß2GPI was higher than positivity for LAC and IgM aCL or aß2GPI. Within pregnancy morbidity, combined positivity for LAC and IgG or positivity for LAC and IgM did not increase the OR compared 
to the current criteria aPL-panel. Combined positivity for LAC, IgG, and IgM was more associated with pregnancy morbidity than the current aPL-panel with three out of the four tested solid phase assays.

Diagnosis of APS is dependent on laboratory tests detecting aPL antibodies [10,14,40]. Currently no gold standard exists for the detection of aPL antibodies. Solid phase assays are poorly standardized and many studies have shown that different results are obtained by measuring the same sample $[10,14]$. In addition, studies have shown that solid phase assays are associated with a large inter-laboratory variation $[10,41]$. In order to be independent of the solid phase assay used and minimize the interlaboratory and interindividual variation in aPL detection, a single operator performed all assays within one laboratory. Although we demonstrated a largely similar clinical performance for all platforms, these data indicate that results for single parameters may vary between platforms. One of the four tested solid phase assay was unable to demonstrate a significant association between IgG aCL or a $32 \mathrm{GPI}$ antibodies and pregnancy morbidity within a multivariate model, while IgG aCL or a $22 \mathrm{GPI}$ was an independent variable within the other tested solid phase assays. In addition, combinations of IgG and IgM showed higher variation of OR among the solid phase assays. Combined positivity for LAC, IgG, and IgM aCL or aß2GPI antibodies was highly associated with thrombosis and pregnancy morbidity. However, calculated OR varied strongly among solid phase assays, accompanied with wide $95 \%$ confidence intervals.

In conclusion, in a large multicenter study $\mathrm{aCL}$ and $\mathrm{a} \beta 2 \mathrm{GPI} \lg \mathrm{M}$ antibodies were significantly correlated with clinical features of APS. However, IgM is only independently associated with pregnancy morbidity and not with thrombosis. Altogether, our data support the usage of two separate decision trees for thrombosis versus pregnancy morbidity, in which aCL and a $32 \mathrm{GPI}$ IgM is tested in women suspected of obstetric APS but not in patients suspected of thrombotic APS (Figure 2A-B). However, IgM aPL might be useful as a second line test to improve thrombotic risk stratification in LAC- and/or lgG-positive patients (Figure 2A). 


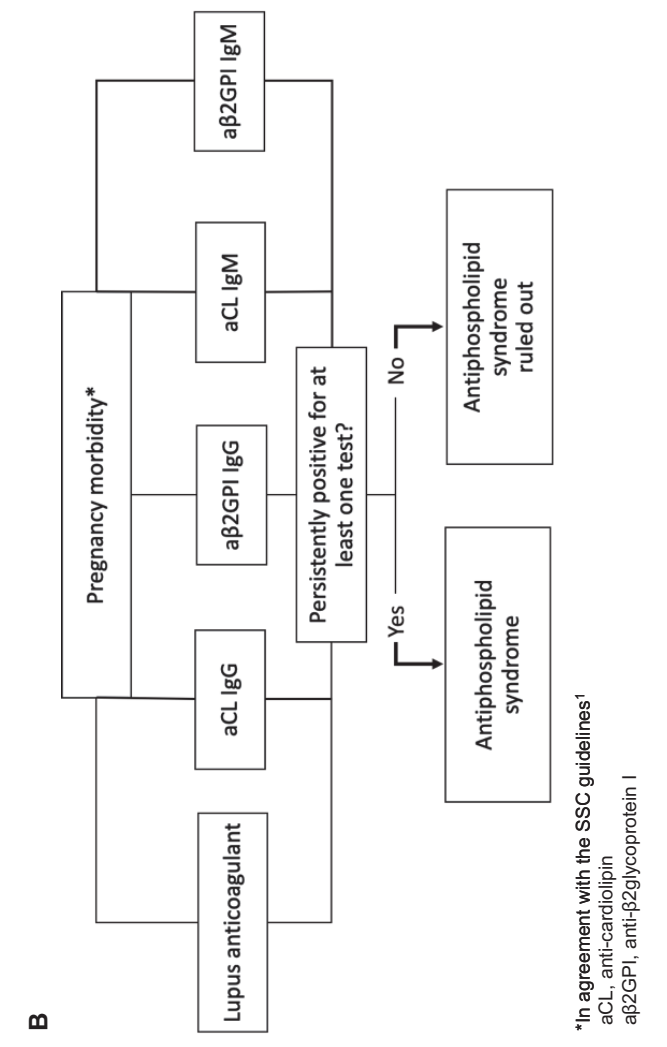

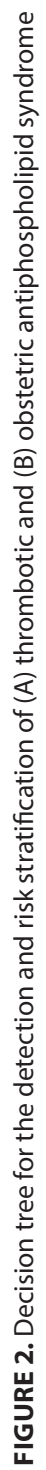




\section{ACKNOWLEDGEMENTS}

The authors thank Michael Luypaert for his technical assistance; Bio-Rad Laboratories, ThermoFisher/Phadia, Instrumentation Laboratory and Inova Diagnostics for providing the test kits for the detection of $\mathrm{a} \beta 2 \mathrm{GPI}$ and $\mathrm{aCL} \lg \mathrm{G}$ and $\operatorname{lgM}$ antibodies and Stéphane Zuily (Centre Hospitalier Regional Universitaire de Nancy, Nancy, France), Armando Tripodi (Angelo Bianchi Bonomi Hemophilia and Thrombosis Center, Department of Internal Medicine, Università degli Studi di Milano, Milan, Italy), Pierre Fontana (University of Geneva, Geneva, Switzerland) and Jasper Remijn (Gelre Hospitals, Apeldoorn, The Netherlands) for providing patient samples.

\section{CONFLICTS OF INTEREST}

G. W. Moore reports personal fees from DSM Pentapharm, outside the submitted work. The other authors state that they have no conflict of interest.

\section{AUTHORSHIP CONTRIBUTIONS}

K.M.J.D., B.d.L and H.K designed the study. K.M.J.D. organized the sample collection of the different centers. K.M.J.D., G.W.M., J-C.G., J.M. and D.W. collected samples and identified sample characteristics. Samples were analyzed under supervision of K.M.J.D. W.C., K.M.J.D, B.d.L and H.K interpreted data, performed statistical analyses and wrote the manuscript. G.W.M., J-C.G., J.M., D.W and P.G.d.G. critically reviewed the manuscript. 


\section{REFERENCES}

1 Miyakis S, Lockshin MD, Atsumi T, Branch DW, Brey RL, Cervera R, Derksen RHWM, DE Groot PG, Koike T, Meroni PL, Reber G, Shoenfeld Y, Tincani A, Vlachoyiannopoulos PG, Krilis SA. International consensus statement on an update of the classification criteria for definite antiphospholipid syndrome (APS). J Thromb Haemost 2006; 4: 295-306.

2 Garcia D, Erkan D. Diagnosis and Management of the Antiphospholipid Syndrome. Longo DL, editor. N Engl J Med 2018; 378: 2010-21.

3 Devreese KMJ, Ortel TL, Pengo V, de Laat B, Subcommittee on Lupus Anticoagulant/ Antiphospholipid Antibodies. Laboratory criteria for antiphospholipid syndrome: communication from the SSC of the ISTH. J Thromb Haemost 2018; 16: 809-13.

4 Kelchtermans H, Pelkmans L, Laat B de, Devreese KM. IgG/lgM antiphospholipid antibodies present in the classification criteria for the antiphospholipid syndrome: a critical review of their association with thrombosis. J Thromb Haemost 2016; 14: 1530-48.

5 Keeling D, Mackie I, Moore GW, Greer IA, Greaves M. Guidelines on the investigation and management of antiphospholipid syndrome. Br J Haematol 2012; 157: 47-58.

6 Opatrny L, David M, Kahn SR, Shrier I, Rey E. Association between antiphospholipid antibodies and recurrent fetal loss in women without autoimmune disease: a metaanalysis. J Rheumatol 2006;33: 2214-21.

7 Galli M, Reber G, Moerloose PD, Groot PGD. Invitation to a debate on the serological criteria that define the antiphospholipid syndrome. J Thromb Haemost 2008; 6: 399-401.

8 Pengo V. A contribution to the debate on the laboratory criteria that define the antiphospholipid syndrome. J Thromb Haemost 2008; 6: 1048-9.

9 Galli M, Borrelli G, Jacobsen EM, Marfisi RM, Finazzi G, Marchioli R, Wisloff F, Marziali S, Morboeuf O, Barbui T. Clinical significance of different antiphospholipid antibodies in the WAPS (warfarin in the antiphospholipid syndrome) study. Blood 2007; 110: 1178-83.

10 Devreese KMJ. Antiphospholipid antibody testing and standardization. Int J Lab Hematol 2014; 36: 352-63.

11 Damoiseaux J, Peeters L, Hupperts R, Boreas A, Cate HT, Tervaert JWC. Prevalence of Anticardiolipin Antibodies in Patient Cohorts with Distinct Clinical Manifestations of the Antiphospholipid Syndrome. Ann NY Acad Sci 2009; 1173: 146-51.

12 Dignat-George F, Camoin-Jau L, Sabatier F, Arnoux D, Anfosso F, Bardin N, Veit V, Combes V, Gentile S, Moal V, Sanmarco M, Sampol J. Endothelial microparticles: a potential contribution to the thrombotic complications of the antiphospholipid syndrome. Thromb Haemost 2004; 91:667-73.

13 Favaloro EJ, Silvestrini R, Mohammed A. Clinical Utility of Anticardiolipin Antibody Assays: High Inter-Laboratory Variation and Limited Consensus by Participants of External Quality Assurance Programs Signals a Cautious Approach. Pathology 1999; 31: 142-7. 
14 Favaloro EJ, Wheatland L, Jovanovich S, Roberts-Thomson P, Wong RCW. Internal quality control and external quality assurance in testing for antiphospholipid antibodies: Part I-Anticardiolipin and anti- $\beta 2$-glycoprotein I antibodies. Semin Thromb Hemost 2012; 38: 390403.

15 Kearon C, Parpia S, Spencer FA, Baglin T, Stevens SM, Bauer KA, Lentz SR, Kessler CM, Douketis JD, Moll S, Kaatz S, Schulman S, Connors JM, Ginsberg JS, Spadafora L, Bhagirath V, Liaw PC, Weitz JI, Julian JA. Antiphospholipid antibodies and recurrent thrombosis after a first unprovoked venous thromboembolism. Blood 2018; 131: 2151-60.

16 Pengo V, Ruffatti A, Legnani C, Gresele P, Barcellona D, Erba N, Testa S, Marongiu F, Bison E, Denas G, Banzato A, Jose SP, Iliceto S. Clinical course of high-risk patients diagnosed with antiphospholipid syndrome. J Thromb Haemost 2010; 8: 237-42.

17 Wahl D. "Antiphospholipids": the more, the worse? Blood 2018; 131: 2092-4.

18 Gris J-C, Bouvier S, Molinari N, Galanaud J-P, Cochery-Nouvellon E, Mercier E, Fabbro-Peray $P$, Balducchi J-P, Marès $P$, Quéré I, Dauzat $M$. Comparative incidence of a first thrombotic event in purely obstetric antiphospholipid syndrome with pregnancy loss: the NOH-APS observational study. Blood 2012; 119: 2624-32.

19 Chayoua W, Kelchtermans H, Moore GW, Musiał J, Wahl D, Laat B de, Devreese KMJ. Identification of high thrombotic risk triple positive antiphospholipid syndrome patients is dependent on anti-cardiolipin and anti-ß2glycoprotein I antibody detection assays. J Thromb Haemost 2018; 16 2016-23.

20 Pengo V, Tripodi A, Reber G, Rand JH, Ortel TL, Galli M, Groot PGD. Update of the guidelines for lupus anticoagulant detection. J Thromb Haemost 2009; 7: 1737-40.

21 Devreese KMJ, Pierangeli SS, de Laat B, Tripodi A, Atsumi T, Ortel TL, Subcommittee on Lupus Anticoagulant/Phospholipid/Dependent Antibodies. Testing for antiphospholipid antibodies with solid phase assays: guidance from the SSC of the ISTH. J Thromb Haemost 2014; 12: 792-5.

22 Del Ross T, Ruffatti A, Cuffaro S, Tonello M, Calligaro A, Favaro M, Facchinetti M, Hoxha A, Punzi L. The clinical relevance of the IgM isotype of antiphospholipid antibodies in the vascular antiphospholipid syndrome. Thromb Res 2015; 136: 883-6.

23 Locht $\mathrm{H}$, Wiik A. IgG and IgM isotypes of anti-cardiolipin and anti- $\beta 2$-glycoprotein i antibodies reflect different forms of recent thrombo-embolic events. Clin Rheumatol 2006; 25: 246-50.

24 Mehrani T and Petri M. IgM Anti-ß 2 Glycoprotein I Is Protective Against Lupus Nephritis and Renal Damage in Systemic Lupus Erythematosus. The Journal of Rheumatology 2011; 38: 450-3.

25 Lockshin MD, Kim M, Laskin CA, Guerra M, Branch DW, Merrill J, Petri M, Porter F, Sammaritano L, Stephenson MD, Buyon J, Salmon JE. Lupus anticoagulant, but not anticardiolipin antibody, predicts adverse pregnancy outcome in patients with antiphospholipid antibodes. Arthritis Rheum 2012; 64: 2311-8. 
26 Galli M. Lupus anticoagulants are stronger risk factors for thrombosis than anticardiolipin antibodies in the antiphospholipid syndrome: a systematic review of the literature. Blood 2003; 101: 1827-32.

27 Groot PGD, Derksen RHWM. The importance of measuring anticardiolipin antibodies. J Thromb Haemost 2006; 4: 41-3.

28 Wilson WA, Gharavi AE, Koike T, Lockshin MD, Branch DW, Piette J-C, Brey R, Derksen R, Harris EN, Hughes GRV, Triplett DA, Khamashta MA. International consensus statement on preliminary classification criteria for definite antiphospholipid syndrome: Report of an International workshop. Arthritis Rheum 1999; 42: 1309-11.

29 Devreese KMJ, Ortel TL, Pengo V, Laat B de. Laboratory criteria for antiphospholipid syndrome: reply. J Thromb Haemost 2018; 16: 2117-9.

30 Tincani A, Andreoli L, Casu C, Cattaneo R, Meroni P. Antiphospholipid antibody profile: implications for the evaluation and management of patients. Pierangeli SS, Bertolaccini ML, Khamashta MA, editors. Lupus 2010; 19: 432-5.

31 Abou-Nassar K, Carrier M, Ramsay T, Rodger MA. The association between antiphospholipid antibodies and placenta mediated complications: A systematic review and meta-analysis. Thromb Res 2011; 128: 77-85.

32 Silver RM, Parker CB, Reddy UM, Goldenberg R, Coustan D, Dudley DJ, Saade GR, Stoll B, Koch MA, Conway D, Bukowski R, Hogue CJR, Pinar H, Moore J, Willinger M, Branch DW. Antiphospholipid Antibodies in Stillbirth. Obstet Gynecol 2013; 122: 641-57.

33 Sciascia S, Baldovino S, Schreiber K, Solfietti L, Radin M, Cuadrado MJ, Menegatti E, Erkan D, Roccatello D. Thrombotic risk assessment in antiphospholipid syndrome: the role of new antibody specificities and thrombin generation assay. Clin Mol Allergy 2016; 14.

34 Pengo V, Banzato A, Bison E, Bracco A, Denas G, Ruffatti A. What Have We Learned about Antiphospholipid Syndrome from Patients and Antiphospholipid Carrier Cohorts? Semin Thromb Hemost 2012; 38: 322-7.

35 Sciascia S, Murru V, Sanna G, Roccatello D, Khamashta MA, Bertolaccini ML. Clinical accuracy for diagnosis of antiphospholipid syndrome in systemic lupus erythematosus: evaluation of 23 possible combinations of antiphospholipid antibody specificities. J Thromb Haemost 2012; 10: 2512-8.

36 Mekinian A, Loire-Berson P, Nicaise-Roland P, Lachassinne E, Stirnemann J, Boffa M-C, CholletMartin S, Carbillon L, Fain O. Outcomes and treatment of obstetrical antiphospholipid syndrome in women with low antiphospholipid antibody levels. J Reprod Immunol 2012; 94: 222-6.

37 Simchen MJ, Dulitzki M, Rofe G, Shani H, Langevitz P, Schiff E, Pauzner R. High positive antibody titers and adverse pregnancy outcome in women with antiphospholipid syndrome. Acta Obstet et Gynecol Scand 2011; 90: 1428-33.

38 Pengo V, Biasiolo A, Pegoraro C, Cucchini U, Noventa F, lliceto S. Antibody profiles for the diagnosis of antiphospholipid syndrome. Thromb Haemost 2005; 93: 1147-52. 
39 Zoghlami-Rintelen C, Vormittag R, Sailer T, Lehr S, Quehenberger P, Rumpold H, Male C, Pabinger I. The presence of IgG antibodies against $\beta 2$-glycoprotein I predicts the risk of thrombosis in patients with the lupus anticoagulant. J Thromb Haemost 2005; 3: 1160-5.

40 Favaloro E, Bonar R, Marsden K. Internal Quality Control and External Quality Assurance in Testing for Antiphospholipid Antibodies: Part II-Lupus Anticoagulant. Semin Thromb Hemost 2012; 38: 404-11.

41 Devreese K, Hoylaerts MF. Challenges in the diagnosis of the antiphospholipid syndrome. Clin Chem 2010; 56: 930-40. 

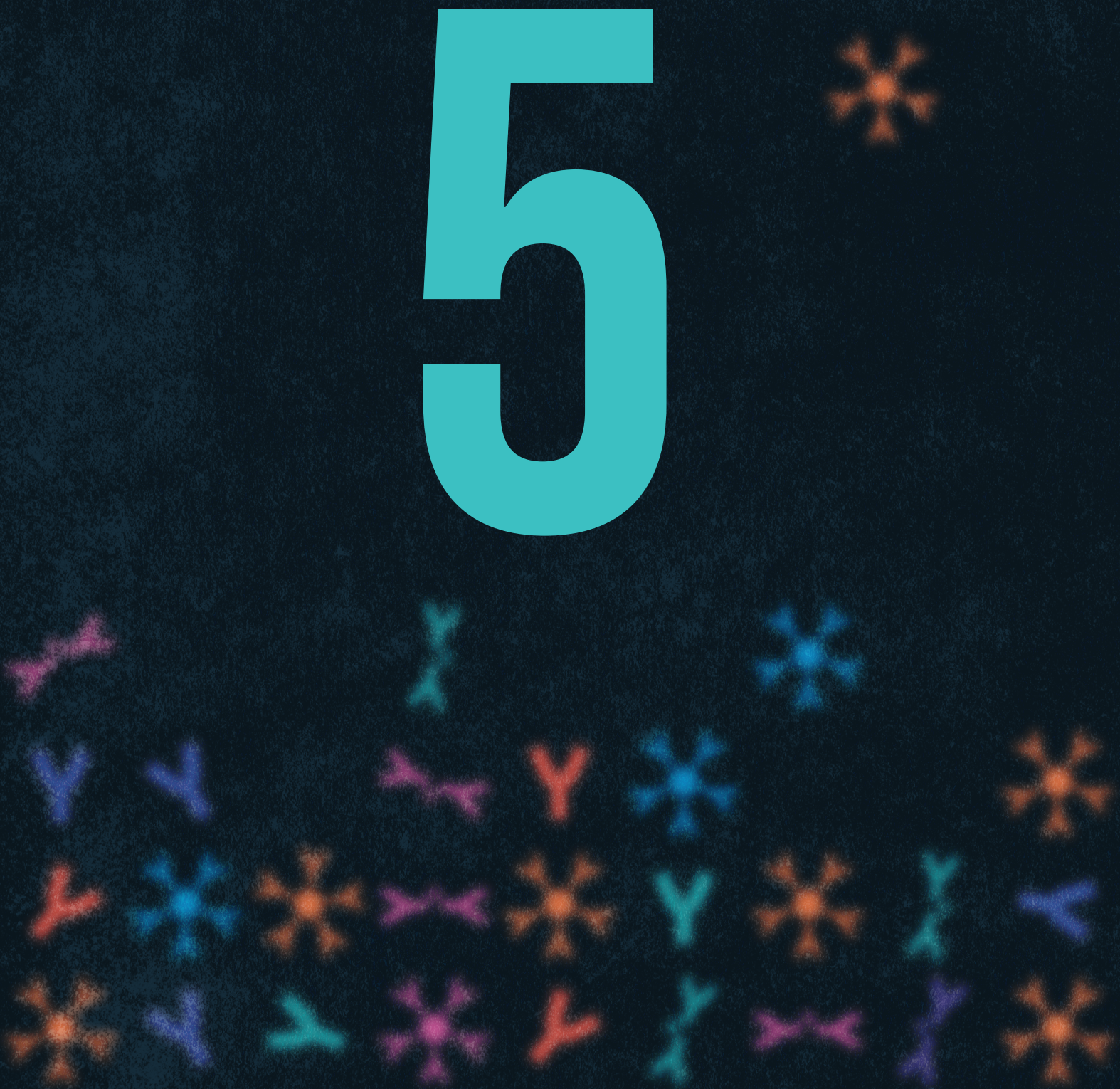


\section{Is there an additional value in detecting anticardiolipin and anti- $\beta 2$ glycoprotein I IgA antibodies in the antiphospholipid syndrome?}

Walid Chayoua, Dong-mei Yin, Hilde Kelchtermans, Gary W. Moore, Jean-Christophe Gris, Jacek Musiał, Stéphane Zuily, Hugo ten Cate, Bas de Laat, Katrien M. J. Devreese

Thromb Haemost. 2020; 11: 1557-68 


\section{ABSTRACT}

Background: Anticardiolipin ( $\mathrm{aCL}$ ) and anti- $\beta 2$ glycoprotein I (aß2GPI) immunoglobulin A ( $\lg A)$ antiphospholipid antibodies (aPL) have shown to associate with thrombosis and pregnancy morbidity. However, inclusion of IgA aPL in the classification criteria of the antiphospholipid syndrome (APS) has been debated.

Objectives: We investigated the value of $\mathrm{aCL}$ and $\mathrm{a} \beta 2 \mathrm{GPI} \operatorname{IgA} \mathrm{aPL}$ in the detection of thrombosis and pregnancy morbidity in addition to the current aPL panel for APS.

Methods: We included 1,608 patients from eight European medical centers: 259 thrombotic APS patients, 122 obstetric APS patients, 204 non-APS thrombosis patients, 33 non-APS obstetric patients, 60 APS patients with unspecified clinical manifestations, 196 patients with autoimmune diseases and 194 controls. aCL and aß2GPI lgG/M/A were detected with four commercial assays and lupus anticoagulant was determined by the local center.

Results: Positivity for IgA aPL was found in 17 to $26 \%$ of the patients with clinical manifestations of APS and in 6 to $13 \%$ of the control population. Both aCL and aß2GPI $\lg A$ were significantly associated with thrombosis and pregnancy morbidity. Isolated IgA positivity was rare in patients with clinical manifestations of APS (0.3-5\%) and not associated with thrombosis and/or pregnancy morbidity. Addition of IgA to the current criteria panel did not increase odds ratios for thrombosis nor pregnancy morbidity.

Conclusions: $\mathrm{aCL}$ and $\mathrm{a} \beta 2 \mathrm{GPI} \operatorname{lgA}$ are associated with clinical manifestations of APS. However, isolated IgA positivity was rare and not associated with thrombosis or pregnancy morbidity. These data do not support testing for $\mathrm{aCL}$ and aß2GPI IgA subsequent to conventional aPL assays in identifying patients with thrombosis or pregnancy morbidity. 


\section{INTRODUCTION}

Clinical manifestations of the antiphospholipid syndrome (APS) include thrombosis and pregnancy morbidity (1). However, these manifestations occur frequently and often independent of APS. Therefore, classification of APS predominantly relies on antiphospholipid (aPL) assays detecting lupus anticoagulant (LAC) by coagulation tests or detection of anticardiolipin ( $\mathrm{aCL}$ ) and anti- $\beta 2$ glycoprotein I (a $\beta 2 \mathrm{GPI})$ antibodies from the immunoglobulin $\mathrm{G}$ ( $\mathrm{lgG}$ ) or immunoglobulin $\mathrm{M}(\mathrm{lgM})$ isotype by solid-phase assays $(1,2)$. $a C L$ and $a \beta 2 G P I$ antibodies from the $\lg A$ isotype are not included in the current classification criteria $(1,2)$. Multiple studies have illustrated an association of $\mathrm{aCL}$ and a $32 \mathrm{GPI}$ immunoglobulin A ( $\lg \mathrm{A})$ antibodies with thrombosis and pregnancy morbidity (3-12). Still, $a C L$ and $a \beta 2 G P I \lg A$ are not included in the current guidelines $(1,2)$. The main reason is unavailability of data to show the clinical significance of $a C L$ or aß2GPI IgA with clinical manifestations of APS in addition to the current aPL panel $(1,13)$.

In a mouse model for thrombosis, IgA antibodies isolated from APS patients resulted in increased thrombus area, faster thrombus formation and decreased time of thrombus disappearance compared with control IgA (14). Outcomes of clinical studies have been contradictory regarding the association of $\mathrm{aCL}$ and/or aß2GPI IgA with clinical symptoms of APS and their role in identifying additional APS patients with thrombosis or pregnancy morbidity $(3-12,15,16)$. Multiple studies have shown that $\lg A$ is associated with thrombosis and pregnancy morbidity (3-12), other studies report no association of $\mathrm{aCL}$ or $\mathrm{a} \beta 2 \mathrm{GPI} \lg \mathrm{A}$ with thrombosis or pregnancy morbidity $(15,16)$. Isolated $\mathrm{aCL}$ and/or aß2GPI IgA positivity was often found not to be associated with thrombosis or pregnancy morbidity $(4,9,15-17)$. However, some studies concluded that $\mathrm{aCL}$ and/ or aß2GPI IgA is an independent risk factor for thrombosis $(6,10,18)$. In addition to the clinical manifestations of APS, IgA positivity has also been associated with systemic lupus erythematosus (SLE), thrombocytopenia, heart valve disease, livedo reticularis and epilepsy $(5,19)$. Comparison of clinical studies is difficult as multiple study designs are used with a wide variety of aPL assays and aPL cut-off values. Furthermore, solidphase assays detecting $\mathrm{aCL}$ and $\mathrm{a} \beta 2 \mathrm{GPI}$ antibodies are poorly standardized and produce variable results in a head-to-head comparison (20-22).

In this multicenter study, we used four commercially available solid-phase assays to detect $\mathrm{aCL}$ and $\mathrm{a} \beta 2 \mathrm{GPI} \lg \mathrm{G} / \mathrm{M} / \mathrm{A}$, to assess for an association of $\mathrm{aCL}$ and $\mathrm{a} \beta 2 \mathrm{GPI} \lg A$ and thrombosis or obstetric complications. A total of 1,608 patients were included of which 678 patients with clinical manifestations of APS and 390 patients who served 
as controls. We aimed to assess the added value of $\mathrm{aCL}$ and $\mathrm{a} \beta 2 \mathrm{GPI} \lg \mathrm{A}$ antibodies as a biomarker for thrombosis and pregnancy morbidity within the current aPL panel consisting of $L A C, \mathrm{aCL} \lg \mathrm{G} / \mathrm{M}$, and $\mathrm{a} \beta 2 \mathrm{GPI} \lg \mathrm{G} / \mathrm{M}$.

\section{MATERIALS AND METHODS}

\section{Study population}

A total of 1,608 patient samples were collected from eight medical European centers. The Sydney classification criteria were followed for the classification of thrombotic and obstetric APS (Table 1) (1). Classification of thrombotic or obstetric APS was determined by the local center. In addition to APS patients, we included patients with an AID other than APS (e.g., 54\% SLE and 29\% systemic sclerosis) without thrombotic complications (AID controls); patients that were referred for aPL testing for other reasons (e.g., subfertility and prolonged activated partial thromboplastin time [aPTT]) than the clinical criteria of APS (controls); patients with a previous thrombotic event and negatively tested for aPL (non-APS thrombosis); and patients who experienced obstetric complications in the absence of aPL (non-APS obstetric). The study was approved by the local ethical committees.

\section{LABORATORY ASSAYS}

\section{Lupus anticoagulant}

LAC assays were performed by the local center, according to the International Society of Thrombosis and Haemostasis-Scientific Standardization Subcommittee (ISTHSSC) guideline (23). Briefly, citrated plasma was tested in a multiple-step procedure (screening, mixing, confirmation step) with two test systems based on different principles (LAC-sensitive aPTT and dilute Russell viper venom time) $(1,23)$.

\section{Solid-phase assays}

Commercially available solid-phase assays were selected based on frequently used assays in the external quality control program of the ECAT (External quality Control of diagnostic Assays and Tests, Voorschoten, The Netherlands) and the willingness of manufacturers for providing the reagents. $\mathrm{aCL}$ and a $32 \mathrm{GPI}$ antibodies from the $\lg \mathrm{G}$, IgM and $\lg A$ isotype were detected at one occasion by four solid-phase assays: BioPlex2200 (Bio-Rad, Bio-Rad Laboratories, Hercules, USA), Phadia (Thermo Fisher Scientific/Phadia, Uppsala, Sweden), HemosIL AcuStar (Instrumentation Laboratories, Bedford, USA) and 


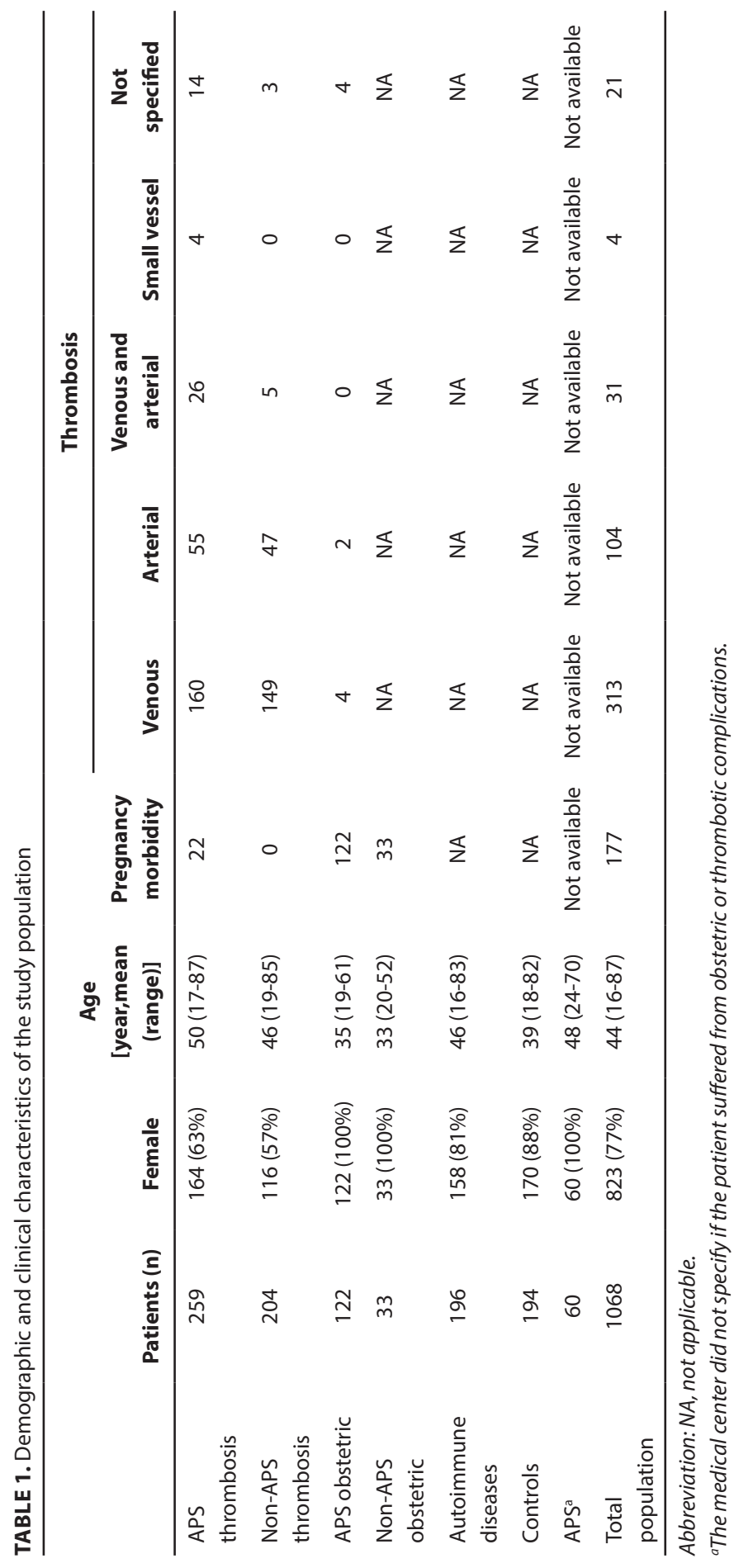


QUANTA Lite ELISA (Inova Diagnostics, San Diego, USA) in the Ghent University Hospital (Ghent, Belgium). Detection of aCL and aß2GPI antibodies was performed according to manufacturer's instructions. Manufacturer's recommended cut-off values were used upon confirmation in 20 healthy volunteers, in accordance with the ISTH-SSC guideline (Supplemental Table 1) (24).

\section{Statistical analyses}

Associations of $\mathrm{aCL}$ and aß2GPI IgA positivity and clinical manifestations of APS were assessed by calculating odds ratios (ORs) with their respective $95 \%$ confidence intervals (Cls). Thrombotic association with IgA aPL was assessed within patients with thrombotic APS, non-APS thrombosis, AID controls and, controls $(n=853)$. Obstetric association with $\lg A$ aPL was assessed within female patients with obstetric APS, non-APS obstetric APS, AID controls and controls $(n=483)$. The additional diagnostic value of $\mathrm{aCL}$ and aß2GPI IgA antibodies was assessed by $2 \times 2$ contingency tables. Kruskal-Wallis test was used to evaluate differences in IgA titers. To compare numbers (percentages) of positive tests between systems, the comparison of two proportions (from independent samples) was used. Statistical analyses were performed using the statistical package for social sciences (SPSS 23.0; SPSS, Chicago, IL) and MedCalc Statistical Software version 17.7.2 (MedCalc Software bvba, Ostend, Belgium). Statistical significance was set at $P$-value less than 0.05 .

\section{RESULTS}

\section{Patient characteristics}

We included 1,608 patients of which 678 patients had clinical manifestations of APS and 390 controls (Table 1). In thrombotic APS, venous thrombosis was more prevalent than arterial thrombosis (160 [62\%] versus 55 [21\%] patients, respectively; Table 1). From the 204 non-APS thrombotic patients, 149 (73\%) had a history of venous thrombosis and $47(23 \%)$ had a history of arterial thrombosis (Table 1). From the 259 thrombotic APS patients, the majority (40\%) received Vitamin $\mathrm{K}$ antagonists, $5 \%$ received lowmolecular-weight heparin, 4\% direct oral anticoagulants, 10\% antiplatelet therapy, $8 \%$ a combination of oral anticoagulants and antiplatelet therapy. Details on anticoagulant and antiplatelet therapy of the remaining 83 (32\%) patients are not available. Patients classified as non-APS thrombosis and non-APS obstetric were negatively tested for criteria aPL by the local medical center. However, retesting of the 204 non-APS thrombosis patients resulted in 1.5 to $8 \%$ positives for $\mathrm{aCL}$ and/or a $32 \mathrm{GPI}$ lgG/lgM, 
depending on the solid-phase assay (Table 2). Retesting of 33 non-APS obstetric patients resulted in 0 to $12 \%$ positives for $\mathrm{aCL}$ and/or a $32 \mathrm{GPI} \operatorname{lgG} / \lg \mathrm{M}$, depending on the solid-phase assay (Table 2 ).

\section{Prevalence of (isolated) aCL and/or aß2GPI IgA}

Among patients with clinical manifestations of APS, 17 to $26 \%$ tested positive for aCL and/or aß2GPI IgA antibodies (Table 2). Positivity for aCL and/or aß2GPI IgA antibodies in thrombotic APS ranged between 26 and 37\%, depending on the solid-phase assay used to detect IgA antibodies (Table 2). Within obstetric APS, positivity for aCL and/or aß2GPI IgA ranged between 16 and 34\%, depending on the solid-phase assay (Table 2). In the control group, consisting of AID patients and controls 6 to $8 \%$ were positive for $\mathrm{aCL}$ and/or a $32 \mathrm{GPI} \lg \mathrm{A}$ aPL (Table 2). Isolated positivity for $\mathrm{aCL}$ and/or a $32 \mathrm{GPI} \lg \mathrm{A}$ (positive for $\lg A$ with negative $L A C, \lg G$ and $\lg M$ results) was rare in thrombotic and obstetric patients with a prevalence of 0 to $3 \%$ and 1 to $5 \%$, respectively (Table 2 ). Within AID and controls, isolated $\mathrm{aCL}$ and/or a $32 \mathrm{GPI} \operatorname{lgA}$ positivity ranged between 1 and 4\% (Table 2). With two (BioPlex2200 and HemosIL AcuStar) out of the four tested solid-phase assays, only $1 \%$ of the total study population was positive for $\lg A$ with negative $L A C, \lg G$, and IgM results (Table 2). The other two solid-phase assays detected more isolated IgA patients, 2\% (Phadia) and 3\% (QUANTA Lite ELISA) (Table 2).

\section{Correlation of aCL and/or aß2GPI IgA with criteria aPL}

Within the total population consisting of 1,608 patients, 408 (38\%) were positive for LAC, thereby the most prevalent aPL (Supplemental Table 2). IgG was the most prevalent $\mathrm{aCL}$ or a $32 \mathrm{GPI}$ antibody isotype in the total study population (Supplemental Table 2). Only $6 \%$ of the total patient population was positive for $\mathrm{aCL} \lg \mathrm{A}$, detected with QUANTA Lite ELISA (Supplemental Table 2). By a comparison of two proportions, a significant difference $(P<0.0001)$ was found for the number of patients positive for $\mathrm{aCL} \lg \mathrm{A}$ and $\mathrm{aCL} \operatorname{lgM}$, detected with either BioPlex2200 or Phadia. Detection of aß2GPI $\lg \mathrm{M}$ and $\lg \mathrm{A}$ resulted in a significant difference in number of positive samples with the BioPlex2200 system only ( $P=0.0001)$. a $32 \mathrm{GPI}$ IgG was more prevalent than a $32 \mathrm{GPI} \lg A$ antibodies, except when detected with BioPlex2200 ( $P=0.0007)$. By a comparison of two proportions, significant differences were found between aCL IgG and aCL IgA for all solid-phase assays. Prevalence of aPL in the subgroups (controls, AID, APS thrombosis, non-APS thrombosis, APS obstetric, non-APS obstetric, and APS patients) are shown in Supplemental Table 2. LAC and aCL or a 2 GPI IgA were highly correlated, as 63 to $80 \% \lg A$-positive patients were also characterized by positive LAC results (data not shown). Similarly, 72 to $83 \%$ of the patients positive for aCL IgG, were also positive for LAC. aß2GPI lgG and LAC showed an overlap of 77 to $87 \%$. Positive results for aCL IgM 


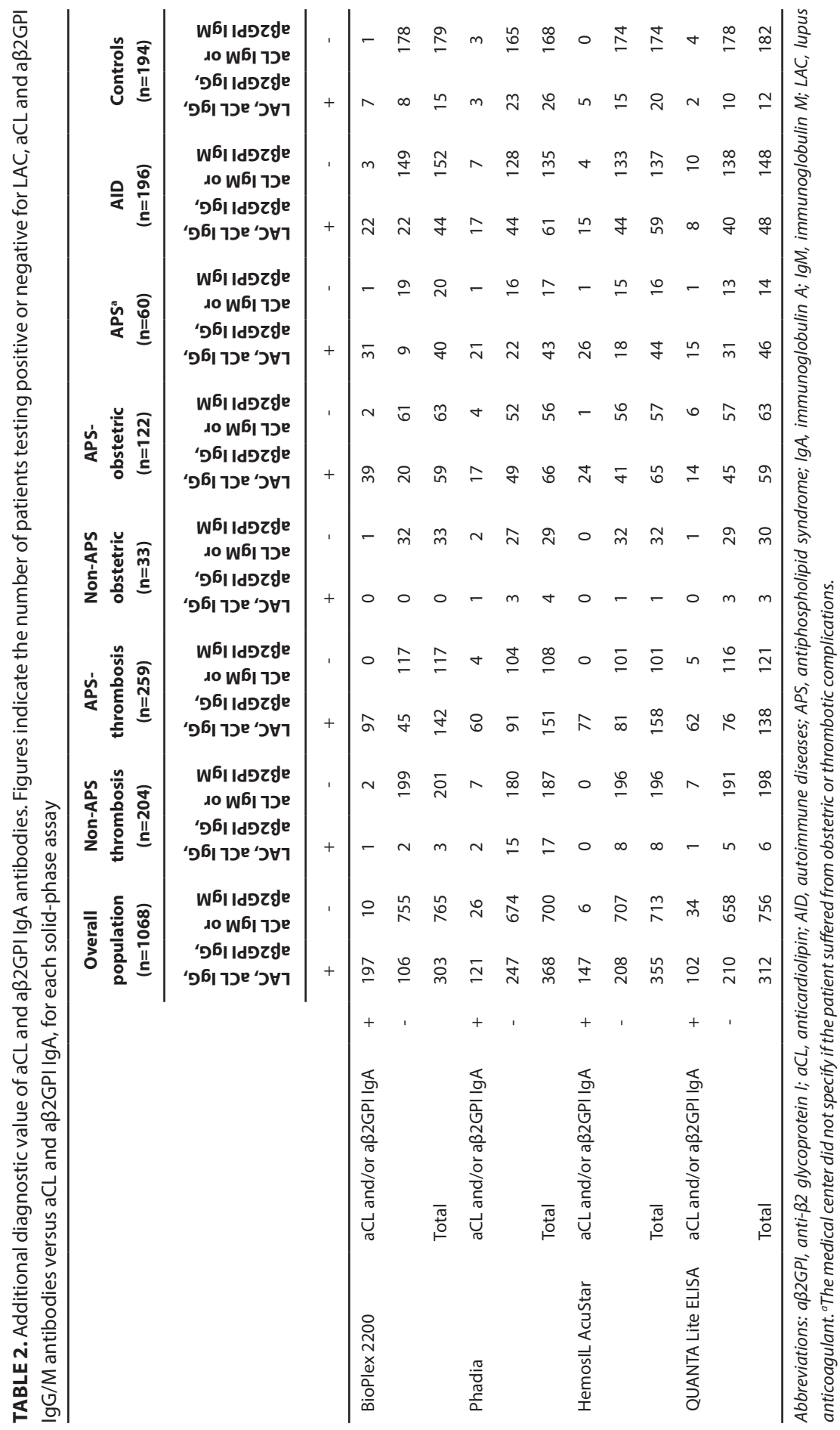


or aß2GPI IgM were less correlated with LAC, $59-74 \%$ and $72-75 \%$, respectively. Upon detection with BioPlex2200, positivity for IgA aPL also highly correlated with triple positivity. Within the total population, the BioPlex2200 identified 221 triple positive patients of which 162 (73\%) were positive for aCL and/or a $32 \mathrm{GPI} \lg A$ antibodies. Other solid-phase assays tested showed less correlation between $\lg \mathrm{A}$ aPL and triple positivity (Phadia [49\%], HemosIL AcuStar [60\%] and QUANTA Lite ELISA [48\%]).

\section{Association of aCL and/or aß2GPI IgA with thrombosis and pregnancy morbidity}

Both $\mathrm{aCL}$ and aß2GPI IgA positivity were significantly associated with thrombosis (Table 3). Positivity for aCL $\lg A$ reached ORs for thrombosis of $3.0(95 \% \mathrm{Cl}, 1.9-4.9)$ to $9.9(95 \%$ Cl, 3.5-27.8) (Table 3). aß2GPI IgA positivity showed ORs for thrombosis between 2.4 $(95 \% \mathrm{Cl}, 1.5-3.9)$ and $3.1(95 \% \mathrm{Cl}, 1.9-5.2)$ (Table 3). A stronger thrombotic association was found with aCL IgA assays than with the a 32 GPI IgA assay (Table 3). Detection of aCL IgA with QUANTA Lite ELISA reached the highest OR for thrombosis $19.9 ; 95 \% \mathrm{Cl}$, 3.5-27.8) (Table 3). However, from the 47 patients positive for aCL IgA, only 43 patients with a history of thrombosis were detected with this assay, while the $\mathrm{aCL} \operatorname{lgA}$ assay from BioPlex2200 detected 130 patients of which 100 patients with a history of thrombosis (Table 3). Positivity for aCL and/or aß2GPI IgA reached comparable ORs for thrombosis, between the tested assays with ORs between $2.2(95 \% \mathrm{Cl}, 1.4-3.5)$ and $3.0(95 \% \mathrm{Cl}, 2.0-$ 4.5) (Table 3).

Positivity for both aCL and $\mathrm{a} \beta 2 \mathrm{GPI}$ from the same isotype is considered to be more reliable for diagnosis of APS. ORs for thrombosis did not increase in patients positive for $\mathrm{aCL}$ and $\mathrm{a} \beta 2 \mathrm{GPI} \lg \mathrm{A} a \mathrm{APL}$, compared with patients positive for $\mathrm{aCL} \lg \mathrm{A}$ or a $32 \mathrm{GPI} \lg \mathrm{A}$ when detected with the BioPlex2200 and HemosIL AcuStar (Table 3). The other two tested solid-phase assay showed an increase of OR for thrombosis in patients positive for $\mathrm{aCL}$ and $\mathrm{a} \beta 2 \mathrm{GPI}$ IgA compared with ORs obtained from the $\mathrm{aCL}$ and $\mathrm{a} \beta 2 \mathrm{GPI} \lg \mathrm{A}$ assay separately, most pronounced for QUANTA Lite ELISA (Table 3). In comparison, patients positive for both $\mathrm{aCL}$ and $\mathrm{a} \beta 2 \mathrm{GPI}$ IgG were characterized with a similar or slightly higher OR than positivity for aCL IgG or aß2GPI IgG (Supplemental Table 3). However, the increase in OR for double lgG positivity for QUANTA Lite ELISA was less pronounced compared with the increase observed in double IgA positivity for that platform. Also, for the IgM isotype similar results were obtained (Supplemental Table 3). Patients positive for both $\mathrm{aCL}$ and $\mathrm{a} \beta 2 \mathrm{GPI}$ IgM antibodies were characterized with similar ORs for thrombosis than OR from an aCL IgM or aß2GPI IgM assay alone (Supplemental Table 3). 
TABLE 3. Thrombotic and obstetric association of $\mathrm{aCL}$ and $\mathrm{a} \beta 2 \mathrm{GPI} \lg \mathrm{A}$ antibodies

\begin{tabular}{|c|c|c|c|c|}
\hline & BioPlex2200 & Phadia & HemosIL AcuStar & QUANTA Lite ELISA \\
\hline \multicolumn{5}{|l|}{ Thrombosis } \\
\hline $\mathrm{aCL}$ & $3.3(2.1-5.1)$ & $3.1(1.6-6.1)$ & $3.0(1.9-4.9)$ & $9.9(3.5-27.8)$ \\
\hline $\mathrm{n}$ & 130 & 49 & 101 & 47 \\
\hline $\mathrm{a} \beta 2 \mathrm{GPI}$ & $2.8(1.8-4.3)$ & $2.4(1.5-3.9)$ & $2.5(1.5-4.0)$ & $3.1(1.9-5.2)$ \\
\hline $\mathrm{n}$ & 124 & 94 & 88 & 91 \\
\hline $\mathrm{aCL}$ and/or aß2GPI & $3.0(2.0-4.5)$ & $2.2(1.4-3.5)$ & $3.0(1.9-4.9)$ & $3.0(1.8-4.8)$ \\
\hline $\mathrm{n}$ & 133 & 103 & 101 & 99 \\
\hline $\mathrm{aCL}$ and $\mathrm{a} \beta 2 \mathrm{GPI}$ & $3.1(2.0-4.8)$ & $4.2(1.8-9.6)$ & $2.4(1.5-4.0)$ & $35.8(4.8-254.5)$ \\
\hline $\mathrm{n}$ & 121 & 40 & 88 & 39 \\
\hline \multicolumn{5}{|c|}{ Pregnancy morbidity } \\
\hline $\mathrm{aCL}$ & $3.6(2.1-6.1)$ & $3.5(1.5-8.3)$ & $2.4(1.3-4.5)$ & $5.0(1.5-16.5)$ \\
\hline $\mathrm{n}$ & 67 & 23 & 47 & 13 \\
\hline $\mathrm{a} \beta 2 \mathrm{GPI}$ & $2.9(1.7-4.9)$ & $1.9(1.0-3.5)$ & $2.2(1.2-4.1)$ & $2.7(1.4-5.3)$ \\
\hline $\mathrm{n}$ & 65 & 42 & 45 & 37 \\
\hline $\mathrm{aCL}$ and/or aß2GPI & $3.6(2.1-5.9)$ & $1.8(1.0-3.4)$ & $2.6(1.4-4.7)$ & $2.4(1.3-4.6)$ \\
\hline $\mathrm{n}$ & 73 & 49 & 48 & 41 \\
\hline $\mathrm{aCL}$ and $\mathrm{a} \beta 2 \mathrm{GPI}$ & $2.9(1.7-5.0)$ & $4.9(1.7-14.5)$ & $2.1(1.1-3.9)$ & $17.8(2.2-143.6)$ \\
\hline $\mathrm{n}$ & 59 & 16 & 44 & 9 \\
\hline
\end{tabular}

Abbreviations: $a \beta 2 G P I$, anti- $\beta 2$ glycoprotein l; $a C L$, anticardiolipin; $C l$, confidence interval; $n$, number of patients positive for aCL or aß2GPI IgA within the population; OR, odds ratio. Note: Odds ratios for thrombosis are calculated in a subpopulation including controls, AID, non-APS thrombosis, and APS thrombosis patients $(n=853)$. Odds ratios for pregnancy morbidity are calculated in a female subpopulation including controls, AID, non-APS obstetric, and APS obstetric patients $(n=483)$.

IgA aPL was significantly correlated with pregnancy morbidity, independent of the solid-phase platform (Table 3). Similar to thrombosis, the aCL IgA assay from QUANTA Lite ELISA reached the highest OR $(5.0(95 \% \mathrm{Cl}, 1.5-16.5))$ for pregnancy morbidity (Table 3). Double positivity for IgG or IgM resulted in slightly higher OR for three out of the four platforms (supplemental Table 4). Double positivity for IgA (Table 3) resulted in significant higher OR for one platform (QUANTA Lite ELISA), in agreement with the thrombosis results.

Association of aCL and a $32 \mathrm{GPI}$ IgA was calculated separately for venous and arterial thrombosis (Supplemental Table 5). ORs for venous thrombosis $(\mathrm{n}=309)$ ranged from 1.8 $(95 \% \mathrm{Cl}, 1.1-2.8)$ to $7.0(95 \% \mathrm{Cl}, 2.4-20.7)$ and $1.8(95 \% \mathrm{Cl}, 1.1-3.0)$ to $2.4(95 \% \mathrm{Cl}, 1.4-4.2)$ 
for aCL and aß2GPI IgA, respectively (Supplemental Table 5). ORs for arterial thrombosis $(\mathrm{n}=102)$ ranged from $2.2(95 \% \mathrm{Cl}, 1.2-4.0)$ to $14.1(95 \% \mathrm{Cl}, 4.5-44.3)$ and $2.9(95 \% \mathrm{Cl}, 1.5-$ 5.6) to $3.8(95 \% \mathrm{Cl}, 1.9-7.4)$ for $\mathrm{aCL}$ and aß2GPI IgA, respectively (Supplemental Table 5).

TABLE 4. Thrombotic and obstetric association of isolated $\mathrm{aCL}$ and $\mathrm{a} \beta 2 \mathrm{GPI} \lg \mathrm{A}$ antibodies

\begin{tabular}{|c|c|c|c|c|}
\hline & BioPlex2200 & Phadia & HemosIL AcuStar & QUANTA Lite ELISA \\
\hline \multicolumn{5}{|l|}{ Thrombosis } \\
\hline $\mathrm{aCL}$ & $0.6(0.1-3.4)$ & $1.3(0.4-4.5)$ & $0.5(0.4-0.5)$ & $1.7(0.2-18.7)$ \\
\hline $\mathrm{n}$ & 5 & 10 & 4 & 3 \\
\hline $\mathrm{a} \beta 2 \mathrm{GPI}$ & $0.5(0.4-0.5)$ & $1.1(0.4-2.9)$ & $0.5(0.4-0.5)$ & $0.6(0.3-1.5)$ \\
\hline $\mathrm{n}$ & 4 & 16 & 4 & 23 \\
\hline aCL and/or aß2GPI & $0.4(0.08-2.3)$ & $0.9(0.4-2.2)$ & $0.5(0.4-0.5)$ & $0.7(0.3-1.6)$ \\
\hline $\mathrm{n}$ & 6 & 21 & 4 & 26 \\
\hline $\mathrm{aCL}$ and $\mathrm{a} \beta 2 \mathrm{GPI}$ & $0.5(0.4-0.5)$ & $3.4(0.4-30.5)$ & $0.5(0.4-0.5)$ & - \\
\hline $\mathrm{n}$ & 3 & 5 & 4 & 0 \\
\hline \multicolumn{5}{|c|}{ Pregnancy morbidity } \\
\hline $\mathrm{aCL}$ & $2.1(0.3-15.3)$ & $2.1(0.4-10.7)$ & $0.7(0.1-6.8)$ & $2.1(0.1-34.2)$ \\
\hline $\mathrm{n}$ & 4 & 6 & 4 & 2 \\
\hline $\mathrm{a} \beta 2 \mathrm{GPI}$ & $2.1(0.4-10.7)$ & $1.7(0.5-6.5)$ & $0.7(0.6-0.7)$ & $1.5(0.6-4.0)$ \\
\hline $\mathrm{n}$ & 6 & 9 & 3 & 17 \\
\hline $\mathrm{aCL}$ and/or a $\beta 2 \mathrm{GPI}$ & $2.1(0.4-10.7)$ & $1.1(0.3-3.6)$ & $0.7(0.1-6.8)$ & $1.4(0.5-3.6)$ \\
\hline $\mathrm{n}$ & 6 & 12 & 4 & 18 \\
\hline $\mathrm{aCL}$ and $\mathrm{a} \beta 2 \mathrm{GPI}$ & $2.1(0.3-15.3)$ & $0.3(0.3-0.4)$ & $0.7(0.6-0.7)$ & $0.3(0.3-0.4)$ \\
\hline $\mathrm{n}$ & 4 & 3 & 3 & 1 \\
\hline
\end{tabular}

Abbreviations: a $32 \mathrm{GPI}$, anti- $\beta 2$ glycoprotein l; $a C L$, anticardiolipin; $C l$, confidence interval; $n$, number of patients positive within the indicated subpopulation; OR, odds ratio. Note: Odds ratios for thrombosis are calculated in a subpopulation including controls, AID, non-APS thrombosis, and APS thrombosis patients $(n=853)$. Odds ratios for pregnancy morbidity are calculated in a female subpopulation including controls, AID, non-APS obstetric, and APS obstetric patients $(n=483)$.

\section{Association of isolated aCL and/or aß2GPI IgA with thrombosis and pregnancy morbidity}

Isolated $\mathrm{aCL}$ and/or aß2GPI IgA positivity was not associated with thrombosis (Table 4). ORs varied between 0.4 ( $95 \% \mathrm{Cl}, 0.08-2.3)$ and 0.9 (95\% Cl, 0.4-2.2) (Table 4). In a more detailed analysis, no significant association was found for arterial or venous thrombosis 
and isolated IgA $\mathrm{aCL}$ or a $32 \mathrm{GPI}$ (Supplemental Table 5). Isolated $\mathrm{aCL}$ or a $32 \mathrm{GPI} \lg \mathrm{A}$ positivity was also not significantly associated with pregnancy morbidity with OR ranging from $0.7(95 \% \mathrm{Cl}, 0.1-6.8)$ to $2.1(95 \% \mathrm{Cl}, 0.4-10.7)$ (Table 4).

\section{Titers of isolated aCL and/or aß2GPI IgA-positive patients}

Within the total population, the QUANTA Lite ELISA assay detected the highest number of isolated IgA samples ( $n=34$ patients). Only 12,47 , and $6 \%$ of these 34 patients were also positive for isolated IgA with the BioPlex2200, Phadia and HemosIL AcuStar assay, respectively. Titers of isolated IgA aPL patients were low (Figure 1). Isolated aCL and aß2GPI IgA titers of patients with clinical manifestation were similar to IgA titers in the control population. Of note, upon aPL detection with Phadia, one patient with a history of thrombosis and one patient with known pregnancy morbidity had an aCL and aß2GPI IgA titer $>100 \mathrm{AU}$, while all patients in the control population had titers $<100 \mathrm{AU}$ (Figure 1C-D).

\section{aCL and/or aß2GPI IgA titers of triple positive patients}

The majority of triple positive patients ( $\mathrm{LAC}, \mathrm{aCL}$, and a $32 \mathrm{GPI}$ IgG/M positivity, from the same isotype) had a history of thrombosis and/or pregnancy morbidity (Figure 2). $\mathrm{aCL}$ and aß2GPI IgA titers were found to be significantly different between triple positives and nontriple positives, independent of the solid-phase assay (Figure 2). Triple positives for the $\lg G$ isotype ( $L A C, a C L \lg G$ and a $\beta 2 G P I \lg G$ ) had higher $\mathrm{CCL}$ and a $32 \mathrm{GPI} \lg A$ titers than non-triple positive patients, independent of the solid-phase assay (Figure 2). $\mathrm{aCL}$ and aß2GPI IgA titers from triple positives for the IgM isotype (LAC, aCL IgM, and aß2GPI $\operatorname{lgM}$ ) were also significantly higher than nontriple-positives, independent of the solidphase assay (Figure 2). aCL and a $32 \mathrm{GPI}$ IgA titers of triple positives for the IgG isotype and triple positives for the lgM isotype were not significantly different for all platforms (Figure 2).

\section{Additional value in thrombosis of $\mathrm{aCL}$ and $\mathrm{a} 32 \mathrm{GPI} \operatorname{IgA}$ in the current $\mathrm{aPL}$ panel}

Inclusion of $\mathrm{aCL}$ and $\mathrm{a} \beta 2 \mathrm{GPI} \lg \mathrm{A}$ antibodies in the current aPL panel consisting of LAC, IgG and/or IgM aCL, and/or aß2GPI did not increase ORs for thrombosis (Table 5). Replacement of IgM by IgA aPL resulted in similar ORs for thrombosis compared with the current classification criteria with most solid-phase assays tested (Table 5). However, an aPL panel consisting of $\mathrm{LAC}, \mathrm{aCL} \mathrm{IgG} / \mathrm{M} / \mathrm{A}$, and a $32 \mathrm{GPI} \mathrm{lgG} / \mathrm{M} / \mathrm{A}$ resulted in similar ORs for thrombosis $(2.4$ [95\% Cl, 1.8-3.1] to 2.8 [95\% Cl, 2.1-3.7]) in comparison to calculated $O R$ with an aPL panel consisting of $L A C, a C L$ lgG/M, and aß2GPI lgG/M (2.4 [95\% Cl, 1.8-3.2] to 2.9 [95\% Cl, 2.2-3.9]) (Table 5). 


\section{Additional value in pregnancy morbidity of aCL and aß2GPI IgA in the current aPL panel}

Positivity for at least one of the criteria aPL of APS resulted in significant ORs for pregnancy morbidity between $4.9(95 \% \mathrm{Cl}, 3.2-7.4)$ and $6.6(95 \% \mathrm{Cl}, 4.3-10.0)$, depending on the solid-phase assay (Table 6). An aPL panel for the classification of APS, consisting of $L A C$, IgG aCL or a $32 \mathrm{GPI}, \mathrm{aCL}$ or a $\beta 2 \mathrm{GPI} \lg A$ reached similar ORs, between 4.6 (95\% $\mathrm{Cl}, 3.0-6.9)$ and 5.1 (95\% Cl, 3.4-7.7) (Table 6). Positivity for LAC, IgG, IgM or IgA did not increase the OR for pregnancy morbidity as ORs between $4.6(95 \% \mathrm{Cl}, 3.1-7.0)$ and 6.2 $(95 \% \mathrm{Cl}, 4.1-9.4)$ were obtained (Table 6). 
A
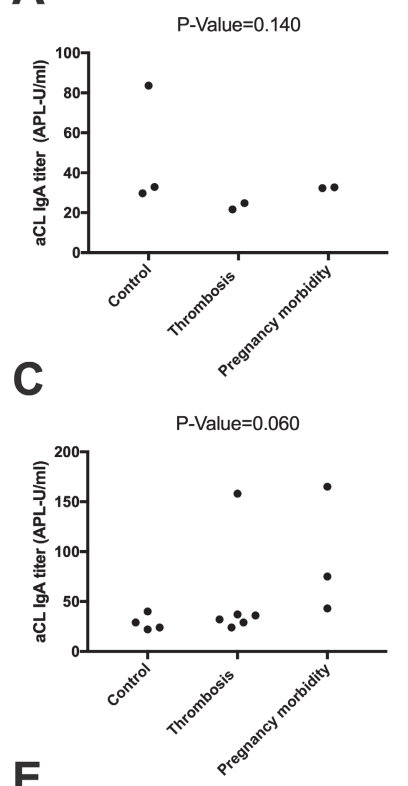

E
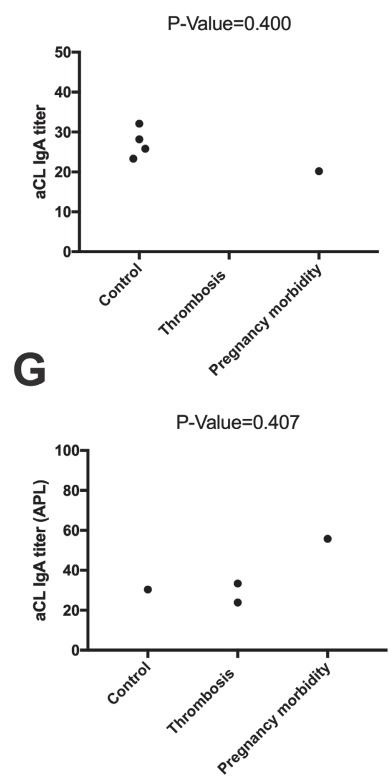

B
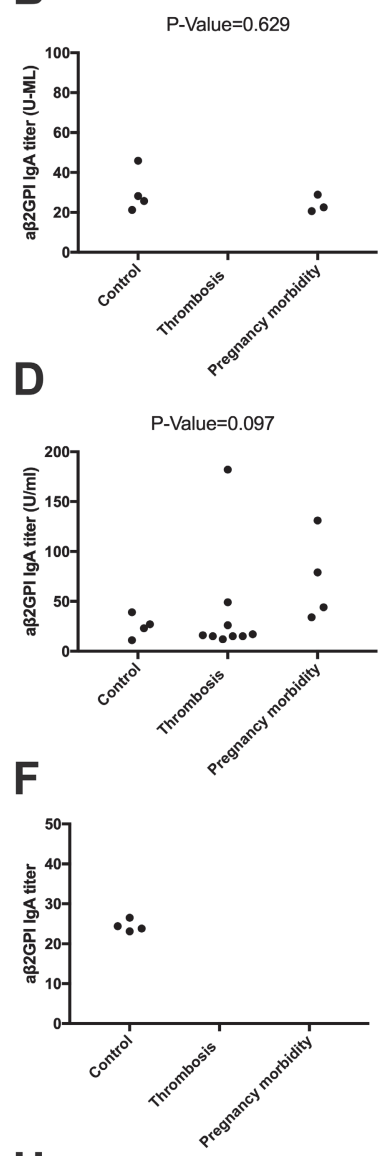

H

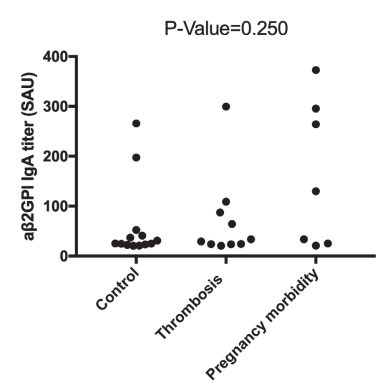

FIGURE 1. Isolated aCL or a $\beta 2$ GPI IgA titers of controls and AID (control), APS thrombosis and non-APS thrombosis (thrombosis), and APS obstetric and non-APS obstetric (pregnancy morbidity). (A) Isolated aCL IgA titers detected with BioPlex 2200; (B) isolated aß2GPI IgA titers detected with BioPlex 2200; (C) isolated $\mathrm{aCL} \lg \mathrm{A}$ titers detected with Phadia; (D) isolated a 2 GPI IgA titers detected with Phadia; (E) isolated $\mathrm{aCL}$ IgA titers detected with HemosIL AcuStar; (F) isolated aß2GPI IgA titers detected with HemosIL AcuStar; (G) isolated aCL IgA titers detected with QUANTA Lite ELISA; $(\mathbf{H})$ and isolated aß2GPI IgA titers detected with QUANTA Lite ELISA. Represented $p$-values were calculated using the Kruskal-Wallis test. a $32 \mathrm{GPI}$, anti- $\beta 2$ glycoprotein l; aCL, anticardiolipin; APS, antiphospholipid syndrome; lgA, immunoglobulin A. 
A
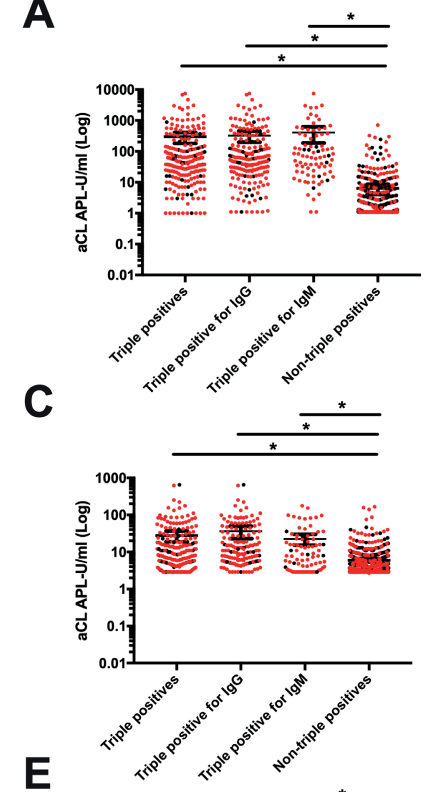

E
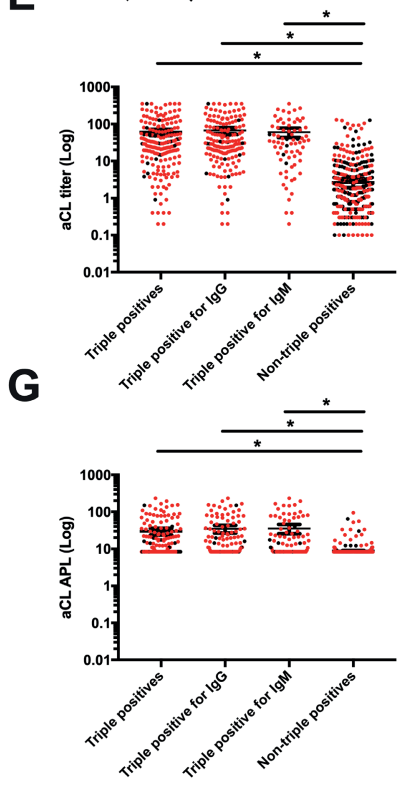

B

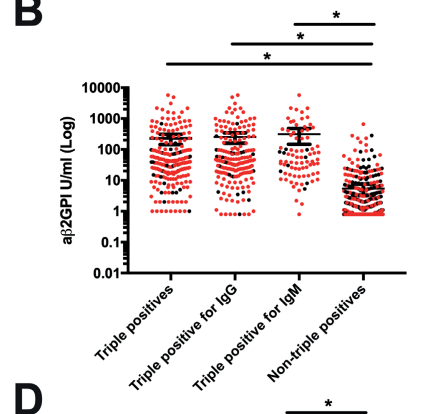

D
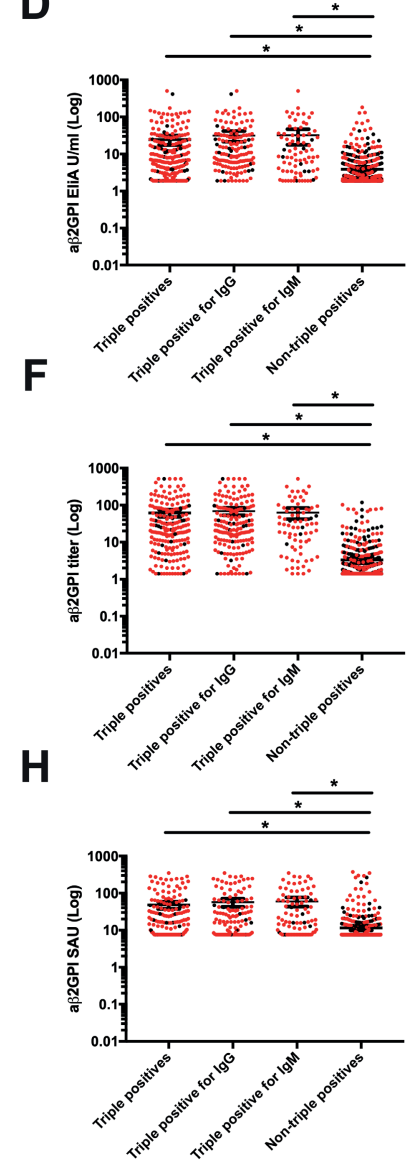

FIGURE 2. $a C L$ or a $32 \mathrm{GPI} \lg A$ titers of triple-positive patients and non-triple-positive patients. Solid dots in black indicate $\mathrm{aCL}$ or a $32 \mathrm{GPI}$ IgA titers of patients without clinical manifestations of APS. Solid dots in red indicate $\mathrm{aCL}$ or $\mathrm{a} \beta 2 \mathrm{GPI} \lg \mathrm{A}$ titers of patients with clinical manifestations of APS. (A) aCL IgA titers detected with BioPlex 2200; (B) aß2GPI IgA titers detected with BioPlex 2200; (C) aCL IgA titers detected with Phadia; (D) a 32 GPI IgA titers detected with Phadia; (E) aCL IgA titers detected with HemosIL AcuStar; (F) a 32 GPI IgA titers detected with HemosIL AcuStar; (G) aCL IgA titers detected with QUANTA Lite ELISA; (H) a 32 GPI IgA titers detected with QUANTA Lite ELISA. Mean IgA titers with their $95 \%$ confidence intervals are shown. Significance was calculated using the Kruskal-Wallis test followed by Mann-Whitney $\mathrm{U}$ test. ${ }^{*}, p$-value $<0.0001$. aß2GPI, anti- $\beta 2$ glycoprotein I; aCL, anticardiolipin; APS, antiphospholipid syndrome; IgA, immunoglobulin A. 
TABLE 5. Additional value of $\mathrm{aCL}$ and $\mathrm{a} \beta 2 \mathrm{GPI} \lg \mathrm{A}$ antibodies in thrombosis

\begin{tabular}{|c|c|c|c|}
\hline & $\begin{array}{l}\text { LAC, aCL IgG, a } \beta 2 \mathrm{GPI} \\
\text { IgG, aCL IgM and/ } \\
\text { or } \mathrm{a} \beta 2 \mathrm{GPI} \text { IgM }\end{array}$ & $\begin{array}{l}\text { LAC, aCL IgG, a } \beta 2 \mathrm{GPI} \\
\operatorname{lgG}, \mathrm{aCL} \lg A \text { and } / \\
\text { or } \mathrm{a} \beta 2 \mathrm{GPI} \lg A\end{array}$ & $\begin{array}{c}\text { LAC, aCL IgG, a } \beta 2 \text { GPI lgG, } \\
\text { aCL IgM, a } \beta 2 \text { GPI IgM, aCL } \\
\text { IgA and/or a } \beta 2 \text { GPI IgA }\end{array}$ \\
\hline & Odds ratio $(95 \% \mathrm{Cl})$ & Odds ratio $(95 \% \mathrm{Cl})$ & Odds ratio $(95 \% \mathrm{Cl})$ \\
\hline BioPlex2200 & $2.9(2.2-3.9)$ & $2.8(2.1-3.7)$ & $2.8(2.1-3.7)$ \\
\hline Phadia & $2.4(1.8-3.2)$ & $3.1(2.3-4.2)$ & $2.4(1.8-3.1)$ \\
\hline HemosIL AcuStar & $2.9(2.1-3.8)$ & $3.0(2.3-4.1)$ & $2.7(2.0-3.6)$ \\
\hline QUANTA Lite ELISA & $2.8(2.1-3.7)$ & $3.1(2.3-4.2)$ & $2.6(2.0-3.5)$ \\
\hline
\end{tabular}

Abbreviations: a $32 \mathrm{GPI}$, anti- $\beta 2$ glycoprotein l; $a C L$, anticardiolipin; $C l$, confidence interval; IgA, immunoglobulin $A$; IgM, immunoglobulin $M$; LAC, lupus anticoagulant.

TABLE 6. Additional value of $\mathrm{aCL}$ and $\mathrm{a} \beta 2 \mathrm{GPI} \lg \mathrm{A}$ antibodies in pregnancy morbidity

\begin{tabular}{|c|c|c|c|}
\hline & $\begin{array}{l}\text { LAC, aCL IgG, a } 32 \mathrm{GPI} \\
\text { IgG, aCL IgM and/ } \\
\text { or a } 32 \mathrm{GPI} \text { IgM }\end{array}$ & $\begin{array}{l}\text { LAC, aCL IgG, a } \beta 2 \mathrm{GPI} \\
\operatorname{lgG}, \mathrm{aCL} \lg A \text { and } / \\
\text { or } \mathrm{a} \beta 2 \mathrm{GPI} \lg A\end{array}$ & $\begin{array}{c}\text { LAC, aCL IgG, a } 32 \text { GPI IgG, } \\
\text { aCL IgM, a } \beta 2 \text { GPI IgM, aCL } \\
\text { IgA and/or a } \beta 2 \text { GPI IgA }\end{array}$ \\
\hline & Odds ratio $(95 \% \mathrm{CI})$ & Odds ratio $(95 \% \mathrm{CI})$ & Odds ratio $(95 \% \mathrm{Cl})$ \\
\hline BioPlex2200 & $5.1(3.4-7.7)$ & $4.6(3.0-6.9)$ & $5.0(3.3-7.6)$ \\
\hline Phadia & $4.9(3.2-7.4)$ & $4.7(3.1-7.0)$ & $4.6(3.1-7.0)$ \\
\hline HemosIL AcuStar & $5.3(3.5-8.0)$ & $4.8(3.2-7.2)$ & $5.2(3.4-7.8)$ \\
\hline QUANTA Lite ELISA & $6.6(4.3-10.0)$ & $5.1(3.4-7.7)$ & $6.2(4.1-9.4)$ \\
\hline
\end{tabular}

Abbreviations: $\beta \beta 2 \mathrm{GPI}$, anti- $\beta 2$ glycoprotein l; aCL, anticardiolipin; $C l$, confidence interval; IgA, immunoglobulin $A$; IgM, immunoglobulin $M$; LAC, lupus anticoagulant.

\section{DISCUSSION}

In this study we evaluated the prevalence of $\mathrm{aCL}$ and aß2GPI IgA antibodies, tested with four solid-phase platforms, in 1,608 patients. We also investigated the added value of $\lg \mathrm{A}$ aPL in APS classification.

Of the 1,608 included patients 6 to $19 \%$ tested positive for aCL $\lg \mathrm{A}$ aCL and 12 to $18 \%$ for aß2GPI IgA antibodies, dependent on the solid-phase assay used. LAC was by far the most prevalent aPL (38\%) in our study population consisting of 1,608 APS patients and controls. In comparison, a retrospective study included 472 patients with aPL testing and found a similar distribution of $\mathrm{aCL} \lg A$ and aß2GPI $\lg A$ antibodies, 6 and 19\% 
respectively (10). Another study included 314 patients suspected for APS or related AIDs (e.g., SLE) and found $28 \%$ patients positive for aß2GPI IgA using the QUANTA Lite ELISA (15). We only found $12 \%$ of the patients positive for a $32 \mathrm{GPI} \lg A$ in the total population using the QUANTA Lite ELISA. The lower prevalence of a 2 GPI IgA antibodies might be due to a different patient population as we included a large number of patients with a history of thrombosis or pregnancy morbidity, but negative for any consensus aPL as control population. Another cross-sectional study included 156 patients that fulfilled the clinical criteria of APS and found a prevalence of 5 and $29 \%$ for aCL IgA and aß2GPI $\lg$ A positivity, respectively (8).

In our study, $\mathrm{aCL}$ as well as a $32 \mathrm{GPI} \lg \mathrm{A}$ antibodies were correlated with clinical manifestations of APS (thrombosis and pregnancy morbidity), independent of the solid-phase platform used. In agreement with our results, multiple studies have shown an association between clinical manifestations of APS and $\mathrm{aCL}$ and/or a $32 \mathrm{GPI} \lg A$ antibodies (3-12). However, some studies were only able to show a clinical association for either $\mathrm{aCL}$ or a $32 \mathrm{GPI}$ IgA aPL detected with an in-house ELISA $(3,9)$. One retrospective study including 439 patient samples within a timespan of 6 years found an association between $a \beta 2$ GPI $\lg A$ and thrombosis, but not for $\mathrm{aCL} \lg \mathrm{A}(3)$. Another retrospective study including 130 SLE patients and 35 patients with primary APS demonstrated a correlation of $\mathrm{aCL} \lg \mathrm{A}$ aPL with a history of thrombosis and recurrent fetal loss, but was unable to show any correlation of aß2GPI IgA aPL with clinical manifestations of APS (9).

An external quality control program illustrated that $\mathrm{aCL}$ and $\mathrm{a} \beta 2 \mathrm{GPI} \lg \mathrm{G} / \mathrm{M}$ assays produce variable results $(20,25)$. We have previously shown that even within commercially available solid-phase assays, detection of $\mathrm{aCL}$ and $\mathrm{a} \beta 2 \mathrm{GPI} \mathrm{lgG} / \mathrm{M}$ differs between platforms (21). Within our total population consisting of 1,608 patients, 19.4, $13.8,14.3$, and $12.7 \%$ patients were found to be positive for $\mathrm{aCL}$ and/or aß2GPI IgA antibodies detected with BioPlex2200, Phadia, HemosIL AcuStar and QUANTA Lite ELISA, respectively. These data indicate that the detection of $\lg A$ aPL also depends on the solid-phase assay that is used. Other studies also showed the lack of standardization in IgA aPL detecting assays (26-28). In a subpopulation from the PROMISSE cohort, a 32 GPI IgA was detected in $18.9 \%$ and $55.6 \%$ of the patients, detected with QUANTA Lite ELISA and BioPlex2200, respectively (26). Taken together, these results indicate that the detection and association of $\operatorname{lgA} \mathrm{aPL}$ is dependent on the solid-phase assay and study population.

In agreement with a previous cross-sectional study, we confirmed the association of aCL and a 32 GPI IgA with arterial and venous thrombosis (8). However, some studies found an association between $\lg \mathrm{A}$ aPL and venous thrombosis, but were unable to show an 
association with arterial thrombosis and vice versa $(17,18,29)$. In contrast, a recent study could not demonstrate an association between a $32 \mathrm{GPI} \operatorname{IgA}$ aPL and thrombosis (15). Positivity for a 32 GPI IgA aPL was found in $31 \%$ of the included APS patients (15), as well as a large portion (30\%) of SLE patients was found to be positive for aß2GPI IgA aPL (15). Upon exclusion of SLE patients, a significant association was found between a $\beta 2$ GPI IgA and venous thrombosis (OR 2.5; 95\% Cl, 1.1-4.9) (15).

In our cohort, positive aCL and/or aß2GPI IgA results were significantly associated with pregnancy morbidity, as defined in the Sydney criteria. However, the non-APS obstetric group was relatively small $(n=33)$, compared with obstetric APS patients $(n=122)$ which might have affected the association of aPL and pregnancy morbidity. Limited data are available on the association between $\operatorname{IgA}$ aPL and obstetric complications $(4,8,9,15)$. Most studies found a value for aCL or a $32 \mathrm{GPI}$ IgA testing in pregnancy morbidity $(4,8,9)$. However, a study that included 314 patients suspected from APS or related autoimmune diseases (e.g., SLE) did not found a significant association for aCL or a $32 \mathrm{GPI} \lg \mathrm{A}$ aPL with pregnancy morbidity (15). Interestingly, no association of aCL $\mathrm{lgG} / \mathrm{M}$ and $\mathrm{a} \beta 2 \mathrm{GPI} \lg \mathrm{G} / \mathrm{M}$ with pregnancy morbidity was found within the same study (15).

Pathogenicity of IgA aPL has been shown in animal models $(14,18)$. In mice, IgA antibodies from APS patients increased the mean thrombus area and mean thrombus disappearance time upon induced thrombus formation of a nonocclusive thrombus by pinch injury (14). IgA antibodies were purified from two APS patients of which one was also positive for $\mathrm{aCL} \lg G$ and $\mathrm{LAC}$. The other patient was positive for $\mathrm{aCL} \operatorname{IgA}$, but negative for $\mathrm{aCL} \operatorname{lgG}, \mathrm{aCL} \operatorname{IgM}$ and LAC (14). However, the authors did not demonstrate that $\mathrm{aCL}$ is solely responsible for the observed effect (14). Another study also showed that IgA isolated from APS patients is pathogenic as thrombus formation and tissue factor activity in mice injected with IgA from APS was increased compared with control IgA (18). However, the plasma of the mice injected with IgA from APS patients showed LAC activity (18). These data indicate that IgA aPL can be pathogenic $(14,18)$. However, pathogenic $\lg \mathrm{A}$ aPL seem to correlate with LAC.

Despite the association of $\mathrm{aCL}$ and/or a $32 \mathrm{GPI} \lg \mathrm{A}$ aPL with thrombosis shown in multiple studies, only some have suggested an added value for lgA testing in patients suspected of thrombotic APS $(6,8,10,12,18,30)$. Although an added value was suggested for so called "isolated IgA" by some studies, many studies did not include LAC testing, hampering assessment of true isolated IgA aPL $(8,12,18,30)$. In a retrospective study testing 472 patients with suspected or confirmed thrombophilia, an autoimmune disease or pregnancy morbidity (10) $\lg \mathrm{A}(\mathrm{aCL}, \mathrm{a} 32 \mathrm{GPI}$ and/or antiphosphatidylserine 
[aPS]) aPL positivity was found to be an independent risk factor for thrombosis using a multivariate analysis [10]. Detection of $\mathrm{aCL}$ and $\mathrm{aPS} \lg \mathrm{g}, \lg \mathrm{M}$, and $\lg \mathrm{A}$ antibodies were performed with another platform than detection of a $32 \mathrm{GPI} \lg G, \lg M$ and $\lg A$ antibodies (10). Considering the high variability between solid-phase platforms in antibody detection, classification of APS patients and the association of aPL might be affected. It is suggested to detect all aPL within the same system for the classification of APS patients (21). In addition, the method used to determine the cut-off value for an aPL assay has also shown to affect between-assay performance (31). Also, antibody heterogeneity has been suggested to attribute to variability in test results (32).

We defined isolated $\mathrm{aCL}$ and/or a $32 \mathrm{GPI} \lg \mathrm{A}$ positivity for $\mathrm{aCL}$ and/or a $32 \mathrm{GPI} \lg \mathrm{A}$ aPL, as negative for $\mathrm{aCL}$ and/or $\mathrm{a} \beta 2 \mathrm{GPI} \lg \mathrm{g} / \mathrm{M}$ and/or $\mathrm{LAC}$. Isolated $\lg \mathrm{A}$ positivity was rare in the total population. Overall, the prevalence of isolated $\lg A$ was comparable between patients with clinical manifestations of APS and patients without a history of thrombosis or pregnancy morbidity. Positivity for isolated IgA aPL was not associated with thrombosis or pregnancy morbidity as calculated OR did not reach statistical significance. Titers of IgA positive patients were characterized by low aCL or a $32 \mathrm{GPI} \lg \mathrm{A}$ titers, around the cut-off value. Other noncriteria aPL like anti-phosphatidylethanolamine, negatively charged phospholipids (other than cardiolipin), anti-vimentin/cardiolipin, Annexin A5, and aPST/prothrombin (PT) antibodies have been suggested to be clinical relevant in patients suspected of APS, but negatively tested for consensus aPL (33). A recent systematic review showed a strong association between aPS/PT aPL and clinical manifestations of APS, with a high association with LAC (34). However, this needs to be validated in a large multicenter study.

In this study, we aimed to investigate the value of $\mathrm{aCL}$ and $\mathrm{a} \beta 2 \mathrm{GPI} \lg \mathrm{A}$ aPL in addition to the current aPL panel (LAC, aCL IgG/M, and aß2GPI IgG/M). Positivity for $\lg A$ aPL was found to be associated with thrombosis and pregnancy morbidity. However, isolated IgA positivity was rare and not correlated with clinical manifestations of APS. Our results do not support testing for $\mathrm{aCL}$ and/or a $32 \mathrm{GPI} \operatorname{lgA}$ in addition to conventional $\mathrm{aPL}$ for the identification of patients with clinical manifestations of APS. 


\section{CONFLICT OF INTEREST}

G. W. Moore reports consultancy fees from Technoclone, outside the submitted work. W. Chayoua, D. Yin and B. de Laat are employees of Synapse Research Institute, part of Diagnostica Stago SAS. The other authors state that they have no relevant conflict of interest.

\section{ACKNOWLEDGEMENTS}

The authors thank Michael Luypaert for his technical assistance, Bio-Rad Laboratories, ThermoFisher/Phadia, Instrumentation Laboratory and Inova Diagnostics for providing the test kits for the detection of a $32 \mathrm{GPI}$ and $\mathrm{aCL} \mathrm{lgG} / \mathrm{M} / \mathrm{A}$ antibodies and Denis Wahl (Centre Hospitalier Regional Universitaire de Nancy, Nancy, France), Armando Tripodi (Angelo Bianchi Bonomi Hemophilia and Thrombosis Center, Department of Internal Medicine, Università degli Studi di Milano, Milan, Italy), Pierre Fontana (University of Geneva, Geneva, Switzerland) and Jasper Remijn (Gelre Hospitals, Apeldoorn, The Netherlands) for providing patient samples. 


\section{REFERENCES}

1. Miyakis S, Lockshin MD, Atsumi T, et al. International consensus statement on an update of the classification criteria for definite antiphospholipid syndrome (APS). J Thromb Haemost 2006; 4: 295-306.

2. Devreese KMJ, Ortel TL, Pengo V, et al. Laboratory criteria for antiphospholipid syndrome: communication from the SSC of the ISTH. J Thromb Haemost 2018; 16: 809-13.

3. Despierres L, Beziane A, Kaplanski G, et al. Contribution of anti- $\beta 2$ glycoprotein I IgA antibodies to the diagnosis of anti-phospholipid syndrome: potential interest of target domains to discriminate thrombotic and non-thrombotic patients. Rheumatology 2014; 53: 1215-8.

4. Carmo-Pereira S, Bertolaccini M, Escudero-Contreras, et al. Value of IgA anticardiolipin and anti-ß2-glycoprotein I antibody testing in patients with pregnancy morbidity. Ann Rheum Dis 2003; 62: 540-3.

5. Lakos G, Kiss E, Czy NR, et al. Isotype distribution and clinical relevance of anti-b2glycoprotein I (b2-GPI) antibodies: importance of IgA isotype. Clinical and Experimental Immunology 1999; 117: 574-9.

6. Mattia E, Ruffatti A, Tonello M, et al. IgA anticardiolipin and IgA anti- $\beta 2$ glycoprotein I antibody positivity determined by fluorescence enzyme immunoassay in primary antiphospholipid syndrome. Clin Chem Lab Med 2014; 52:1329-33

7. Mehrani T, Petri M. Association of IgA Anti-ß2 Glycoprotein I with Clinical and Laboratory Manifestations of Systemic Lupus Erythematosus. J Rheumatol 2011; 38: 64-8.

8. Ruiz-García R, Serrano M, Ángel Martínez-Flores J, et al. Isolated IgA Anti- $\beta 2$ Glycoprotein I Antibodies in Patients with Clinical Criteria for Antiphospholipid Syndrome. J Immunol Res 2014; 2014: 1-8.

9. Samarkos M, Davies KA, Gordon $C$, et al. Clinical significance of IgA anticardiolipin and anti- $\beta 2-G P 1$ antibodies in patients with systemic lupus erythematosus and primary antiphospholipid syndrome. Clinical Rheumatology 2006; 25: 199-204.

10. Shen $Y$, Lee R, Frenkel E, et al. IgA antiphospholipid antibodies are an independent risk factor for thromboses. Lupus 2008; 17: 996-1003.

11. Sweiss NJ, Bo R, Kapadia R, et al. IgA Anti- $\beta 2-$ Glycoprotein I Autoantibodies Are Associated with an Increased Risk of Thromboembolic Events in Patients with Systemic Lupus Erythematosus. PLoS ONE 2010; 5: e12280.

12. Tortosa C, Cabrera-Marante $O$, Serrano $M$, et al. Incidence of thromboembolic events in asymptomatic carriers of IgA anti 32 glycoprotein-I antibodies. PLOS ONE 2017; 12: e0178889.

13. Bertolaccini $M$, Amengual $\mathrm{O}$, Atsumi T, et al. 'Non-criteria' aPL tests: report of a task force and preconference workshop at the 13th International Congress on Antiphospholipid Antibodies, Galveston, TX, USA, April 2010. Lupus 2011; 20: 191-205. 
14. Pierangeli SS, Liu XW, Barker JH, et al. Induction of Thrombosis in a Mouse Model by lgG, $\lg \mathrm{M}$ and IgA Immunoglobulins from Patients with the Antiphospholipid Syndrome. Thromb Haemost 1995; 74: 1361-7.

15. Vlagea A, Pascual-Salcedo D, Álvarez Doforno R, et al. IgA anti- $\beta 2$ glycoprotein I antibodies: Experience from a large center. Thrombosis Research 2018; 162: 38-43.

16. Selva-O'Callaghan A, Ordi-Ros J, Monegal-Ferran F, et al. IgA anticardiolipin antibodies-relation with other antiphospholipid antibodies and clinical significance. Thromb Haemost 1998; 79: 282-5.

17. Bertolaccini $M L$, Atsumi $T$, Contreras $A E$, et al. The value of IgA antiphospholipid testing for diagnosis of antiphospholipid (Hughes) syndrome in systemic lupus erythematosus. $J$ Rheumatol 2001; 12: 2637-43.

18. Murthy V, Willis R, Romay-Penabad Z, et al. Value of Isolated IgA anti- $\beta 2$ GPI Positivity in the Diagnosis of the Antiphospholipid Syndrome. Arthritis Rheum 2013; 65: 3186-93.

19. Lopez LR, Santos ME, Espinoza LR, et al. Clinical significance of immunoglobulin A versus immunoglobulins $\mathrm{G}$ and $\mathrm{M}$ anti-cardiolipin antibodies in patients with systemic lupus erythematosus. Correlation with thrombosis, thrombocytopenia, and recurrent abortion. Am J Clin Pathol 1992; 98: 449-54.

20. Favaloro E, Wheatland L, Jovanovich S, et al. Internal Quality Control and External Quality Assurance in Testing for Antiphospholipid Antibodies: Part I-Anticardiolipin and Anti- $\beta 2$ Glycoprotein I Antibodies. Semin Thromb Hemost 2012; 38: 390-403.

21. Chayoua W, Kelchtermans H, Moore G, et al. Detection of Anti-Cardiolipin and Antiß2glycoprotein I Antibodies Differs between Platforms without Influence on Association with Clinical Symptoms. Thromb Haemost 2019; 5: 797-806.

22. Devreese KMJ. Standardization of antiphospholipid antibody assays. Where do we stand? Lupus 2012; 21: 718-21.

23. Pengo V, Tripodi A, Reber G, et al. Update of the guidelines for lupus anticoagulant detection. J Thromb Haemost 2009; 7: 1737-40.

24. Devreese KMJ, Pierangeli SS, Laat B de, et al. Testing for Antiphospholipid antibodies with Solid Phase Assays: guidance from the SSC of the ISTH. J Thromb Haemost 2014; 12: 792-5.

25. Favaloro EJ, Silvestrini R, Mohammed A. Clinical utility of anticardiolipin antibody assays: high inter-laboratory variation and limited consensus by participants of external quality assurance programs signals a cautious approach. Pathology 1999; 31: 142-7.

26. Tebo $A E$, Willis $R$, Jaskowski TD, et al. Clinical significance and correlations between anti- $\beta 2$ glycoprotein I IgA assays in antiphospholipid syndrome and/or systemic lupus erythematosus. Clin Chim Acta 2016; 460: 107-13.

27. Martínez-Flores JA, Serrano M, Alfaro J, et al. Heterogeneity between Diagnostic Tests for IgA anti-Beta2 Glycoprotein I: Explaining the Controversy in Studies of Association with Vascular Pathology. Anal Chem 2013; 85: 12093-8.

28. Pérez $D$, Martínez-Flores $J A$, Serrano $M$, et al. Evaluation of three fully automated immunoassay systems for detection of IgA anti-beta 2-glycoprotein I antibodies. INT J LAB HEMATOL 2016; 38: 560-8. 
29. Akhter E, Shums Z, Norman GL, et al. Utility of antiphosphatidylserine/prothrombin and IgA antiphospholipid assays in systemic lupus erythematosus. J Rheumatol 2013; 40: 282-6.

30. Greco TP, Amos MD, Conti-Kelly AM, et al. Testing for the antiphospholipid syndrome: importance of IgA anti-beta 2-glycoprotein I. Lupus 2000; 9: 33-41.

31. Vanoverschelde L, Kelchtermans $H$, Musial J, et al. Influence of anticardiolipin and anti- $\beta 2$ glycoprotein I antibody cutoff values on antiphospholipid syndrome classification. Res Pract Thromb Haemost 2019; 3: 515-27.

32. Devreese KMJ. Antiphospholipid antibody testing and standardization. Int J Lab Hematol 2014; 36: 352-63.

33. Pignatelli P, Ettorre E, Menichelli D, et al. Seronegative antiphospholipid syndrome: refining the value of 'non-criteria' antibodies for diagnosis and clinical management. Haematologica 2020; 105: 562-72.

34. Radin M, Foddai SG, Cecchi I, et al. Antiphosphatidylserine/Prothrombin Antibodies: An Update on Their Association with Clinical Manifestations of Antiphospholipid Syndrome. Thromb Haemost 2020; 120: 592-8. 


\section{SUPPLEMENTAL DATA}

SUPPLEMENTAL TABLE 1. Cut off values of aCL lgG/M/A and aß2GPI lgG/M/A detected with BioPlex2200, Phadia, HemosILAcuStar and QUANTA Lite ELISA

\begin{tabular}{lcccccc}
\hline & aCL IgG & $\begin{array}{c}\text { a } \mathbf{\beta 2 G P I} \\
\text { IgG }\end{array}$ & aCL IgM & $\begin{array}{c}\text { aß2GPI } \\
\text { IgM }\end{array}$ & aCL IgA & a $\mathbf{g} 2$ GPI IgA \\
\hline BioPlex2200 & 20 & 20 & 20 & 20 & 20 & 20 \\
Phadia & 10 & 10 & 10 & 10 & 20 & 10 \\
HemosIL AcuStar & 20 & 20 & 20 & 20 & 20 & 20 \\
QUANTA Lite ELISA & 20 & 20 & 20 & 20 & 20 & 20 \\
\hline
\end{tabular}

Abbreviations: aß2GPI, anti- $\beta 2$ glycoprotein l; $a C L$, anticardiolipin; AID, autoimmune diseases; $A P S$, antiphospholipid syndrome; IgA, immuno-globulin A; IgM, immunoglobulin $M$. 


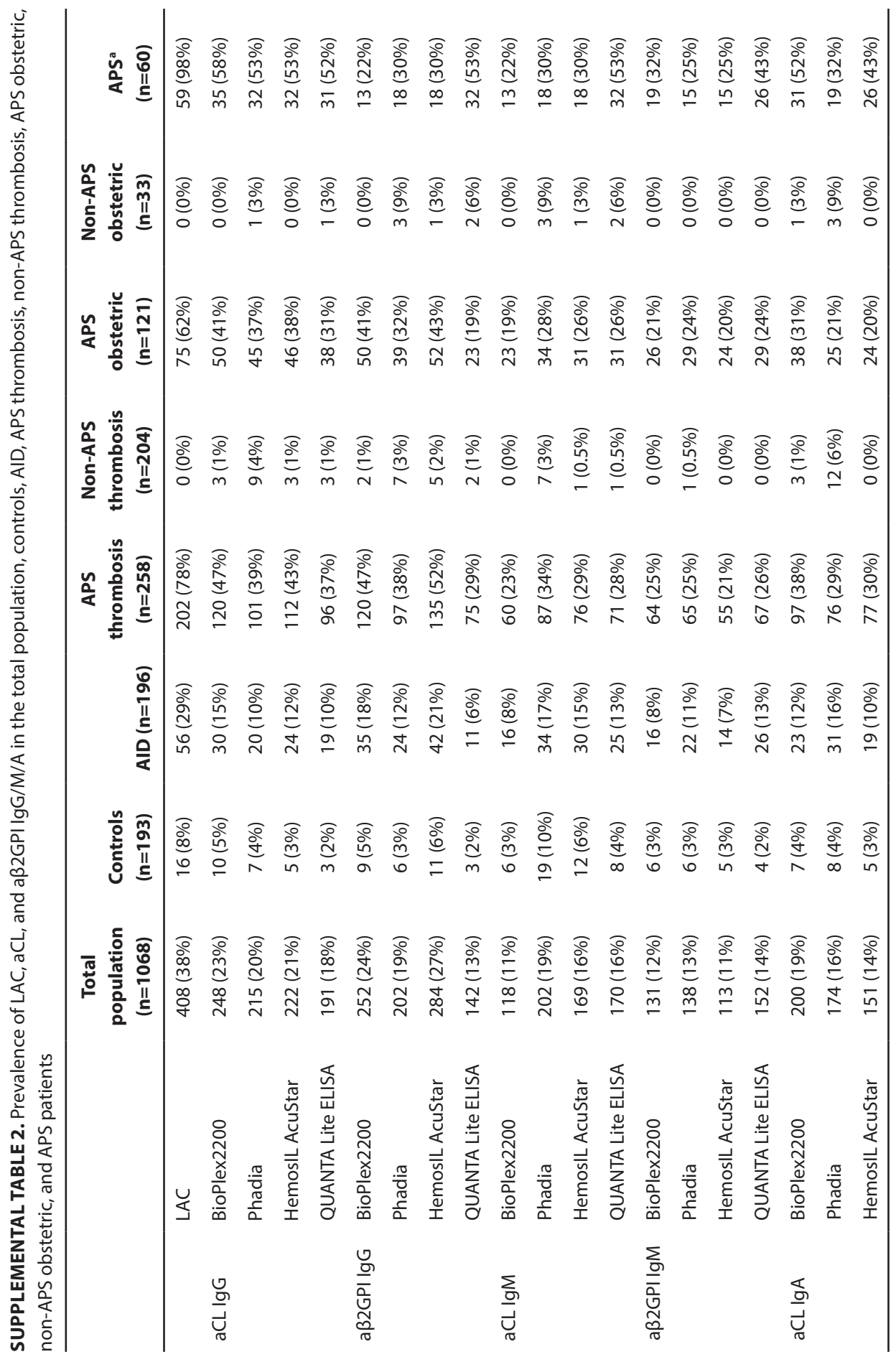




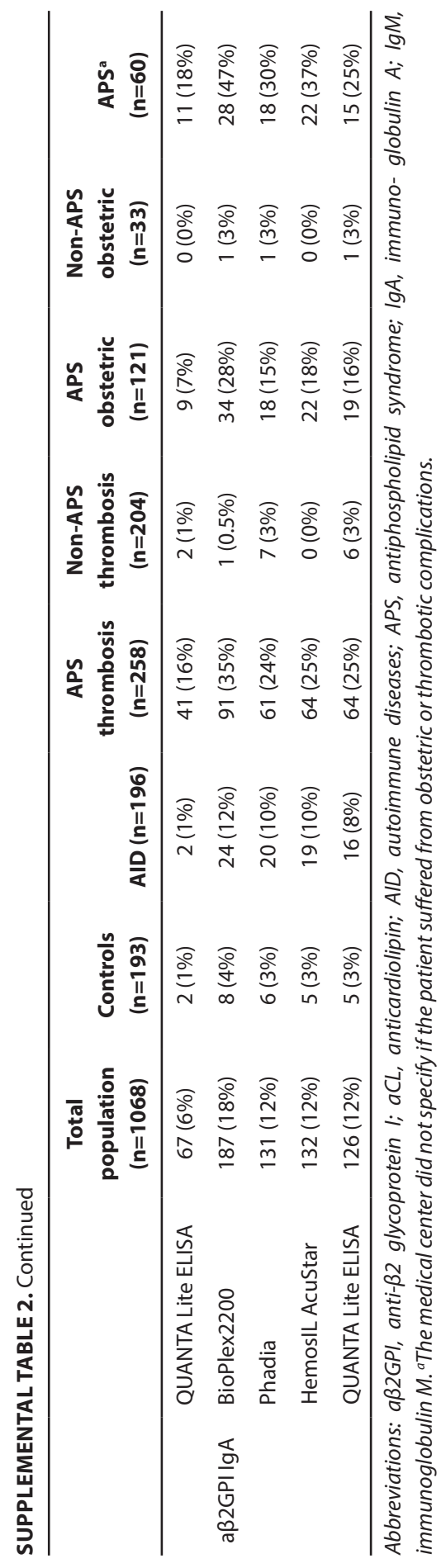


SUPPLEMENTAL TABLE 3. Thrombotic association of $\mathrm{aCL}$ and $\mathrm{a} \beta 2 \mathrm{GPI} \lg \mathrm{G} / \mathrm{M}$ antibodies

\begin{tabular}{|c|c|c|c|c|}
\hline & BioPlex2200 & Phadia & $\begin{array}{l}\text { HemosIL } \\
\text { AcuStar }\end{array}$ & $\begin{array}{c}\text { QUANTA } \\
\text { Lite ELISA }\end{array}$ \\
\hline $\mathrm{aCL} \lg \mathrm{G}$ & $3.2(2.2-4.7)$ & $4.2(2.7-6.5)$ & $4.1(2.7-6.3)$ & $4.5(2.8-7.4)$ \\
\hline $\mathrm{n}$ & 163 & 137 & 144 & 121 \\
\hline $\mathrm{a} \beta 2 \mathrm{GPI} \lg \mathrm{G}$ & $2.8(1.9-4.1)$ & $3.5(2.3-5.4)$ & $2.8(1.9-3.9)$ & $5.4(3.0-9.6)$ \\
\hline $\mathrm{n}$ & 166 & 134 & 193 & 91 \\
\hline $\mathrm{aCL}$ and $\mathrm{a} \beta 2 \mathrm{GPI} \lg \mathrm{G}$ & $3.3(2.2-5.0)$ & $4.1(2.5-6.7)$ & $4.3(2.8-6.8)$ & $5.3(2.9-9.6)$ \\
\hline $\mathrm{n}$ & 157 & 113 & 140 & 84 \\
\hline $\mathrm{aCL} \lg \mathrm{M}$ & $2.5(1.5-4.1)$ & $1.6(1.1-2.3)$ & $1.7(1.1-2.5)$ & $2.0(1.3-3.1)$ \\
\hline $\mathrm{n}$ & 82 & 147 & 119 & 105 \\
\hline $\mathrm{a} \beta 2 \mathrm{GPI} \lg M$ & $2.7(1.6-4.4)$ & $2.2(1.4-3.4)$ & $2.6(1.5-4.5)$ & $2.0(1.3-3.2)$ \\
\hline $\mathrm{n}$ & 86 & 94 & 74 & 97 \\
\hline $\mathrm{aCL}$ and $\mathrm{a} \beta 2 \mathrm{GPI} \lg \mathrm{M}$ & $2.7(1.6-4.7)$ & $2.7(1.6-4.6)$ & $2.7(1.5-4.7)$ & $2.4(1.4-4.2)$ \\
\hline $\mathrm{n}$ & 76 & 79 & 67 & 74 \\
\hline
\end{tabular}

SUPPLEMENTAL TABLE 4. Obstetric association of $\mathrm{aCL}$ and $\mathrm{a} \beta 2 \mathrm{GPI} \lg \mathrm{g} / \mathrm{M}$ antibodies

\begin{tabular}{lcccc}
\hline Pregnancy morbidity & BioPlex2200 & Phadia & $\begin{array}{c}\text { HemosIL } \\
\text { AcuStar }\end{array}$ & $\begin{array}{c}\text { QUANTA } \\
\text { Lite ELISA }\end{array}$ \\
\hline $\mathrm{aCL}$ lgG & $3.5(2.2-5.7)$ & $5.1(3.0-8.7)$ & $4.5(2.7-7.6)$ & $5.2(2.9-9.2)$ \\
$\mathrm{n}$ & 89 & 71 & 74 & 59 \\
$\mathrm{a} \beta 2 \mathrm{GPI} \mathrm{IgG}$ & $3.3(2.1-5.3)$ & $3.6(2.1-6.1)$ & $2.8(1.8-4.4)$ & $4.2(2.1-8.6)$ \\
$\mathrm{n}$ & 91 & 69 & 102 & 36 \\
$\mathrm{aCL}$ and aß2GPI IgG & $3.7(2.3-6.1)$ & $4.6(2.6-8.2)$ & $4.6(2.7-7.7)$ & $3.8(1.8-7.8)$ \\
$\mathrm{n}$ & 85 & 58 & 72 & 34 \\
$\mathrm{aCL}$ lgM & $3.0(1.6-5.7)$ & $2.0(1.2-3.3)$ & $2.0(1.2-3.4)$ & $2.9(1.7-5.0)$ \\
$\mathrm{n}$ & 41 & 81 & 69 & 61 \\
$\mathrm{a} \beta 2 \mathrm{GPI}$ lgM & $3.1(1.7-5.8)$ & $3.2(1.8-5.8)$ & $3.6(1.8-6.9)$ & $2.7(1.5-4.7)$ \\
$\mathrm{n}$ & 46 & 51 & 40 & 55 \\
$\mathrm{aCL}$ and aß2GPI IgM & $3.2(1.6-6.2)$ & $3.3(1.6-6.5)$ & $3.7(1.8-7.5)$ & $2.9(1.5-5.6)$ \\
$\mathrm{n}$ & 40 & 36 & 36 & 38 \\
\hline
\end{tabular}

Abbreviations: $a \beta 2 G P I$, anti- $\beta 2$ glycoprotein l; $a C L$, anticardiolipin; AID, autoimmune diseases; $A P S$, antiphospholipid syndrome; IgM, immunoglobulin M. Note: Odds ratios are calculated in a female subpopulation including controls, AID, non-APS obstetric, and APS obstetric patients ( $n=483$ ). 


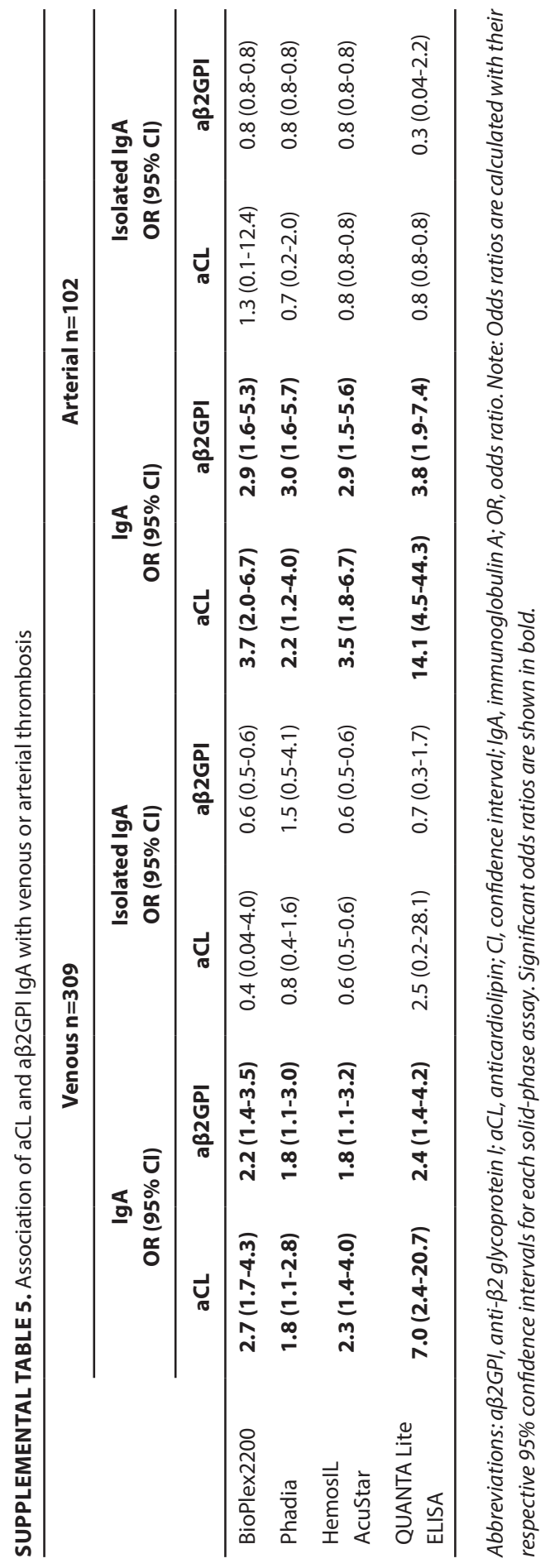




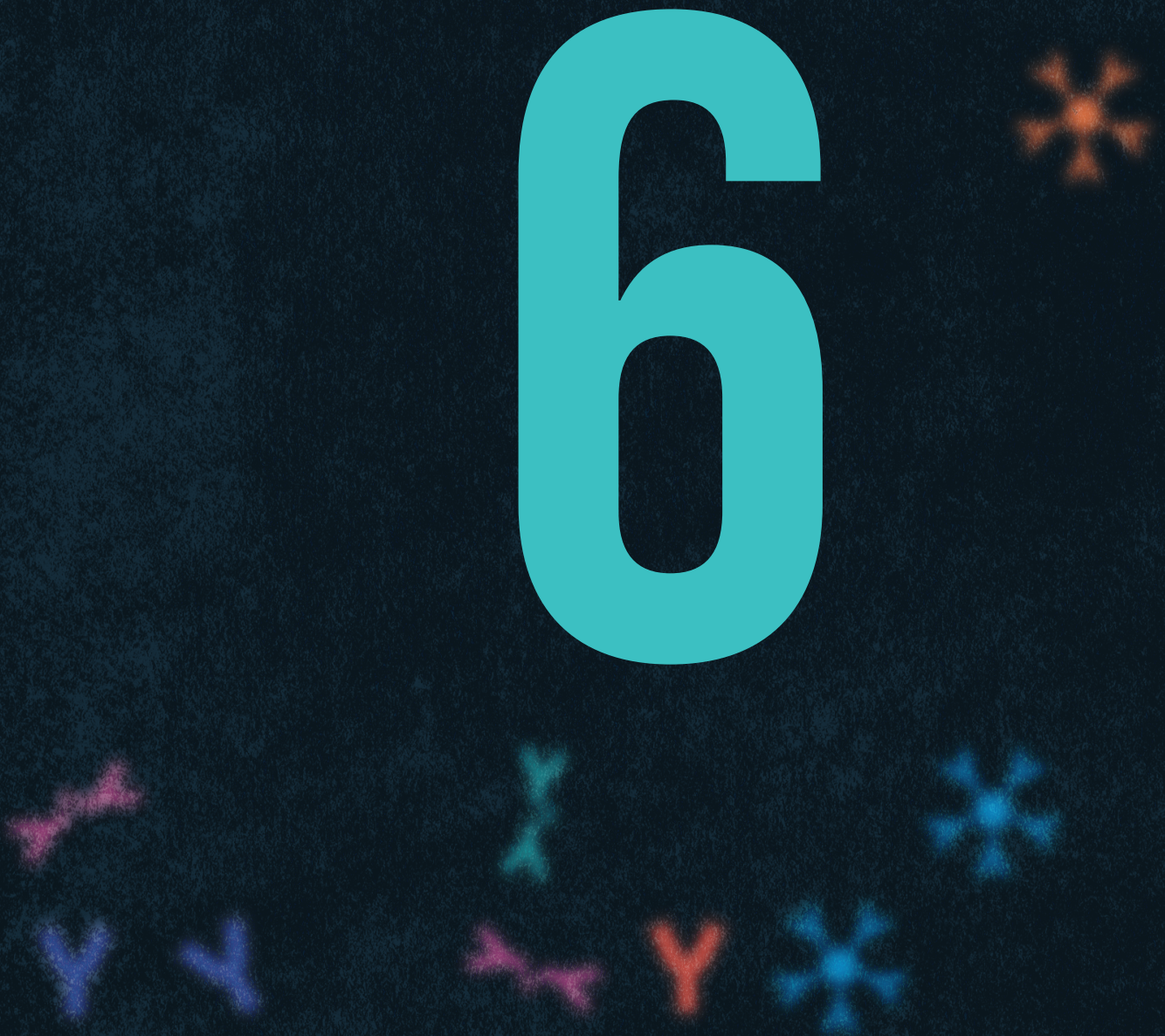

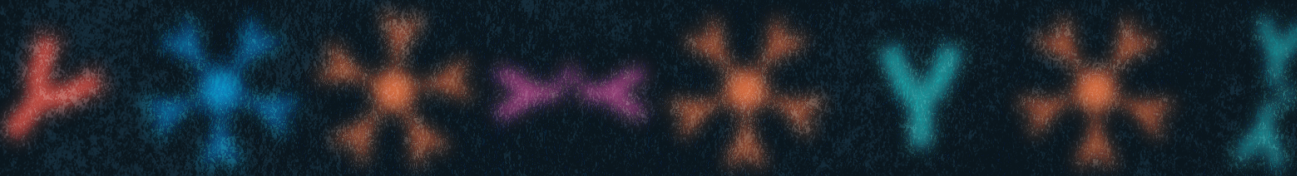
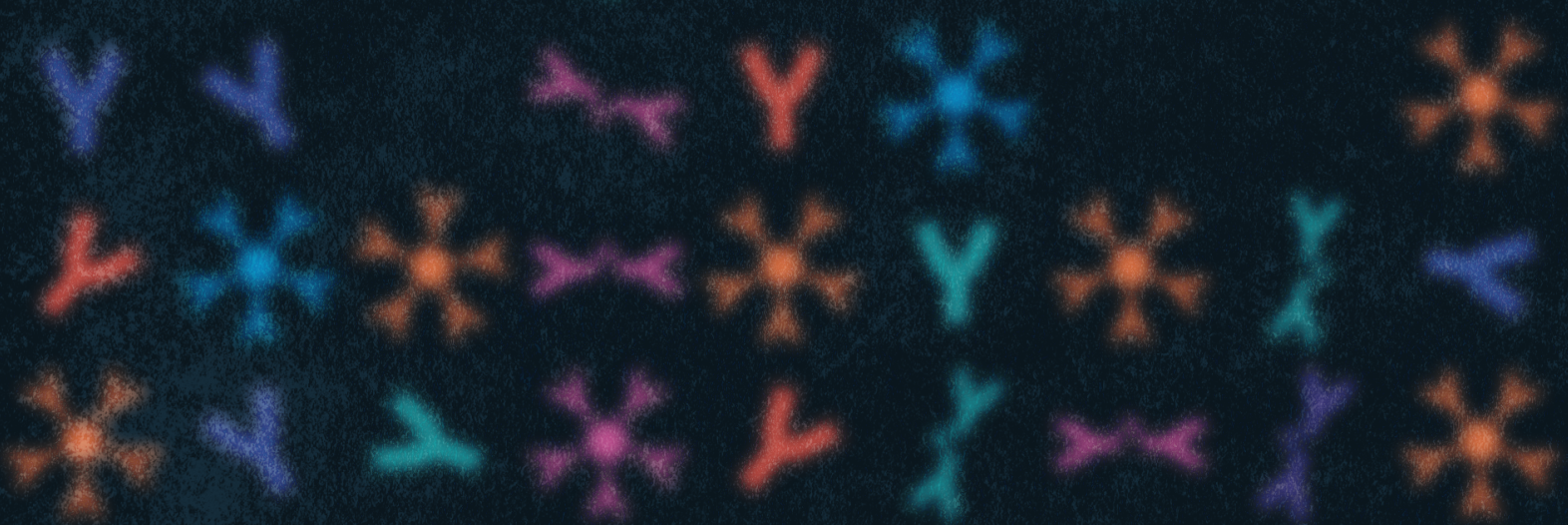


\section{The significance of antibodies against domain I of beta-2 Glycoprotein I in antiphospholipid syndrome}

Hilde Kelchtermans, Walid Chayoua, Bas de Laat

Semin Thromb Haemost. 2018; 44: 458-65 


\section{ABSTRACT}

The antiphospholipid syndrome (APS) is characterized by vascular thrombosis and/ or pregnancy morbidity with the persistent presence of antiphospholipid antibodies (aPLs). Progress is being made in understanding the pathogenesis of the syndrome, but difficulties persist in the identification of patients at risk for thrombosis and/ or pregnancy morbidity. Beta-2 glycoprotein I $\left(\beta_{2} \mathrm{GPI}\right)$, a plasma protein consisting of five sushi domains, is thought to be the main antigenic target of aPLs. Antibodies recognizing domain I of $\beta_{2}$ GPI are predominantly present in patients with an elevated risk of thrombosis, whereas antidomain IV/V antibodies are found in nonthrombotic autoimmune diseases. Indeed, domain I antibodies proved to be pathogenic in multiple studies. Retrospective studies have provided evidence for an added clinical value of antidomain I antibodies in the risk stratification of patients with APS. Still, wide ranges of odds ratio exist between studies, probably due to differences in the study and control population, and detection methods used. Despite the proven pathogenicity of antidomain I antibodies and their correlations with clinical manifestations of APS, heterogeneity of the current studies has prohibited their acceptance in the official diagnostic criteria. Well-designed large longitudinal prospective studies with available and new, preferentially functional, assays for the risk stratification of patients with APS are required. 


\section{INTRODUCTION}

Because of the high incidence of thrombosis and pregnancy morbidity independent from the antiphospholipid syndrome (APS), the diagnosis of APS predominantly relies on laboratory results. ${ }^{1-3}$ As a consequence, the quality of the assays used to detect these antibodies is of utmost importance. The Sydney update of the classification criteria for definite APS lad to a substantial improvement of the APS diagnosis, but several difficult issues remain unsolved. 4,5 Huge progress is being made in understanding the pathogenesis, but difficulties persist in the identification of patients at risk for thrombosis. In the Sydney criteria, three different types of assays to detect antiphospholipid antibodies (aPL) are included: (1) phospholipid-dependent prolongation of coagulation assays (Lupus anticoagulant[LA]); (2) detection of lgM/ IgG antibodies against beta2glycoprotein I ( $\beta_{2} \mathrm{GPI}$ ) antibodies; (3) detection of immunoglobulin $\mathrm{M}(\mathrm{lg} \mathrm{M})$ /immunoglobulin $\mathrm{G}(\mathrm{lgG})$ antibodies against cardiolipin $(\mathrm{CL}){ }^{3}$ While the role of these criteria can be debated, all assays have a place in the diagnostic work-up for APS.

Especially IgG anti-CL/anti- $\beta_{2}$ GPI antibodies have been shown to correlate with thrombosis. A prospective study confirmed that only a minority of patients with APS carry IgM anti-CL/anti- $\beta_{2}$ GPI antibodies and these patients displayed other thrombotic risk factors. ${ }^{6}$ Nonetheless, discrepancies have been found in literature concerning the role of IgM antibodies in the pathogenesis of APS. A recent review of the literature clearly found more significant correlations with thrombosis for the IgG compared with the IgM isotype, but failed to identify the added value of isolated IgM positivity due to the unavailability of paired results of IgG and IgM for each separate patient. ${ }^{7}$

Several other autoantibodies have been proposed to be involved in the pathogenesis of APS, and this review will focus on the possible added clinical value of a subset of antibodies directed against domain I of $\beta_{2}$ GPI.

\section{Discovery of domain I as an immunodominant epitope}

Upon the general acceptance that a main antigenic target of $\mathrm{aPL}$ is phospholipid-bound $\beta_{2} \mathrm{GPI}$, a $50 \mathrm{kDa}$ plasma protein composed of five short consensus repeat domains, many studies tried to identify which domains of $\beta_{2} \mathrm{GPI}$ are involved in the binding of anti- $\beta_{2}$ GPI antibodies. Although more domains of $\beta_{2}$ GPI have been indicated as the target location of anti- $\beta_{2}$ GPI antibodies, ${ }^{8-11}$ strong evidence points towards the first domain of $\beta_{2}$ GPI (domain I). ${ }^{12,13}$ By using domain-deletion mutants, Iverson et al were the first to show that anti- $\beta_{2}$ GPI antibodies recognize an epitope on domain $1 .{ }^{14}$ Later on, this finding was confirmed by others, and especially a positively charged epitope, 


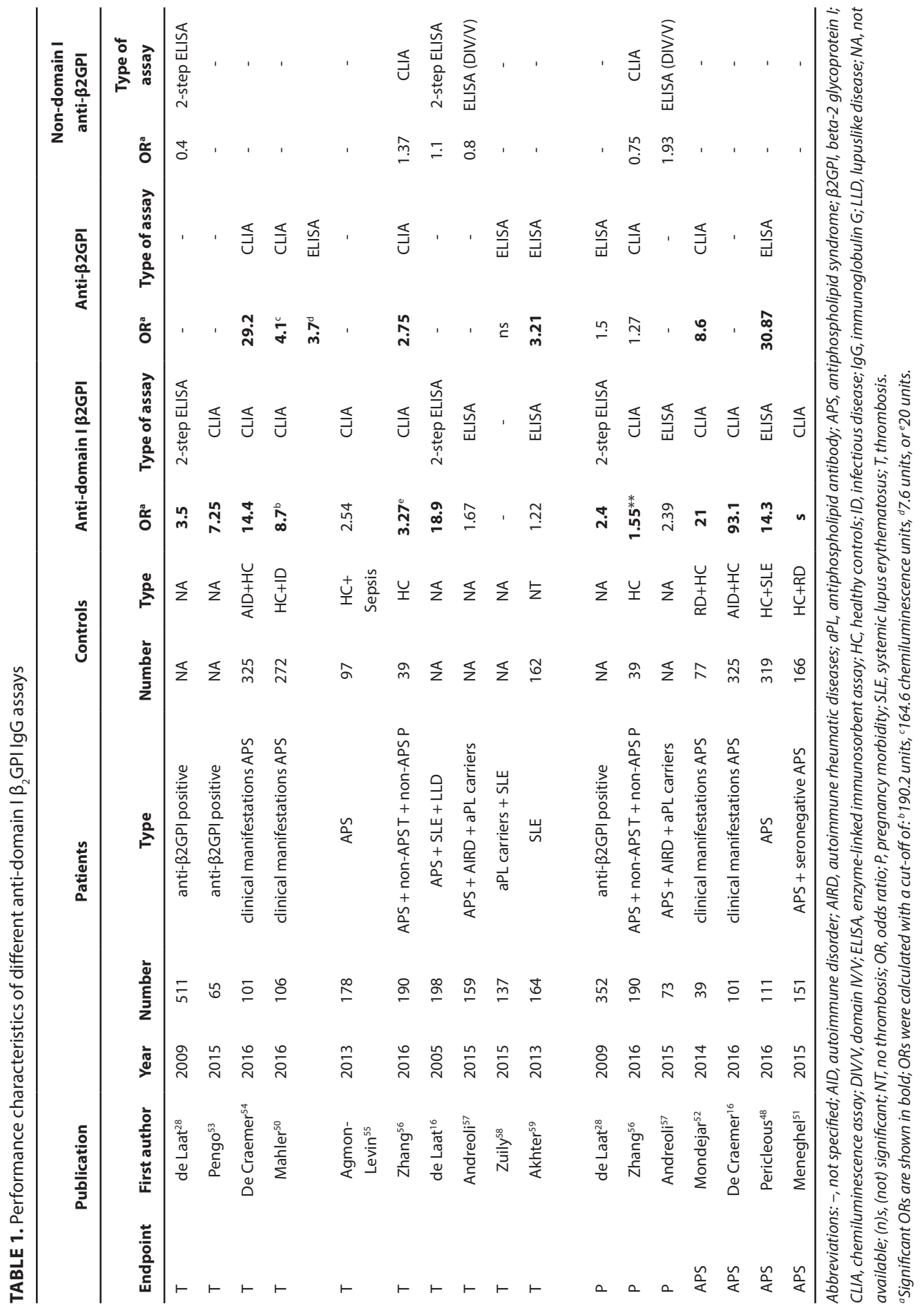


spanning amino acids 39/40-43, proved to be important in the binding of anti- $\beta_{2}$ GPI antibodies. ${ }^{15-18}$ Further research revealed a possible contribution of the domain I-II linker, suggesting that antibodies may bind to discontinuous epitopes in this area. ${ }^{19} \beta_{2} \mathrm{GPI}$ has been shown to exist in different conformations, "open" and "closed". $20,21 \beta_{2}$ GPI is present in plasma in its "closed" native conformation and interaction with anionic surfaces such as phospholipids has been found to induce an activated J-shaped conformation. This conformational change proved to be mandatory for the exposure of the pathogenic epitope G40-R43 on domain I and hence to enable anti- $\beta_{2}$ GPI antibodies to interact with the epitope. ${ }^{22,23}$ The closed and open conformations of $\beta_{2}$ GPI were suggested to resemble two different redox states of $\beta_{2} \mathrm{GPI}$, and patients with APS have a significantly elevated antigen load in the oxidized/open state. ${ }^{24}$ Interestingly, patient-derived anti$\beta_{2}$ GPI antibodies display greater avidity to oxidized versus reduced $\beta_{2}$ GPI. ${ }^{24}$

\section{Evidence for domain I pathogenicity: in vivo/in vitro}

The pathogenicity of antidomain I antibodies has been demonstrated by both in vivo and in vitro studies. In vitro, antidomain I antibodies were found to display LA activity. ${ }^{16,25}$ Furthermore, antidomain I antibodies have been shown to increase resistance against the anticoagulant properties of annexin A5 and against activated protein C. ${ }^{25-29}$ LApositive anti- $\beta_{2}$ GPI antibodies, isolated from a subset of patients with APS, were found to neutralize the inhibitory function of $\beta_{2}$ GPI on von Willebrand Factor induced platelet aggregation. ${ }^{30}$ Given the fact that antidomain I antibodies display LA activity, this effect may be mediated by antidomain I antibodies. Ninivaggi et al have postulated that antidomain I antibodies may interfere with the natural anticoagulant action of "open" $\beta_{2} G P I$, evidenced by its inhibitory effect on thrombin generation. ${ }^{31}$ Our unpublished data using antidomain I antibodies confirm this hypothesis.

A first indication of domain I pathogenicity in vivo comes from the fact that human $\beta_{2} \mathrm{GPI}$ becomes immunogenic only after incubation with apoptotic cells or phospholipids. ${ }^{32,33}$ De Laat et al confirmed the necessity of a conformational change for immunogenicity of $\beta_{2}$ GPI and demonstrated that antibodies displaying LA activity developed in mice injected with domain I but not domain II to IV. ${ }^{22}$ However, another study showed that aPLs were induced by immunization with the phospholipid binding site of $\beta_{2} \mathrm{GPI}$ (domain V), and these proved to be thrombogenic in a mouse model. ${ }^{34}$ Importantly, both affinity purified IgG antidomain I from APS serum and human monoclonal antidomain I lgG have been shown to induce thrombosis and/or fetal loss in mice APS models of venous thrombosis. ${ }^{35-37}$ Interestingly, recombinant human domain I was found to abolish antibody-induced thrombosis. ${ }^{38}$ Accordingly, antidomain I fractions from an APS patient induced a higher increase in tissue factor activity and larger thrombi 
compared with antidomain I poor fractions obtained after affinity purification. ${ }^{39}$ Given the high degree of homology between domain I and an extracellular epitope of toll-like receptor 4 (TLR4), the pathogenicity of antidomain I antibodies has been suggested to result from stimulation of the TLR4-nuclear factor (NFKB) pathway. ${ }^{40}$ In this study, antibodies directed against a cryptic epitope in domain I were found to engage TLR4 directly, in the absence of $\beta_{2} \mathrm{GPI}$, inducing a proinflammatory phenotype in monocytes and endothelial cells.

\section{Detection of domain I antibodies}

Given the cryptic nature of the domain I epitope, detection of domain I antibodies in the current available full-length anti- $\beta_{2}$ GPI assays depends highly on the availability of the epitope. As a sufficiently large fraction of $\beta_{2}$ GPI needs to be in its "open" conformation, the purification/preparation methods of $\beta_{2} \mathrm{GPI}$ and the selection of negatively charged Enzyme-Linked Immuno Sorbent Assay (ELISA) plates play an important role in the detection of antibodies against the cryptic epitope. ${ }^{15,41}$ Interestingly, by using monoclonal antibody P1-117 recognizing specifically epitope G40-R43, exposed only when $\beta_{2} \mathrm{GPI}$ is in the open conformation, versus antibody P2-6 recognizing $\beta_{2}$ GPI regardless of its conformation, we previously demonstrated clear differences in exposure of epitope G40-R43 on domain I of $\beta_{2}$ GPI in commercially available anti- $\beta_{2} \mathrm{GPI}$ IgG assays. ${ }^{42,43}$ Importantly, we found that a significant number of samples positive for domain I reactivity are falsely assigned negative in assays characterized by a decreased availability of this epitope. These findings have been extended to two automated panels for anti-CL and anti- $\beta_{2}$ GPI lgG. ${ }^{44}$ In agreement with these results, a line immunoassay was able to discriminate patients with APS from infectious patients and asymptomatic carriers, likely through the way $\beta_{2}$ GPI is oriented on the matrix, resulting in the exposure of domain I. ${ }^{45}$

Apart from these full-length $\beta_{2}$ GPI assays, specific assays for the detection of domain I antibodies have been developed. First reports on domain I reactivity were using a baculovirus system to express $\beta_{2}$ GPI that lacked one or more domains. ${ }^{14}$ Next, a two-step approach was optimized by coating domain I on both hydrophobic and hydrophilic ELISA plates. ${ }^{16}$ The ratio in optical density (OD) obtained on both plates provides an estimation of the relative amount of antibodies reactive with the cryptic epitope, as interactions between the positive charge of the epitope and the negative charge of the hydrophilic plate hamper interactions of antibodies with that epitope. Additionally, other ELISAs based on human recombinant domain I expressed in bacteria that was refolded after purification; recombinant domain I expressed in insect cells; an N-terminally biotin-(PEG) $)_{2}$ derivative of domain I and competitive inhibition 
between domain I and full-length $\beta_{2}$ GPI have been developed. ${ }^{15,46-49}$ More recently, chemiluminescence immunoassays for the detection of domain I antibodies have been described. ${ }^{50,51}$ Good correlations were demonstrated between the available methods, although small differences in specificity and sensitivity were observed. ${ }^{52,53}$

\section{Clinical significance of antidomain I positivity}

Using the different methods described previously, multiple studies have shown a significant association between the presence of antibodies against the cryptic epitope of domain I and thrombosis/APS classification (Table 1). Using an antidomain I antibody as competitor for patient antibody binding to $\beta_{2} \mathrm{GPI}$, Arvieux et al already demonstrated the presence of antidomain I antibodies in patients with APS with thrombosis, versus, probably nonpathogenic, antibodies against other domains in leprosy patients in which thrombosis is uncommon. ${ }^{60} \mathrm{In}$ a systematic review of the literature, the prevalence of antidomain I antibodies in 548 patients with APS from 11 different centers, proved to be $44 \%{ }^{61}$ In a large retrospective multicenter study on 442 anti- $\beta_{2}$ GPI-positive patients, antidomain I positivity was reported in $55 \%$ of the patients, and the presence of these antibodies associated significantly with an increased risk for thrombosis and pregnancy complications. ${ }^{28}$ The detection of antibodies against the cryptic epitope in domain I frequently proved to be superior over the detection of anti- $\beta_{2} \mathrm{GPI}$ antibodies recognizing other domains or the full-length $\beta_{2} \mathrm{GPI}$, with a higher specificity for both thrombosis and pregnancy morbidity. ${ }^{16,28,50}$ These results are in contrast with two recent studies, in which the clinical performances of anti- $\beta_{2} \mathrm{GPI}$ and antidomain I assays proved to be equal. ${ }^{54,56}$ Both studies agree that antidomain I IgG do not provide added clinical value to the current classification criteria, but disagree about the potential of antidomain I IgG as replacement of anti- $\beta_{2} \mathrm{GPI}$ assays. Other studies confirmed a correlation of antidomain I lgG antibodies and thrombosis, but failed to establish an association with pregnancy morbidity. ${ }^{48,53,56}$ In another study, measuring antidomain I antibodies yielded higher odds ratio (OR) for clinical manifestations of APS compared with anti- $\beta_{2} \mathrm{GPI}$ antibodies (21.0 versus 8.6 , respectively) and proved to be suitable to replace anti- $\beta_{2} \mathrm{GPI}$ assays in an earlier described antiphospholipid score, aPL-S. ${ }^{52,62}$

Importantly, looking at aPL profiles, patients at higher clinical risk, i.e. triple positive patients ${ }^{6}$, were shown to display higher levels of antidomain I antibodies compared with single or double positive patients. ${ }^{47,51,53,54,56,57} \mathrm{lgG}$ antidomain I antibodies were also reported in seronegative patients with APS that fulfilled clinical APS criteria, suggesting that detection of antidomain I antibodies potentially improves the classification of patients with APS. ${ }^{63,64}$ Although most studies investigating antidomain I antibodies 
detect IgG, antidomain I antibodies of all three isotypes have been shown to associate with APS with high specificity. ${ }^{48,61}$ Inconsistently, another study did not find a significant association between antidomain I lgA antibodies and thrombosis. ${ }^{66}$

Looking at the titers of antidomain I antibodies, de Craemer et al demonstrated significantly reduced levels in clinically unaffected patients. ${ }^{54}$ Antidomain I antibodies proved to be highly prevalent in patients with a history of thrombosis, whereas antibodies targeting other domains were shown in patients with and without thrombosis. Interestingly, antidomain I lgG titers proved to be stable over a 12-week period, suggesting that a single antidomain I measurement is sufficient to classify patients with APS. ${ }^{53,54}$

Of note, the reported percentage of antidomain I positivity, as well as the OR for clinical manifestations of APS varies within the different studies presented in Table 1 and this probably can be explained by several causes. First, the patient and control population varies widely in the different studies. Although at first sight the obtained ORs for the risk on thrombosis of 18.9 and 3.5 in two studies performed in our laboratory seem to be contradictory, ${ }^{16,28}$ the difference is easily explained by the starting populations, being broad (APS, systemic lupus erythematosus and lupus like disease patients) versus narrow (anti- $\beta_{2}$ GPI positive patients), respectively. Indeed, recalculating the OR for thrombosis of domain I positivity in the first study specifically for the anti- $\beta_{2}$ GPI positive patients, yields an OR of 2.8, which closely resembles the obtained OR of 3.5 in the second study. Apart from the starting population, differences in exposure of the pathogenic domain I in the domain I detection platforms may add up to the variability. ${ }^{28,42,44,53,56}$ Additionally, differences in ORs may result from the selection of cut-off values, as Zhang et al recently demonstrated an increase in OR with raising cut-off values. ${ }^{56}$ As with the assays currently included in the official APS classification criteria, antidomain I assays urgently require standardization concerning domain I production and coating, cut-off determination and inclusion of reference material. Nonetheless, most studies agree that a significant proportion of patients positive for anti- $\beta_{2} \mathrm{GPI}$ antibodies are negative for antidomain I antibodies and the existence of autoantibodies reacting with non-domain I epitopes has been demonstrated. ${ }^{53,57,66}$ As a result, to avoid false-negative results, replacement of available full-length anti- $\beta_{2}$ GPI assays with specific antidomain I assays may not be advised at this stage. Nevertheless, side by side application may improve risk stratification of clinical events.

Correlations of antidomain I antibodies with clinical symptoms apart from APS have been assessed. Mullen et al performed a prospective study with patients with transient ischemic attack (TIA), in which antidomain I antibodies could not be used as biomarkers 
of risk on stroke or death after TIA, in contrast to anti-phosphatidylserine/prothrombin (anti-PS/PT) antibodies. ${ }^{67}$ Antidomain I antibodies were observed in patients with multiple sclerosis and systemic autoimmune rheumatic disease with no clinical features of APS..$^{57,68}$ However, this may be related to the fact that MS patients display a higher risk of thrombosis compared with healthy individuals. ${ }^{69,70}$ Additionally, antidomain I antibodies have been shown to associate with non-criteria-related manifestations of APS, including livedo reticularis and heart valve disease. ${ }^{11}$

\section{Evidence for other noncriteria antibodies}

Evidence for the pathogenicity of other non-criteria antibodies is growing. Although IgG antibodies against domain IV/V from $\beta_{2}$ GPI have been shown to be increased in single positive anti- $\beta_{2}$ GPI positive patients, their presence did not correlate with thrombosis.72 Epitopes on domain IV or $\mathrm{V}$ have shown to be preferentially recognized by $\lg \mathrm{G}$ antibodies in sera from antiphospholipid-positive asymptomatic carriers, individuals with leprosy or children with atopic dermatitis. ${ }^{73,74}$ In vivo, anti- $\beta_{2}$ GPI antibodies from leprosy patients do not show thrombogenic effects in mice. ${ }^{75}$ These findings arise the possibility that antidomain IV/V antibodies are present in non-thrombotic autoimmune diseases. In the same line, Andreoli et al provided evidence that the ratio of antidomain I to antidomain IV/V antibodies can be used to determine the pathogenic potential of anti- $\beta_{2}$ GPI antibodies and discriminate between autoimmune diseases such as APS and other pathologies. ${ }^{57}$

Anti-PS/PT were suggested to be a good alternative to estimate thrombotic risk in patients where LA results are difficult to interpret due to the intake of anticoagulants. ${ }^{59}$ The clinical significance of these antibodies in APS classification is beyond the scope of this review, but has been reviewed before, ${ }^{76}$ and is the topic of another chapter in this issue of the journal. Given their association with both thrombosis and pregnancy morbidity, their presence may represent a new risk stratification tool, especially in patients negative for the traditional antibodies included in the APS criteria.

Additionally, although IgA antibodies so far have not been included in the current classification criteria, measurement of (isolated) IgA anti- $\beta_{2} \mathrm{GPI}$ antibodies, often a subclass of IgA antibodies targeting domain IV/N, previously showed to identify additional patients with clinical features of APS. ${ }^{48,59,65,77-79}$ The pathogenicity of purified IgA anti- $\beta_{2}$ GPI antibodies, reactive against domain I and IV/V, was demonstrated in a mouse model of thrombosis. ${ }^{77}$ As positivity for lgA antibodies has been shown to largely overlap with other antiphospholipid antibodies, it may be advisable to only measure IgA (particularly anti- $\beta_{2} \mathrm{GPI}$ ) in patients negative for $\mathrm{IgG} / \mathrm{lgM}$ but in whom APS is suspected. ${ }^{79,80}$ 


\section{Future perspectives}

As misdiagnosis has major implications regarding patient treatment, we believe efforts should be taken to improve existing assays for the detection of known pathogenic antibodies, including but not limited to the antidomain I antibodies. Of note, a possible threat that may delay the inclusion of assays detecting antidomain I antibodies in the classification criteria of APS is the wide availability of different assays and their lack of standardization, resulting in large inter-assay variability. Apart from the known standardization that is currently ongoing for the anti- $\beta_{2} G P I$ and anti-CL antibodies, including preparation of standards, reference material, defining international units and establishing cut-off values, additional measures may be required for the antidomain I assays. Taking into account that one of its pathogenic epitopes is cryptic and negatively charged, one can imagine the importance of strict guidelines regarding the production of domain I and the coating procedures. Of note, our antibodies P1-117 and P2-6 may be included in the different antidomain I and full-length $\beta_{2}$ GPI assays as positive controls to ensure satisfactory exposure of the cryptic epitope..$^{42,44}$

Investigation of domain I pathogenicity paved the way for novel therapeutic approaches for APS. The idea to specifically block pathogenic antidomain I antibodies without interfering with host biology seems to be interesting. The development of recombinant domain I or a variant as a potential therapeutic agent has been suggested based on its ability to inhibit pathogenic effects of antidomain I antibodies. ${ }^{38} \mathrm{~A}$ monoclonal antibody against domain I, not able to activate complement was reported as a potential therapeutic tool, in both thrombotic and obstetric complications. ${ }^{37}$ Tolerogenic dendritic cells specific for domain I but not domain $V$ resulted in an efficient reduction of the fetal loss rate in a mouse model, by induction of regulatory T cells. ${ }^{81}$

Importantly, anti- $\beta_{2}$ GPI and anti-CL antibodies, and in the same line antidomain I antibodies, are mainly measured by quantitative endpoint assays. Taking into account that not all antibodies directed against $\beta_{2}$ GPI, cardiolipin/ $\beta_{2}$ GPI and possibly even domain I are pathogenic, such non-functional assays will result in a relatively high false positivity. ${ }^{5}$ To reduce the risk of false positive results, we feel efforts should be made in the development of functional assays. In contrast with the quantitative anti- $\beta_{2} \mathrm{GPI} / \mathrm{CL}$ assays, such functional assays should only detect pathogenic antibodies, including the antidomain I antibodies, but possibly also other (non-discovered) aPL. Currently, LA is the only functional assay included in the Sydney criteria. Probably due to the fact that LA measures a functional effect of the antibodies, LA is a better predictor of thrombosis than quantitative solid-phase immunoassays. These LA tests are far from ideal since they require an adequate plasma preparation and are complicated and labor-intensive, as well as being sensitive to the presence of anticoagulants used as therapy in patients 
with APS. ${ }^{5}$ Their specificity and sensitivity proved to largely depend on the calculation of cut-off values and the choice of the reagents. The relevance of a weak-positive LA, and the influence of oral anticoagulants need to be further addressed.

Other functional assays have been developed as research tool, including $\beta_{2} \mathrm{GPI}$ dependent LAC test and thrombin generation-based assays, and proved to be promising for the diagnosis of APS. ${ }^{82,84}$ Recently, we combined both assays in one functional ellagic acid-triggered thrombin generation assay performed in the absence and presence of cardiolipin. Our assay proved to be sensitive to monoclonal anti- $\beta_{2}$ GPI antibodies and was able to discriminate between antidomain I positive patients with APS and healthy controls in a small patient cohort. Further validation of this assay in a multi-center study is required.

\section{CONCLUSION}

With the increasing evidence that not all anti- $\beta_{2}$ GPI antibodies are pathogenic, the detection of anti- $\beta_{2}$ GPI in the absence of anti-CL and LA may not be sufficient for the classification of patients with APS. For this reason, an update of the Sydney criteria focusing on aPL antibody profiles rather than single positivity seems to be a logical next step. Prospective studies on large population cohorts, including appropriate control groups, are urgently required to further evaluate the significance of both criteria and non-criteria (isolated) antibodies in the classification and risk stratification of patients with APS. To be able to compare results within different centers, a consensus has to be reached first on the standardization of the assays. As to the criteria antibodies, using the different available methodologies will allow to solidly determine the impact of the variable exposure of domain I in the currently available assays on the classification of patients with APS. Although diverse retrospective studies have provided evidence for an added clinical value of antidomain I antibodies in the risk stratification of patients with APS, large longitudinal prospective studies are lacking. In the meanwhile, the search for new, preferentially functional, assays should continue. The risk stratification potential of thrombin generation assays needs to be properly assessed. Large patient studies hopefully will lead to an update of the classification criteria for APS determined in Sydney. The accompanied reduction in the false-positive and false-negative rate and optimized risk stratification may eventually lead to an improved treatment strategy in APS. 


\section{REFERENCES}

1 Ortel TL. Antiphospholipid syndrome: laboratory testing and diagnostic strategies. Am J Hematol 2012; 87 Suppl 1: S75-81

2 Devreese KM, Pierangeli SS, de Laat B, et al. Testing for antiphospholipid antibodies with solid phase assays: guidance from the SSC of the ISTH. J Thromb Haemost 2014; 12: 792-795

3 Miyakis S, Lockshin MD, Atsumi T, et al. International consensus statement on an update of the classification criteria for definite antiphospholipid syndrome (APS). J Thromb Haemost 2006; 4: 295-306

4 Devreese KM. Antiphospholipid antibodies: evaluation of the thrombotic risk. Thromb Res 2012; 130 Suppl 1: S37-40

5 Devreese K, Hoylaerts MF. Laboratory diagnosis of the antiphospholipid syndrome: a plethora of obstacles to overcome. Eur J Haematol 2009; 83: 1-16

6 Pengo V, Ruffatti A, Legnani $C$, et al. Clinical course of high-risk patients diagnosed with antiphospholipid syndrome. J Thromb Haemost 2010; 8: 237-242

7 Kelchtermans H, Pelkmans L, de Laat B, Devreese KM. IgG/IgM antiphospholipid antibodies present in the classification criteria of the antiphospholipid syndrome: a critical review of their association with thrombosis. J Thromb Haemost 2016; 14: 1530-1548

8 Kasahara $\mathrm{H}$, Matsuura $\mathrm{E}$, Kaihara $\mathrm{K}$, et al. Antigenic structures recognized by anti-beta2glycoprotein I auto-antibodies. Int Immunol 2005; 17: 1533-1542

9 Wang MX, Kandiah DA, Ichikawa K, et al. Epitope specificity of monoclonal anti-beta 2-glycoprotein I antibodies derived from patients with the antiphospholipid syndrome. J Immunol 1995; 155: 1629-1636

10 Guerin J, Sim R, Yu BB, Ferluga J, Feighery C, Jackson J. Heterogeneous recognition of beta 2-glycoprotein I by antibodies from antiphospholipid syndrome patients. Thromb Haemost 2000; 84: 374-380

11 George J, Gilburd B, Hojnik M, et al. Target recognition of beta2-glycoprotein I (beta2GPI)dependent anticardiolipin antibodies: evidence for involvement of the fourth domain of beta2GPI in antibody binding. J Immunol 1998; 160: 3917-3923

12 Iverson GM, Victoria EJ, Cockerill KA, Linnik MD. Advances in understanding what we measure when detecting anticardiolipin autoantibodies. Clin Chim Acta 2004; 343: 37-44

13 Chighizola CB, Gerosa M, Meroni PL. New tests to detect antiphospholipid antibodies: antidomain I beta-2-glycoprotein-I antibodies. Curr Rheumatol Rep 2014; 16: 402

14 Iverson GM, Victoria EJ, Marquis DM. Anti-beta2 glycoprotein I (beta2GPI) autoantibodies recognize an epitope on the first domain of beta2GPI. Proc Natl Acad Sci U S A 1998; 95 : 15542-15546

15 Iverson GM, Reddel S, Victoria EJ, et al. Use of single point mutations in domain I of beta 2-glycoprotein I to determine fine antigenic specificity of antiphospholipid autoantibodies. J Immunol 2002; 169: 7097-7103 
16 de Laat B, Derksen RH, Urbanus RT, de Groot PG. IgG antibodies that recognize epitope Gly40-Arg43 in domain I of beta 2-glycoprotein I cause LAC, and their presence correlates strongly with thrombosis. Blood 2005; 105: 1540-1545

17 McNeeley PA, Dlott JS, Furie RA, et al. Beta2-glycoprotein I-dependent anticardiolipin antibodies preferentially bind the amino terminal domain of beta2-glycoprotein I. Thromb Haemost 2001; 86: 590-595

18 Reddel SW, Wang YX, Sheng YH, Krilis SA. Epitope studies with anti-beta 2-glycoprotein I antibodies from autoantibody and immunized sources. J Autoimmun 2000; 15: 91-96

19 Ioannou Y, Pericleous C, Giles I, Latchman DS, Isenberg DA, Rahman A. Binding of antiphospholipid antibodies to discontinuous epitopes on domain I of human beta(2)glycoprotein I: mutation studies including residues R39 to R43. Arthritis Rheum 2007; 56: 280-290

20 Agar C, van Os GM, Morgelin M, et al. Beta2-glycoprotein I can exist in 2 conformations: implications for our understanding of the antiphospholipid syndrome. Blood 2010; 116: 1336-1343

21 Hammel M, Kriechbaum M, Gries A, Kostner GM, Laggner P, Prassl R. Solution structure of human and bovine beta(2)-glycoprotein I revealed by small-angle X-ray scattering. J Mol Biol 2002; 321: 85-97

22 de Laat B, van Berkel M, Urbanus RT, et al. Immune responses against domain I of beta(2)glycoprotein I are driven by conformational changes: domain I of beta(2)-glycoprotein I harbors a cryptic immunogenic epitope. Arthritis Rheum 2011; 63: 3960-3968

23 de Laat B, Derksen RH, van Lummel M, Pennings MT, de Groot PG. Pathogenic antibeta2-glycoprotein I antibodies recognize domain I of beta2-glycoprotein I only after a conformational change. Blood 2006; 107: 1916-1924

24 Ioannou Y. The Michael Mason Prize: Pathogenic antiphospholipid antibodies, stressed out antigens and the deployment of decoys. Rheumatology (Oxford) 2012; 51: 32-36

25 de Laat B, Wu XX, van Lummel M, Derksen RH, de Groot PG, Rand JH. Correlation between antiphospholipid antibodies that recognize domain I of beta2-glycoprotein I and a reduction in the anticoagulant activity of annexin A5. Blood 2007; 109: 1490-1494

26 de Laat B, Mertens K, de Groot PG. Mechanisms of disease: antiphospholipid antibodiesfrom clinical association to pathologic mechanism. Nat Clin Pract Rheumatol 2008; 4: $192-$ 199

27 Wahezi DM, llowite NT, Wu XX, et al. Annexin A5 anticoagulant activity in children with systemic lupus erythematosus and the association with antibodies to domain I of beta2glycoprotein I. Lupus 2013; 22: 702-711

28 de Laat B, Pengo V, Pabinger I, et al. The association between circulating antibodies against domain I of beta2-glycoprotein I and thrombosis: an international multicenter study. J Thromb Haemost 2009; 7: 1767-1773

29 Hunt BJ, Wu XX, de Laat B, Arslan AA, Stuart-Smith S, Rand JH. Resistance to annexin A5 anticoagulant activity in women with histories for obstetric antiphospholipid syndrome. Am J Obstet Gynecol 2011; 205: 485 e417-423 
30 Hulstein JJ, Lenting PJ, de Laat B, Derksen RH, Fijnheer R, de Groot PG. beta2-Glycoprotein I inhibits von Willebrand factor dependent platelet adhesion and aggregation. Blood 2007; 110: 1483-1491

31 Ninivaggi $M$, Kelchtermans $H$, Lindhout T, de Laat B. Conformation of beta2glycoprotein I and its effect on coagulation. Thromb Res 2012; 130 Suppl 1: S33-36

32 Subang R, Levine JS, Janoff AS, et al. Phospholipid-bound beta 2-glycoprotein I induces the production of anti-phospholipid antibodies. J Autoimmun 2000; 15: 21-32

33 Levine JS, Subang R, Koh JS, Rauch J. Induction of anti-phospholipid autoantibodies by beta2-glycoprotein I bound to apoptotic thymocytes. J Autoimmun 1998; 11: 413-424

34 Gharavi AE, Pierangeli SS, Colden-Stanfield M, Liu XW, Espinola RG, Harris EN. GDKV-induced antiphospholipid antibodies enhance thrombosis and activate endothelial cells in vivo and in vitro. J Immunol 1999; 163: 2922-2927

35 Pierangeli SS, Liu X, Espinola R, et al. Functional analyses of patient-derived IgG monoclonal anticardiolipin antibodies using in vivo thrombosis and in vivo microcirculation models. Thromb Haemost 2000; 84: 388-395

36 Giles I, Pericleous C, Liu X, et al. Thrombin binding predicts the effects of sequence changes in a human monoclonal antiphospholipid antibody on its in vivo biologic actions. J Immunol 2009; 182: 4836-4843

37 Agostinis C, Durigutto P, Sblattero D, et al. A non-complement-fixing antibody to beta2 glycoprotein I as a novel therapy for antiphospholipid syndrome. Blood 2014; 123: 34783487

38 Ioannou Y, Romay-Penabad Z, Pericleous C, et al. In vivo inhibition of antiphospholipid antibody-induced pathogenicity utilizing the antigenic target peptide domain I of beta2glycoprotein I: proof of concept. J Thromb Haemost 2009; 7: 833-842

39 Pericleous C, Ruiz-Limon P, Romay-Penabad Z, et al. Proof-of-concept study demonstrating the pathogenicity of affinity-purified IgG antibodies directed to domain I of beta2glycoprotein I in a mouse model of anti-phospholipid antibody-induced thrombosis. Rheumatology (Oxford) 2015; 54: 722-727

40 Colasanti T, Alessandri C, Capozzi A, et al. Autoantibodies specific to a peptide of beta2glycoprotein I cross-react with TLR4, inducing a proinflammatory phenotype in endothelial cells and monocytes. Blood 2012; 120: 3360-3370

41 Iverson GM, Matsuura E, Victoria EJ, Cockerill KA, Linnik MD. The orientation of beta2GPI on the plate is important for the binding of anti-beta2GPI autoantibodies by ELISA. J Autoimmun 2002; 18: 289-297

42 Pelkmans L, Kelchtermans H, de Groot PG, et al. Variability in exposure of epitope G40-R43 of domain i in commercial anti-beta2-glycoprotein I lgG ELISAs. PLoS One 2013; 8: e71402

43 Dienava-Verdoold I, Boon-Spijker MG, de Groot PG, et al. Patient-derived monoclonal antibodies directed towards beta2 glycoprotein-1 display lupus anticoagulant activity. J Thromb Haemost 2011; 9: 738-747 
44 Devreese K, Kelchtermans H, de Laat B. Differences in sensitivity of two automated panels for anticardiolipin and andti-beta2glycoprotein I antibodies in the laboratory diagnosis of antiphospholipid syndrome due to the exposure of domain I epitope of beta2glycoprotein I on the solid phase. [Abstract] Thromb Haemost 2014; 12(S1): 55

45 Roggenbuck D, Borghi MO, Somma V, et al. Antiphospholipid antibodies detected by line immunoassay differentiate among patients with antiphospholipid syndrome, with infections and asymptomatic carriers. Arthritis Res Ther 2016; 18: 111

46 Pozzi N, Banzato A, Bettin S, Bison E, Pengo V, De Filippis V. Chemical synthesis and characterization of wild-type and biotinylated N-terminal domain 1-64 of beta2-glycoprotein I. Protein Sci 2010; 19: 1065-1078

47 Banzato A, Pozzi N, Frasson R, et al. Antibodies to Domain I of beta(2)Glycoprotein I are in close relation to patients risk categories in Antiphospholipid Syndrome (APS). Thromb Res 2011; 128: 583-586

48 Pericleous C, Ferreira I, Borghi O, et al. Measuring IgA Anti-beta2-Glycoprotein I and IgG/lgA Anti-Domain I Antibodies Adds Value to Current Serological Assays for the Antiphospholipid Syndrome. PLoS One 2016; 11: e0156407

49 Ioannou Y, Giles I, Lambrianides A, et al. A novel expression system of domain I of human beta2 glycoprotein I in Escherichia coli. BMC Biotechnol 2006; 6: 8

50 Mahler M, Albesa R, Zohoury N, et al. Autoantibodies to domain 1 of beta 2 glycoprotein I determined using a novel chemiluminescence immunoassay demonstrate association with thrombosis in patients with antiphospholipid syndrome. Lupus 2016; 25: 911-916

51 Meneghel L, Ruffatti A, Gavasso S, et al. Detection of IgG anti-Domain I beta2 Glycoprotein I antibodies by chemiluminescence immunoassay in primary antiphospholipid syndrome. Clin Chim Acta 2015; 446: 201-205

52 Mondejar R, Gonzalez-Rodriguez C, Toyos-Saenz de Miera FJ, et al. Role of antiphospholipid score and anti-beta2-glycoprotein I Domain I autoantibodies in the diagnosis of antiphospholipid syndrome. Clin Chim Acta 2014; 431: 174-178

53 Pengo V, Ruffatti A, Tonello M, et al. Antiphospholipid syndrome: antibodies to Domain 1 of beta2-glycoprotein 1 correctly classify patients at risk. J Thromb Haemost 2015; 13: 782-787

54 De Craemer AS, Musial J, Devreese KM. Role of anti-domain 1-b2 glycoprotein I antibodies in the diagnosis and risk stratification of antiphospholipid syndrome. J Thromb Haemost 2016;14(9): 1779-1787

55 Agmon-Levin N, Seguro L, Rosário C, et al. Anti-ß2GP1-Domain-1 Antibodies Are a Marker of APS Severity. [abstract]. Arthritis Rheum 2013;65(Suppl 10):1

56 Zhang S, Wu Z, Chen S, et al. Evaluation of the diagnostic potential of antibodies to beta2glycoprotein 1 domain 1 in Chinese patients with antiphospholipid syndrome. Sci Rep 2016;6:23839

57 Andreoli L, Chighizola CB, Nalli C, et al. Clinical characterization of antiphospholipid syndrome by detection of IgG antibodies against b2 -glycoprotein i domain 1 and domain 4/5: ratio of anti-domain 1 to anti-domain $4 / 5$ as a useful new biomarker for antiphospholipid syndrome. Arthritis Rheumatol 2015;67(8): 2196-2204 
58 Zuily S, de Laat B, Mohamed S, et al; TAC(I)T investigators. Validity of the global antiphospholipid syndrome score to predict thrombosis: a prospective multicentre cohort study. Rheumatology (Oxford) 2015;54(11):2071-2075

59 Akhter E, Shums Z, Norman GL, Binder W, Fang H, Petri M. Utility of antiphosphatidylserine/ prothrombin and IgA antiphospholipid assays in systemic lupus erythematosus. J Rheumatol 2013; 40(3):282-286

60 Arvieux J, Renaudineau Y, Mane I, Perraut R, Krilis SA, Youinou P. Distinguishing features of anti-beta2 glycoprotein I antibodies between patients with leprosy and the antiphospholipid syndrome. Thromb Haemost 2002;87(4):599-605

61 Rodríguez-García V, loannou Y, Fernández-Nebro A, Isenberg DA, Giles IP. Examining the prevalence of non-criteria anti-phospho- lipid antibodies in patients with anti-phospholipid syndrome: a systematic review. Rheumatology (Oxford) 2015;54(11): 2042-2050

62 Otomo K, Atsumi T, Amengual O, et al. Efficacy of the antiphospholipid score for the diagnosis of antiphospholipid syndrome and its predictive value for thrombotic events. Arthritis Rheum 2012;64(2):504-512

63 Cousins L, Pericleous C, Khamashta M, et al. Antibodies to domain I of b-2-glycoprotein I and IgA antiphospholipid antibodies in patients with 'seronegative' antiphospholipid syndrome. Ann Rheum Dis 2015;74(1):317-319

64 Mekinian A, Bourrienne MC, Carbillon L, et al. Non-conventional antiphospholipid antibodies in patients with clinical obstetrical APS: prevalence and treatment efficacy in pregnancies. Semin Arthritis Rheum 2016;46(2):232-237

65 Despierres L, Beziane A, Kaplanski G, et al. Contribution of anti-b2glycoprotein I IgA antibodies to the diagnosis of anti- phospholipid syndrome: potential interest of target domains to discriminate thrombotic and non-thrombotic patients. Rheumatology (Oxford) 2014;53(7):1215-1218

66 Artenjak A, Locatelli I, Brelih H, et al. Immunoreactivity and avidity of Ig G anti-b2-glycoprotein I antibodies from patients with autoimmune diseases to different peptide clusters of b2glycoprotein I. Immunol Res 2015;61(1-2):35-44

67 Mullen MT, Messé SR, Kasner SE, et al. Anti-phosphatidylserine- prothrombin antibodies are associated with outcome in a TIA cohort. Front Neurol 2012;3:137

68 Filippidou N, Krashias G, Pericleous C, et al. The association between IgG and IgM antibodies against cardiolipin, b2-glyco-protein I and domain I of b2-glycoprotein I with disease profile in patients with multiple sclerosis. Mol Immunol 2016;75:161-167

69 Marrie RA, Cohen J, Stuve O, et al. A systematic review of the incidence and prevalence of comorbidity in multiple sclerosis: overview. Mult Scler 2015;21(3):263-281

70 Peeters PJ, Bazelier MT, Uitdehaag BM, Leufkens HG, De Bruin ML, de Vries F. The risk of venous thromboembolism in patients with multiple sclerosis: the Clinical Practice Research Datalink. J Thromb Haemost 2014;12(4):444-451

71 Cieśla M, Wypasek E, Undas A. IgA antiphospholipid antibodies and anti-domain 1 of Beta 2 glycoprotein 1 antibodies are associated with livedo reticularis and heart valve disease in antiphospholipid syndrome. Adv Clin Exp Med 2014;23(5): 729-733 
72 Pengo V, Ruffatti A, Tonello M, et al. Antibodies to domain 4/5 (Dm4/5) of b2-glycoprotein 1 (b2GP1) in different antiphospho- lipid (aPL) antibody profiles. Thromb Res 2015;136(1):161163

73 Andreoli L, Nalli C, Motta M, et al. Anti-b2-glycoprotein I lgG antibodies from 1-year-old healthy children born to mothers with systemic autoimmune diseases preferentially target domain 4/5: might it be the reason for their 'innocent' profile? Ann Rheum Dis 2011;70(2):380-383

74 Ambrozic A, Avicin T, Ichikawa K, et al. Anti-beta(2)-glycoprotein I antibodies in children with atopic dermatitis. Int Immunol 2002; 14(7):823-830

75 Forastiero R, Martinuzzo M, de Larrañaga G, Vega-Ostertag $M$, Pierangeli S. Antib2glycoprotein I antibodies from leprosy pa- tients do not show thrombogenic effects in an in vivo animal model. J Thromb Haemost 2011;9(4):859-861

76 Sciascia S, Khamashta MA, Bertolaccini ML. New tests to detect antiphospholipid antibodies: antiprothrombin (aPT) and anti- phosphatidylserine/prothrombin (aPS/PT) antibodies. Curr Rheu- matol Rep 2014;16(5):415

77 Murthy V, Willis R, Romay-Penabad Z, et al. Value of isolated IgA anti-b2-glycoprotein I positivity in the diagnosis of the antiphospholipid syndrome. Arthritis Rheum 2013;65(12): 3186-3193

78 Andreoli L, Fredi M, Nalli C, et al. Clinical significance of IgA anti- cardiolipin and IgA antib2glycoprotein I antibodies. Curr Rheu- matol Rep 2013;15(7):343

79 Lakos G, Favaloro EJ, Harris EN, et al. International consensus guidelines on anticardiolipin and anti-b2-glycoprotein I testing: report from the 13th International Congress on Antiphospholipid Antibodies. Arthritis Rheum 2012;64(1):1-10

80 Bertolaccini ML, Amengual O, Andreoli L, et al. 14th International Congress on Antiphospholipid Antibodies Task Force. Report on antiphospholipid syndrome laboratory diagnostics and trends. Autoimmun Rev 2014;13(9):917-930

81 Zandman-Goddard G, Pierangeli SS, Gertel S, Blank M. Tolerogenic dendritic cells specific for b2-glycoprotein-I domain-I, attenuate experimental antiphospholipid syndrome. J Autoimmun 2014; 54:72-80

82 De Laat B, Derksen RH, Reber G, et al. An international multi- centre-laboratory evaluation of a new assay to detect specifically lupus anticoagulants dependent on the presence of antibeta2- glycoprotein autoantibodies. J Thromb Haemost 2011;9(1): 149-153

83 Pengo V, Biasiolo A, Pegoraro C, Iliceto S. A two-step coagulation test to identify antibetaglycoprotein I lupus anticoagulants. J Thromb Haemost 2004;2(5):702-707

84 Devreese KM. A functional coagulation test to identify anti-beta2- glycoprotein I dependent lupus anticoagulants. Thromb Res 2007; 119(6):753-759 

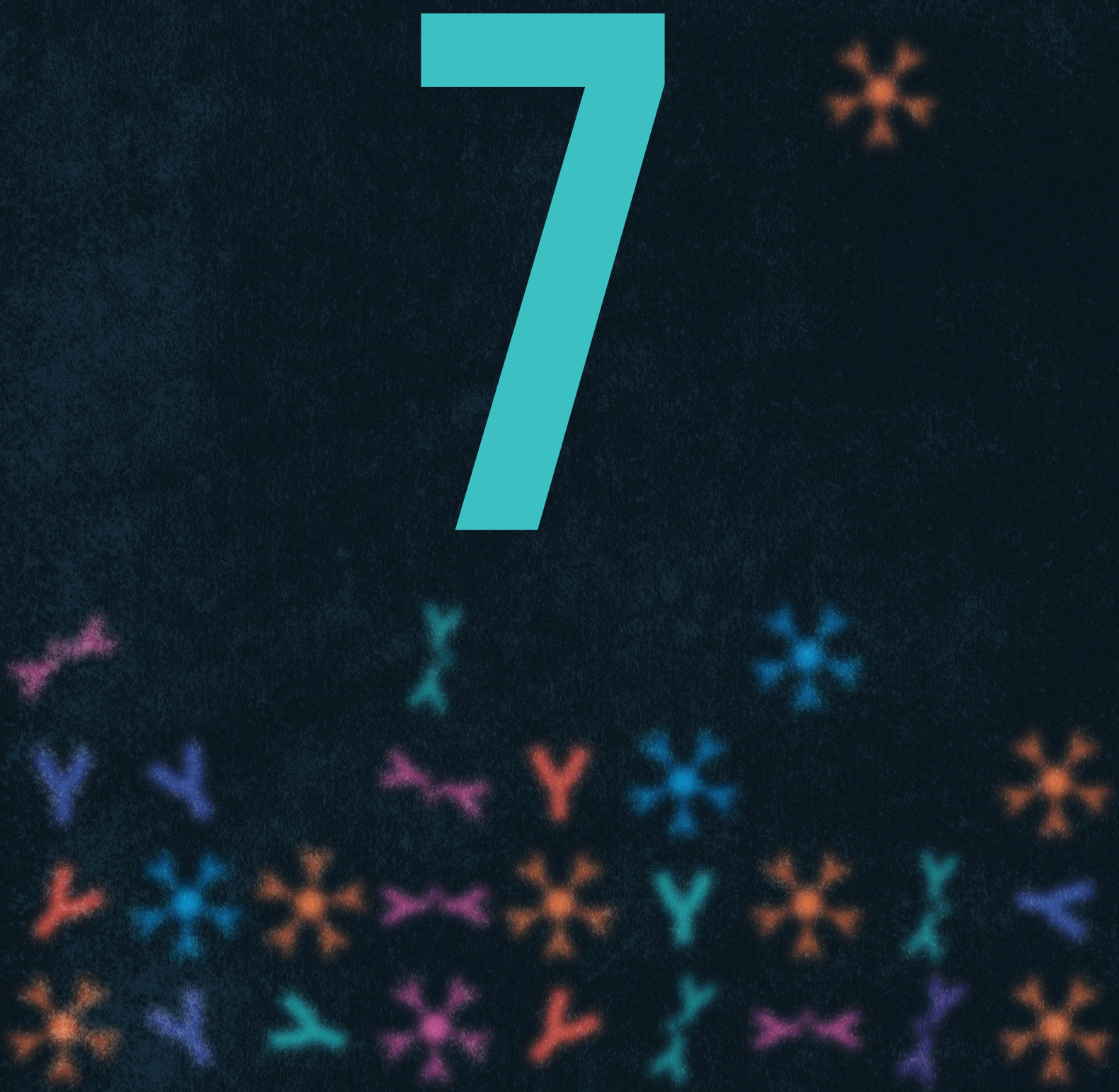

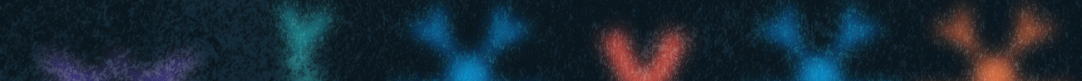




\section{Detection of anti-domain I antibodies by chemiluminescence enables the identification of high-risk antiphospholipid syndrome patients: A multicenter multiplatform study}

Dong-mei Yin, Walid Chayoua, Hilde Kelchtermans, Philip de Groot, Gary W. Moore, Jean-Christophe Gris, Stéphane Zuily, Jacek Musiał, Bas de Laat, Katrien M. J. Devreese 


\section{ABSTRACT}

Background: Classification of the antiphospholipid syndrome (APS) relies predominantly on detecting antiphospholipid antibodies (aPLs). Antibodies against a domain I (DI) epitope of anti- $\beta 2$ glycoprotein I ( $\beta 2 \mathrm{GPI}$ ) proved to be pathogenic, but are not included in the current classification criteria.

Objectives: Investigate the clinical value of detecting anti-DI lgG in APS.

Patients/Methods: From eight European centers 1005 patients were enrolled. Anticardiolipin (CL) and anti- $\beta 2$ GPI were detected by four commercially available solid phase assays; anti-DI IgG by the QUANTA Flash ${ }^{\circledR} \beta 2$ GPI domain I assay.

Results: Odds ratios (ORs) of anti-DI lgG for thrombosis and pregnancy morbidity proved to be higher than those of the conventional assays. Upon restriction to patients positive for anti- 32 GPI lgG, anti-DI IgG positivity still resulted in significant ORs. When anti-DI IgG was added to the criteria aPLs or used as a substitute for a $\beta 2 G P I$ IgG/antiCL IgG, ORs for clinical symptoms hardly improved. Upon removing anti-DI positive patients, LAC remained significantly correlated with clinical complications. Anti-DI IgG are mainly present in high-risk triple positive patients, showing higher levels. Combined anti-DI and triple positivity confers a higher risk for clinical symptoms compared to only triple positivity.

Conclusions: Detection of anti-DI IgG resulted in higher ORs for clinical manifestations than the current APS classification criteria. Regardless of the platform used to detect anti- $\beta 2$ GPI/anti-CL, addition of anti-DI lgG measured by QUANTA Flash ${ }^{\circledR}$ did not improve the clinical associations, possibly due to reduced exposure of the pathogenic epitope of DI. Our results demonstrate that anti-DI lgG potentially helps in identifying high-risk patients. 


\section{INTRODUCTION}

Antiphospholipid syndrome (APS) is a systemic autoimmune disease characterized by recurrent thrombosis and/or pregnancy morbidity in combination with the persistent presence of antiphospholipid antibodies (aPLs). ${ }^{1}$ Due to the high prevalence of thrombosis and pregnancy morbidity in the general population, classification of APS mainly relies on laboratory results. ${ }^{2}$ Five different assays that detect aPLs are included in the current revised laboratory criteria: lupus anticoagulant (LAC), detecting a phospholipid-dependent prolongation of in vitro clotting times and two immunological quantitative assays measuring immunoglobulin (Ig) $G$ and/or $\lg M$ anti-cardiolipin antibodies (anti-CL) and anti- $\beta 2$ glycoprotein I (anti- $\beta 2 \mathrm{GPI}$ ) antibodies. Positive tests should be repeated with an interval of at least 12 weeks, to avoid transient positivity due to infections. ${ }^{3}$

Although laboratory testing of aPLs is critical to the classification of APS, the application and interpretation of these tests remain challenging. ${ }^{4,5}$ The variable clinical performance in conventional commercial and home-made aPL assays not only results from the lack of standardization, ${ }^{6,7}$ but also from the heterogeneity in aPLs. ${ }^{8}$

Accumulating evidence revealed that aPLs are directed against phospholipid-bound plasma proteins, of which $\beta 2 \mathrm{GPI}$ proved to be the main target.9-11 $\beta 2 \mathrm{GPI}$ consists of five homologous domains (Domain [D]I-DV). In the native circular or S-shaped conformation, the critical DI epitope is not exposed. Upon binding to an anionic phospholipid (PL) surface through the positively charged patch on DV, $\beta 2 \mathrm{GPI}$ undergoes a conformational change. ${ }^{12}$ Consequently, the DI-IV spreads out resulting in a more open J shape, exposing a cryptic epitope G40-R43 on DI and allowing a subset of anti-DI $\beta 2 \mathrm{GPI}$ autoantibodies to bind. ${ }^{13-15}$ Various subsets of a nti- $\beta 2 \mathrm{GPI}$ antibodies targeting different domains of the protein have been described with clear differences in clinical potential. The subpopulation of aPLs that recognize this epitope comprising at least G40-R43 on DI proved to be pathogenic in vitro/in vivo, and in clinical studies, ${ }^{16-20}$ while aPLs that recognize other domains of $\beta 2 \mathrm{GPI}$ seem to be benign. ${ }^{21-24}$

The aim of this study is to assess the clinical relevance of antibodies against DI of $\beta 2 \mathrm{GPI}$ in APS patients in an international multicenter study and evaluate the added value of detecting anti-DI IgG compared to the conventional assays, as well as whether the added value of the anti-DI lgG assay measured by this QUANTA Flash ${ }^{\circledR}$ depends on the platform used to detect anti- $\beta 2 \mathrm{GPI}$ and anti-CL IgG. The commercially available chemiluminescence $(\mathrm{CIA})$ assay for anti-DI lgG was used in combination with anti$\mathrm{CL}$ and anti- $\beta 2 \mathrm{GPI}$ assays of different manufacturers. Assays were selected based on 
frequently used assays in the external quality control program of the ECAT (External quality Control of diagnostic Assays and Tests, Voorschoten, the Netherlands) and willingness of manufacturers for collaboration.

\section{METHODS}

\section{Study population}

Patient and control samples were collected from eight European medical centers. The study was approved by the local ethics committees. General characteristics (eg, age, gender, ethnicity), clinical characteristics (eg, thrombotic events with specification of the type, pregnancy morbidity, autoimmune disease), and previous laboratory determinations (eg, LAC tests, IgG/lgM anti-CL, and anti- $\beta 2$ GPI reactivity) were recorded. In total, the database enrolled 1005 samples and samples were allocated to six different groups according to the information of the centers.

The classification of APS was based on the Sydney criteria. ${ }^{3}$ Classification was determined using the local aPL assay panel for LAC and IgG/lgM anti-CL or anti- $\beta 2$ GPI antibodies. Control populations consisted of patients with an autoimmune disease other than APS (eg, systemic lupus erythematosus and systemic sclerosis), meeting the criteria for the classification of autoimmune disease without Sydney criteria thrombotic or pregnancy morbidity complications (autoimmune disease other than APS [AID] controls); patients that were referred for aPLs testing for other reasons than the clinical criteria of APS (eg, subfertility and prolonged activated partial thromboplastin time [aPTT], normal controls); patients with a previous thrombotic event negatively tested for aPLs (nonAPS thrombosis); and patients that experienced obstetric complications in the absence of aPLs (non-APS obstetric). In the normal control-female population $(n=169)$ there was no history of pregnancy morbidity. Of the 169 women 119 (70.4\%) were characterized by subfertility without previous pregnancy; of the 50 other control females information on whether they were (successfully) pregnant before was not available.

\section{Methodology}

Anti-CL IgG, anti-CL IgM, anti- $\beta 2$ GPI lgG, and anti- $\beta 2$ GPI IgM were detected by four solid phase assays: BioPlex ${ }^{\circledR} 200$ (Bio-Rad, Bio-Rad Laboratories), Phadia ${ }^{\circledR}$ (Thermo Fisher Scientific/Phadia), HemosIL AcuStar ${ }^{\circledast}$ (Instrumentation Laboratories), and QUANTA Lite $^{\circledR}$ ELISA (Inova Diagnostics). Anti-DI IgG was detected by the CIA of QUANTA Flash ${ }^{\circledR}$ $\beta 2 \mathrm{GPI}$ domain I assay (Inova Diagnostics) on the ACL AcuStar ${ }^{\circledR}$ platform. All tests were performed between February 2016 and October 2016 by a single technician in the Ghent University Hospital following the instructions of the manufacturer. Values below 
the calculated limit of detection (LOD) were replaced by the LOD. The cutoff values from the manufacturers' recommendation were confirmed in 20 healthy individuals according to the Clinical and Laboratory Standards Institute (CLSI) guidelines ${ }^{25}$ and guidance from the Scientific and Standardization Committee (SSC) of the International Society on Thrombosis (ISTH). ${ }^{5}$ Based on the cut-off values (20 arbitrary units ie $\mathrm{U} / \mathrm{mL}$, GPL, MPL, SGU, SMU on platforms of HemosIL AcuStar ${ }^{\circledR}$, BioPlex $^{\circledR} 2200$, and QUANTA Lite $^{\circledR}$ ELISA; 10 arbitrary units on Phadia ${ }^{\circledR}$ for anti-CL $\operatorname{lgG} / \lg M$ and anti- $\beta 2$ GPI $\lg G / \lg M$; 20 chemiluminescence units [CU] on QUANTA Flash ${ }^{\circledR}$ for anti-DI lgG), positive samples were identified. LAC positivity was determined by the individual center, according to the ISTH guidelines. ${ }^{7}$

\section{Statistics}

Statistical analyses were performed using IBM SPSS ${ }^{\circledR}$ Statistics 24 (IBM SPSS). To avoid a possible bias induced by the classification performed by the eight individual centers, we selected "clinically affected versus clinically not affected" as outcome variable instead of "APS versus non-APS classification." Relationships between the different laboratory assays and the clinical events (thrombosis or pregnancy morbidity) of the patients were investigated by calculating odds ratios (ORs) and 95\% confidence intervals (95\% $\mathrm{Cl}$ ) in the respective subpopulations. To determine the association with thrombosis and pregnancy morbidity, analysis was restricted to the thrombosis subpopulation (thrombotic APS, non-APS thrombosis, AID, and normal controls [ $n=851]$ ) and the pregnancy morbidity subpopulation (obstetric APS, non-APS obstetric, female AID, and female normal controls [ $n=481]$ ), respectively. Subsequently, the chi-squared test was used for the comparison of dichotomous variables, and anti-DI lgG titers were compared between groups by the Kruskal-Wallis $\mathrm{H}$ test (more than two groups) or Mann-Whitney $U$ test (two groups). Finally, the kappa agreement of anti-DI IgG and conventional aPL tests was studied via the chi-squared test, and the correlation between the titer of antiDI lgG, anti- $\beta 2$ GPI lgG, and anti-CL IgG was performed by a Spearman rank correlation test. $\mathrm{P}<.05$ (two-tailed) were considered statistically significant.

\section{RESULTS}

\section{Characteristics of the study population}

The patients' demographic data and clinical characteristics are summarized in Table 1. To evaluate associations with thrombotic events and pregnancy morbidity separately, the characteristics of two subpopulations are shown in Table 1. 
TABLE 1. Demographic and clinical characteristics of the study population

\begin{tabular}{|c|c|c|c|c|}
\hline & \multicolumn{4}{|c|}{ A. The thrombosis subpopulation $(\mathrm{N}=851$ ) } \\
\hline & Thrombotic APS & AID & Non-APS thrombosis & Normal controls \\
\hline Patients (N) & 258 & 196 & 204 & 193 \\
\hline \multicolumn{5}{|l|}{ Gender } \\
\hline Female $[\mathrm{N}(\%)]$ & $165(64.0)$ & $158(80.6)$ & $116(56.9)$ & $169(87.6)$ \\
\hline Age (Mean $\pm S D$, years) & $49.6 \pm 14.7$ & $46.4 \pm 14.2$ & $46.5 \pm 14.1$ & $39.4 \pm 11.0$ \\
\hline \multicolumn{5}{|l|}{ Clinical features [N (\%)] } \\
\hline Thrombosis & $258(100.0)$ & 0 & $204(100)$ & 0 \\
\hline AT & $54(20.9)$ & 0 & $47(23.0)$ & 0 \\
\hline VT & $160(62.0)$ & 0 & $149(73.0)$ & 0 \\
\hline $\mathrm{AT}+\mathrm{VT}$ & $26(10.1)$ & 0 & $5(2.5)$ & 0 \\
\hline Small vessel & $4(1.6)$ & 0 & $0(0)$ & 0 \\
\hline Pregnancy morbidity & $23(8.9)$ & $2(1.0)$ & 0 & 0 \\
\hline A & $6(2.3)$ & 0 & 0 & 0 \\
\hline B & $6(2.3)$ & 0 & 0 & 0 \\
\hline C & $6(2.3)$ & 0 & 0 & 0 \\
\hline NS/ non-Sydney criteria & $5(1.9)$ & $2(1.0)$ & 0 & 0 \\
\hline
\end{tabular}

B. The pregnancy morbidity subpopulation $(\mathrm{N}=481)$

\begin{tabular}{|c|c|c|c|c|}
\hline & \\
\hline & Obstetric APS & AID-female & Non-APS obstetric & $\begin{array}{c}\text { Normal controls } \\
\text { female }\end{array}$ \\
\hline Patients (N) & 121 & 158 & 33 & 169 \\
\hline Age (Mean $\pm S D$, years) & $34.3 \pm 6.6$ & $45.4 \pm 14.5$ & $32.7 \pm 5.6$ & $38.4 \pm 9.6$ \\
\hline \multicolumn{5}{|l|}{ Clinical features [N (\%)] } \\
\hline Thrombosis & $9(7.4)$ & 0 & 0 & 0 \\
\hline AT & $3(2.5)$ & 0 & 0 & 0 \\
\hline VT & $5(4.1)$ & 0 & 0 & 0 \\
\hline$A T+V T$ & $1(0.8)$ & 0 & 0 & 0 \\
\hline Small vessel & $0(0)$ & 0 & 0 & 0 \\
\hline Pregnancy morbidity & $121(100.0)$ & $2(1.3)$ & $33(100.0)$ & 0 \\
\hline A & $35(28.9)$ & 0 & $9(27.3)$ & 0 \\
\hline B & $10(8.3)$ & 0 & $4(12.1)$ & 0 \\
\hline C & $67(55.4)$ & 0 & $6(18.2)$ & 0 \\
\hline$B+C$ & $2(1.7)$ & 0 & $1(3.0)$ & 0 \\
\hline$A+C$ & $3(2.5)$ & 0 & $1(3.0)$ & 0 \\
\hline NS/non-Sydney criteria & $4(3.3)$ & $2(1.3)$ & $12(36.4)$ & 0 \\
\hline
\end{tabular}

Note: $A$, history of three or more consecutive unexplained losses $<10$ weeks gestation; $B$, history of fetal death after 10 weeks before gestation; C, history of premature birth(s) before 34 weeks due to preeclampsia or placental insufficiency based on the Sydney classification criteria. NS, non-specified pregnancy complications; non-Sydney criteria, not fulfilling Sydney criteria for pregnancy morbidity. Abbreviations: AID, autoimmune disease other than APS; APS, antiphospholipid syndrome; AT, arterial thrombosis; $N$, number of patients; $S D$, standard deviation; VT, venous thrombosis. 


\section{Association between anti-DI IgG and clinical symptoms of APS}

Independent of the platform, a significant association with clinical events was found for all tested aPL assays, with ORs varying from 2.7 (95\% Cl 1.9-3.9) to $5.4(95 \% \mathrm{Cl} 3.0-$ 9.6) for thrombosis, $2.3(95 \% \mathrm{Cl} 1.5-3.3)$ to 4.1 (95\% Cl 2.5-6.6) for arterial thrombosis, $2.0(95 \% \mathrm{Cl} 1.4-2.8)$ to $2.8(95 \% \mathrm{Cl} 1.9-4.2)$ for venous thrombosis, and $2.7(95 \% \mathrm{Cl} 1.7-$ 4.3) to $5.6(95 \% \mathrm{Cl} 3.1-9.9)$ for pregnancy morbidity (Table 2A). Compared to the criteria aPL assays, detection of anti-DI IgG was less sensitive (21.9\%/26.6\% for thrombosis/ pregnancy morbidity), but more specific (94.9\%/93.9\% for thrombosis/pregnancy morbidity), overall resulting in higher ORs for both clinical criteria of APS compared to LAC, anti- $\beta 2 \mathrm{GPI}$, or anti-CL IgG except for the QUANTA Lite ${ }^{\oplus}$ ELISA platform. Similar ORs of anti-DI were found for thrombosis and pregnancy morbidity, and no difference in association was observed between venous versus arterial thrombosis. Interestingly, upon restriction to patients positive for anti- $\beta 2 \mathrm{GPI} \lg \mathrm{G}$, anti-DI IgG positivity still resulted in significant-albeit lower-ORs for both clinical criteria of APS except for the QUANTA Lite ${ }^{\circledR}$ ELISA platform (Table 2B).

\section{Additional clinical value of detecting anti-DI IgG on top of the currently used laboratory tests}

Table 3 shows the number of patients testing positive or negative for anti-DI IgG in relation to positivity for LAC or anti- $\beta 2 \mathrm{GPI} \lg$ G or at least one of the criteria aPL panel measured by HemosIL AcuStar ${ }^{\circledast}$ considering the previously defined subpopulations. The results of the other three solid phase assays can be found in Table S1 in supporting information.

From Table 3, looking at the thrombosis subpopulation, 13 out of the 19 LAC negative anti-DI positive patients had thrombosis. Additionally, the four samples testing negative for anti- $\beta 2$ GPI IgG by HemosIL AcuStar ${ }^{\circledR}$ but positive for anti-DI IgG all had thrombosis. Similarly, the two individuals testing negative for the criteria aPL panel by HemosIL AcuStar $^{\circledast}$ and positive for anti-DI lgG both suffered from thrombosis. Concerning the pregnancy morbidity subpopulation, 12 out of the 18 LAC negative anti-DI lgG positive patients experienced pregnancy morbidity. One patient testing negative for anti$\beta 2$ GPI lgG by HemosIL AcuStar ${ }^{\circledast}$ and positive for anti-DI lgG had pregnancy morbidity. Moreover, only one individual negative for the criteria aPL panel by HemosIL AcuStar ${ }^{\oplus}$ tested positive for anti-DI IgG and suffered from pregnancy morbidity. Looking at Table $\mathrm{S} 1$, both for the thrombosis subpopulation or the pregnancy morbidity subpopulation, similar results were found when anti- $\beta 2 \mathrm{GPI}$ or anti-CL $\operatorname{lgG} / \mathrm{lgM}$ were detected by BioPlex ${ }^{\oplus} 2200$ although more samples tested negative for anti- $\beta 2$ GPI IgG by Phadia ${ }^{\circledR}$ 
TABLE 2. Additional diagnostic value of $\mathrm{aCL}$ and $\mathrm{a} \beta 2 \mathrm{GPI} \lg \mathrm{A}$ antibodies. Figures indicate the number of patients testing positive

A. In the total population

\begin{tabular}{|c|c|c|c|c|c|c|c|c|c|}
\hline & \multirow[b]{2}{*}{ Manufacturer } & \multicolumn{5}{|c|}{ Thrombosis ${ }^{\mathrm{a}}$} & \multicolumn{3}{|c|}{ Arterial thrombosis $^{\mathrm{a}, \mathrm{d}}$} \\
\hline & & $\mathbf{N}$ & $\begin{array}{l}\text { Sensitivity } \\
\text { (\%) }\end{array}$ & $\begin{array}{l}\text { Specificity } \\
\text { (\%) }\end{array}$ & OR & $95 \% \mathrm{Cl}$ & $\mathrm{N} \#$ & $\begin{array}{l}\text { Sensitivity } \\
(\%)\end{array}$ & $\begin{array}{l}\text { Specificity } \\
(\%)\end{array}$ \\
\hline LAC & & 851 & 43.7 & 81.5 & 3.4 & 2.5-4.7 & 834 & 47.0 & 71.8 \\
\hline \multirow{4}{*}{$\begin{array}{l}\text { Anti-CL } \\
\lg G\end{array}$} & HemosIL AcuStar ${ }^{\oplus}$ & 851 & 24.7 & 92.5 & 4.1 & $2.6-6.3$ & 834 & 31.8 & 86.2 \\
\hline & BioPlex $^{\circledast} 2200$ & 851 & 26.4 & 89.7 & 3.1 & $2.1-4.6$ & 834 & 34.1 & 83.9 \\
\hline & Phadia $^{\oplus}$ & 851 & 23.6 & 93.1 & 4.1 & $2.7-6.5$ & 834 & 31.1 & 87.2 \\
\hline & QUANTA Lite ELISA ${ }^{\oplus}$ & 851 & 21.4 & 94.3 & 4.6 & 2.8-7.4 & 834 & 28.8 & 88.6 \\
\hline \multirow{4}{*}{$\begin{array}{l}\text { Anti- } \\
\beta 2 G P I \\
\text { lgG }\end{array}$} & HemosIL AcuStar ${ }^{\circledast}$ & 851 & 30.1 & 86.4 & 2.7 & 1.9-3.9 & 834 & 36.4 & 80.2 \\
\hline & BioPlex $^{\oplus} 2200$ & 851 & 26.2 & 88.7 & 2.8 & $1.9-4.1$ & 834 & 34.1 & 83.5 \\
\hline & Phadia $^{\circledR}$ & 851 & 22.5 & 92.3 & 3.5 & $2.6-5.4$ & 834 & 29.5 & 87.0 \\
\hline & QUANTA Lite ELISA ${ }^{\oplus}$ & 851 & 16.7 & 96.4 & 5.4 & $3.0-9.6$ & 834 & 25.8 & 92.2 \\
\hline $\begin{array}{l}\text { Anti-DI } \\
\lg G\end{array}$ & QUANTA Flash $^{\circledR}$ & 851 & 21.9 & 94.9 & 5.2 & 3.1-8.5 & 834 & 27.3 & 88.5 \\
\hline \multirow{4}{*}{$\begin{array}{l}\text { Triple } \\
\text { positivity }\end{array}$} & HemosIL AcuStar ${ }^{\oplus}$ & 851 & 24.0 & 94.1 & 5.0 & 3.1-8.1 & 834 & 28.8 & 87.2 \\
\hline & BioPlex ${ }^{\oplus} 2200$ & 851 & 25.5 & 92.8 & 4.4 & 2.9-6.9 & 834 & 31.1 & 86.2 \\
\hline & Phadia $^{\oplus}$ & 851 & 21.9 & 93.8 & 4.3 & $2.7-6.8$ & 834 & 26.5 & 88.0 \\
\hline & QUANTA Lite ELISA ${ }^{\oplus}$ & 851 & 19.3 & 95.6 & 5.2 & $3.0-8.9$ & 834 & 24.2 & 90.3 \\
\hline \multirow{4}{*}{$\begin{array}{l}\text { Anti-DI } \\
\text { IgG plus } \\
\text { triple } \\
\text { positivity }\end{array}$} & HemosIL AcuStar ${ }^{\oplus}$ & 851 & 18.8 & 96.7 & 6.7 & $3.7-12.2$ & 834 & 24.2 & 90.9 \\
\hline & BioPlex ${ }^{\circledast} 2200$ & 851 & 19.0 & 96.7 & 6.8 & $3.7-12.4$ & 834 & 24.2 & 90.7 \\
\hline & Phadia ${ }^{\circledast}$ & 851 & 16.9 & 96.9 & 6.4 & 3.4-11.9 & 834 & 22.0 & 91.9 \\
\hline & QUANTA Lite ELISA ${ }^{\oplus}$ & 851 & 15.6 & 97.4 & 7.0 & $3.6-13.8$ & 834 & 21.2 & 92.7 \\
\hline \multicolumn{10}{|c|}{ B. ORs of anti-DI IgG QUANTA Lite ELISA ${ }^{\oplus}$ for the indicated clinical manifestation of APS in anti- $\beta 2$ GPI IgG positive individual } \\
\hline & & \multicolumn{5}{|c|}{ Thrombosis $^{\mathbf{a}}$} & \multicolumn{3}{|c|}{ Pregnancy complications ${ }^{b}$} \\
\hline & $\begin{array}{l}\text { Manufacturer } \\
\text { for anti- } \beta 2 \mathrm{GPI}\end{array}$ & $\mathbf{N}$ & $\begin{array}{l}\text { Sensitivity } \\
\text { (\%) }\end{array}$ & $\begin{array}{l}\text { Specificity } \\
\text { (\%) }\end{array}$ & OR & $95 \% \mathrm{Cl}$ & $\mathbf{N}$ & $\begin{array}{l}\text { Sensitivity } \\
(\%)\end{array}$ & $\begin{array}{l}\text { Specificity } \\
(\%)\end{array}$ \\
\hline \multirow{4}{*}{$\begin{array}{l}\text { anti-DI } \\
\lg G\end{array}$} & HemosIL AcuStar ${ }^{\oplus}$ & 192 & 69.8 & 62.3 & 3.8 & $2.0-7.4$ & 101 & 78.4 & 60.0 \\
\hline & BioPlex $^{\circledast} 2200$ & 165 & 79.3 & 54.5 & 4.6 & $2.2-9.6$ & 90 & 81.6 & 51.2 \\
\hline & Phadia $^{\oplus}$ & 134 & 82.7 & 40.0 & 3.2 & $1.3-7.8$ & 68 & 87.2 & 37.9 \\
\hline & QUANTA Lite ELISA ${ }^{\oplus}$ & 91 & 89.6 & 14.3 & 1.4 & $0.3-7.6$ & 35 & 95.5 & 7.7 \\
\hline
\end{tabular}

Note: Significant ORs are shown in bold and calculated according to the outcome variable "clinically affected versus clinically not-

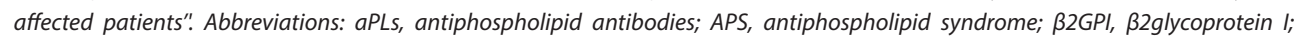
$C L$, cardiolipin; DI, domain I; IgG, immunoglobulin G; LAC, lupus anticoagulant; N, number of patients; OR, odds ratio; $95 \% C l, 95 \%$ confidence interval; Triple positivity, LAC positive, anti-CL IgG/lgM positive and anti- $\beta 2 G P I$ lgG/lgM positive. ${ }^{a} T h r o m b o t i c ~ A P S+n o n-$ APS thrombosis versus non-thrombotic population (AID + normal controls). ${ }^{b} O b s t e t r i c ~ A P S+$ non-APS obstetric versus non-obstetric population (AID-female + normal controls-female). In the thrombosis subpopulation, 17 individuals without specified thrombosis

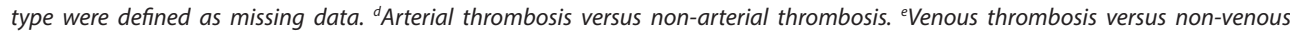
thrombosis. 
or negative for LAC, aCL and aß2GPI IgG/M antibodies versus aCL and aß2GPI IgA, for each solid-phase assay.

ride

\begin{tabular}{|c|c|c|c|c|c|c|c|c|c|c|c|}
\hline \multirow[b]{2}{*}{ OR } & \multirow[b]{2}{*}{$95 \% \mathrm{Cl}$} & \multicolumn{5}{|c|}{ Venous thrombosis ${ }^{\mathrm{a}, \mathrm{e}}$} & \multicolumn{5}{|c|}{ Pregnancy complications ${ }^{b}$} \\
\hline & & $\mathbf{N} \#$ & $\begin{array}{l}\text { Sensitivity } \\
(\%)\end{array}$ & $\begin{array}{l}\text { Specificity } \\
(\%)\end{array}$ & OR & $95 \% \mathrm{Cl}$ & $\mathbf{N}$ & $\begin{array}{l}\text { Sensitivity } \\
(\%)\end{array}$ & $\begin{array}{l}\text { Specificity } \\
(\%)\end{array}$ & OR & $95 \% \mathrm{Cl}$ \\
\hline 2.3 & $1.5-3.3$ & 834 & 43.2 & 77.1 & 2.6 & $1.9-3.5$ & 481 & 48.7 & 81.7 & 4.2 & $2.8-6.4$ \\
\hline 2.9 & $1.9-4.4$ & 834 & 24.4 & 88.7 & 2.5 & 1.7-3.7 & 481 & 29.2 & 91.4 & 4.4 & $2.6-7.4$ \\
\hline 2.7 & $1.8-4.1$ & 834 & 25.9 & 85.8 & 2.1 & $1.5-3.0$ & 481 & 31.8 & 88.1 & 3.4 & $2.1-5.5$ \\
\hline 3.1 & 2.0-4.7 & 834 & 22.6 & 89.1 & 2.4 & $1.6-3.5$ & 481 & 29.2 & 92.4 & 5.0 & $2.9-8.5$ \\
\hline 3.1 & $2.0-4.9$ & 834 & 20.9 & 90.5 & 2.5 & 1.7-3.7 & 481 & 24.7 & 93.9 & 5.0 & $2.8-9.0$ \\
\hline 2.3 & $1.6-3.5$ & 834 & 30.0 & 82.8 & 2.1 & $1.5-2.9$ & 481 & 33.1 & 84.7 & 2.7 & $1.7-4.3$ \\
\hline 2.6 & 1.7-3.9 & 834 & 25.6 & 85.0 & 2.0 & $1.4-2.8$ & 481 & 31.8 & 87.5 & 3.3 & $2.0-5.2$ \\
\hline 2.8 & $1.8-4.3$ & 834 & 21.8 & 88.7 & 2.2 & $1.5-3.2$ & 481 & 25.3 & 91.1 & 3.5 & 2.1-5.9 \\
\hline 4.1 & $2.5-6.6$ & 834 & 15.3 & 92.5 & 2.2 & $1.4-3.5$ & 481 & 14.3 & 96.0 & 4.0 & $2.0-8.2$ \\
\hline 2.9 & $1.8-4.5$ & 834 & 21.5 & 91.1 & 2.8 & $1.9-4.2$ & 481 & 26.6 & 93.9 & 5.6 & 3.1-9.9 \\
\hline 2.7 & $1.8-4.3$ & 834 & 24.1 & 90.7 & 3.1 & 2.1-4.6 & 481 & 22.1 & 93.3 & 3.9 & $2.2-7.0$ \\
\hline 2.8 & $1.8-4.3$ & 834 & 24.7 & 89.1 & 2.7 & 1.8-3.9 & 481 & 22.7 & 91.7 & 3.3 & $1.9-5.6$ \\
\hline 2.7 & $1.7-4.2$ & 834 & 21.5 & 90.7 & 2.7 & $1.8-4.0$ & 481 & 19.5 & 93.6 & 3.5 & $1.9-6.4$ \\
\hline 3.0 & $1.9-4.8$ & 834 & 18.5 & 92.5 & 2.8 & $1.8-4.3$ & 481 & 13.0 & 95.1 & 2.9 & $1.5-5.8$ \\
\hline 3.2 & $2.0-5.1$ & 834 & 18.2 & 93.1 & 3.0 & $1.9-4.7$ & 481 & 18.8 & 96.0 & 5.6 & 2.8-11.1 \\
\hline 3.1 & $2.0-5.0$ & 834 & 18.5 & 93.1 & 3.1 & $2.0-4.8$ & 481 & 18.8 & 96.0 & 5.6 & 2.8-11.1 \\
\hline 3.2 & 1.9-5.2 & 834 & 16.2 & 93.7 & 2.9 & $1.8-4.6$ & 481 & 16.2 & 96.3 & 5.1 & $2.5-10.4$ \\
\hline 3.4 & $2.1-5.7$ & 834 & 14.7 & 94.1 & 2.8 & $1.7-4.5$ & 481 & 12.3 & 96.9 & 4.5 & $2.0-9.8$ \\
\hline OR & $95 \% \mathrm{Cl}$ & & & & & & & & & & \\
\hline 5.5 & $2.3-13.1$ & & & & & & & & & & \\
\hline 4.7 & $1.8-12.0$ & & & & & & & & & & \\
\hline 4.2 & $1.3-13.8$ & & & & & & & & & & \\
\hline 1.8 & $0.1-30.6$ & & & & & & & & & & \\
\hline
\end{tabular}




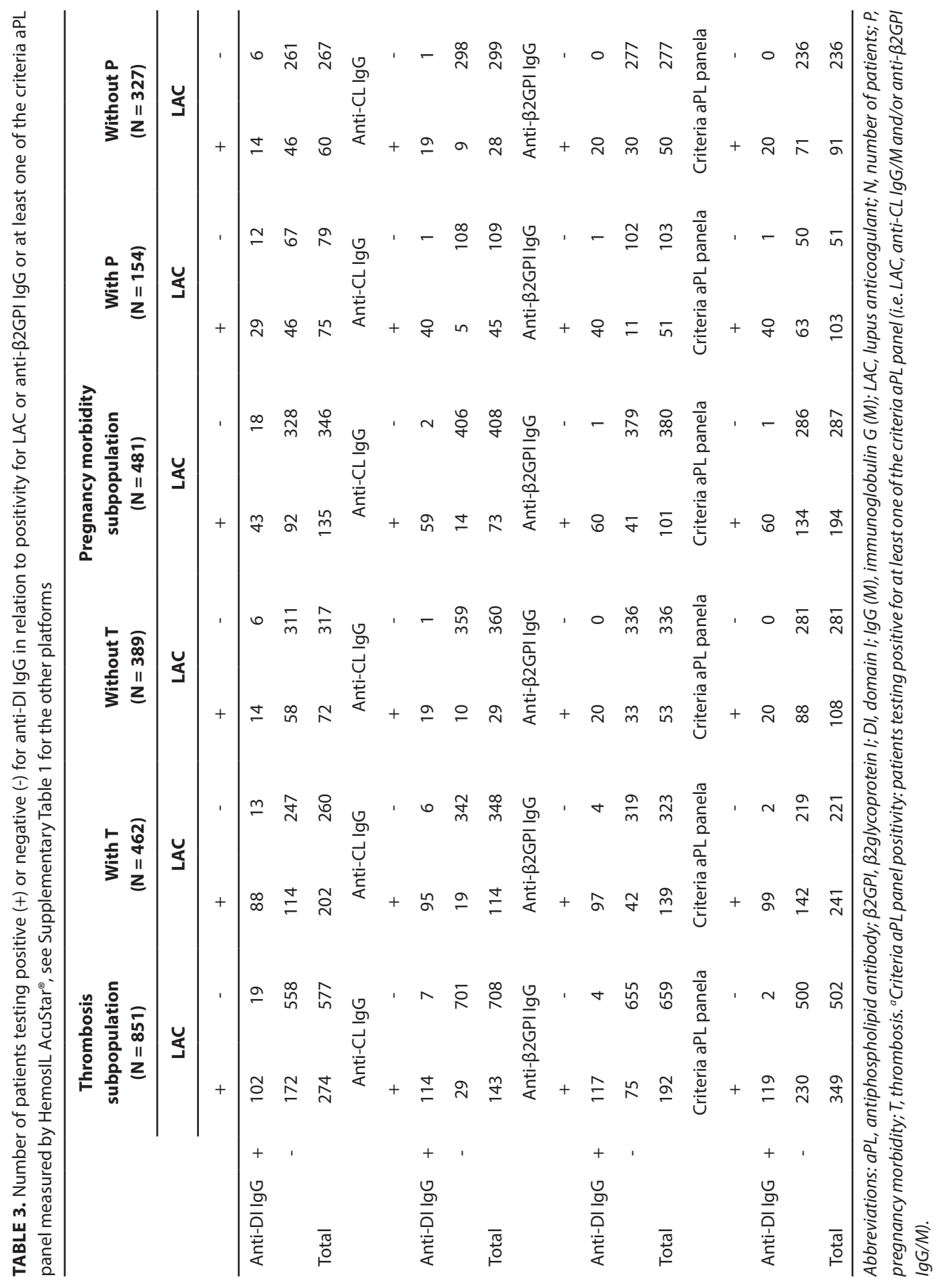




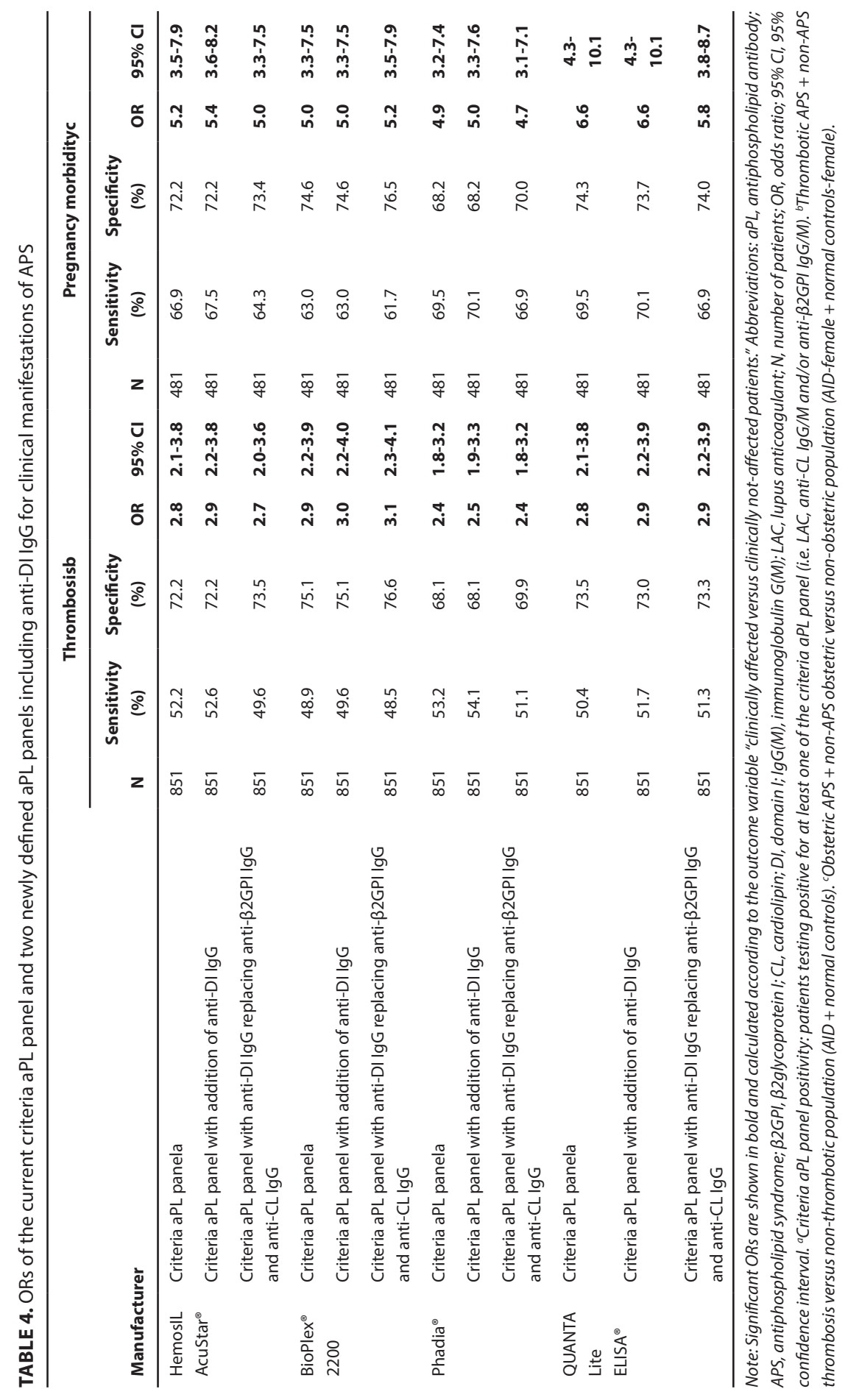


and QUANTA Lite ${ }^{\circledR}$ ELISA but positive for anti-DI lgG, and most of them had thrombosis or pregnancy morbidity. Including LAC, fewer individuals negative for the criteria aPL panel tested positive for anti-DI IgG and suffered from clinical events.

To assess the additional clinical value of anti-DI IgG on top of the currently used aPL measured by different platforms, anti-DI lgG was added to the criteria aPL panel or used as a substitute for anti- $\beta 2$ GPI lgG and anti-CL IgG in the criteria aPL panel. For all platforms, the addition of anti-DI IgG to the current criteria aPL panel hardly resulted in an increase of the OR for thrombosis or pregnancy morbidity. Replacement of anti$\beta 2$ GPI IgG and anti-CL IgG by anti-DI lgG resulted in comparable ORs for both clinical symptoms. For all platforms, a small increase was observed in specificity when replacing anti- $\beta 2$ GPI IgG and anti-CL lgG by anti-DI lgG, mostly accompanied by a decrease in sensitivity (Table 4).

To investigate if anti-DI antibodies are the only pathogenic antibodies, we re-evaluated the correlation of LAC, anti-CL IgG, and anti- $\beta 2$ GPI lgG with clinical manifestations of APS in anti-DI IgG negative patients. Interestingly, upon removal of anti-DI positive samples, positivity for LAC still resulted in significant ORs for thrombosis $(2.5,95 \% \mathrm{Cl}$ 1.7-3.5) and for pregnancy morbidity $(3.9,95 \% \mathrm{Cl} 2.4-6.4)$ while correlations for anti$\beta 2 \mathrm{GPI}$ lgG and anti-CL IgG antibodies were no longer statistically significant except for when the anti-CL IgG was measured by Phadia ${ }^{\circledR}$ and QUANTA Lite ${ }^{\circledR}$ ELISA (OR for thrombosis of 2.3 (95\% Cl 1.1-4.8) and 2.4 (95\% Cl 1.0-5.5), respectively; Table 5).

\section{Distribution of anti-DI IgG titers according to the patient's antibody profile}

For both the thrombosis and pregnancy morbidity subpopulation, all individuals were grouped according to their aPL profile into triple positive $(\mathrm{LAC}+$, anti-CL $\operatorname{lgG} / \lg M+$, anti- $\beta 2$ GPI lgG/lgM +), double positive (LAC -, anti-CL IgG/lgM +, anti- $\beta 2 G P I \lg G / \lg M$ + or LAC +, anti-CL lgG/lgM +, anti- $\beta 2 \mathrm{GPI} \operatorname{lgG} / \lg M$ - or $\mathrm{LAC}+$, anti-CL $\operatorname{lgG} / \lg M$-, anti$\beta 2 \mathrm{GPI} \operatorname{lgG} / \operatorname{lgM}+$ ), and single positive (isolated positive for $L A C$, anti-CL $\lg G / \lg M$, or anti- $\beta 2$ GPI IgG/lgM). Results were compared with those of patients without any aPL reactivity (negative control). The different antibody profiles with their characteristics are shown in Table 6 for anti- $\beta 2$ GPI and anti-CL measured by HemosIL AcuStar ${ }^{\circledR}$ and in Table S2-S4 in supporting information for anti- $\beta 2 \mathrm{GPI}$ and anti-CL measured by the three other solid-phase assays.

Furthermore, we compared anti-DI lgG titers in the triple positive, solid-phase doublepositive (anti-CL IgG/lgM positive and anti- $\beta 2$ GPI lgG/ IgM positive but LAC negative), combined single-positive group (isolated $\mathrm{LAC}+$, and isolated anti-CL $\lg \mathrm{G} / \operatorname{lgM}+$, and 
isolated anti- $\beta 2 \mathrm{GPI} \operatorname{lgG} / \lg M+$ ), and the negative control. Comparison of anti-DI IgG titers between four aPL profile groups for anti- $\beta 2 \mathrm{GPI}$ and anti-CL measured by four assays is shown in Figure 1. Looking at HemosIL AcuStar ${ }^{\circledR}$, in both the thrombosis subpopulation and pregnancy morbidity subpopulation anti-DI titers were significantly higher in triple positive samples compared to the other aPL profile groups, followed by the solid-phase double-positive samples. No difference was observed between antiDI titers of combined single positive and negative samples. Similar results were found for the three other assays, except that there was a significant difference between antiDI titers of combined single positive and negative samples for anti- $\beta 2 \mathrm{GPI}$ and anti-CL measured by QUANTA Lite ${ }^{\circledR}$ ELISA (Figure 1).

TABLE 5. ORs of $L A C$, anti-CL IgG and anti- $\beta 2$ GPI IgG with clinical manifestations of APS upon the removal of anti-DI lgG positive patients

\begin{tabular}{|c|c|c|c|c|c|c|c|c|c|}
\hline & \multirow[b]{2}{*}{ Manufacturer } & \multicolumn{4}{|c|}{ Thrombosis ${ }^{\mathrm{a}}$} & \multicolumn{4}{|c|}{ Pregnancy morbidity } \\
\hline & & $\begin{array}{c}\text { Population } \\
\left(\mathrm{N}^{\#}\right)\end{array}$ & $\begin{array}{c}\text { Positive } \\
\left(N^{\$}\right)\end{array}$ & OR & $95 \% \mathrm{Cl}$ & $\begin{array}{c}\text { Population } \\
\left(\mathrm{N}^{*}\right)\end{array}$ & $\begin{array}{c}\text { Positive } \\
\left(\mathbf{N}^{\$}\right)\end{array}$ & OR & $95 \% \mathrm{Cl}$ \\
\hline LAC & & 730 & 172 & 2.5 & $1.7-3.5$ & 420 & 92 & 3.9 & $2.4-6.4$ \\
\hline \multirow{4}{*}{$\begin{array}{l}\text { Anti-CL } \\
\lg G\end{array}$} & HemosIL AcuStar ${ }^{\oplus}$ & 730 & 29 & 2.0 & $0.9-4.4$ & 420 & 14 & 1.5 & $0.5-4.7$ \\
\hline & BioPlex $^{\oplus} 2200$ & 730 & 47 & 1.3 & $0.7-2.3$ & 420 & 29 & 1.2 & $0.5-2.8$ \\
\hline & Phadia $^{\oplus}$ & 730 & 35 & 2.3 & $1.1-4.8$ & 420 & 16 & 2.2 & $0.8-6.0$ \\
\hline & QUANTA Lite ELISA ${ }^{\otimes}$ & 730 & 26 & 2.4 & $1.0-5.5$ & 420 & 11 & 2.3 & $0.7-7.8$ \\
\hline \multirow{4}{*}{$\begin{array}{l}\text { Anti- } \\
\beta 2 G P I \\
\text { lgG }\end{array}$} & HemosIL AcuStar ${ }^{\oplus}$ & 730 & 75 & 1.3 & $0.8-2.2$ & 420 & 41 & 1.0 & $0.5-2.1$ \\
\hline & BioPlex ${ }^{\oplus} 2200$ & 730 & 49 & 1.1 & $0.6-1.9$ & 420 & 30 & 1.2 & $0.5-2.7$ \\
\hline & Phadia ${ }^{\circledR}$ & 730 & 30 & 1.6 & $0.7-3.3$ & 420 & 16 & 1.2 & $0.4-3.7$ \\
\hline & QUANTA Lite ELISA ${ }^{\oplus}$ & 730 & 10 & 4.2 & $0.9-19.7$ & 420 & 2 & 2.7 & $0.2-44.1$ \\
\hline
\end{tabular}

Note: Significant ORs are shown in bold and calculated according to the outcome variable "clinically affected versus clinically not-affected patients." Abbreviations: APS, antiphospholipid syndrome; $\beta 2 \mathrm{GPI}$, $\beta 2$ glycoprotein I; CL, cardiolipin; DI, domain l; IgG, immunoglobulin $G ; L A C$, lupus anticoagulant; $N^{*}$, number of patients; $N^{5}$, number of biomarker positive cases; OR, odds ratio; $95 \%$ $\mathrm{Cl}, 95 \%$ confidence interval. ${ }^{a}$ Thrombotic APS + non-APS thrombosis versus non-thrombotic population (AID + normal controls). ${ }^{b}$ Obstetric APS + non-APS obstetric versus non-obstetric population (AID -female + normal controls - female).

\section{Association of triple positivity with anti-DI positivity}

The association between DI positivity and triple positivity was studied in detail for anti-ß2GPI and anti-CL measured by the Acustar $^{\oplus}$ (Table 6). As to the thrombosis subpopulation (Table 6), positive values of anti-DI IgG were found in 100 out of 134 individuals with triple positivity (74.6\%), compared with $44.1 \%(15 / 34)$ in the solidphase double-positive group (Pearson chi-square, $\mathrm{P}=.002$ ). Combined single-positive $(2 / 146=1.4 \%)$ and $\mathrm{aPL}$-negative patients $(2 / 502=0.4 \%)$ hardly showed any anti-DI IgG 


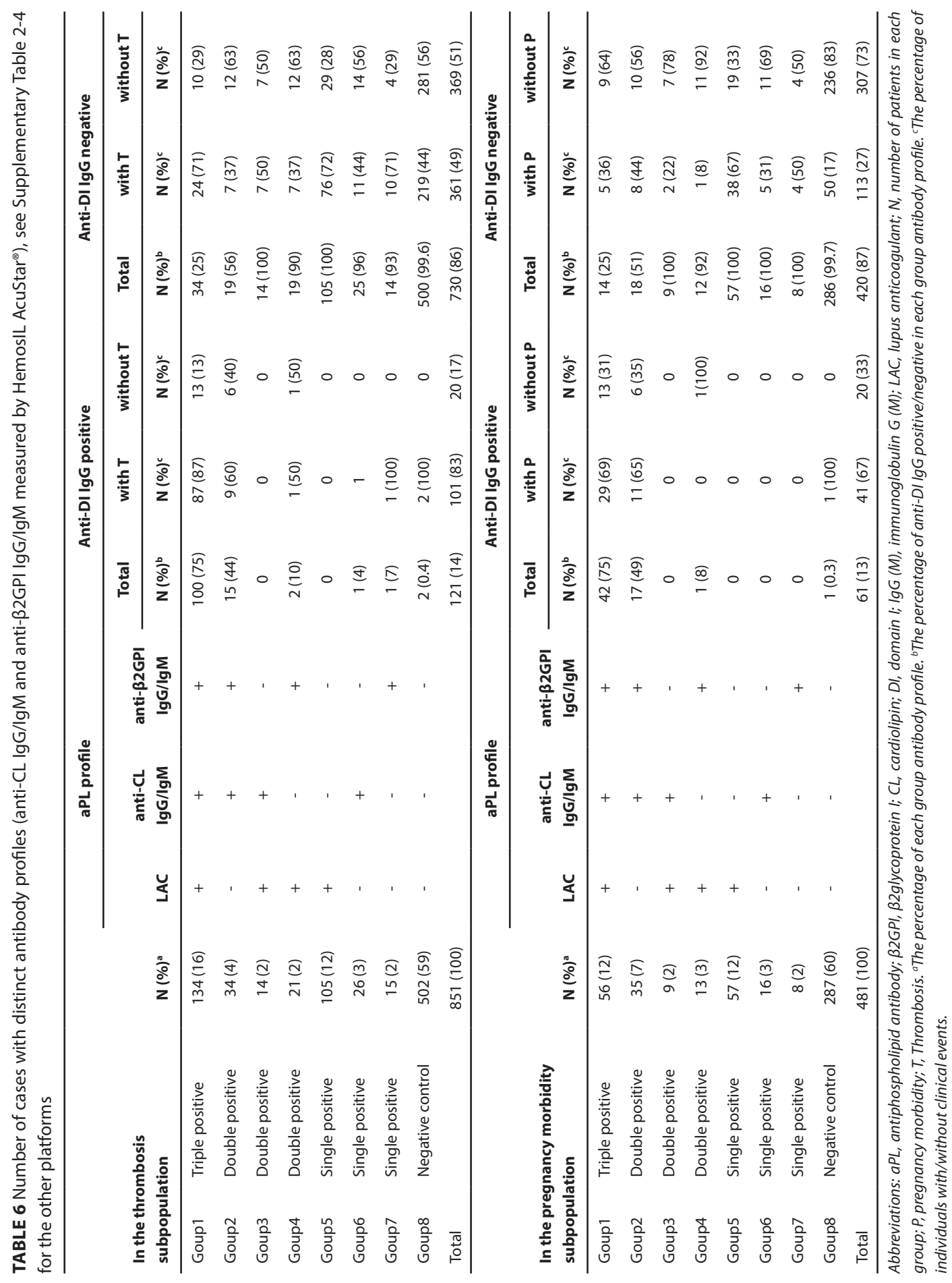



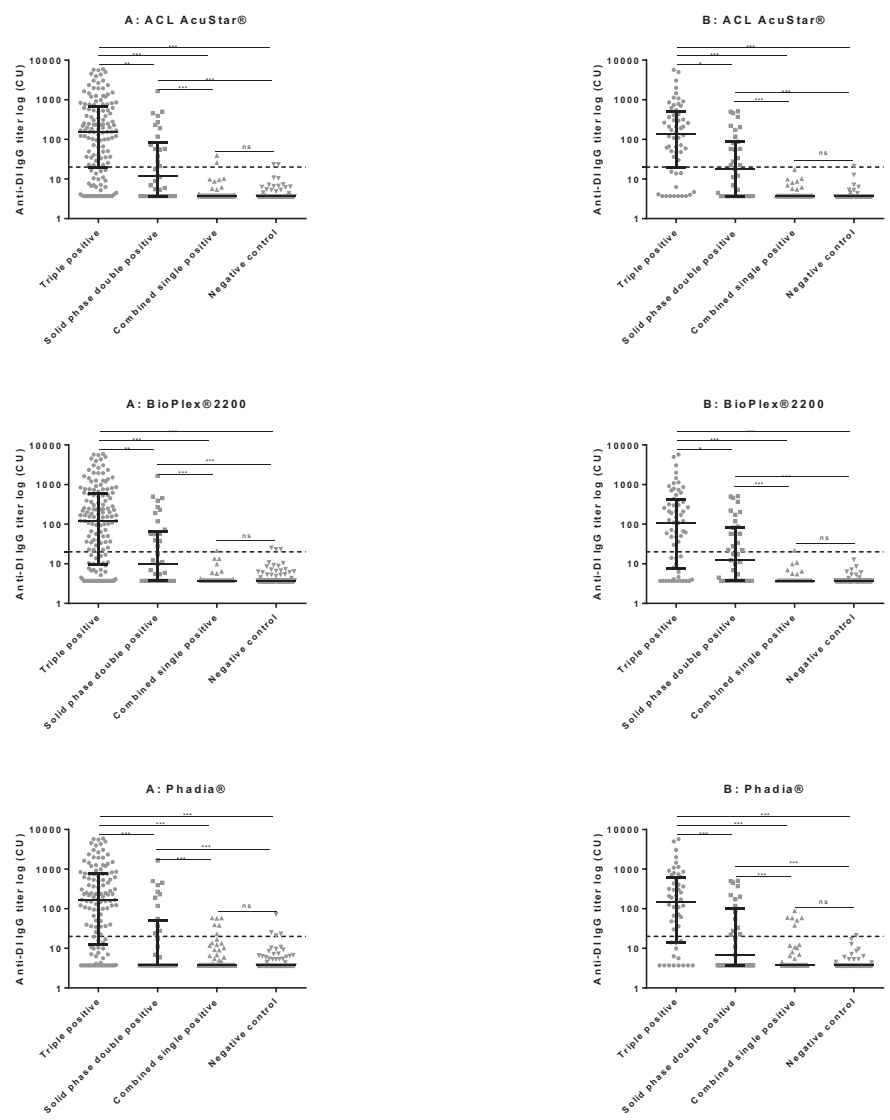

A: QUANTA Lite@ ELISA

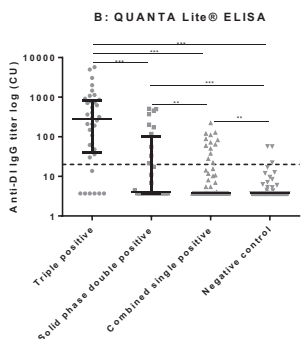

FIGURE 1. Distribution of the titer of anti-DI IgG according to distinct antibody profiles for anti-CL and anti$\beta 2$ GPI measured by HemosIL AcuStar ${ }^{\oplus}$, BioPlex ${ }^{\oplus} 2200$, Phadia ${ }^{\oplus}$, and QUANTA Lite $^{\oplus}$ ELISA in the thrombosis subpopulation (A) and pregnancy morbidity subpopulation (B). Investigated aPL profiles include triple positive ( $L A C+$, anti-CL $\lg G / \operatorname{lgM}+$, anti- $\beta 2 \mathrm{GPI} \lg G / \operatorname{lgM}+$ ), solid phase double positive (LAC -, anti-CL $\lg G / \operatorname{lgM}$ + , anti- $\beta 2 \mathrm{GPI} \operatorname{lgG} / \operatorname{lgM}+$ ), and combined single positive (isolated $L A C+$, and isolated anti-CL $\lg G / \operatorname{lgM}+$, and isolated anti- $\beta 2 \mathrm{GPI} \operatorname{lgG} / \operatorname{lgM}+$ ). Patients without any aPL reactivity were defined as negative controls. Titer of anti-DI lgG are expressed as the median with interquartile ranges within each profile; dashed lines indicate the cut-off value of anti-DI lgG $(20 \mathrm{CU}) .{ }^{*} \mathrm{P}<.05,{ }^{* * P}<.01,{ }^{* * *} \mathrm{P}<.0001$, ns: not significant. Abbreviations: aPL, antiphospholipid antibody; DI, domain I; lgG, immunoglobulin G; CU, chemiluminescence units 


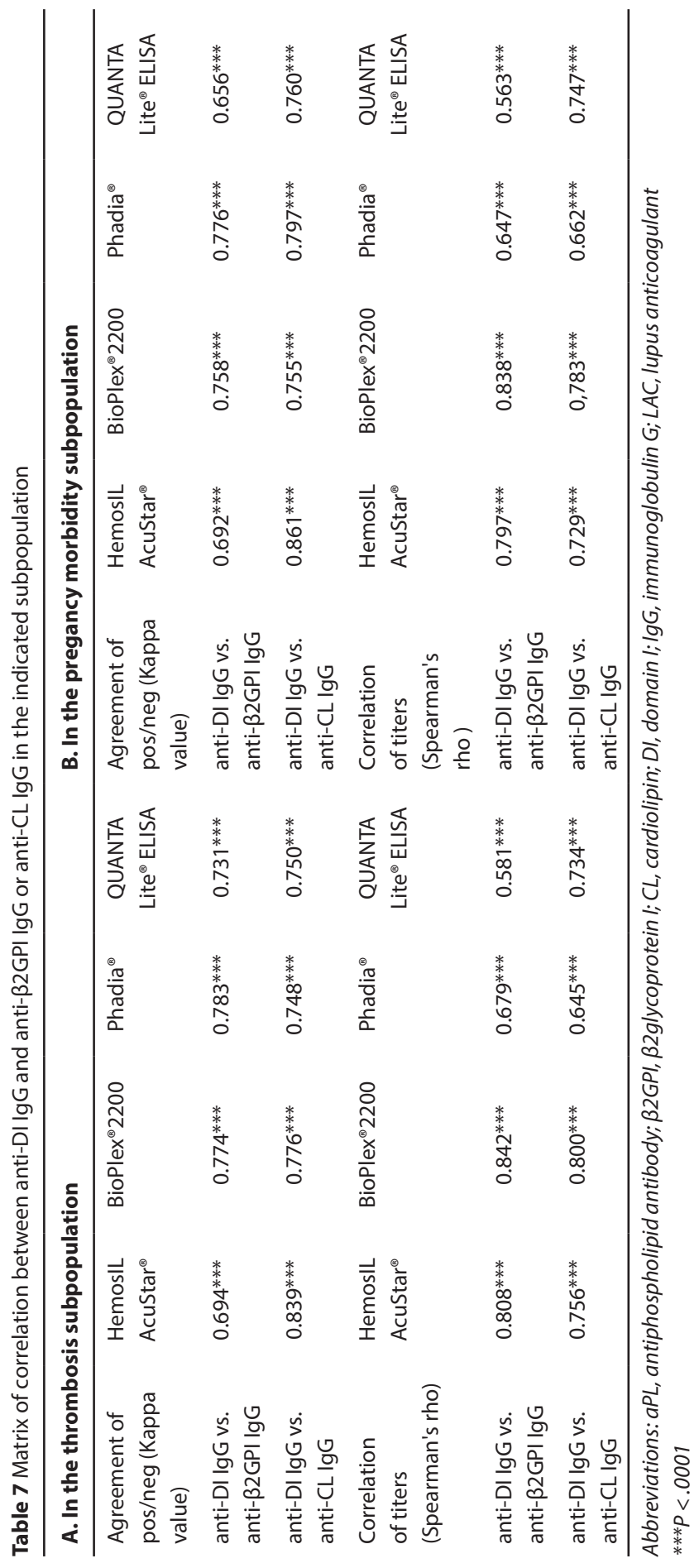


reactivity (Fisher's exact test, $\mathrm{P}<.0001)$. A good agreement was found between triple positivity and anti-DI lgG positivity (Kappa value $=0.746, \mathrm{P}<.0001$ ). In this triple positive group, $87.0 \%(87 / 100)$ of anti-DI lgG positive individuals had a history of thrombosis, compared with $70.6 \%$ (24/34) of anti-DI lgG negative patients (Pearson chi-square, $\mathrm{P}=$ .028).

Concerning the pregnancy morbidity subpopulation (Table 6), positive values of anti-DI IgG were found in 42 out of 56 individuals with triple positivity (75.0\%), compared with $48.6 \%(17 / 35)$ in the solid-phase double-positive group (Pearson chi-square, $P=.013$ ). As seen in the thrombosis subpopulation, the combined single-positive group $(0 / 81=0 \%)$ and $\mathrm{aPL}$ negative patients $(1 / 287=0.3 \%)$ hardly showed anti-DI lgG reactivity (Fisher's exact test, $\mathrm{P}<0.0001$ ). Albeit lower than for the thrombosis subpopulation, also in the pregnancy morbidity subpopulation a good agreement was demonstrated between triple positivity and anti-DI IgG (Kappa value $=0.679, \mathrm{P}<.0001$ ). In this triple-positive group, $69.0 \%$ (29/42) of anti-DI lgG positive individuals had a history of pregnancy morbidity, compared with $35.7 \%$ (5/14) of anti-DI lgG negative patients (Fisher's exact test, $\mathrm{P}=.027$ ). In general, similar conclusions can be drawn when anti- $\beta 2 \mathrm{GPI}$ and anti-CL were measured by the other assays (Tables S2-S5 in supporting information).

Interestingly, both for thrombosis and pregnancy morbidity, the ORs of anti-DI IgG were higher than the ORs of triple positivity except when anti-CL and anti- $\beta 2 \mathrm{GPI}$ were measured by the QUANTA Lite ${ }^{\circledR}$ ELISA platform for thrombosis. To verify if antiDI positivity has an added value in risk stratification compared to triple positivity, ORs of combined triple positivity and DI positivity were calculated for thrombosis and pregnancy morbidity. As to thrombosis, combined positivity resulted in higher OR compared to the separate OR for both triple positivity and DI reactivity. For pregnancy morbidity, ORs of anti-DI plus triple positivity were higher compared to ORs of triple positivity, but hardly improved compared to OR of anti-DI positivity (Table 2A).

Furthermore, as to the thrombosis subpopulation, within the triple-positive group for anti- $\beta 2$ GPI and anti-CL measured by Acustar ${ }^{\circledast}$, anti-DI IgG titers varied greatly but no significant difference was observed between patients with thrombosis $(n=111)$ and unaffected individuals ( $\mathrm{n}=23$ ), with a median (quartile[Q]25-Q75) anti-DI IgG titer of, respectively, 169.0 CU (25.7-761.3) and 63.7CU (3.7-625.7) (Mann-Whiney U test, $P=.084)$. Similarly, concerning the pregnancy morbidity subpopulation, anti-DI IgG titers differed greatly but no significant difference between patients with pregnancy morbidity $(n=34)$ and unaffected individuals $(n=22)$ could be demonstrated with a median (Q25-Q75) anti-DI lgG titer of 200.2 CU (49.6-462.1) and 65.0 CU (3.7-654.3), respectively (Mann-Whiney $U$ test, $P=.179$ ). Similar results were obtained with the three 
other assays, although for the BioPlex ${ }^{\circledR} 2200$ (thrombosis and pregnancy morbidity) and Phadia $^{\circledR}$ (thrombosis) results reached statistical significance (Table S6 in supporting information).

\section{Correlation between detection of anti-DI IgG and anti- $\beta 2$ GPI IgG and anti- CL IgG}

Concordance was evaluated by comparing the results of the detection of IgG anti-DI antibodies with anti- $\beta 2$ GPI lgG and anti-CL IgG measured by four solid-phase assays (Table 7). A good agreement was established between IgG anti-DI antibodies and IgG anti-CL as well as with IgG anti- $\beta 2$ GPI antibodies (Kappa value $=0.656-0.861$ ) in the thrombosis subpopulation (Table 7A) and the pregnancy morbidity subpopulation (Table 7B). The IgG anti-DI antibody titers were likewise significantly correlated with IgG anti-CL titers and IgG anti- $\beta 2$ GPI titers (Spearman's rho $=0.563-0.842$ ) in the thrombosis subpopulation (Table 7A) and the pregnancy morbidity subpopulation (Table 7B; all P $<.0001)$.

\section{DISCUSSION}

Solid phase aPL assays included in the laboratory criteria suffer from a lack of standardization, limiting their utility in clinical practice. Variability results not only from methodological shortcomings but also from the heterogeneity of aPLs. ${ }^{5,7}$ More and more literature evidence suggests that detection of a subset of aPLs reactive against $\mathrm{DI}$ of $\beta 2 \mathrm{GPI}$ is a promising classification or risk stratification tool in APS. ${ }^{26,27}$ However, a recent review concluded inconsistent results about the added value of the detection of anti-DI lgG compared to conventional aPL tests, most probably due to differences in study design, study population, and the methodology to detect the anti-DI antibodies. ${ }^{28}$

In this multicenter study, all samples were measured for aPL reactivity by one technician in the same lab to avoid variability coming from differences in working conditions. In most studies evaluating the added value of anti-DI lgG, the only commercially available assay (CIA of QUANTA Flash ${ }^{\oplus}$ ) is compared with anti- $\beta 2 \mathrm{GPI}$ and anti-CL of the same manufacturer. ${ }^{29-35}$ Importantly, we hypothesized that the added value of the anti-DI IgG assay measured by QUANTA Flash ${ }^{\circledast}$ depends on the platform used to detect anti$\beta 2 \mathrm{GPI}$ and anti-CL IgG. This hypothesis comes from our previously published results demonstrating a variable exposure of the G40-R43 epitope on domain I of $\beta 2 \mathrm{GPI}$ coated in the different commercially available anti-CL and anti- $\beta 2$ GPI assays. ${ }^{8,36,37}$ In this 
multicenter study, we therefore determined the added value of anti-DI testing to the current APS classification criteria, when anti-CL and anti- $\beta 2 \mathrm{GPI}$ were measured by our different commercially available assays.

As literature is inconclusive whether the same aPL subset induces thrombosis and pregnancy morbidity, separate analyses were performed in a thrombosis and pregnancy morbidity subpopulation, including proper control populations. Both for the thrombosis and the pregnancy morbidity subpopulation, we found that the detection of anti-DI IgG was less sensitive but more specific compared to the laboratory criteria aPL tests, resulting in a higher $\mathrm{OR}$ for thrombosis and pregnancy morbidity compared to LAC, anti- $\beta 2 \mathrm{GPI}$, or anti-CL IgG, except for the QUANTA Lite ${ }^{\circledast}$ ELISA. Interestingly, upon restriction to patients positive for anti- $\beta 2 \mathrm{GPI} \operatorname{lgG}$, anti-DI IgG positivity still resulted in significant ORs for clinical complications, except for the QUANTA Lite ${ }^{\circledast}$ ELISA (Table $2 B$ ); that could be explained by the lower number of anti- $\beta 2 \mathrm{GPI} \lg G$ detected by this assay (Table S1). These findings are consistent with previous studies. ${ }^{19,20,29,30,32}$ Based on these results, apart from those obtained by the QUANTA Lite ${ }^{\oplus}$ ELISA, we expected antiDI IgG to have an additional value on top of the current laboratory criteria, or to be a candidate to replace the anti- $\beta 2$ GPI lgG detection. Contrary to our expectation, the addition of anti-DI or replacement of anti- $\beta 2 \mathrm{GPI}$ lgG by anti-DI hardly improved the ORs for thrombosis or pregnancy morbidity. The absence of an added value of anti-DI to the current aPL criteria panel was also found in previous studies. ${ }^{34,35}$

This at-first-sight contradiction can be explained by the results presented in Table 3 and Table S1. Independent of the assay used, only few individuals $(n=11)$ negative for the criteria aPL panel (with one or more platforms) become positive when anti-DI lgG is added to the criteria aPLs panel or used as a substitute for anti- $\beta 2 \mathrm{GPI}$ IgG and/or anti-CL $\operatorname{lgG}$, even though most of them experienced clinical events $(n=7$ with thrombosis, $n=$ 2 with pregnancy morbidity). Of note, despite anti-DI IgG positivity, the titers of anti-DI $\lg \mathrm{G}$ in these individuals proved to be low (from 21.1 to $73.2 \mathrm{CU}$ ).

Interestingly, upon removal of anti-DI IgG positive patients, anti-CL IgG and anti$\beta 2 \mathrm{GPI}$ IgG were no longer significantly correlated with thrombosis and pregnancy morbidity, except for anti-CL IgG measured by Phadia ${ }^{\circledR}$ and by QUANTA Lite ${ }^{\circledast}$ ELISA (OR for thrombosis of 2.3 [95\% Cl 1.1-4.8] and 2.4 [95\% Cl 1.0-5.5], respectively; Table 5). Although the OR for thrombosis of anti-CL IgG measured by Phadia ${ }^{\circledR}$ and by QUANTA Lite $^{\oplus}$ ELISA was still significant, the lower limit was adjacent to 1 . These findings are in agreement with previous studies demonstrating that especially anti-DI antibodies are pathogenic while antibodies targeting other domains such as domain $4 / 5$ are innocent or even protective antibodies. ${ }^{20,23,38,39}$ 
We previously demonstrated that the large variability observed in commercially available anti- $\beta 2$ GPI assays results at least in part from a variable exposure of the pathogenic G40-R43 DI epitope. ${ }^{8}$ Importantly, our recent data show that, as for anti- $\beta 2$ GPI lgG assays, the pathogenic DI epitope is not exposed correctly in the commercially available anti-DI CIA assay. ${ }^{28}$ Furthermore, both as categorical variables (positive/negative) and as quantitative variables (titer), anti-DI IgG strongly correlated with anti-CL IgG and anti- $\beta 2$ GPI IgG on the same AcuStar ${ }^{\circledR} \mathrm{CIA}$. The high correlation between anti-DI IgG and anti- $\beta 2$ GPI IgG suggests a high overlap between both assays performed on the automated CIA platform. Previous studies also observed a high agreement (69\%-92\%) between anti-DI lgG and anti- 32 GPI lgG when measured using the CIA methodology. ${ }^{29,34,35,40}$ These results may explain the absence of an added value of measuring anti-DI using this assay. In this study, and also for the other platforms, a high agreement was found between anti-DI and the anti-CL IgG and anti-ß2GPI IgG and no added value of measuring anti-DI could be demonstrated (Table 7).

Of note, apart from the anti-DI CIA assay used in this study, other methods are available to detect anti-DI antibodies. ${ }^{28}$ Previously a home-made two-step ELISA strongly indicated that testing for IgG anti-DI enables identification of the patients at highest risk for developing thrombosis or pregnancy morbidity. ${ }^{19,20}$ In contrast to the results obtained by CIA assays, only $50 \%$ of the anti- $\beta 2$ GPI IgG antibodies tested by this home-made two-step ELISA were demonstrated to be reactive against DI. Importantly, using this two-step ELISA assay, correct exposure of the G40-R43 epitope was already confirmed. ${ }^{20}$ The added value of measuring anti-DI reactivity using this assay remains to be determined.

Interestingly, LAC remained significantly correlated with thrombosis and pregnancy morbidity upon removal of anti-DI lgG positive patients. Further illustrated by the only fair to moderate agreement between lgG anti-DI and functional LAC in the thrombosis subpopulation (Kappa value $=0.398$ ) and the pregnancy morbidity subpopulation (Kappa value $=0.320$ ), these data illustrate that the CIA anti-DI lgG assay only detects part of the pathogenic aPLs. The presence of pathogenic anti-phosphatidylserine/ prothrombin (anti-PS/PT) antibodies able to induce LAC positivity may explain the remaining correlation between LAC and thrombosis. Indeed, previous studies have demonstrated correlations of anti-PS/PT with clinical symptoms in APS patients and positivity proved to be associated with LAC. ${ }^{41,42}$

Evidence is growing that the determination of combined antibody positivity helps to categorize patients according to their risk profile. Especially triple-positive patients (positive for LAC and anti-CL and anti- $\beta 2$ GPI lgG/lgM) show a strong association with 
thrombotic and obstetric manifestations ${ }^{43,44}$ Clinical studies confirm that triple positivity in APS patients and asymptomatic aPL carriers indicates a high risk of recurrence of thrombosis or development of a first thrombotic event, respectively. ${ }^{44,45}$ Although identification of triple positives is dependent on the solid-phase assay used, ${ }^{46}$ the percentage of anti-DI IgG positives in individuals with distinct antibody profiles were comparable for the four tested solid-phase assays. In this study, a very good agreement was found between triple positivity and anti-DI IgG positivity, irrespective of the solidphase assay used (Table S5), which is consistent with previous studies..$^{30-32,35,40}$ Moreover, independent of the platform used to measure anti-CL and anti- $\beta 2 \mathrm{GPI} \operatorname{lgG} / \mathrm{lgM}$, we observed that anti-DI lgG antibodies are mainly present in triple positive individuals, also showing significantly higher titers compared to patients with other aPL profiles. More importantly, within the triple positive group, a higher percentage of clinically affected cases was present in the anti-DI IgG positive compared to the anti-DI IgG negative group. Furthermore, the higher ORs of combined DI and triple positivity for both thrombosis and pregnancy morbidity compared to only triple positivity, support the idea that detection of anti-DI lgG is interesting to identify patients at risk.

We acknowledge that our study has some limitations. First, as in both the thrombotic and obstetric patient groups, a small number of patients ( $8.9 \%$ and $7.4 \%$, respectively) also suffers from the other clinical manifestation, the correlation with the specific clinical manifestation may be affected by the comorbidity of the other manifestation. Also, the different groups in our study population did not match according to age and gender, but were representative to population groups tested in daily practice. Another limitation of our study is the retrospective design. Interestingly, in the AID and normal control group, a number of the triple positives were also positive for anti-DI reactivity (depending on the platform 11/22 [50\%]-9/14 [64\%] for AID; 1/3 [33\%]-2/4 [50\%] for the normal controls). Prospective studies are necessary to verify the risk of patients with these characteristics to develop clinical manifestations of APS, with possible implications for their treatment.

This study showed again that the choice of the commercial assays used to detect the presence of antiphospholipid antibodies influences the classification of APS. It is impossible to determine which commercial assay is the best because we lack a gold standard. However, a good agreement with a domain I specific assay seems to be essential because antibodies against DI have shown to be pathogenic in animal models of APS. 


\section{CONCLUSION}

Despite the higher OR of anti-DI antibody detection for clinical manifestations of APS, our study was unable to demonstrate an added value of measuring anti-DI IgG on top of the laboratory criteria, independent of the platform used to measure anti-CL and anti$\beta 2 \mathrm{GPI}$. We put the hypothesis forward that the reduced exposure of the pathogenic DI epitope in this automated assay possibly explains the absence of an added value. Therefore, it may be interesting to re-evaluate the added value of anti-DI using the inhouse anti-DI assay previously developed, for which correct exposure of the pathogenic epitope was already demonstrated. The high correlation between anti-DI lgG and triple positivity indicates that anti-DI lgG positivity confirms the patients at higher risk for clinical events in APS. Importantly, combined DI and triple positivity confirms a higher risk for both thrombosis and pregnancy morbidity compared to only triple positivity. As LAC positivity remains significantly correlated with thrombosis and pregnancy morbidity upon removal of anti-DI positive patients, the anti-DI IgG assay only detects part of the pathogenic aPLs. 


\section{ADDENDUM}

K. M. J. Devreese, B. de Laat and H. Kelchtermans designed the study. K. M. J. Devreese organized the sample collection at the different centers. K. M. J. Devreese, G. W. Moore, J-C Gris, S. Zuily and J. Musiał collected samples and identified sample characteristics. Samples were analyzed under the supervision of K. M. J. Devreese. D.Yin, K. M. J. Devreese, B. de Laat, H. Kelchtermans and W. Chayouâ interpreted data, performed statistical analyses and wrote the manuscript. P. G. de Groot, G. W. Moore, J-C Gris, S. Zuily and J. Musiał critically reviewed the manuscript.

\section{ACKNOWLEDGEMENTS}

The authors thank HemosIL AcuStar ${ }^{\circledast}$ (Instrumentation Laboratories, Bedford, USA), BioPlex ${ }^{\circledR} 2200$ (Bio-Rad, Bio-Rad Laboratories, Hercules, USA), Phadia ${ }^{\circledR}$ (Thermo Fisher Scientific/Phadia, Uppsala, Sweden), QUANTA Lite ELISA ${ }^{\oplus}$ (Inova Diagnostics, San Diego, USA) and QUANTA Flash ${ }^{\circledR}$ (Inova Diagnostics, San Diego, USA) for providing the assay kits and/or the corresponding devices. We also warmly thank Michael Luypaert of the Coagulation Lab of Ghent University Hospital for performing all solid phase assays and D. Wahl, A. Tripodi, P. Fontana and J. Remijn for providing patient samples.

Dongmei Yin (File no. 201609120011) has been awarded a scholarship under the State Scholarship Fund to pursue her study in the Netherlands as a PhD student by the China Scholarship Council (CSC).

\section{DISCLOSURE OF CONFLICTS OF INTERESTS}

All authors state that they have no conflict of interest. 


\section{REFERENCES}

1 Ruiz-Irastorza G, Crowther M, Branch W, Khamashta MA. Antiphospholipid syndrome. Lancet 2010; 376: 1498-509.

2 Ortel TL. Antiphospholipid syndrome: laboratory testing and diagnostic strategies. Am J Hematol 2012; 87 Suppl 1: S75-81.

3 Miyakis S, Lockshin MD, Atsumi T, Branch DW, Brey RL, Cervera R, Derksen RH, PG DEG, Koike T, Meroni PL, Reber G, Shoenfeld Y, Tincani A, Vlachoyiannopoulos PG, Krilis SA. International consensus statement on an update of the classification criteria for definite antiphospholipid syndrome (APS). J Thromb Haemost 2006; 4: 295-306.

4 Bertolaccini ML, Amengual O, Andreoli L, Atsumi T, Chighizola CB, Forastiero R, de Groot P, Lakos G, Lambert M, Meroni P, Ortel TL, Petri M, Rahman A, Roubey R, Sciascia S, Snyder M, Tebo AE, Tincani A, Willis R. 14th International Congress on Antiphospholipid Antibodies Task Force. Report on antiphospholipid syndrome laboratory diagnostics and trends. Autoimmun Rev 2014; 13: 917-30.

5 Devreese KM, Pierangeli SS, de Laat B, Tripodi A, Atsumi T, Ortel TL, Subcommittee on Lupus Anticoagulant/Phospholipid/Dependent A. Testing for antiphospholipid antibodies with solid phase assays: guidance from the SSC of the ISTH. J Thromb Haemost 2014; 12: 792-5.

6 Devreese K. Standardization of antiphospholipid antibody assays.Where do we stand? Lupus 2012; 21: 718-21.

7 Devreese KM, Ortel TL, Pengo V, de Laat B. Subcommittee on Lupus Anticoagulant/ Antiphospholipid Antibodies. Laboratory criteria for antiphospholipid syndrome: communication from the SSC of the ISTH. J Thromb Haemost 2018; 16: 809-13.

8 Pelkmans L, Kelchtermans H, de Groot PG, Zuily S, Regnault V, Wahl D, Pengo V, de Laat B. Variability in exposure of epitope G40-R43 of domain i in commercial anti-beta2glycoprotein I lgG ELISAs. PLoS One 2013; 8: e71402.

9 Fischetti F, Durigutto P, Pellis V, Debeus A, Macor P, Bulla R, Bossi F, Ziller F, Sblattero D, Meroni $\mathrm{P}$, Tedesco F. Thrombus formation induced by antibodies to beta2-glycoprotein I is complement dependent and requires a priming factor. Blood 2005; 106: 2340-6.

10 Arad A, Proulle V, Furie RA, Furie BC, Furie B. beta(2)-Glycoprotein-1 autoantibodies from patients with antiphospholipid syndrome are sufficient to potentiate arterial thrombus formation in a mouse model. Blood 2011; 117: 3453-9.

11 Jankowski M, Vreys I, Wittevrongel C, Boon D, Vermylen J, Hoylaerts MF, Arnout J. Thrombogenicity of $\beta 2$-glycoprotein I-dependent antiphospholipid antibodies in a photochemically induced thrombosis model in the hamster. Blood 2003; 101: 157-62.

12 de Groot PG, Meijers JC. beta(2) -Glycoprotein I: evolution, structure and function. J Thromb Haemost 2011; 9: 1275-84.

13 de Laat B, Derksen RH, van Lummel M, Pennings MT, de Groot PG. Pathogenic antibeta2-glycoprotein I antibodies recognize domain I of beta2-glycoprotein I only after a conformational change. Blood 2006; 107: 1916-24. 
14 Agar C, van Os GM, Morgelin M, Sprenger RR, Marquart JA, Urbanus RT, Derksen RH, Meijers JC, de Groot PG. Beta2-glycoprotein I can exist in 2 conformations: implications for our understanding of the antiphospholipid syndrome. Blood 2010; 116: 1336-43.

de Laat B, van Berkel M, Urbanus RT, Siregar B, de Groot PG, Gebbink MF, Maas C. Immune responses against domain I of beta(2)-glycoprotein I are driven by conformational changes: domain I of beta(2)-glycoprotein I harbors a cryptic immunogenic epitope. Arthritis Rheum 2011; 63: 3960-8.

16 Iverson GM, Reddel S, Victoria EJ, Cockerill KA, Wang YX, Marti-Renom MA, Sali A, Marquis DM, Krilis SA, Linnik MD. Use of Single Point Mutations in Domain I of B2-Glycoprotein I to Determine Fine Antigenic Specificity of Antiphospholipid Autoantibodies. J Immunol 2002; 169: 7097-103.

17 Pericleous C, Ruiz-Limon P, Romay-Penabad Z, Marin AC, Garza-Garcia A, Murfitt L, Driscoll PC, Latchman DS, Isenberg DA, Giles I, loannou Y, Rahman A, Pierangeli SS. Proof-of-concept study demonstrating the pathogenicity of affinity-purified IgG antibodies directed to domain I of beta2-glycoprotein I in a mouse model of anti-phospholipid antibody-induced thrombosis. Rheumatology (Oxford) 2015; 54: 722-7.

18 Ioannou Y, Romay-Penabad Z, Pericleous C, Giles I, Papalardo E, Vargas G, Shilagard T, Latchman DS, Isenberg DA, Rahman A, Pierangeli S. In vivo inhibition of antiphospholipid antibody-induced pathogenicity utilizing the antigenic target peptide domain I of beta2glycoprotein I: proof of concept. J Thromb Haemost 2009; 7: 833-42.

19 de Laat B, Derksen RH, Urbanus RT, de Groot PG. IgG antibodies that recognize epitope Gly40-Arg43 in domain I of beta 2-glycoprotein I cause LAC, and their presence correlates strongly with thrombosis. Blood 2005; 105: 1540-5.

20 de Laat B, Pengo V, Pabinger I, Musial J, Voskuyl AE, Bultink IE, Ruffatti A, Rozman B, Kveder T, de Moerloose P, Boehlen F, Rand J, Ulcova-Gallova Z, Mertens K, de Groot PG. The association between circulating antibodies against domain I of beta2-glycoprotein I and thrombosis: an international multicenter study. J Thromb Haemost 2009; 7: 1767-73.

21 Pelkmans L, de Laat B. Antibodies against domain I of beta2-glycoprotein I: the one and only? Lupus 2012; 21: 769-72.

22 Pengo V, Ruffatti A, Tonello M, Hoxha A, Bison E, Denas G, Padayattil Jose S, Zoppellaro G, Bracco A, Banzato A. Antibodies to Domain 4/5 (Dm4/5) of beta2-Glycoprotein 1 (beta2GP1) in different antiphospholipid (aPL) antibody profiles. Thromb Res 2015; 136: 161-3.

23 Andreoli L, Nalli C, Motta M, Norman GL, Shums Z, Encabo S, Binder WL, Nuzzo M, Frassi M, Lojacono A, Avcin T, Meroni PL, Tincani A. Anti-beta(2)-glycoprotein I IgG antibodies from 1-year-old healthy children born to mothers with systemic autoimmune diseases preferentially target domain 4/5: might it be the reason for their 'innocent' profile? Ann Rheum Dis 2011; 70: 380-3.

24 Artenjak A, Locatelli I, Brelih H, Simonic DM, Ulcova-Gallova Z, Swadzba J, Musial J, Iwaniec T, Stojanovich L, Conti F, Valesini G, Avcin T, Cohen Tervaert JW, Shoenfeld Y, Blank M, Ambrozic 
A, Sodin-Semrl S, Bozic B, Cucnik S. Immunoreactivity and avidity of IgG anti-beta2glycoprotein I antibodies from patients with autoimmune diseases to different peptide clusters of beta2-glycoprotein I. Immunol Res 2015; 61: 35-44.

25 Wayne P. Defining, establishing, and verifying reference intervals in the clinical laboratory: approved guidelinethird edition. CLSI documalet C28-A3C 3rd ed Wayne (PA): Clinical and Laboratory Standards Institute 2008.

26 Arachchillage DRJ, Laffan M. Pathogenesis and management of antiphospholipid syndrome. Br J Haematol 2017; 178: 181-95.

27 Kelchtermans H, Chayoua W, Laat B. The Significance of Antibodies against Domain I of Beta2 Glycoprotein I in Antiphospholipid Syndrome. Semin Thromb Hemost 2018; 44: 458-65.

28 Yin D, de Laat B, Devreese KMJ, Kelchtermans $\mathrm{H}$. The clinical value of assays detecting antibodies against domain I of beta2-glycoprotein I in the antiphospholipid syndrome. Autoimmun Rev 2018; 17: 1210-8.

29 Zhang S, Wu Z, Chen S, Li J, Wen X, Li L, Zhang W, Zhao J, Zhang F, Li Y. Evaluation of the diagnostic potential of antibodies to beta2-glycoprotein 1 domain 1 in Chinese patients with antiphospholipid syndrome. Sci Rep 2016; 6: 23839.

30 Mondejar R, Gonzalez-Rodriguez C, Toyos-Saenz de Miera FJ, Melguizo-Madrid E, Zohoury N, Mahler M, Romero Losquino I, Fabiani F. Role of antiphospholipid score and anti-beta2glycoprotein I Domain I autoantibodies in the diagnosis of antiphospholipid syndrome. Clin Chim Acta 2014; 431: 174-8.

31 Meneghel L, Ruffatti A, Gavasso S, Tonello M, Mattia E, Spiezia L, Tormene D, Hoxha A, Fedrigo M, Simioni P. Detection of IgG anti-Domain I beta2 Glycoprotein I antibodies by chemiluminescence immunoassay in primary antiphospholipid syndrome. Clin Chim Acta 2015; 446: 201-5.

32 Mahler M, Albesa R, Zohoury N, Bertolaccini ML, Ateka-Barrutia O, Rodriguez-Garcia JL, Norman GL, Khamashta M. Autoantibodies to domain 1 of beta 2 glycoprotein I determined using a novel chemiluminescence immunoassay demonstrate association with thrombosis in patients with antiphospholipid syndrome. Lupus 2016; 25: 911-6.

33 Oku K, Amengual O, Kato M, Bohgaki T, Horita T, Yasuda S, Sakamoto N, leko M, Norman $\mathrm{GL}$, Atsumi T. Significance of fully automated tests for the diagnosis of antiphospholipid syndrome. Thromb Res 2016; 146: 1-6.

34 Iwaniec T, Kaczor MP, Celinska-Lowenhoff M, Polanski S, Musial J. Clinical significance of antidomain 1 beta2-glycoprotein I antibodies in antiphospholipid syndrome. Thromb Res 2017; 153: 90-4.

35 De Craemer AS, Musial J, Devreese KM. Role of anti-domain 1-beta2 glycoprotein I antibodies in the diagnosis and risk stratification of antiphospholipid syndrome. J Thromb Haemost 2016; 14: 1779-87.

36 Devreese K, Kelchtermans $\mathrm{H}$, de Laat B. Differences in sensitivity of two automated panels for anticardiolipin and anti-beta2glycoprotein I antibodies in the laboratory diagnosis of antiphospholipid syndrome due to the exposure of the domain I epitope of beta2glycoprotein I on the solid phase [abstract]. ISTH SSC 2014 Meeting Abstracts. J Thromb Haemost 2014; 12: 55. 
37 Chayoua W, Kelchtermans H, Moore GW, Gris JC, Musial J, Wahl D, Zuily S, Gianniello F, Fontana P, Remijn J, Urbanus RT, de Laat B, Devreese KMJ. Detection of Anti-Cardiolipin and Anti-beta2glycoprotein I Antibodies Differs between Platforms without Influence on Association with Clinical Symptoms. Thromb Haemost 2019.

38 Andreoli L, Chighizola CB, Nalli C, Gerosa M, Borghi MO, Pregnolato F, Grossi C, Zanola A, Allegri F, Norman GL, Mahler M, Meroni PL, Tincani A. Clinical characterization of antiphospholipid syndrome by detection of IgG antibodies against beta2 -glycoprotein i domain 1 and domain 4/5: ratio of anti-domain 1 to anti-domain 4/5 as a useful new biomarker for antiphospholipid syndrome. Arthritis Rheumatol 2015; 67: 2196-204.

39 Chighizola CB, Pregnolato F, Andreoli L, Bodio C, Cesana L, Comerio C, Gerosa M, Grossi C, Kumar R, Lazzaroni MG, Mahler M, Mattia E, Nalli C, Norman GL, Raimondo MG, Ruffatti A, Tonello M, Trespidi L, Tincani A, Borghi MO, Meroni PL. Beyond thrombosis: Anti-beta2GPI domain 1 antibodies identify late pregnancy morbidity in anti-phospholipid syndrome. $J$ Autoimmun 2018; 90: 76-83.

40 Pengo V, Ruffatti A, Tonello M, Cuffaro S, Banzato A, Bison E, Denas G, Padayattil Jose S. Antiphospholipid syndrome: antibodies to Domain 1 of beta2-glycoprotein 1 correctly classify patients at risk. J Thromb Haemost 2015; 13: 782-7.

41 Sciascia S, Sanna G, Murru V, Roccatello D, Khamashta MA, Bertolaccini ML. Anti-prothrombin (aPT) and anti-phosphatidylserine/prothrombin (aPS/PT) antibodies and the risk of thrombosis in the antiphospholipid syndrome. A systematic review. Thromb Haemost 2014; 111: 354-64.

42 Hoxha A, Mattia E, Tonello M, Grava C, Pengo V, Ruffatti A. Antiphosphatidylserine/ prothrombin antibodies as biomarkers to identify severe primary antiphospholipid syndrome. Clin Chem Lab Med 2017; 55: 890-8.

43 Ruffatti A, Tonello M, Visentin MS, Bontadi A, Hoxha A, De Carolis S, Botta A, Salvi S, Nuzzo M, Rovere-Querini P, Canti V, Mosca M, Mitic G, Bertero MT, Pengo V, Boffa MC, Tincani A. Risk factors for pregnancy failure in patients with anti-phospholipid syndrome treated with conventional therapies: a multicentre, case-control study. Rheumatology (Oxford) 2011; 50: 1684-9.

44 Pengo V, Ruffatti A, Legnani C, Gresele P, Barcellona D, Erba N, Testa S, Marongiu F, Bison E, Denas G, Banzato A, Padayattil Jose S, Iliceto S. Clinical course of high-risk patients diagnosed with antiphospholipid syndrome. J Thromb Haemost 2010; 8: 237-42.

45 Pengo V, Ruffatti A, Legnani C, Testa S, Fierro T, Marongiu F, De Micheli V, Gresele P, Tonello M, Ghirarduzzi A, Bison E, Denas G, Banzato A, Padayattil Jose S, lliceto S. Incidence of a first thromboembolic event in asymptomatic carriers of high-risk antiphospholipid antibody profile: a multicenter prospective study. Blood 2011; 118: 4714-8.

46 Chayoua W, Kelchtermans H, Moore GW, Musial J, Wahl D, de Laat B, Devreese KMJ. Identification of high thrombotic risk triple-positive antiphospholipid syndrome patients is dependent on anti-cardiolipin and anti-beta2glycoprotein I antibody detection assays. $J$ Thromb Haemost 2018; 16: 2016-23. 


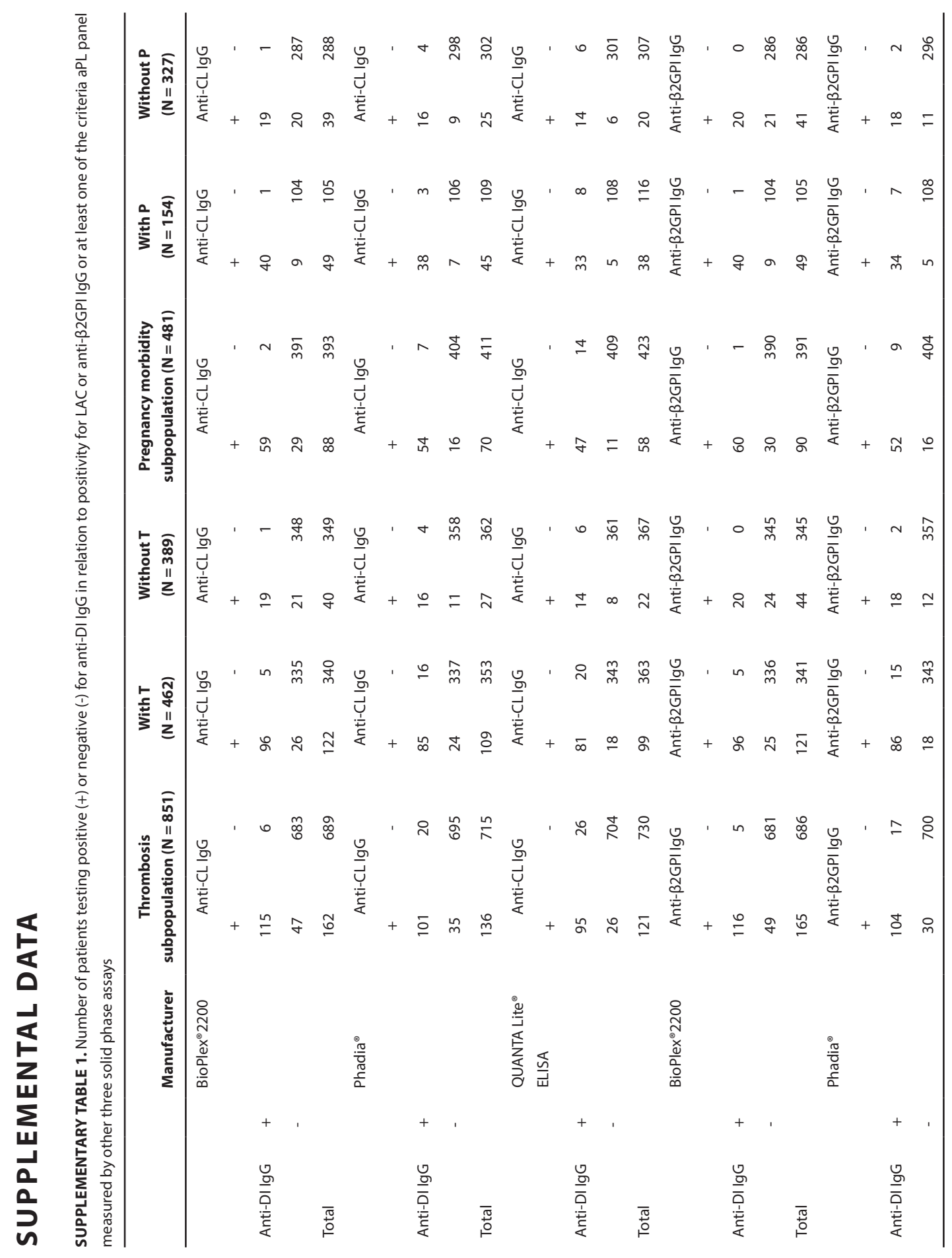




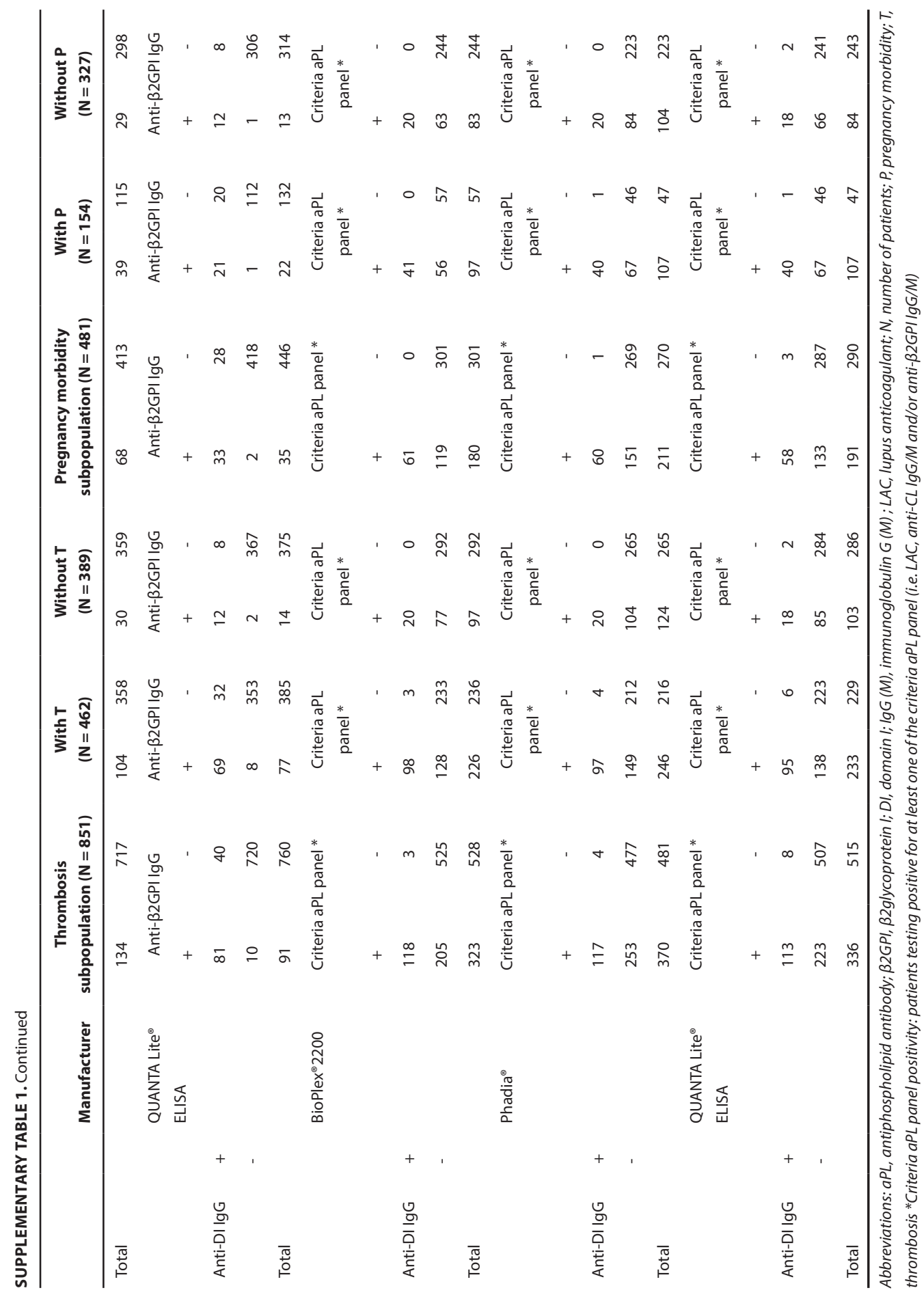




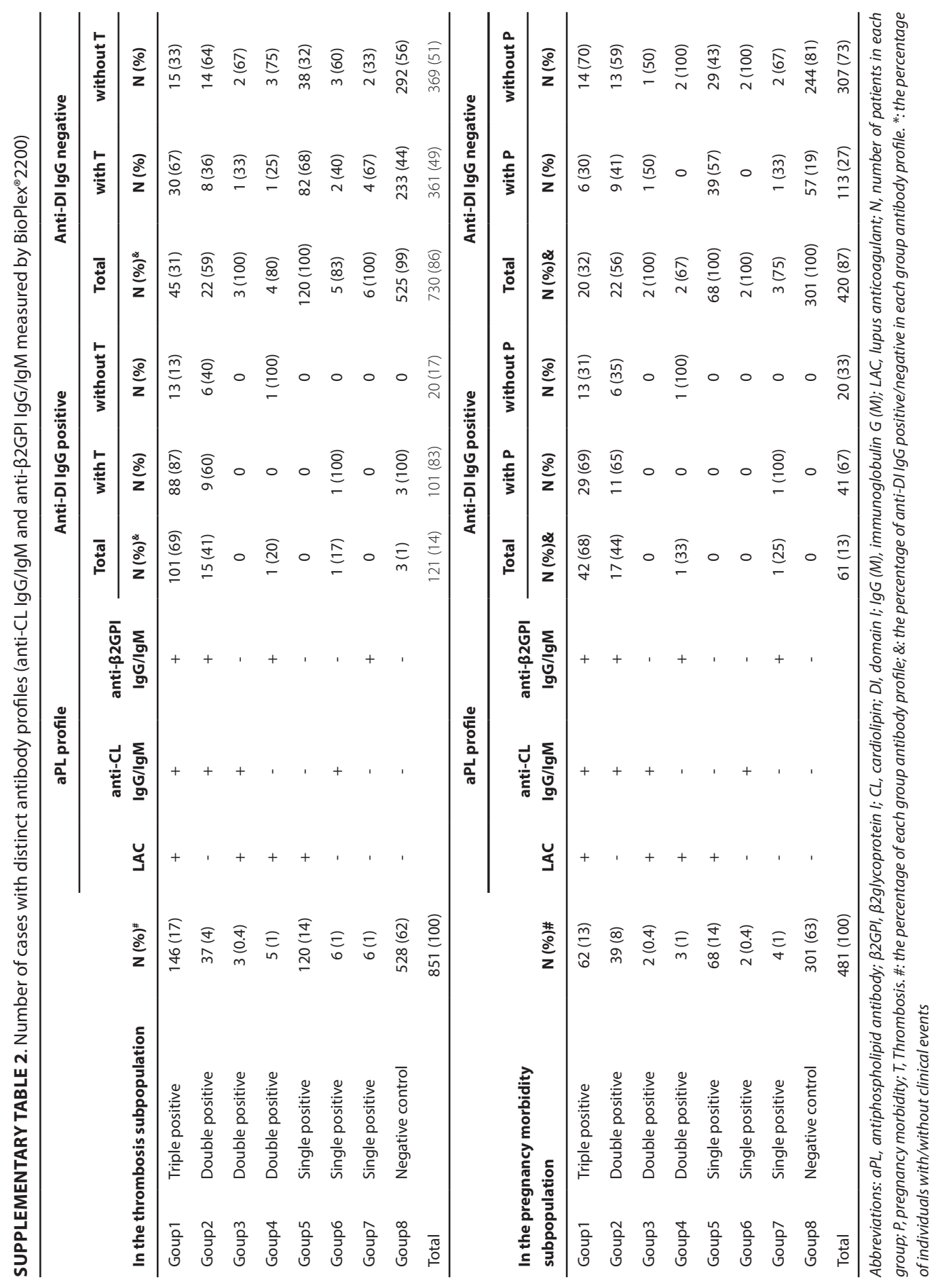




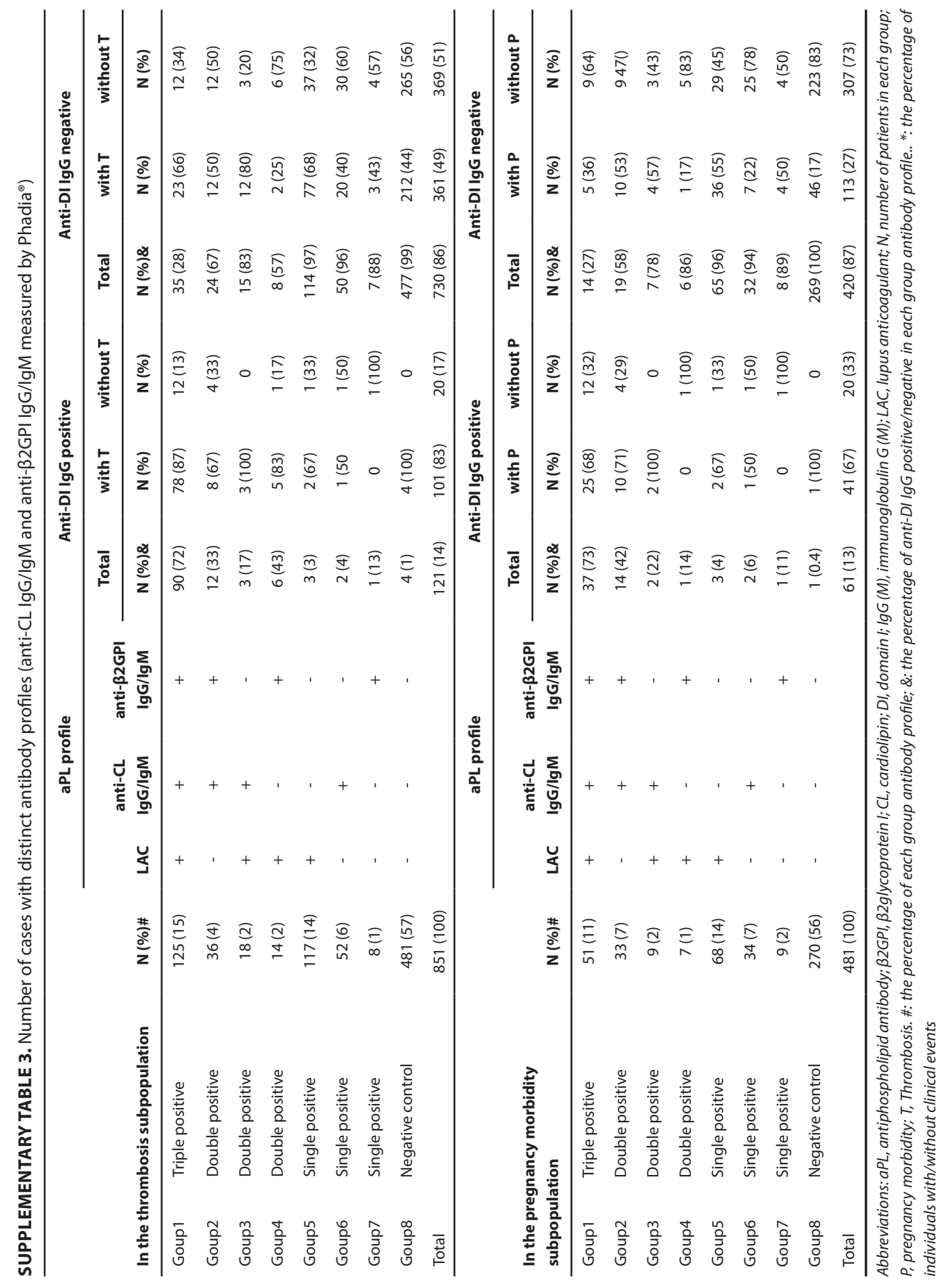




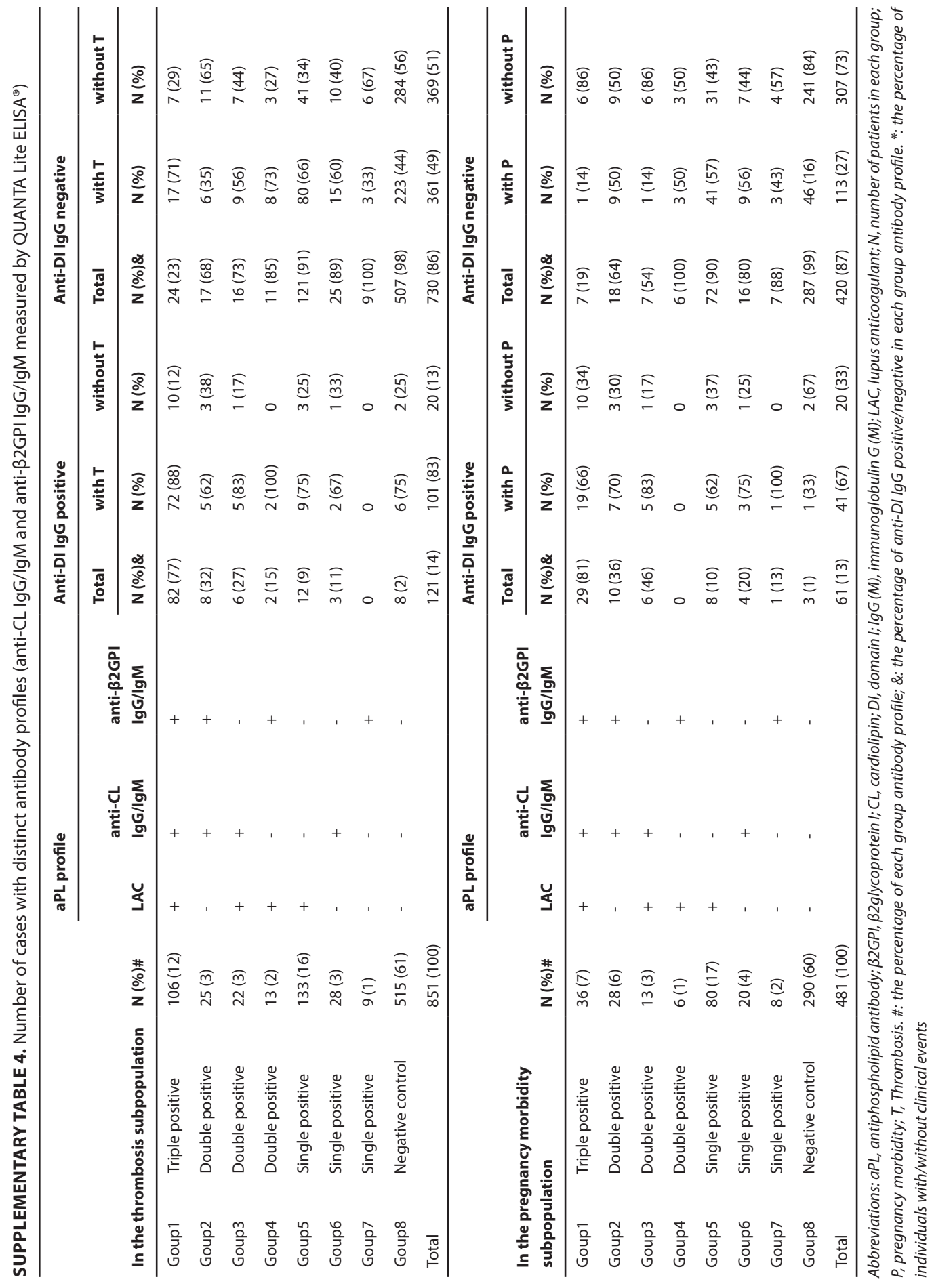


SUPPLEMENTARY TABLE 5. Agreement between anti-DI lgG positivity and triple positivity for four platforms in the different subpopulations

\begin{tabular}{|c|c|c|c|c|}
\hline Agreement 1 & $\begin{array}{l}\text { HemosIL } \\
\text { AcuStar }^{\circledast}\end{array}$ & BioPlex $^{\circledR} 2200$ & Phadia ${ }^{\circledR}$ & $\begin{array}{c}\text { QUANTA } \\
\text { Lite }^{\circledR} \text { ELISA }\end{array}$ \\
\hline $\begin{array}{l}\text { In the thrombosis } \\
\text { subpopulation }\end{array}$ & $0.746^{* * *}$ & $0.712^{* * *}$ & $0.686^{* * *}$ & $0.680^{* * *}$ \\
\hline $\begin{array}{l}\text { In the pregnancy } \\
\text { morbidiy } \\
\text { subpopulation }\end{array}$ & $0.679 * * *$ & $0.636^{* * *}$ & $0.616^{* * *}$ & $0.556^{* * *}$ \\
\hline
\end{tabular}

${ }^{1}$ Kappa values are shown

*** $P<0.0001$

SUPPLEMENTARY TABLE 6. Comparison of anti-DI IgG titers between triple positive patients with and without clinial events

\begin{tabular}{|c|c|c|c|c|c|c|}
\hline \multirow{2}{*}{$\begin{array}{l}\text { Manufacturers } \\
\text { for anti-CL and } \\
\text { anti- } \beta 2 \text { GPI }\end{array}$} & \multicolumn{3}{|c|}{ In the thrombosis population } & \multicolumn{3}{|c|}{$\begin{array}{l}\text { In the pregnnacy } \\
\text { morbidity population }\end{array}$} \\
\hline & With T & Without T & $P$ value & With P & Without P & $P$ value \\
\hline HemosIL AcuStar ${ }^{\circledast}$ & $\begin{array}{c}169.0 \mathrm{CU} \\
(25.7-761.3)\end{array}$ & $\begin{array}{c}63.7 \mathrm{CU} \\
(3.7-625.7)\end{array}$ & 0.084 & $\begin{array}{c}200.2 \mathrm{CU} \\
(49.6-462.1)\end{array}$ & $\begin{array}{c}65.0 \mathrm{CU} \\
(3.7-654.3)\end{array}$ & 0.179 \\
\hline BioPlex $^{\circledast} 2200$ & $\begin{array}{c}156.1 \mathrm{CU} \\
(18.9-635.2)\end{array}$ & $\begin{array}{c}11.8 \mathrm{CU} \\
(3.7-349.4)\end{array}$ & 0.014 & $\begin{array}{c}191.2 \mathrm{CU} \\
(47.9-433.6)\end{array}$ & $\begin{array}{c}13.8 \mathrm{CU} \\
(3.7-364.2)\end{array}$ & 0.024 \\
\hline Phadia $^{\circledR}$ & $\begin{array}{c}202.5 \mathrm{CU} \\
(30.1-769.6)\end{array}$ & $\begin{array}{c}25.1 \mathrm{CU} \\
(3.7-560.3)\end{array}$ & 0.044 & $\begin{array}{c}200.2 \mathrm{CU} \\
(47.9-588.2)\end{array}$ & $\begin{array}{c}66.4 \mathrm{CU} \\
(4.6-682.8)\end{array}$ & 0.238 \\
\hline QUANTA Lite ELISA ${ }^{\circledR}$ & $\begin{array}{c}229.0 \mathrm{CU} \\
(39.8-833.4)\end{array}$ & $\begin{array}{c}66.4 \mathrm{CU} \\
(3.7-799.6)\end{array}$ & 0.236 & $\begin{array}{c}308.2 \mathrm{CU} \\
(160.2-881.7)\end{array}$ & $\begin{array}{c}87.4 \mathrm{CU} \\
(3.7-829.3)\end{array}$ & 0.285 \\
\hline
\end{tabular}

Abbreviations: $\beta 2 G P I, \beta 2$ glycoprotein l; $C L$, cardiolipin; $C U$, chemiluminescence units; DI, domain l; $P$, pregnancy morbidity; $T$, thrombosis

Titer of anti-DI IgG are expressed as the median (quartile(Q)25- Q75), Mann-Whiney U test was used to compare difference of two groups, the significant $p$ values are showed in bold 

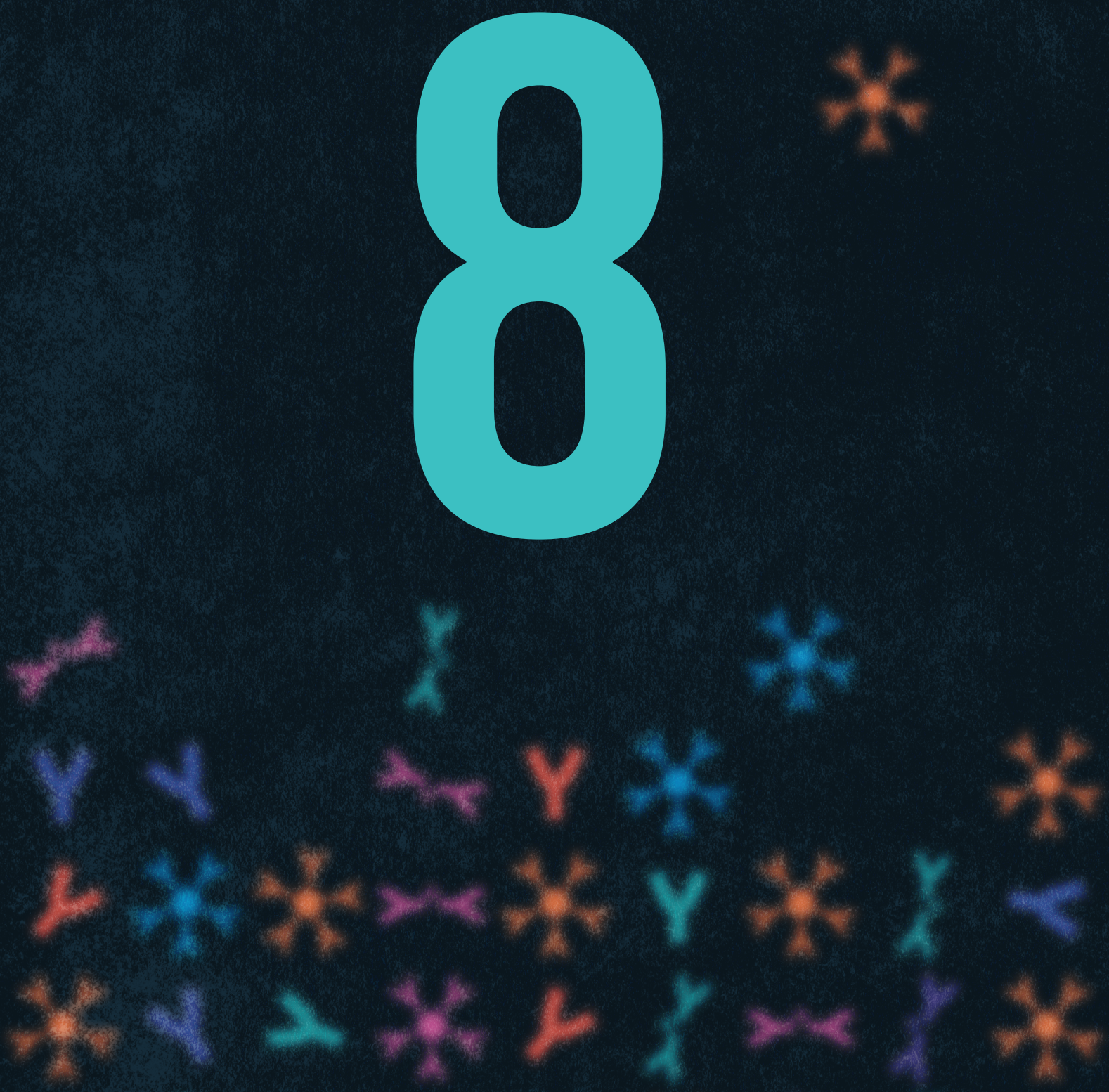


\section{Antiprothrombin antibodies induce platelet activation: a possible explanation for anti-FXa therapy failure in patients with antiphospholipid syndrome?}

Walid Chayoua, Phillip L.R. Nicolson, Joost C.M. Meijers, Caroline Kardeby, Lourdes GarciaQuintanilla, Katrien M.J. Devreese, Bas de Laat, Stephen P. Watson, Philip G. de Groot

Submitted 


\section{ABSTRACT}

Background: Arterial and venous thrombosis are both common in antiphospholipid syndrome (APS). Recent studies have shown that anti-FXa therapy in APS patients leads to a greater number of patients with arterial thrombosis than with warfarin. We hypothesise that this may be due to the lowering of prothrombin levels by warfarin.

Objectives: To investigate whether antiprothrombin antibodies induce platelet aggregation and to identify the platelet receptors involved. A second aim was to investigate the effect of reduced prothrombin levels on antiprothrombin antibodyinduced platelet aggregation.

Methods: Enzyme-linked immunosorbent assays (ELISAs) were performed to measure binding of antiprothrombin antibodies to prothrombin fragment $1+2$ and prothrombin. Platelet aggregation assays in washed platelets were performed. FcyRIIA was immunoprecipitated and tyrosine-phosphorylated FcyRIIA was measured by western blot.

Results: The antiprothrombin antibodies 28F4 and 3B1 had lupus anticoagulant (LAC) activity and caused platelet aggregation in the presence of $\mathrm{Ca}^{2+}$ and prothrombin. Antiprothrombin antibodies without LAC activity did not activate platelets. Inhibition of Syk, Src and FcyRIIA blocked platelet aggregation. Fab and F(ab')2 fragments of $28 \mathrm{~F} 4$ were unable to induce platelet aggregation. Immunoprecipitations showed that whole $28 \mathrm{~F} 4 \mathrm{lgG}$ induced tyrosine phosphorylation of FcyRIIA. Platelet aggregation was significantly reduced when prothrombin levels were reduced from $1 \mu \mathrm{M}$ to $0.2 \mu \mathrm{M}$.

Conclusions: Antiprothrombin antibodies with LAC activity are able to activate platelets via FcyRIIA. Decreased prothrombin levels resulted in less antiprothrombin antibody-mediated platelet aggregation. This may explain the lower incidence of arterial thrombosis in patients treated with warfarin than with anti-FXa therapy. 


\section{INTRODUCTION}

Antiphospholipid syndrome (APS) is characterized by thrombosis and/or pregnancy complications due to the persistent presence of antiphospholipid (aPL) antibodies [1]. Laboratory criteria for classification of APS include detection of lupus anticoagulant (LAC), anti- $\beta 2$-glycoprotein I (aß2GPI) and anticardiolipin ( $\mathrm{aCL}$ ) lgG/M antibodies [1]. Clinical criteria for classification of thrombotic APS include venous, arterial and small vessel thrombosis. The updated European League Against Rheumatism (EULAR) recommendations on managing thrombotic APS patients recommend long-term vitamin $\mathrm{K}$ antagonists as the standard of care [2].

Direct oral anticoagulants (DOACs) like rivaroxaban, a direct FXa inhibitor, are currently prescribed to patients with venous thromboembolism and atrial fibrillation. The advantage of DOACs is that they are given at a fixed dose and do not need laboratory monitoring. Interestingly, two trials reported predominantly arterial thrombosis in patients treated with rivaroxaban with a high rate of stroke [3,4]. No cases of stroke were reported in patients treated with warfarin $[3,4]$. Recent professional guidance statements have been issued regarding the use of DOACs in APS patients and recommended against DOACs in triple positive APS patients (defined by the presence of LAC, aß2GPI and $\mathrm{aCL}$ antibodies) and in arterial thrombosis [5].

Blood platelets play a key role in arterial thrombosis [6]. Antibodies against $\beta 2 \mathrm{GPI}$ are known to activate platelets via glycoprotein (GP) Iba and apolipoprotein E receptor $2[7,8]$. Triple positive APS patients have the highest risk of thrombotic complications and these patients usually have both a $32 \mathrm{GPI}$ antibodies and anti-phosphatidylserine/ prothrombin (aPS/PT) antibodies [9]. A systematic review identified aPS/PT antibodies as a risk factor for arterial thrombosis [10]. Still, experimental data on aPS/PT antibodies and platelet aggregation are lacking.

The overall aim was to investigate whether antiprothrombin antibodies stimulate platelet activation and to identify the underlying mechanism. This included investigation of the effect of reduced prothrombin levels on platelet aggregation as warfarin reduces the synthesis of prothrombin, while DOACs do not [11]. Decreased levels of prothrombin may explain why warfarin-treated APS patients are protected against arterial thrombosis while those treated with rivaroxaban are not. 


\section{MATERIAL AND METHODS}

\section{Reagents}

Purified human prothrombin was from Synapse Research Institute (Maastricht, The Netherlands) and rivaroxaban (Xarelto) was from Bayer Schering Pharma AG (Berlin, Germany). Anti-FcyRIIA mAb IV.3 was purified in the laboratory from a hybridoma [12]. The antiprothrombin monoclonal antibody (mAb) 28F4 is a mouse lgG antibody as described previously $[13,14]$. Antiprothrombin fragment $1+2 \mathrm{mAbs} 3 \mathrm{~B} 1,6 \mathrm{~A} 3,11 \mathrm{H} 2$ and $8 \mathrm{H} 11$ were developed and produced according to standard procedures [15]. LAC was measured by activated Partial Thromboplastin Time (aPTT; Diagnostica Stago, Asnières sur Seine, France), dilute Russell Viper Venom Time (dRVVT; Diagnostica Stago), and Ecarin Clotting Time (ECT; Diagnostic Reagents, Thame, UK). The Pierce Classic IP Kit from Thermo Fisher Scientific (Waltam, MA, USA) was used for immunoprecipitation. High-binding ELISA plates from Costar (New York, NY, USA) were used for the ELISAs. Sheep anti-human prothrombin IgG HRP labeled antibody was from Affinity Biologicals, Inc. (Ancaster, ON, Canada), prothrombin fragment $1+2$ was from Haematologic Technologies, Inc. (Essex Junction, VT, USA). All other reagents are previously described or are from Sigma-Aldrich (Poole, UK) [16].

\section{Preparation of washed platelets}

Blood was drawn by venipuncture into $4 \%$ sodium citrate from consenting, selfreported healthy volunteers. Platelet rich plasma (PRP) was obtained by centrifugation at $200 \mathrm{~g}$ for 20 minutes at room temperature. Washed platelets were obtained by further centrifugation of PRP at 1,000 g for 10 minutes in the presence of $0.2 \mu \mathrm{g} / \mathrm{mL}$ prostacyclin and resuspended in modified-Tyrode's-HEPES buffer (134 mM NaCl, 0.34 mM Na2HPO4, 2.9 mM KCl, 12 mM NaHCO3, 20 mM HEPES, 5mM glucose, 1 mM MgCl2; $\mathrm{pH} 7.3$ ) as previously described [16]. Platelets were used at $2 \times 108 / \mathrm{mL}$ and $4 \times 108 / \mathrm{mL}$ for aggregation studies and immunoprecipitation, respectively.

\section{Fab and $F\left(a b^{\prime}\right)_{2}$ antibody fragments}

Fab fragments from 28F4 were generated by 4 hour incubation of $5 \mathrm{mg} / \mathrm{mL}$ antibody with immobilized Ficin in the presence of $25 \mathrm{mM}$ cysteine (Pierce, ThermoFisher) at $37^{\circ} \mathrm{C}$. $\mathrm{F}\left(\mathrm{ab} \mathrm{b}_{2}\right)_{2}$ fragments from $28 \mathrm{~F} 4$ were generated by 24 hour incubation of $5 \mathrm{mg} / \mathrm{mL}$ antibody with immobilized Ficin in the presence of $4 \mathrm{mM}$ cysteine (Pierce) at $37^{\circ} \mathrm{C}$. Preparations were then applied to an immobilized protein A column (Pierce) followed by dialysis to remove any remaining cysteine. The purity of the $F a b$ and $F(a b ')$, fragments was verified by SDS-PAGE. 


\section{Lupus anticoagulant testing}

Normal pooled plasma was incubated with $50 \mu \mathrm{g} / \mathrm{ml} \mathrm{mAb}$ for $10 \mathrm{~min}$ at $37^{\circ} \mathrm{C}$ prior to LAC testing. LAC was performed according to the SSC guidelines and manufacturer's instructions for ECT were followed $[17,18]$.

\section{ELISA}

The mAb 28F4 $(5 \mu \mathrm{g} / \mathrm{ml})$ was coated onto an ELISA plate overnight at $4^{\circ} \mathrm{C}$. Blocking buffer consisted of $5 \%$ Bovine Serum Albumin (BSA) and $5 \mathrm{mM} \mathrm{CaCl}_{2}$ in Tris Buffered Saline (TBS), ( $\mathrm{pH}$ 7.6). Washing buffer was $5 \mathrm{mM} \mathrm{CaCl}_{2}$ and $0.1 \%$ Tween in TBS, pH 7.6. Increasing concentrations of antigen (prothrombin fragment 1+2, purified prothrombin or platelet poor plasma) was incubated for 1 hour at room temperature. Sheep antihuman prothrombin lgG HRP-labeled antibody (1:1000) was used as secondary antibody followed by staining with tetra methyl benzidine (TMB) (ThermoFisher). The reaction was stopped with $2 \mathrm{M} \mathrm{H}_{2} \mathrm{SO}_{4}$ and absorption was measured at $405 \mathrm{~nm}$.

\section{Platelet aggregation assay}

Platelet aggregation was assessed by light transmission aggregometry (LTA) in a PAP-8E (Bio/Data Corporation, Horsham, PA, USA) aggregometer for up to 30 minutes. Washed platelets were incubated with aPT antibodies for 5 min with an antiprothrombin antibody $(50 \mu \mathrm{g} / \mathrm{mL})$ followed by $\mathrm{CaCl}_{2}(10 \mathrm{mM})$ and purified human prothrombin (1 $\mu \mathrm{M})$. In some studies, platelets were preincubated with eptifibatide $(9 \mu \mathrm{M})$, vorapaxar $(1 \mu \mathrm{M})+$ BMS-986120 $(1 \mu \mathrm{M})$, indomethacin $(10 \mu \mathrm{M})$, ticagrelor $(10 \mu \mathrm{M})$, PRT-060318 $(5$ $\mu \mathrm{M})$, dasatinib $(10 \mu \mathrm{M}), \mathrm{mAb}$ IV.3 $(10 \mu \mathrm{g} / \mathrm{ml})$ or rivaroxaban $(200,400,800$, or $1000 \mathrm{nM})$ for $10 \mathrm{~min}$.

\section{Immunoprecipitation and western blotting}

Washed platelets were pretreated with $9 \mu \mathrm{M}$ eptifibatide to block integrin allb $\beta 3$. Crosslinking of IV.3 lgG (10 $\mu \mathrm{g} / \mathrm{ml})$ with $10 \mu \mathrm{g} / \mathrm{ml}$ anti-Fc (Biolegend, San Diego, CA, USA) served as a positive control. Platelets were stimulated at $37^{\circ} \mathrm{C}$ with stirring at $1200 \mathrm{rpm}$ on a PAP-8E aggregometer. Reactions were terminated by addition of ice-cold lysis buffer (0.025M Tris, 0.15M NaCl, 0.001M EDTA, 1\% NP-40, 5\% glycerol, pH 7.4). Lysates were incubated overnight with $\mathrm{mAb}$ IV.3 to form immune complexes. Precipitated proteins were separated by reducing SDS-PAGE, electro-transferred and Western blotted with the anti-phosphotyrosine antibody, clone 4G10.

\section{Ethics}

Ethical approval for collecting blood healthy volunteers was granted by Birmingham University Internal Ethical Review (ERN_11-0175). 


\section{Statistical analysis}

All data are presented as mean \pm standard deviation (SD). A p-value $<0.05$ was considered statistically significant. Statistical analysis was performed using Wilcoxon signed rank test, Kruskal-Wallis test with Dunn's Multiple Comparison Test and MannWhitney $U$ test as stated. All statistical analyses were performed using GraphPad Prism 7 (GraphPad Software Inc. La Jolla, Ca).

\section{RESULTS}

\section{Lupus anticoagulant activity}

The five antiprothrombin mAbs $(28 \mathrm{~F} 4,3 \mathrm{~B} 1,6 \mathrm{~A} 3,11 \mathrm{H} 2$ and $8 \mathrm{H} 11)$ were raised against $\mathrm{F} 1+2$, the activation peptide of prothrombin. Of these mAbs, only $28 \mathrm{~F} 4$ and $3 \mathrm{~B} 1$ caused LAC activity in the dilute Russell Viper Venom Time (dRVVT) and activated Partial Thromboplastin Time (aPTT) tests. The other three mAbs $(11 \mathrm{H} 2,6 \mathrm{~A} 3$ and $8 \mathrm{H} 11)$ had no effect on the clotting time (Supplemental Table 1). The Ecarin Clotting Time (ECT) reagent converts prothrombin into thrombin, independently of phospholipids. The mAbs 28F4 and 3B1 did not prolong the ECT and did not inhibit thrombin activity when tested with a fluorescent substrate. However, mAb 28F4 did bind to prothrombin fragment $1+2$, purified prothrombin and native prothrombin in plasma in an Enzymelinked immunosorbent assay (Supplemental Figure 1).

\section{Platelet aggregation}

Adding mAbs $28 \mathrm{~F} 4$ and $3 \mathrm{~B} 1$, but not $11 \mathrm{H} 2,6 \mathrm{~A} 3$ and $8 \mathrm{H} 11$, resulted in aggregation of washed platelets in the presence of prothrombin and $\mathrm{Ca}^{2+}$ (Figure $1 \mathrm{~A}$ ), indicating a correlation between LAC-activity and platelet aggregation. mAb 28F4 induced aggregation in washed platelets in the presence but not absence of $\mathrm{Ca}^{2+}$ (Supplemental Figure 2) or prothrombin (not shown). 28F4 was the most potent at inducing platelet aggregation and LAC-activity. Preincubation of washed platelets with $1 \mu \mathrm{g} / \mathrm{ml} 28 \mathrm{~F} 4$ resulted in partial aggregation. Full platelet aggregation was achieved with $10 \mu \mathrm{g} / \mathrm{ml}$ $28 F 4$. Addition of 200 - $1000 \mathrm{nM}$ rivaroxaban to washed platelets did not influence the aggregation profile.

\section{Platelet signalling}

Inhibitors were used to investigate the mechanism involved in antiprothrombininduced platelet aggregation to low $(10 \mu \mathrm{g} / \mathrm{ml})$ and high $(50 \mu \mathrm{g} / \mathrm{ml})$ concentrations of $\mathrm{mAb} 28 \mathrm{~F} 4$. Pretreatment of platelets with the allb $\beta 3$ antagonist eptifibatide inhibited platelet aggregation to both concentrations of mAb 28F4 (Table 1). Indomethacin and 
ticagrelor, which block cyclooxygenase and the $\mathrm{P} 2 \mathrm{Y}_{12}$ receptor, respectively, attenuated but did not block platelet aggregation. Platelet aggregation induced by mAb 28F4 was not altered in the combined presence of the PAR-1 and PAR-4 antagonists, vorapaxar and BMS-986120, respectively. The same Low-dose of mAb $28 \mathrm{~F} 4(10 \mu \mathrm{g} / \mathrm{ml})$ and high dose of $\mathrm{mAb} 28 \mathrm{~F} 4(50 \mu \mathrm{g} / \mathrm{ml})$ was used to assess the effect of platelet antagonists. Platelet aggregation was measured as increase of light transmission. Results are shown as mean $\pm S D(n=3)$ concentrations of the two antagonists blocked thrombin mediated platelet aggregation (data not shown). The Syk and Src inhibitors, PRT-060318 and dasatinib, respectively, blocked aggregation to both concentrations of $\mathrm{mAb} 28 \mathrm{~F} 4$, which indicates involvement of signalling via receptors containing an immunoreceptor tyrosine-based activation motif (ITAM). Three ITAM-containing receptors of human platelets are known including: C-type lectin-like receptor 2 (CLEC-2), glycoprotein VI (GPVI) and FcyRIIA (Fc receptor for lgG).
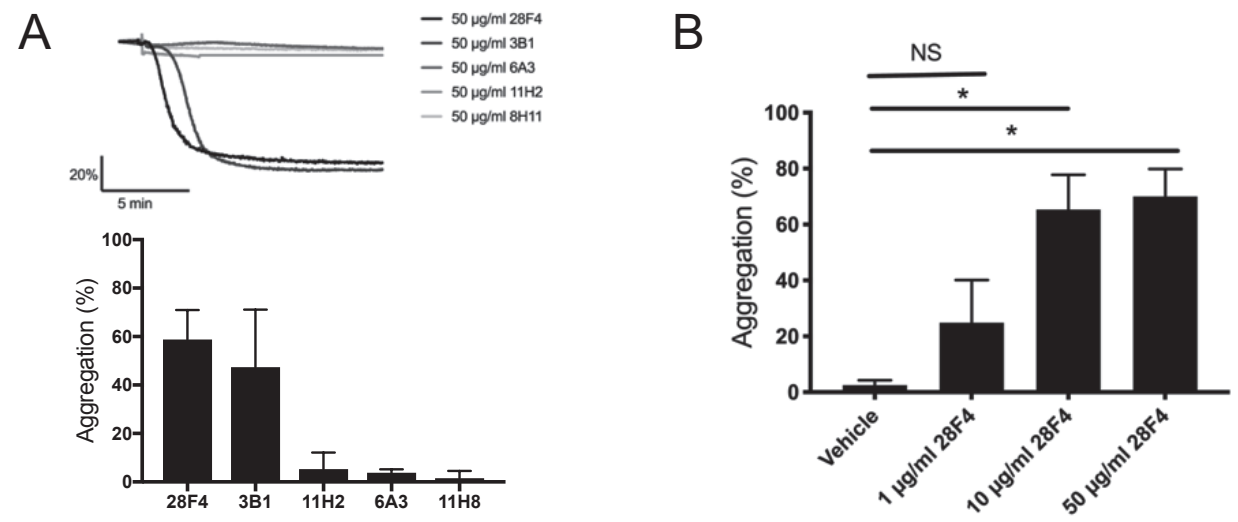

FIGURE 1. The mAbs $28 \mathrm{~F} 4$ and $3 \mathrm{~B} 1$ induce platelet aggregation in the presence of $\mathrm{Ca}^{2+}$ and prothrombin. A) Representative traces of light transmission aggregometry using washed platelets at a concentration of $2 \times 10^{8} / \mathrm{ml}$. Aliquots of platelet suspension were stimulated with $50 \mu \mathrm{g} / \mathrm{ml}$ of $\mathrm{mAbs} 28 \mathrm{~F} 4,3 \mathrm{~B} 1$, $6 \mathrm{~A} 3,11 \mathrm{H} 2$, or $8 \mathrm{H} 11$ in the presence of $10 \mathrm{mM} \mathrm{Ca}^{2+}$ and $1 \mu \mathrm{M}$ prothrombin $(n=3)$. B) Quantification of platelet aggregation induced by increasing doses of $\mathrm{mAb} 28 \mathrm{~F} 4$. Platelet aggregation was measured as increase of light transmission. Results are shown as mean $\pm S D(n=3)$. Statistical significance was analyzed using the Kruskal-Wallis test. ${ }^{*} \mathrm{P}<0.05$. NS, not significant. 
TABLE 1. ITAM signaling is involved in antiprothrombin induced platelet aggregation

\begin{tabular}{lcc}
\hline & $\begin{array}{c}\mathbf{2 8 F 4}(\mathbf{1 0} \boldsymbol{\mu g} / \mathbf{m l}) \\
\text { \% aggregation } \mathbf{\pm} \mathbf{S D}\end{array}$ & $\begin{array}{c}\mathbf{2 8 F 4}(\mathbf{5 0} \boldsymbol{\mu g} / \mathbf{m l}) \\
\text { \% aggregation } \pm \mathbf{S D}\end{array}$ \\
\hline Vehicle & $65.4 \pm 10.2$ & $70.0 \pm 8.1$ \\
Eptifibatide $(9 \mu \mathrm{M})$ & $4.5 \pm 1.4$ & $18.0 \pm 9.2$ \\
Indomethacin $(10 \mu \mathrm{M})$ & $22.3 \pm 11.2$ & $38.9 \pm 18.2$ \\
PRT-06318 $(5 \mu \mathrm{M})$ & $2.5 \pm 2.8$ & $3.9 \pm 1.8$ \\
Ticagrelor $(10 \mu \mathrm{M})$ & $11.0 \pm 6.0$ & $19.6 \pm 15.7$ \\
Dasatinib $(10 \mu \mathrm{M})$ & $2.7 \pm 1.7$ & $4.2 \pm 2.6$ \\
Vorapaxar $(1 \mu \mathrm{M})+\mathrm{BMS}-986120(1 \mu \mathrm{M})$ & $65.8 \pm 2.3$ & $74.6 \pm 4.1$ \\
\hline
\end{tabular}

\section{Involvement of FcyRIIA}

Of the three platelet ITAM-containing receptors, the FcyRIIA receptor was felt to be the most likely to be involved in the response to the antiprothrombin antibodies as it is a low affinity receptor for the Fc domain. Tyrosine phosphorylation of FcyRIIA was induced by mAb 28F4 as measured by immunoprecipitation and western blotting (Figure 2). Crosslinked IV.3 (anti-FcyRIIA antibody) was used as a positive control. As expected, rhodocytin and CRP, known stimulators of CLEC-2 and GPVI respectively, did not result in tyrosine phosphorylation of FcyRIIA. Non-crosslinked mAb IV.3 inhibited 28F4 and 3B1-induced platelet aggregation (Figure 3 and not shown). Fab and F(ab')2 antibody fragments of mAb 28F4 were unable to induce platelet aggregation (not shown) confirming the critical role of the Fc domain.

\section{The link between prothrombin levels and platelet aggregation}

We investigated whether prothrombin levels affected mAb 28F4-induced platelet aggregation as a possible explanation for anti-FXa therapy failure in patients with APS. Platelet aggregation was assessed in washed platelets in the presence of $50 \mu \mathrm{g} / \mathrm{ml} 28 \mathrm{~F} 4$ with two concentrations of prothrombin. Aggregation was found to be attenuated by $59 \%$ when prothrombin levels were reduced from $1 \mu \mathrm{M}$ to $0.2 \mu \mathrm{M}$, suggesting a direct link between prothrombin levels and platelet aggregation (Figure 4). 

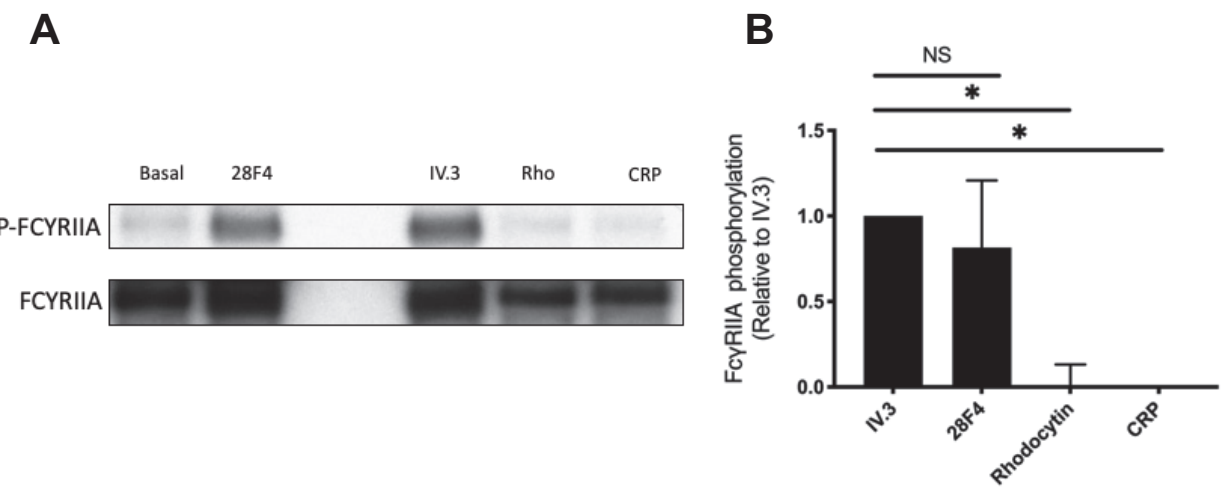

FIGURE 2. FcyRIIA is tyrosine-phosphorylated in the presence of mAb 28F4. A. Representative blot of five experiments. B. Mean data of signal for p-FcyRIIA. The signal obtained from cross-linked mAb IV.3 was normalized against total FcyRIIA and set as a reference (1 AU). Differences were analyzed with the KruskalWallis test. Results are shown as mean $\pm S D$ with $n=5$. ${ }^{*} P<0.05$. NS, not significant.

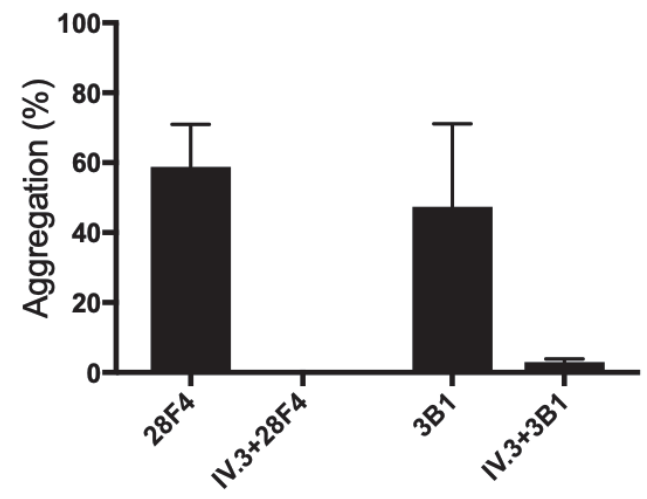

FIGURE 3. Antiprothrombin induced platelet aggregation can be blocked by mAb IV.3 (anti-FcyRIIA) antibody. Aliquots of platelet suspension were preincubated with mAb IV.3 $(10 \mu \mathrm{g} / \mathrm{ml})$ followed by stimulation using mAbs $28 \mathrm{~F} 4(50 \mu \mathrm{g} / \mathrm{ml})$ or $3 B 1(50 \mu \mathrm{g} / \mathrm{ml})$. Platelet aggregation was measured as increase of light transmission. Results are shown as mean $\pm S D(n=5)$. Statistical significance was analyzed using the Mann-Whitney U test $\left.{ }^{*} p<0.05\right)$. 
A

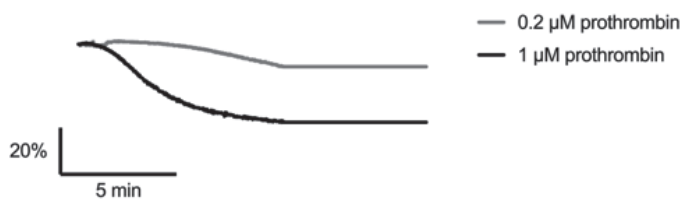

B

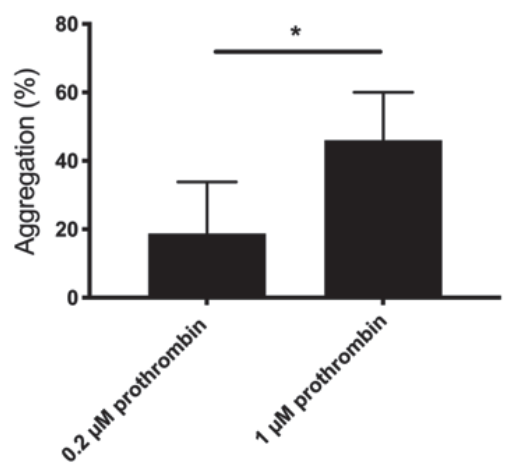

FIGURE 4. Decreased prothrombin levels results in attenuated platelet aggregation. A) Representative traces of light transmission aggregometry using washed platelets at a concentration of $2 \times 10^{8} / \mathrm{ml}$. Aliquots of platelet suspension were preincubated with $0.2 \mu \mathrm{M}$ prothrombin or $1 \mu \mathrm{M}$ prothrombin, followed by stimulation using $50 \mu \mathrm{g} / \mathrm{ml} \mathrm{mAb} 28 \mathrm{~F} 4$. B) Quantification of platelet aggregation in the presence of two concentrations of prothrombin. Platelet aggregation was measured as increase of light transmission. Results are shown as mean $\pm S D(n=5)$. Statistical significance was analyzed using the Mann-Whitney $U$ test $\left({ }^{*} p<0.05\right)$.

\section{DISCUSSION}

In this study, we show that (i) antiprothrombin antibodies with LAC activity, but not those without LAC activity, are able to activate platelets via the FcyRIIA receptor and (ii) decreased prothrombin levels result in less antiprothrombin antibody-mediated platelet aggregation. These results suggest an important role of antiprothrombin antibodies with LAC activity in platelet activation. We speculate that the LAC activity is required for binding of the prothrombin/antiprothrombin complex to the platelet surface leading to binding of the Fc portion of the antiprothrombin antibodies to FcyRIIA and platelet activation.

Antiprothrombin antibodies with LAC activity are associated with APC resistance [19]. We were able to demonstrate platelet aggregation caused by antiprothrombin antibodies with LAC activity, indicating that antiprothrombin antibodies with LAC activity are potentially pathogenic. Antiprothrombin antibodies can be detected by coating prothrombin on irradiated ELISA plates or using phosphatidylserine (PS) prothrombin complex as antigen [10]. The presence of aPS/PT antibodies is considered to be a stronger predictor of thrombosis than antiprothrombin antibodies [10]. However, we demonstrated binding of $\mathrm{mAb} 28 \mathrm{~F} 4$ to prothrombin in the absence of PS, by ELISA. $A$ 
recent study showed that at least two subpopulations of aPS/PT antibodies exist; aPS/PT antibodies that bind to the "open" conformation of prothrombin and aPS/PT antibodies able to react with "closed" prothrombin [20]. There were, however, no different pathological effects found between the two subpopulations of aPS/PT antibodies. In contrast, we were able to distinguish between antiprothrombin antibodies that were able to induce platelet aggregation and those that did not by measuring LAC activity. From the five antiprothrombin antibodies investigated, only mAbs $28 \mathrm{~F} 4$ and $3 \mathrm{~B} 1$ were able to induce platelet aggregation and LAC activity. Although mAb $28 \mathrm{~F} 4$ is able to bind closed prothrombin, thrombin activity was not inhibited. Which could be explained by the affinity of the investigated mAbs towards the activation peptide of prothrombin, fragment $1+2$, and not thrombin. These data indicate that $L A C$ activity determines the ability of antiprothrombin antibodies to induce platelet aggregation.

Data on the role of antiprothrombin antibodies in platelet activation are limited, probably because platelet aggregation studies are performed in citrated plasma and prothrombin needs $\mathrm{Ca}^{2+}$ to bind to platelets [21]. Although platelet function assays were not performed, one study showed the potency of $\mathrm{mAb} 28 \mathrm{~F} 4$ to induce platelet activation by measuring thromboxane $B_{2}$ levels, phospholipid related platelet procoagulant activity, and thrombin generation [19]. The platelet-dependent effect of mAb 28F4 was found to be reduced in the presence of an integrin allb $\beta 3$ inhibitor, but not with IV.3 [19]. The inability of showing involvement of the FcyRIIA receptor might be due to the low concentration of mAb IV.3 used in their study [19]. We have showed involvement of the FcyRlIA receptor in $\mathrm{mAb} 28 \mathrm{~F} 4$ induced platelet activation in three ways; (i) inhibited platelet aggregation by IV.3, (ii) tyrosine phosphorylation of the FcyRIIA receptor, and (iii) the inability of Fab and $\left.\mathrm{F}(\mathrm{ab})_{2}\right)_{2}$ fragments of $\mathrm{mAb} 28 \mathrm{~F} 4$ to aggregate platelets. In this respect, the mechanism of platelet activation by aPT antibodies mimics another auto-immune disease; heparin-induced thrombocytopenia (HIT) and thrombosis [22]. The presence of $\mathrm{Ca}^{2+}$ proved to be essential for platelet aggregation induced by antiprothrombin antibodies, suggesting $\mathrm{Ca}^{2+}$ dependent binding of antiprothrombinprothrombin immune complexes to negatively charged phospholipids expressed by platelets. Here we show a major role for FcyRIIA in antiprothrombin-induced platelet aggregation.

The TRAPS trial included APS patients with exclusively triple positive aPL (LAC, aCL and aß2GPI antibodies) in which rivaroxaban was compared with warfarin therapy [3]. Although aPS/PT antibodies were not measured in the trial, aPS/PT antibodies have shown to correlate well with triple positivity in other studies [20,23]. We found that platelet aggregation was attenuated when prothrombin levels were reduced. The link between prothrombin levels and platelet aggregation may explain the failure of anti- 
FXa therapy in patients with APS as rivaroxaban does not affect prothrombin levels in plasma, while vitamin $\mathrm{K}$ antagonists (e.g. warfarin) reduce active prothrombin (antigen) levels.

There are several limitations in our study, we used mAbs that recognize the prothrombin $\mathrm{F} 1+2$ fragment, but we did not further specify the site of recognition. In addition, we did not confirm our findings with patient antibodies and did not evaluate antiprothrombininduced platelet activation in patients receiving vitamin $\mathrm{K}$ antagonists or rivaroxaban therapy. Additional data are needed on the specification of antiprothrombin antibodies and their effect on platelets.

Here, we have shown that only antiprothrombin antibodies with LAC activity are able to activate platelets via the FcyRIIA receptor. Decreased prothrombin levels resulted in attenuated platelet aggregation which might be an explanation for the low prevalence of arterial thrombosis in APS patients treated with warfarin compared to rivaroxaban therapy. 


\section{ACKNOWLEDGEMENTS}

The authors thank Ying Di for her technical assistance. W.C. was supported by a grant (HS-BAFTA, Harry Struijker-Boudier Award For Talented Academics) issued by Cardiovascular Research Institute Maastricht (CARIM).

\section{AUTHORSHIP CONTRIBUTIONS}

W.C., P.G.dG., P.L.R.N., and S.P.W. designed the study. W.C., P.L.R.N., C.K., and L.G-Q. performed the measurements. LAC was measured under supervision of J.C.M.M. and K.M.J.D. W.C., P.L.R.N., S.P.W., B.dL., and P.G.dG. interpreted data, performed statistical analyses and wrote the manuscript. J.C.M.M., C.K., L.G-Q., and K.M.J.D. critically reviewed the manuscript.

\section{DISCLOSURE OF CONFLICTS OF INTEREST}

W.C. and B.dL. are employees of Synapse Research Institute, part of Diagnostica Stago SAS. P.G.dG is an advisor of Synapse Research Institute. SPW holds a BHF Chair (03/003). The other authors state that they have no relevant conflict of interest. 


\section{REFERENCES}

1 Miyakis S, Lockshin MD, Atsumi T, Branch DW, Brey RL, Cervera R, Derksen RHWM, Groot PGD, Koike T, Meroni PL, Reber G, Shoenfeld Y, Tincani A, Vlachoyiannopoulos PG, Krilis SA. International consensus statement on an update of the classification criteria for definite antiphospholipid syndrome (APS). Journal of Thrombosis and Haemostasis 2006; 4: 295-306.

2 Tektonidou MG, Andreoli L, Limper M, Amoura Z, Cervera R, Costedoat-Chalumeau N, Cuadrado MJ, Dörner T, Ferrer-Oliveras R, Hambly K, Khamashta MA, King J, Marchiori F, Meroni PL, Mosca M, Pengo V, Raio L, Ruiz-Irastorza G, Shoenfeld Y, Stojanovich L, et al. EULAR recommendations for the management of antiphospholipid syndrome in adults. Ann Rheum Dis 2019; 78: 1296-304.

3 Pengo V, Denas G, Zoppellaro G, Jose SP, Hoxha A, Ruffatti A, Andreoli L, Tincani A, Cenci C, Prisco D, Fierro T, Gresele P, Cafolla A, De Micheli V, Ghirarduzzi A, Tosetto A, Falanga A, Martinelli I, Testa S, Barcellona $D$, et al. Rivaroxaban vs warfarin in high-risk patients with antiphospholipid syndrome. Blood 2018; 132: 1365-71.

4 Ordi-Ros J, Sáez-Comet L, Pérez-Conesa M, Vidal X, Riera-Mestre A, Castro-Salomó A, CuquetPedragosa J, Ortiz-Santamaria V, Mauri-Plana M, Solé C, Cortés-Hernández J. Rivaroxaban Versus Vitamin K Antagonist in Antiphospholipid Syndrome: A Randomized Noninferiority Trial. Ann Intern Med 2019; .

5 Zuily $\mathrm{S}$, Cohen $\mathrm{H}$, Isenberg $\mathrm{D}$, Woller SC, Crowther M, Dufrost V, Wahl D, Doré CJ, Cuker A, Carrier M, Pengo V, Devreese KMJ. Use of direct oral anticoagulants in patients with thrombotic antiphospholipid syndrome: Guidance from the Scientific and Standardization Committee of the International Society on Thrombosis and Haemostasis. J Thromb Haemost 2020; 18: 2126-37.

6 Koupenova M, Kehrel BE, Corkrey HA, Freedman JE. Thrombosis and platelets: an update. Eur Heart J 2016; : ehw550.

7 Urbanus RT, Pennings MTT, Derksen RHWM, Groot PGD. Platelet activation by dimeric $\beta 2$ glycoprotein I requires signaling via both glycoprotein Iba and apolipoprotein E receptor 2'. Journal of Thrombosis and Haemostasis 2008; 6: 1405-12.

8 Shi T, Giannakopoulos B, Yan X, Yu P, Berndt MC, Andrews RK, Rivera J, Iverson GM, Cockerill KA, Linnik MD, Krilis SA. Anti- $\beta 2$-glycoprotein I antibodies in complex with $\beta 2$-glycoprotein I can activate platelets in a dysregulated manner via glycoprotein Ib-IX-V. Arthritis \& Rheumatism 2006; 54: 2558-67.

9 Litvinova E, Darnige L, Kirilovsky A, Burnel Y, de Luna G, Dragon-Durey M-A. Prevalence and Significance of Non-conventional Antiphospholipid Antibodies in Patients With Clinical APS Criteria. Front Immunol 2018; 9.

10 Sciascia S, Sanna G, Murru V, Roccatello D, Khamashta MA, Bertolaccini ML. Anti-prothrombin (aPT) and anti-phosphatidylserine/prothrombin (aPS/PT) antibodies and the risk of thrombosis in the antiphospholipid syndrome: A systematic review. Thromb Haemost 2014; 111: 354-64. 
11 Horton JD, Bushwick BM. Warfarin Therapy: Evolving Strategies in Anticoagulation. AFP 1999; 59: 635.

12 Arman M, Krauel K, Tilley DO, Weber C, Cox D, Greinacher A, Kerrigan SW, Watson SP. Amplification of bacteria-induced platelet activation is triggered by FcyRIIA, integrin allb $\beta 3$, and platelet factor 4. Blood 2014; 123: 3166-74.

13 Arnout J, Vanrusselt M, Nevens C, Smans K, Wittevrongel C and Vermylen J. Some Murine Monoclonal Antibodies Against Human Prothrombin have Lupus Anticoagulant Activity. Thromb Haemost 1999; Suppl August: 65.

14 Querrec AL, Arnout J, Arnoux D, Borg JY, Caron C, Darnige L, Delahousse B, Reber G, Sié P. Quantification of Lupus Anticoagulants in Clinical Samples Using Anti- $\beta 2$ GP1 and AntiProthrombin Monoclonal Antibodies. Thromb Haemost 2001; 86: 584-9.

15 Köhler G, Milstein C. Continuous cultures of fused cells secreting antibody of predefined specificity. Nature 1975; 256: 495-7.

16 Nicolson PLR, Hughes CE, Watson S, Nock SH, Hardy AT, Watson CN, Montague SJ, Clifford H, Huissoon AP, Malcor J-D, Thomas MR, Pollitt AY, Tomlinson MG, Pratt G, Watson SP. Inhibition of Btk by Btk-specific concentrations of ibrutinib and acalabrutinib delays but does not block platelet aggregation mediated by glycoprotein VI. Haematologica 2018; 103: 2097-108.

17 Devreese KMJ, de Groot PG, De laat B, Erkan D, Favaloro EJ, Mackie I, Martinuzzo M, Ortel TL, Pengo V, Rand JH, Tripodi A, Wahl D, Cohen H. Guidance from the Scientific and Standardization Committee for lupus anticoagulant/antiphospholipid antibodies of the International Society on Thrombosis and Haemostasis. J Thromb Haemost.

18 Moore GW, Culhane AP, Maloney JC, Archer RA, Breen KA, Hunt BJ. Taipan snake venom time coupled with ecarin time enhances lupus anticoagulant detection in nonanticoagulated patients. Blood Coagul Fibrinolysis 2016; 27: 477-80.

19 Membre A, Wahl D, Latger-Cannard V, Max J-P, Lacolley P, Lecompte T, Regnault V. The effect of platelet activation on the hypercoagulability induced by murine monoclonal antiphospholipid antibodies. Haematologica 2008; 93: 566-73.

20 Chinnaraj M, Planer W, Pengo V, Pozzi N. Discovery and characterization of 2 novel subpopulations of aPS/PT antibodies in patients at high risk of thrombosis. Blood Adv 2019; 3: $1738-49$.

21 Palatinus AA, Ahuja KDK, Adams MJ. Effects of antiphospholipid antibodies on in vitro platelet aggregation. Clin Appl Thromb Hemost 2012; 18: 59-65.

22 Warkentin TE, Greinacher A. Management of heparin-induced thrombocytopenia. Curr Opin Hematol 2016; 23: 462-70.

23 Pengo V, Banzato A, Bison E, Denas G, Zoppellaro G, Bracco A, Padayattil Jose S, Hoxha A, Ruffatti A. Laboratory testing for antiphospholipid syndrome. International Journal of Laboratory Hematology 2016; 38 Suppl 1: 27-31. 


\section{SUPPLEMENTAL DATA}

SUPPLEMENTAL TABLE 1. mAbs $28 \mathrm{~F} 4$ and $3 \mathrm{~B} 1$ induce LAC activity.

\begin{tabular}{lll}
\hline & dRVVT (ratio) & aPTT (ratio) \\
\hline NPP & 1.0 & 1.0 \\
$28 \mathrm{~F} 4$ & 2.05 & 2.05 \\
$3 \mathrm{~B} 1$ & 1.56 & 1.30 \\
$6 \mathrm{~A} 3$ & 1.08 & 1.03 \\
$11 \mathrm{H} 2$ & 1.03 & 1.02 \\
$8 \mathrm{H} 11$ & 1.06 & 1.02 \\
\hline
\end{tabular}

Normal pooled plasma (NPP) was incubated with $50 \mu \mathrm{g} / \mathrm{ml}$ monoclonal antibody (28F4, $3 B 1,6 \mathrm{~A} 3,11 \mathrm{H} 2$ or $8 \mathrm{H} 11)$ for $10 \mathrm{~min}$ at $37^{\circ} \mathrm{C}$ prior to $\mathrm{LAC}$ testing. $\mathrm{LAC}$ was performed according to the SSC guidelines [17]. Cut-off ratio for dRVVT and aPTT was 1.2, positive LAC results are shown in bold.

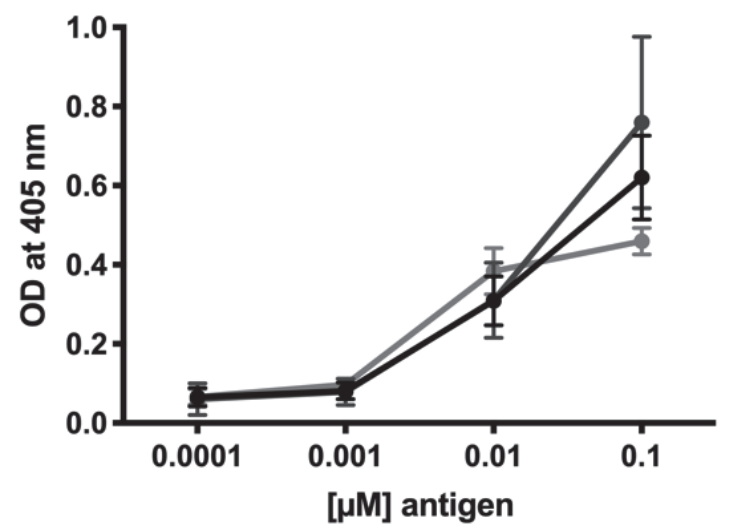

$\rightarrow$ Prothrombin fragment $1+2$

$\rightarrow$ Prothrombin

$\rightarrow$ Platelet poor plasma

Supplemental Figure 1. The mAb 28F4 binds to closed prothrombin. $28 \mathrm{~F} 4(5 \mu \mathrm{g} / \mathrm{ml})$ was incubated onto an ELISA plate with increasing antigen concentration; prothrombin fragment $1+2$, (purified) prothrombin or platelet poor plasma in the presence of $\mathrm{Ca}^{2+}$ for 1 hour. Results are shown as mean $\pm \mathrm{SD}(n=3)$. OD, optical density. 


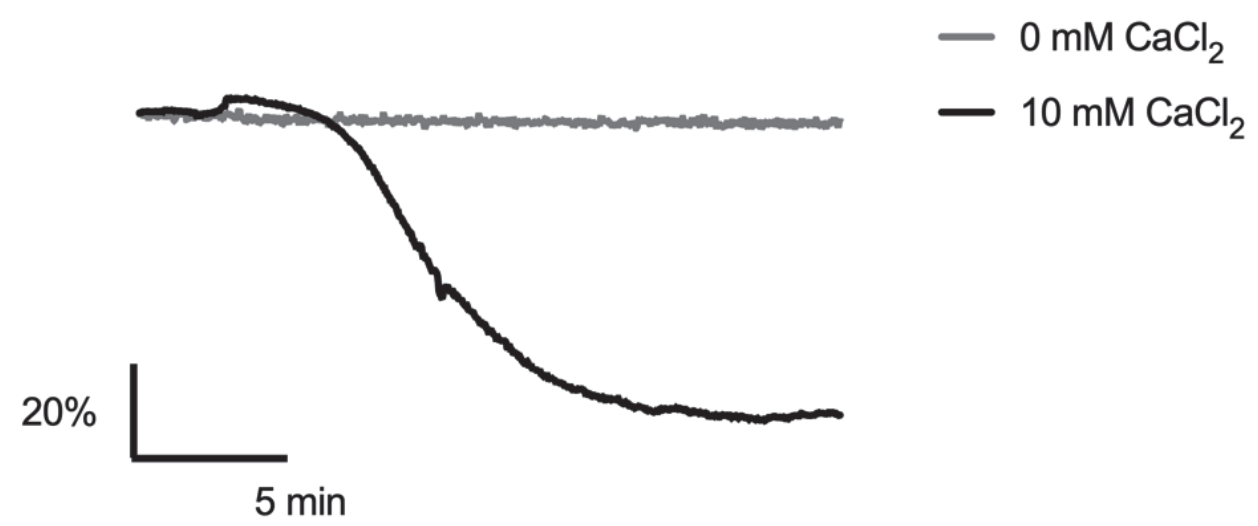

Supplemental Figure 2. $\mathrm{Ca}^{2+}$ is essential for $\mathbf{2 8 F 4 - i n d u c e d ~ p l a t e l e t ~ a g g r e g a t i o n . ~ R e p r e s e n t a t i v e ~ t r a c e s ~}$ of light transmission aggregometry using washed platelets at a concentration of $2 \times 108 / \mathrm{ml}$. Aliquots of platelet suspension were stimulated with $50 \mu \mathrm{g} / \mathrm{ml}$ of mAbs $28 \mathrm{~F} 4$ in the presence of $10 \mathrm{mM} \mathrm{Ca}^{2+}$ and $1 \mu \mathrm{M}$ prothrombin or in the absence of $\mathrm{Ca}^{2+}$. $(n=2)$ 

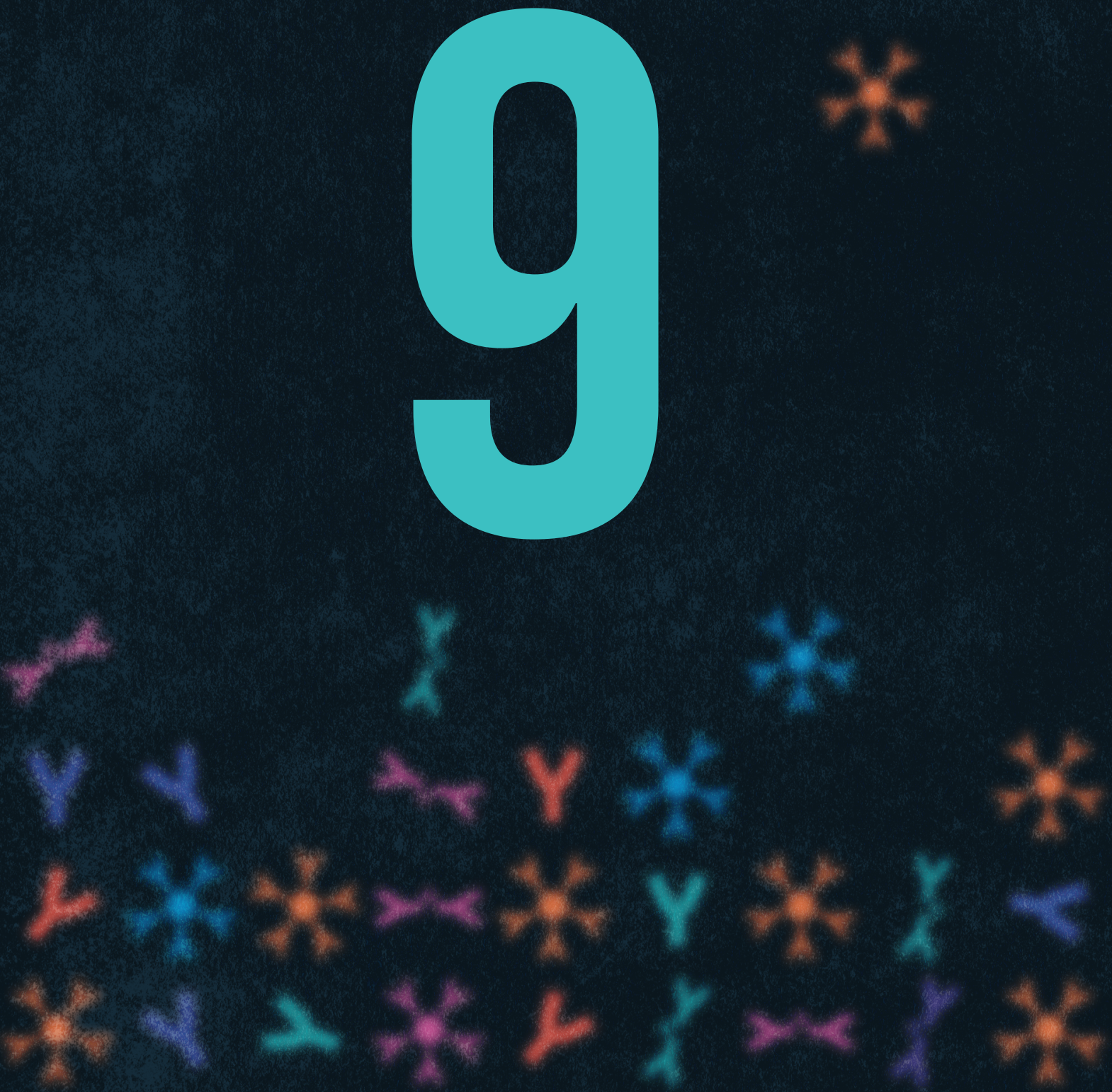
General discussion, summary and future perspectives 



\section{GENERAL DISCUSSION, SUMMARY AND FUTURE PERSPECTIVES}

The antiphospholipid syndrome (APS) is defined by thrombosis and/or specific pregnancy morbidity with the persistent presence of lupus anticoagulant (LAC), anticardiolipin ( $\mathrm{aCL}$ ) lgG/M and/or anti- $\beta 2$ glycoprotein I (aß2GPI) lgG/M antibodies [1]. Detection of antiphospholipid ( $\mathrm{aPL}$ ) antibodies is therefore of great importance for the diagnosis of APS. aCL and a $32 \mathrm{GPI}$ antibodies are traditionally detected using an enzyme linked immunosorbent assay (ELISA). However, technology has paved the way for new methods for the detection of $\mathrm{aCL}$ and $\mathrm{a} \beta 2 \mathrm{GPI}$ antibodies [2-6]. Detection of non-criteria aPL antibodies, e.g. aCL IgA, aß2GPI IgA, anti-phosphatidylserine/prothrombin (aPS/PT) $\mathrm{lgG/M}$ have been proposed in the updated classification criteria [7-13]. However, their relevance in the current $\mathrm{PPL}$ panel is unknown due to a lack of well-designed studies with large patient cohorts. Moreover, the role of the different aPL antibodies in clinical manifestations of APS and their interplay is not fully understood.

\section{Antiphospholipid antibodies and their importance in the laboratory diagnosis of APS}

Since the 1960's, correlations have been established between aPL antibodies and clinical manifestations of APS (thrombosis and/or pregnancy morbidity) [14]. In chapter 2, 3 and 4 we confirmed that $\mathrm{aCL} \operatorname{lgG} / \mathrm{M}$ and $\mathrm{a} \beta 2 \mathrm{GPI} \mathrm{IgG} / \mathrm{M}$ antibodies correlate with thrombotic events and/or pregnancy morbidity. ELISAs detecting $\mathrm{aCL}$ and $\mathrm{a} \beta 2 \mathrm{GPI}$ antibodies are poorly standardized and external quality control programs have shown that aPL assays produce variable results $[15,16]$. In chapter 2 we report low agreement of a new generation ELISA and automated systems detecting $\mathrm{aCL}$ and a $32 \mathrm{GPI}$ lgG/M antibodies, which could affect diagnosis of APS. Remarkably, the diagnostic accuracy was comparable, which was also illustrated in other studies [5,6,17-19].

Combined positivity for $\mathrm{LAC}, \mathrm{aCL}$ and aß2GPI antibodies (triple positivity) is a highrisk profile of which the identification is suggested to be less affected by intermethod variation [20]. However, as described in chapter 3, identification of triple positivity is dependent on the solid phase assay used to detect $\mathrm{aCL}$ and $\mathrm{a} \beta 2 \mathrm{GPI}$ antibodies. Interestingly, computed ORs for thrombosis were comparable. Since the laboratory diagnosis of APS relies on the detection of aPL antibodies, LAC testing and immunoassays should be reliable. Unfortunately, aPL antibody immunoassays obtained from different manufacturers are accompanied by a large inter-assay and inter- 
laboratory variation [16,21-24]. With five different aPL assays in the current criteria, many possible combinations (aPL profiles) are possible. However, knowledge about the clinical value of all possible aPL profiles is limited.

There is an ongoing discussion on the role of $\operatorname{lgM}$ aPL antibodies in the laboratory diagnosis of thrombotic APS [4,25-30]. A review of literature found more correlations for $\mathrm{aCL}$ and aß2GPI IgG antibodies than for the IgM isotype [25]. However, due to unavailability of paired IgG and IgM results, the added value of IgM aPL antibodies within the current aPL panel could not be established $[1,25]$. In chapter 4 , the added value of $\mathrm{aCL}$ and $\mathrm{a} \beta 2 \mathrm{GPI}$ IgM antibodies was investigated within the current $\mathrm{aPL}$ panel [1]. In agreement with literature, we found a higher association for IgG aPL antibodies with thrombosis and pregnancy morbidity than the IgM isotype [25]. IgM positivity was not independently associated with thrombosis, but was independently associated with pregnancy morbidity. The complement system has proven to play an important role in aPL antibody induced pregnancy morbidity [31]. Complement C3 activation has shown to be required for IgG aPL antibody induced fetal loss in mice [32]. IgM aPL antibodies might also induce fetal loss via a similar mechanism. However, data on complement activation by $\operatorname{lgM}$ aPL antibodies is lacking [33].

Non-criteria aPL (e.g. aCL IgA, a 32 GPI IgA, aPS/PT IgG and aPS/PT IgM antibodies) have been suggested to improve the laboratory diagnosis of APS. Chapter 5, describes the added value of detecting $\mathrm{aCL}$ and $\mathrm{a} \beta 2 \mathrm{GPI} \lg \mathrm{A}$ antibodies in APS. In agreement with multiple studies, $\mathrm{aCL}$ and $\mathrm{a} \beta 2 \mathrm{GPI} \lg \mathrm{A}$ antibodies correlated with thrombosis and/or pregnancy morbidity [8-11,34-39]. However, we were unable to demonstrate an added value for $\mathrm{aCL}$ and $\mathrm{a} \beta 2 \mathrm{GPI} \lg \mathrm{A}$ antibodies testing on top of the current $\mathrm{aPL}$ panel. Other groups have suggested that $\mathrm{aCL}$ and $\mathrm{a} \beta 2 \mathrm{GPI} \lg \mathrm{A}$ solid phase assays should be included in the classification criteria of APS as they could demonstrate a significant association of so-called "isolated" aCL and aß2GPI lgA antibodies with clinical manifestations of APS [8-13]. However, many of these studies did not include LAC testing, hampering assessment of truly isolated IgA positivity [9,11-13].

Antibodies against domain I of $\beta 2 \mathrm{GPI}$ (anti-DI) have been proven to be pathogenic in multiple studies [40-49]. In chapter 6, the performance characteristics of different anti-DI lgG assays is summarized and the significance of anti-DI antibodies in APS is discussed. We found a large variation in odds ratios (ORs) between studies, probably due to differences in patient and control population, but also as a result of differences in the detection method. In chapter $\mathbf{7}$ we were able to demonstrate a significant correlation of anti-DI positivity with previous thrombosis or pregnancy morbidity. However, addition of anti-DI lgG into the current aPL panel did not improve the association with clinical 
manifestations of APS. As suggested in our review, the clinical association could be the result of the solid phase assay used to detect anti-DI lgG antibodies [50]. A recent review, confirmed this hypothesis and demonstrated that the chemiluminescence assay $(\mathrm{CIA})$ used in chapter 7 to detect anti-DI does not expose the essential epitope containing Gly40-Arg43 on the antigen correctly [51].

In chapter 8 we demonstrated platelet aggregation induced by anti-prothrombin antibodies via the platelet FcyRIIA receptor. Interestingly, only the anti-prothrombin antibodies that also caused LAC activity could induce platelet aggregation. This would indicate that anti-prothrombin antibodies with LAC activity are a distinct group of anti-prothrombin antibodies. Decreased prothrombin levels resulted in less antiprothrombin antibody-mediated platelet aggregation. The link between prothrombin levels and platelet aggregation may explain the results of the clinical trials describing the failure of anti-FXa therapy (e.g. rivaroxaban) in patients with APS [52,53]. Because anti-FXa therapy does not affect prothrombin levels in plasma, anti-prothrombin antibodies can still induce platelet aggregation. On the contrary, vitamin K antagonists (e.g. warfarin) reduce active prothrombin (antigen) levels, thereby also reducing platelet aggregation mediated by anti-prothrombin antibodies

\section{Other reasons to test for anti-phospholipid antibodies}

Testing for aPL antibodies is mandatory to fulfill the laboratory criterion in the diagnosis of APS. Also, detection of aPL antibodies could be useful to explain the occurrence of thrombotic or obstetric events. In vitro experiments have shown that the presence of aPL antibodies can induce a pro-thrombogenic and inflammatory state [54-59]. In vivo, aPL antibodies have shown to induce thrombosis and pregnancy morbidity in animal models [49,60-63]. Another more important reason to detect aPL antibodies is assessing the risk of a future thrombotic event as clinical studies have shown that APS patients have a higher risk of a thrombotic recurrence compared to thrombotic patients without aPL antibodies $[64,65]$. Patients with thrombotic APS are therefore often prescribed long-term anticoagulation $[66,67]$. To avoid overdiagnosis, testing for aPL antibodies is only useful in patients with a significant probability of having APS. The presence of $\mathrm{aPL}$ antibodies can help to explain the occurrence of thrombotic or obstetric event and predict the risk of a recurrent clinical event.

Besides thrombosis and pregnancy morbidity, aPL antibodies have also been associated with non-criteria manifestations such as thrombocytopenia, nephropathy, cardiac valve disease, cognitive dysfunction and skin ulcers [68]. Detection of aPL antibodies is also 
one of the items for the classification of systemic lupus erythematosus (SLE). Also when a patient has an unexplained prolonged activated partial thromboplastin time (aPTT), aPL detection (LAC) could explain this [69].

\section{To more harmonized anti-phospholipid antibody testing}

The detection of LAC is associated with considerable inter-laboratory variability and high rates of false negative and false positive results $[16,70,71]$. However, the aim here is to elaborate on solid phase assays detecting aPL antibodies.

\section{Why we should consider centralized laboratory testing}

Detection of aPL antibodies by ELISAs are known to be associated with large inter-assay and inter-laboratory variation [21,22]. External quality programs have shown variation in antibody titers and classification of the same sample using aCL and aß2GPI ELISAs [22]. Pre-, post- and analytical conditions contribute to the variability in test results for aPL antibodies [21]. The contributing factors are both biological and methodical; the heterogeneity of the autoimmune antibodies, inadequate standardization of assays, differences in local working conditions, discussions or limited knowledge on the relevance of the antibodies, difficulties in correct interpretation of the results, lack of large prospective evaluation studies and the determination of the pathological cut-off level. Moreover, the lack of a link between antibody potency and recurrent thrombosis also contributes to the observed variation [4,21]. In the last 25 years, guidelines and proposals have been published in an attempt to standardize aPL antibody assays [4]. Moreover, complete standardization of aPL antibody assays is far from reached. With a lack of well standardized solid phase assays, centralized laboratory testing for aPL antibodies by solid phase assays could be an effective and adequate (interim) solution.

\section{The ideal solid phase assay}

Technology has advanced since the first description of a radioimmunoassay for the detection of aCL antibodies in 1983 [72]. Shortly after, an ELISA for the detection of aCL antibodies was described [73]. Nowadays automated assays have become available that use different solid phases (e.g. magnetic particles, microbeads, membranes, and coated polystyrene cups) with various detection methods (e.g. fluorescence, chemiluminescence and multiplex systems) [2-6]. Automated systems can reduce the inter-laboratory and intra-laboratory variation, but inter-assay variation still exists $[23,74]$. Despite the large inter-assay variation, diagnostic performance of solid phase assays detecting $\mathrm{aCL}$ and $\mathrm{a} \beta 2 \mathrm{GPI}$ antibodies is comparable [23]. Antibodies directed against Gly40-Arg43, located in DI of $\beta 2$ GPI have shown to be pathogenic $[40,75]$. In agreement, we found that the solid phase assay, that was most sensitive in detecting 
a monoclonal antibody against Gly40-Arg43, reached the highest odds ratio (OR) for thrombosis [23]. In addition, sensitivity to the cryptic epitope Gly40-Arg43 ensures correct exposure of $\beta 2$ GPI [76]. Therefore, a suitable assay should be preferably fully automated and sensitive to (pathogenic) antibodies against Gly40-Arg43.

\section{The ideal reference laboratory}

The aPL antibody performing laboratory should be a center of expertise within APS and able to evaluate the obtained results from solid phase assays in correlation with LAC results. Academic hospitals are located across the country, have an expertise in rare syndromes and have mostly fully equipped laboratories. Centralized testing opens the door to new possibilities like initiating a database and biobank for further research into APS. Conducting research is one of the core tasks of academic hospitals, making them excellent candidates for reference laboratories.

\section{Wide range of solid phase assays}

A variety of aPL antibody assays are available for the laboratories [66]. Some clinical laboratories do not measure all recommended $\mathrm{PPL}$ antibodies, while other laboratories also measure non-recommended aPL antibodies (e.g. aPS/PT IgG, aPS/PT IgM, aCL IgA and aß2GPI IgA) for the diagnosis of APS [77]. With a reference lab, this issue can be resolved by offering testing for all required assays (aCL IgG, aß2GPI IgG, aCL IgM and aß2GPI IgM). In addition, aPL antibody assays that have shown to be valuable in risk stratification like aPS/PT IgG and anti-DI aß2GPI IgG can also be offered [51].

\section{Clinical cut-off values}

An issue influencing interpretation of the results, is that most laboratories are unable to calculate in-house cut-off values from a sufficient number of healthy volunteers $[78,79]$. Alternatively, manufacturer's cut-off values may be transferred after validation using 20 healthy volunteers [2]. However, it is unsure whether the manufacturer calculated their cut-off value in an appropriate manner $[3,78]$. Specialized laboratories might be able to calculate cut-off values in a multicenter and clinical approach, which may improve diagnosis of APS [78].

\section{Paving a way for standardization}

Centralized laboratory testing might be a (interim) solution to reduce analytical and post analytical errors. However, we still have to acknowledge that variation between solid phase assays will still exist. Therefore, the designated laboratories should participate in quality control programs to improve harmonization. 
Efforts have been made for standardization by international reference materials including Harris standards (pool of patient material) and Koike standards (monoclonal antibodies) [21]. However, both standards have their disadvantage. The Harris standards are limited in production and Koike standards are directed against a single epitope, thus decreasing the sensitivity of the assay in which it is used [21]. Initiatives have been taken to ensure availability of international standards for the $\mathrm{aCL}$ and a $32 \mathrm{GPI}$ assay [80].

Centralized testing can pave the way for more harmonized aPL antibody testing by concentration of data from patient samples that might provide new insights in APS. Of note, logistical problems might arise in centralized testing.

\section{Testing for antiphospholipid antibodies in an academic, general and rural hospital}

Every patient should have access to the best healthcare available. However, in some cases, hospitals are limited by knowledge about rare diseases and/or the possibility to perform specific diagnostic assays. Here, we aim to discuss which laboratory tests should be performed in case a patient is suspected of APS and admitted to an academic hospital, general hospital or rural hospital in a developing country.

\section{Academic hospital}

Academic hospitals are equipped with specialized facilities and provide specialized care. If a patient is suspected of having APS, an academic hospital must be able to perform extensive testing. $\mathrm{LAC}$, aCL IgG/M and a $32 \mathrm{GPI} \mathrm{lgG} / \mathrm{M}$ testing are recommended for the classification of APS in patients with thrombosis or pregnancy morbidity. Although additional aPL antibodies can be tested, we need to bear in mind that immunoassays are associated with false negative and positive results [4].

\section{aCL and aß2GPI IgM antibodies in thrombotic APS}

Studies that investigated the added value of $\operatorname{lgM}$ aPL in large patient cohorts are limited $[25,81]$. In our multicenter study, the detection of $\mathrm{aCL}$ and a $32 \mathrm{GPI}$ IgM antibodies was found to be of little value in thrombotic APS [81]. Prospective data on the role of aCL and $a \beta 2$ GPI IgM antibodies within the current $\mathrm{aPL}$ panel is needed to exclude $\lg \mathrm{M}$ aPL from the classification criteria for APS. 


\section{Antiphospholipid antibody profiles}

Multiple studies have shown that it is more important to evaluate all aPL antibody results (aPL antibody profile) instead of single serological markers for APS [64,65,82-84]. Evaluation of complete aPL antibody profiles can be used to evaluate the "reliability" of diagnosis and to evaluate the risk of a recurrent event [82].

\section{Reliability of diagnosis}

The clinical relevance of single and double positivity for $\mathrm{aCL}$ and $\mathrm{a} \beta 2 \mathrm{GPI} \lg \mathrm{G} / \mathrm{M}$ is uncertain [82]. One of the reasons might be interferences with solid phase assays that induce false positive results. Evaluation of the complete aPL antibody profile can be used to evaluate the "reliability" of diagnosis. Figure 1 illustrates different aPL profiles from patients with negative LAC results and three possible interferences. Rheumatoid factor can give false positive $\mathrm{aCL}$ and/or a $32 \mathrm{GPI}$ IgM results $[1,85]$. If diagnosis of APS is solely dependent on $\operatorname{lgM} \mathrm{aPL}$, rheumatoid factor testing might be considered for the correct interpretation of the $\mathrm{aPL}$ antibody results $[1,85]$. Positivity for aCL but not for aß2GPI antibodies might be the result of an infectious disease (e.g. Syphilis and HIV) [85]. However, aß2GPI antibodies have shown to be present in patients with infectious diseases (e.g. leprosy) [73,86]. Interestingly, epitopes on domain IV or V have shown to be preferentially recognized by $\lg G$ antibodies in sera from antiphospholipidpositive individuals with leprosy $[50,86]$. While anti-DI antibodies, and not anti-D4/D5 antibodies are considered pathogenic [49]. Further evaluation of epitope specificity in aPL antibody positive patients with negative LAC results could distinguish between pathological and non-pathological aPL antibodies. Common infectious diseases should be ruled out if a patient is suspected of having APS with isolated aCL positivity. Finally, disagreement of the isotype should be labeled as inappropriate and re-testing should be considered [82].

\section{Risk stratification}

Once a patient is diagnosed with APS, it might be interesting to evaluate the aPL antibody profile for thrombotic risk stratification. Triple positivity is considered as a highrisk profile for thrombosis $[87,88]$. However, triple positivity does not take the isotype for which it is positive into an account [82]. Positivity for LAC, aCL IgG and aß2GPI IgG is considered a triple positive aPL profile. Likewise, positive results for $L A C, a C L$ IgM and $\mathrm{a} \beta 2 \mathrm{GPI} \lg \mathrm{M}$ and positive results for $\mathrm{LAC}, \mathrm{aCL} \lg \mathrm{G}, \mathrm{a} \beta 2 \mathrm{GPI} \lg \mathrm{G}, \mathrm{aCL} \lg \mathrm{M}$ and $\mathrm{a} \beta 2 \mathrm{GPI} \lg \mathrm{M}$ are considered triple positive. 


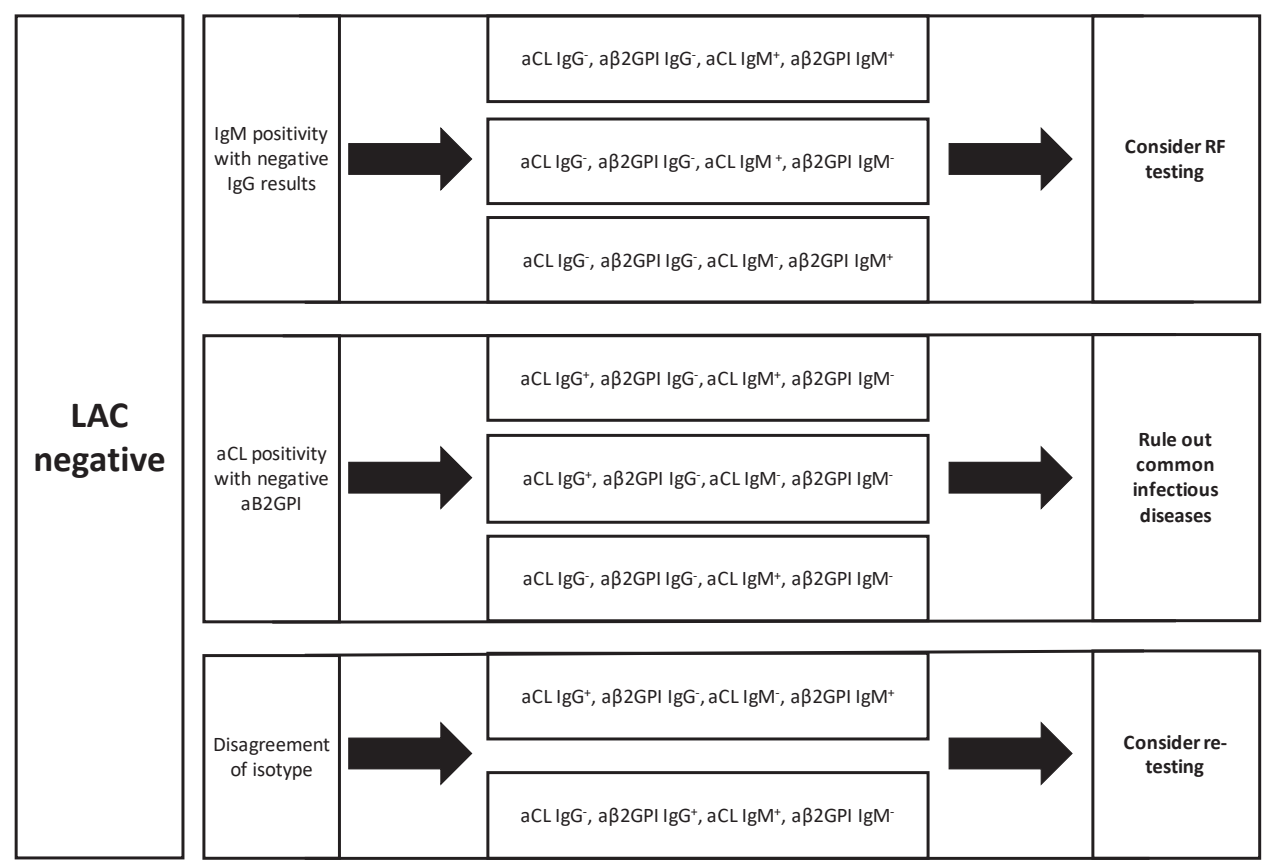

FIGURE 1. Reliability of aCL and aß2GPI IgG/M results in LAC negative patients suspected of APS. Rheumatoid factor is associated with false positive IgM results and should be considered testing if IgG aPL antibodies are negative. Positivity for aCL antibodies with negative a $32 \mathrm{GPI}$ could be an indication for infectious diseases. Re-testing should be considered if there is a disagreement of isotype.

In our study, we have shown that the thrombotic association of triple positivity is predominately caused by $\operatorname{lgG}$ aPL antibodies [24]. Patients with positive LAC, aCL IgM and $a ß 2 \mathrm{GPI} \operatorname{IgM}$ (i.e. triple positive) results are strongly associated with a previous thrombosis [24]. However, if IgG aPL are absent, the clinical significance is low [24]. Positivity for LAC, aCL IgG and aß2GPI IgG is strongly correlated with thrombosis even if $\operatorname{lgM}$ aPL antibodies are negative. The presence of all criteria aPL antibodies (LAC, aCL $\mathrm{IgG} / \mathrm{M}$ and $\mathrm{a} \beta 2 \mathrm{GPI} \mathrm{IgG} / \mathrm{M}$ ) results in the strongest association with thrombosis [24]. Therefore, all criteria aPL antibodies results should be considered to evaluate the clinical significance of an aPL profile (Figure 2).

\section{Additional testing for risk stratification}

Additional aPL antibody testing might be performed in triple positive patients within an academic setting. Anti-DI aPL antibodies might be detected for risk stratification as combined anti-DI and triple positivity resulted in a higher OR than only triple positivity [51]. Also, the presence of aPS/PT IgG has shown to increase ORs in triple positive patients positive for $L A C, a C L \lg G$ and $a ß 2 G P I \lg G$ [24]. 
Other laboratory markers for thrombosis could be considered for thrombotic risk stratification in definite APS patients. Activated protein $C$ resistance together with LAC positivity has shown to be strongly correlated with thrombosis [89]. Activated protein $C$ resistance can also be determined with a thrombin generation-based test and has shown to be associated with thrombosis in LAC positive patients [90]. Using thrombin generation, LAC titers can be quantified and could be useful for thrombotic risk stratification together with soluble P-selectin and factor VII results [91]. However, data on the value of each single laboratory marker within thrombotic risk stratification of APS patients is lacking. A well-designed prospective multicenter study is needed for the evaluation of additional aPL antibody assays and established laboratory markers in thrombotic risk stratification of APS patients.

\section{General hospital}

In case that centralization of testing is not available, general hospital laboratories should provide LAC, aCL IgG/M and aß2GPI IgG/M assays for the detection of APS. Due to the high variability among immunoassays detecting $\mathrm{aCL}$ and $\mathrm{a} \beta 2 \mathrm{GPI}$ antibodies, it seems important that in daily practice, $\mathrm{aCL}$ lgG/M and a $32 \mathrm{GPI} \mathrm{lgG} / \mathrm{M}$ antibodies are measured with the same platform. A medical laboratory should take this into an account if not all assays are available in-house and additional aPL testing is needed elsewhere.

\section{Automated algorithm for the interpretation of lupus anticoagulant}

Nowadays, LAC assays have integrated a screening and confirmation step into one single assay, which may increase the accuracy and inter-laboratory agreement [92]. However, the mixing procedure should still be performed [92]. Difficulties in performing the mixing step, interpretation of results and calculation of cut-off values may lead to false positive or false negative results $[3,4,21,92]$. The introduction of an automated algorithm for the interpretation of LAC might be a practical solution [93]. Research has shown that such an algorithm has a high sensitivity and specificity for LAC detection and reduced hands-on time with $60 \%$ [93]. An automated algorithm for the interpretation of LAC might also take established interfering factors into consideration including anticoagulation, coagulation factor deficiencies, reduced fibrinogen and elevated C-reactive protein (CRP) levels [94]. For instance, isolated positivity for the aPTT-based LAC assay might require testing of plasma CRP levels as research has shown that CRP levels $>50 \mathrm{mg} / \mathrm{L}$ can mimic the presence of LAC in all three steps of the aPTT but not in the dilute Russell Viper Venom Time (dRVVT)-LAC assay [95]. Isolated positivity for the aPTT-LAC assay with high CRP levels should therefore be interpreted with care and retesting at a later moment can be considered. A universal automated algorithm could help general hospital laboratories with the interpretation of $L A C$ results. 


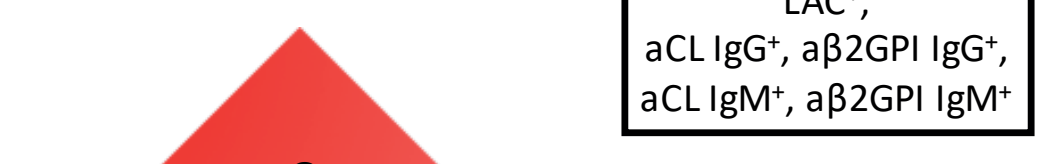

\section{$\mathrm{LAC}^{+}$}

CLIgG+, aß2GPIIgG+,
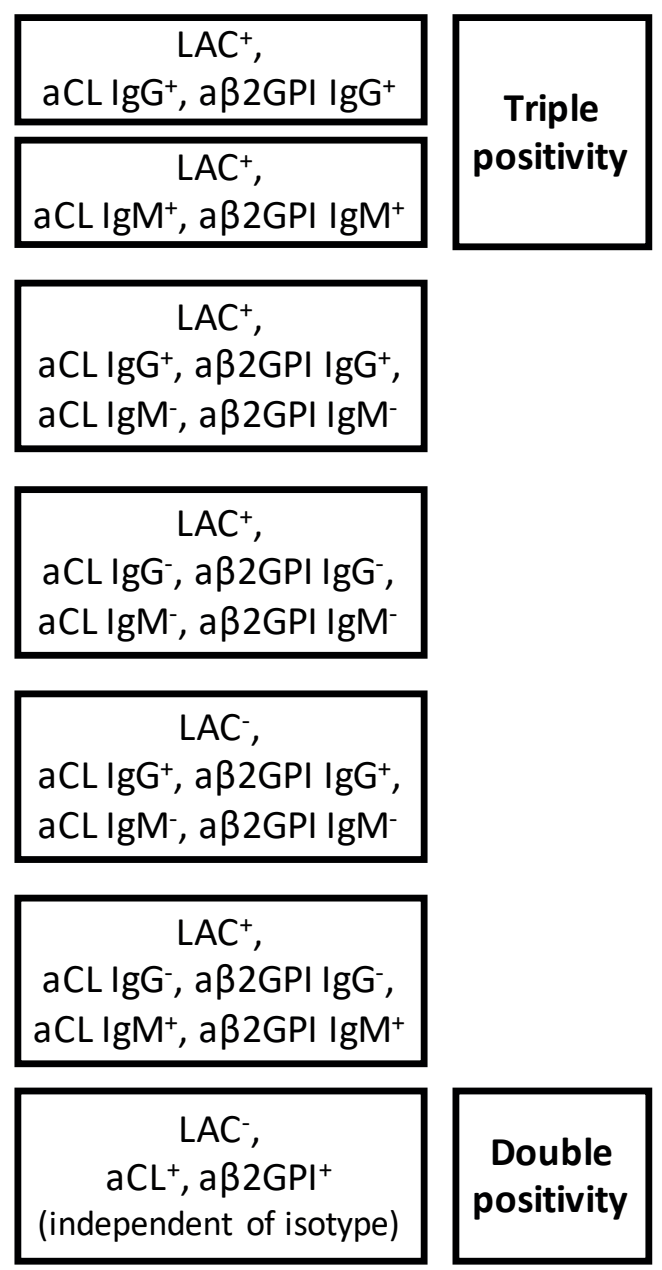

\section{Double} positivity

\section{LAC-}

$\mathrm{aCL}_{\text {IgG-}}, \mathrm{a}$ a $2 \mathrm{GPI}$ IgG-, $\mathrm{aCL} \operatorname{lgM}^{+}, \mathrm{a} \beta 2 \mathrm{GPI} \lg \mathrm{M}^{+}$

FIGURE 2. Significance of aPL antibody profiles in thrombosis. 


\section{Risk stratification}

General hospital laboratories should evaluate the profile of patients with thrombotic APS. One could consider extensive testing similar to an academic setting. However, a distinction between APS patients that are triple positive and patients without triple positivity might be sufficient. Triple positivity is generally accepted to be a high-risk profile for thrombosis. Triple positive patients with additional aPL antibodies could have a higher risk for recurrent thrombosis. However, treatment of triple-positive patients with additional aPL antibodies is most likely not different from patients with triple positivity alone $[66,67,83]$. Therefore, it would be more convenient to limit risk stratification of patients with thrombotic APS to triple positivity or non-triple positivity and avoid additional aPL antibody testing for risk stratification in general hospitals.

\section{Rural hospitals in developing countries}

Rural hospitals in developing countries have limited resources and only selected laboratory assays available. It is therefore not evident to perform all assays suggested by the Sydney criteria [1]. From all types of aPL antibodies in the current criteria, LAC is considered the strongest predictor of thrombosis and pregnancy morbidity [96-98]. However, LAC is labor intensive and complicated to interpret which makes it difficult to perform the assay in a rural hospital with limited resources.

\section{Point of care-lupus anticoagulant}

Point of care (POC) diagnostics might be a solution in a low resource setting as rural hospitals in developing countries. Unfortunately, no POC assay exists for the detection of LAC. International guidelines recommend the use of a dRVVT and APTT based assay in LAC detection $[1,99,100]$. With the existence of POC assays measuring prothrombin time (PT) and aPTT, a POC-LAC assay seems to be technically feasible [101]. However, more research is needed to evaluate the feasibility of a POC-LAC that is in agreement with the current guidelines $[1,100]$. In developing countries, infectious diseases are very common and considered to cause the development of aPL antibodies. International guidelines should be followed for the detection of LAC, also in a POC testing $[1,99,100]$. An automated algorithm for clear LAC results is preferred in this setting.

\section{Solid phase assays in rural hospitals}

Detection of $\mathrm{aCL}$ and $\mathrm{a}$ (2GPI antibodies by ELISA is labor intensive and requires trained personnel. Automated systems are less labor intensive and easy to perform. However, such systems and reagents are too expensive for rural laboratories in developing 
countries. Exclusion of $\mathrm{aCL} \lg \mathrm{G} / \mathrm{M}$ and $\mathrm{a} \beta 2 \mathrm{GPI} \lg \mathrm{G} / \mathrm{M}$ testing might result in decreased sensitivity for APS diagnosis. Another limitation is the inability of risk stratification without $\mathrm{aCL}$ and $\mathrm{a} \beta 2 \mathrm{GPI}$ results.

\section{Lupus anticoagulant versus $a C L$ and aß2GPI antibodies}

In developing countries, the prevalence of infectious diseases is high [102]. Viral infectious diseases like HIV and syphilis can give arise to false positive aPL antibody results [103]. Still, LAC has shown to be strongly associated with stroke in a population from urban and rural Tanzania [104]. The presence of aPL antibodies detected by solid phase assays ( $\mathrm{aCL}$, aß2GPI and aPS/PT) was found to be of only little value as a biomarker for stroke [104]. Therefore, the development of a POC-LAC assay could be a useful biomarker for (arterial) thrombosis in rural areas. Due to the limited data available on prevention of a recurrent stroke, several therapy strategies are possible [66,105-107]. The European League Against Rheumatism (EULAR) recommend the use of VKA over low-dose aspirin (LDA) in APS patients with a first arterial thrombosis [67]. However, in APS patients with a first stroke, therapy with either VKA or clopidogrel is also justified [66]. Antiplatelet therapy could be a good alternative for the prevention of recurrent stroke in APS patients as VKA therapy requires regular monitoring and is therefore not preferred in rural areas of developing countries. Still, more data is needed to evaluate the importance of a POC-LAC assay and its implication on treatment strategies in rural hospitals.

\section{CONCLUSION}

This thesis describes the importance of detecting aPL antibodies by immunoassays in the laboratory diagnosis of APS. The newer generation aPL antibody assays are still associated with high inter-assay variation, even in triple positive patients. Isolated $\mathrm{aCL}$ and $\mathrm{a} \beta 2 \mathrm{GPI}$ IgM antibody results should be interpreted with care in thrombotic APS. Detection of $\mathrm{aCL}$ and $\mathrm{a} \beta 2 \mathrm{GPI} \lg \mathrm{A}$ antibodies did not add value to the laboratory diagnosis of APS within the current aPL panel. The presence of anti-DI antibodies may help in identifying high-risk patients. Well-designed prospective multicenter studies are needed to evaluate $\mathrm{aPL}$ antibody profiles and the risk of recurrent thrombosis in APS patients. Anti-prothrombin antibodies with LAC activity are able to induce platelet aggregation via the FcyRIIA receptor. However, more data is needed to determine the role of anti-prothrombin antibodies in the failure of anti-FXa therapy in patients with APS. 


\section{REFERENCES}

1 Miyakis S, Lockshin MD, Atsumi T, Branch DW, Brey RL, Cervera R, Derksen RHWM, DE Groot PG, Koike T, Meroni PL, Reber G, Shoenfeld Y, Tincani A, Vlachoyiannopoulos PG, Krilis SA. International consensus statement on an update of the classification criteria for definite antiphospholipid syndrome (APS). J Thromb Haemost 2006; 4: 295-306.

2 Devreese KMJ, Pierangeli SS, de Laat B, Tripodi A, Atsumi T, Ortel TL, Subcommittee on Lupus Anticoagulant/Phospholipid/Dependent Antibodies. Testing for antiphospholipid antibodies with solid phase assays: guidance from the SSC of the ISTH. J Thromb Haemost 2014; 12: 792-5.

3 Devreese KMJ. Testing for antiphospholipid antibodies: Advances and best practices. Int J Lab Hematol 2020; 42 Suppl 1: 49-58.

4 Devreese KMJ. Antiphospholipid antibody testing and standardization. Int J Lab Hematol 2014; 36: 352-63.

5 De Moerloose P, Reber G, Musial J, Arnout J. Analytical and clinical performance of a new, automated assay panel for the diagnosis of antiphospholipid syndrome. J Thromb Haemost 2010; 8: 1540-6.

6 Hoecke FV, Persijn L, Decavele A-S, Devreese K. Performance of two new, automated chemiluminescence assay panels for anticardiolipin and anti-beta2-glycoprotein I antibodies in the laboratory diagnosis of the antiphospholipid syndrome. International Journal of Laboratory Hematology 2012; 34: 630-40.

7 Pérez D, Tincani A, Serrano M, Shoenfeld Y, Serrano A. Antiphospholipid syndrome and IgA anti-beta2-glycoprotein I antibodies: when Cinderella becomes a princess. Lupus 2018; 27: 177-8.

8 Mattia E, Ruffatti A, Tonello M, Meneghel L, Robecchi B, Pittoni M, Gallo N, Salvan E, Teghil $V$, Punzi L, Plebani M. IgA anticardiolipin and IgA anti- $\beta 2$ glycoprotein I antibody positivity determined by fluorescence enzyme immunoassay in primary antiphospholipid syndrome. Clinical Chemistry and Laboratory Medicine 2014; 52.

9 Ruiz-García R, Serrano M, Ángel Martínez-Flores J, Mora S, Morillas L, Martín-Mola MÁ, Morales JM, Paz-Artal E, Serrano A. Isolated IgA Anti- $\beta 2$ Glycoprotein I Antibodies in Patients with Clinical Criteria for Antiphospholipid Syndrome. J Immunol Res 2014; 2014.

10 Shen Y, Lee R, Frenkel E, Sarode R. IgA antiphospholipid antibodies are an independent risk factor for thromboses. Lupus 2008; 17: 996-1003.

11 Tortosa C, Cabrera-Marante O, Serrano M, Martínez-Flores JA, Pérez D, Lora D, Morillas L, Paz-Artal E, Morales JM, Pleguezuelo D, Serrano A. Incidence of thromboembolic events in asymptomatic carriers of IgA anti $ß 2$ glycoprotein-I antibodies. Kuwana M, editor. PLOS ONE 2017; 12: e0178889.

12 Murthy V, Willis R, Romay-Penabad Z, Ruiz-Limón P, Martínez-Martínez LA, Jatwani S, Jajoria P, Seif A, Alarcón GS, Papalardo E, Liu J, Vilá LM, McGwin G, McNearney TA, Maganti R, 
Sunkureddi P, Parekh T, Tarantino M, Akhter E, Fang H, et al. Value of Isolated IgA anti- $\beta 2$ GPI Positivity in the Diagnosis of the Antiphospholipid Syndrome. Arthritis Rheum 2013; 65: 3186-93.

13 Greco TP, Amos MD, Conti-Kelly AM, Naranjo JD, ljdo JW. Testing for the antiphospholipid syndrome: importance of IgA anti-beta 2-glycoprotein I. Lupus 2000; 9: 33-41.

14 Bowie EJ, Thompson JH, Pascuzzi CA, Owen CA. Thrombosis in systemiclupus erythematosus despite circulating anticoagulants. J Lab Clin Med 1963; 62: 416-30.

15 Favaloro EJ, Silvestrini R, Mohammed A. Clinical Utility of Anticardiolipin Antibody Assays: High Inter-Laboratory Variation and Limited Consensus by Participants of External Quality Assurance Programs Signals a Cautious Approach. Pathology 1999; 31: 142-7.

16 Favaloro E, Bonar R, Marsden K. Internal Quality Control and External Quality Assurance in Testing for Antiphospholipid Antibodies: Part II-Lupus Anticoagulant. Seminars in Thrombosis and Hemostasis 2012; 38: 404-11.

17 Decavele AS, Schouwers S, Devreese KMJ. Evaluation of three commercial ELISA kits for anticardiolipin and anti-beta2-glycoprotein I antibodies in the laboratory diagnosis of the antiphospholipid syndrome. Int J Lab Hematol 2011; 33: 97-108.

18 Persijn L, Decavele A-S, Schouwers S, Devreese K. Evaluation of a new set of automated chemiluminescense assays for anticardiolipin and anti-beta2-glycoprotein I antibodies in the laboratory diagnosis of the antiphospholipid syndrome. Thromb Res 2011; 128: 565-9.

19 Martins TB, Heikal N, Miller J, Willis R, Schmidt RL, Tebo AE. Assessment of diagnostic methods for the detection of anticardiolipin and anti-ßeta2 glycoprotein I antibodies in patients under routine evaluation for antiphospholipid syndrome. Clinica Chimica Acta 2018; 485: 7-13.

20 Iwaniec T, Kaczor MP, Celińska-Löwenhoff M, Polański S, Musiał J. Identification of patients with triple antiphospholipid antibody positivity is platform and method independent. Pol Arch Med Wewn 2016; 126: 19-24.

21 Devreese K. Standardization of antiphospholipid antibody assays. Where do we stand? Lupus; 2012; 21: 718-21.

22 Favaloro EJ, Wheatland L, Jovanovich S, Roberts-Thomson P, Wong RCW. Internal quality control and external quality assurance in testing for antiphospholipid antibodies: Part I-Anticardiolipin and anti- $\beta 2-$ glycoprotein I antibodies. Semin Thromb Hemost 2012; 38: 390 403.

23 Chayoua W, Kelchtermans H, Moore GW, Gris J-C, Musiał J, Wahl D, Zuily S, Gianniello F, Fontana P, Remijn J, Urbanus RT, De laat B, Devreese KMJ. Detection of anti-cardiolipin and anti- $\beta 2$ glycoprotein I antibodies differs between platforms without influence on association with clinical symptoms. Thromb haemost 2019; 5:797-806.

24 Chayoua W, Kelchtermans H, Moore GW, Musiał J, Wahl D, Laat B de, Devreese KMJ. Identification of high thrombotic risk triple positive antiphospholipid syndrome patients is dependent on anti-cardiolipin and anti- $\beta 2$ glycoprotein I antibody detection assays. Journal of Thrombosis and Haemostasis 2018; 10:2016-23. 
25 Kelchtermans H, Pelkmans L, Laat B de, Devreese KM. IgG/IgM antiphospholipid antibodies present in the classification criteria for the antiphospholipid syndrome: a critical review of their association with thrombosis. Journal of Thrombosis and Haemostasis 2016; 14: 1530 48.

26 Keeling D, Mackie I, Moore GW, Greer IA, Greaves M. Guidelines on the investigation and management of antiphospholipid syndrome. British Journal of Haematology 157: 47-58.

27 Opatrny L, David M, Kahn SR, Shrier I, Rey E. Association between antiphospholipid antibodies and recurrent fetal loss in women without autoimmune disease: a metaanalysis. The Journal of Rheumatology: 9.

28 Galli M, Reber G, Moerloose PD, Groot PGD. Invitation to a debate on the serological criteria that define the antiphospholipid syndrome. Journal of Thrombosis and Haemostasis 2008; 6 : 399-401.

29 Pengo V. A contribution to the debate on the laboratory criteria that define the antiphospholipid syndrome. Journal of Thrombosis and Haemostasis 6: 1048-9.

30 Galli M, Borrelli G, Jacobsen EM, Marfisi RM, Finazzi G, Marchioli R, Wisloff F, Marziali S, Morboeuf $\mathrm{O}$, Barbui T. Clinical significance of different antiphospholipid antibodies in the WAPS (warfarin in the antiphospholipid syndrome) study. Blood 2007; 110: 1178-83.

31 Schreiber K, Hunt BJ. Managing antiphospholipid syndrome in pregnancy. Thrombosis Research 2019; 181: S41-6.

32 Holers VM, Girardi G, Mo L, Guthridge JM, Molina H, Pierangeli SS, Espinola R, Xiaowei LE, Mao D, Vialpando CG, Salmon JE. Complement C3 activation is required for antiphospholipid antibody-induced fetal loss. J Exp Med 2002; 195: 211-20.

33 Chaturvedi S, Brodsky RA, McCrae KR. Complement in the Pathophysiology of the Antiphospholipid Syndrome. Front Immunol 2019; 10: 449.

34 Despierres L, Beziane A, Kaplanski G, Granel B, Serratrice J, Cohen W, Bretelle F, Rossi P, Morange P-E, Weiller PJ, Robert Harlé J, Bongrand P, Bardin N. Contribution of anti$\beta 2$ glycoprotein I IgA antibodies to the diagnosis of anti-phospholipid syndrome: potential interest of target domains to discriminate thrombotic and non-thrombotic patients. Rheumatology 2014; 53: 1215-8.

35 Carmo-Pereira S, Bertolaccini M, Escudero-Contrera... A, Khamashta M, Hughes G. Value of $\lg \mathrm{A}$ anticardiolipin and anti-ß2-glycoprotein I antibody testing in patients with pregnancy morbidity. Ann Rheum Dis 2003; 62: 540-3.

36 Lakos G, Kiss E, Czy NR, Sipka S, Szegedi G. Isotype distribution and clinical relevance of antib2-glycoprotein I (b2-GPI) antibodies: importance of IgA isotype. Clinical and Experimental Immunology 1999; 3:574-9.

37 Mehrani T, Petri M. Association of IgA Anti-ß2 Glycoprotein I with Clinical and Laboratory Manifestations of Systemic Lupus Erythematosus. The Journal of Rheumatology 2011; 38: 64-8.

38 Samarkos M, Davies KA, Gordon C, Loizou S. Clinical significance of IgA anticardiolipin and anti- $\beta 2-G P 1$ antibodies in patients with systemic lupus erythematosus and primary antiphospholipid syndrome. Clinical Rheumatology 2006; 25: 199-204. 
39 Sweiss NJ, Bo R, Kapadia R, Manst D, Mahmood F, Adhikari T, Volkov S, Badaracco M, Smaron

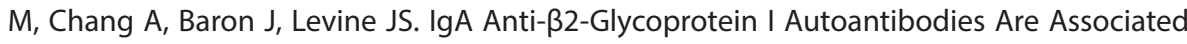
with an Increased Risk of Thromboembolic Events in Patients with Systemic Lupus Erythematosus. Unutmaz D, editor. PLoS ONE 2010; 5: e12280.

40 de Laat B, Derksen RHWM, Urbanus RT, de Groot PG. IgG antibodies that recognize epitope Gly40-Arg43 in domain I of beta 2-glycoprotein I cause LAC, and their presence correlates strongly with thrombosis. Blood 2005; 105: 1540-5.

41 de Laat B, Wu X-X, van Lummel M, Derksen RHWM, de Groot PG, Rand JH. Correlation between antiphospholipid antibodies that recognize domain I of beta2-glycoprotein I and a reduction in the anticoagulant activity of annexin A5. Blood 2007; 109: 1490-4.

42 de Laat B, Mertens K, de Groot PG. Mechanisms of disease: antiphospholipid antibodiesfrom clinical association to pathologic mechanism. Nat Clin Pract Rheumatol 2008; 4: 192-9.

43 Wahezi DM, Ilowite NT, Wu XX, Pelkmans L, Laat B, Schanberg LE, Rand JH, Atherosclerosis Prevention in Pediatric Lupus Erythematosus Investigators. Annexin A5 anticoagulant activity in children with systemic lupus erythematosus and the association with antibodies to domain I of $\beta 2$-glycoprotein I. Lupus 2013; 22: 702-11.

44 de Laat B, Pengo V, Pabinger I, Musial J, Voskuyl AE, Bultink IEM, Ruffatti A, Rozman B, Kveder T, de Moerloose P, Boehlen F, Rand J, Ulcova-Gallova Z, Mertens K, de Groot PG. The association between circulating antibodies against domain I of beta2-glycoprotein I and thrombosis: an international multicenter study. J Thromb Haemost 2009; 7: 1767-73.

45 Hunt BJ, Wu X-X, de Laat B, Arslan AA, Stuart-Smith S, Rand JH. Resistance to annexin A5 anticoagulant activity in women with histories for obstetric antiphospholipid syndrome. $A m$ J Obstet Gynecol 2011; 205: 485.e17-23.

46 Hulstein JJJ, Lenting PJ, de Laat B, Derksen RHWM, Fijnheer R, de Groot PG. beta2Glycoprotein I inhibits von Willebrand factor dependent platelet adhesion and aggregation. Blood 2007; 110: 1483-91.

47 Pierangeli SS, Liu X, Espinola R, Olee T, Zhu M, Harris NE, Chen PP. Functional analyses of patient-derived IgG monoclonal anticardiolipin antibodies using in vivo thrombosis and in vivo microcirculation models. Thromb Haemost 2000; 84: 388-95.

48 Agostinis C, Durigutto P, Sblattero D, Borghi MO, Grossi C, Guida F, Bulla R, Macor P, Pregnolato F, Meroni PL, Tedesco F. A non-complement-fixing antibody to $\beta 2$ glycoprotein I as a novel therapy for antiphospholipid syndrome. Blood 2014; 123: 3478-87.

49 Durigutto P, Grossi C, Borghi MO, Macor P, Pregnolato F, Raschi E, Myers MP, de Groot PG, Meroni PL, Tedesco F. New insight into antiphospholipid syndrome: antibodies to 32 glycoprotein I-domain 5 fail to induce thrombi in rats. Haematologica 2019; 104: 819-26.

50 Kelchtermans H, Chayouâ W, Laat B de. The Significance of Antibodies against Domain I of Beta-2 Glycoprotein I in Antiphospholipid Syndrome. Semin Thromb Hemost 2018; 44: 45865.

51 Yin D, de Laat B, Devreese KMJ, Kelchtermans $\mathrm{H}$. The clinical value of assays detecting antibodies against domain I of $\beta 2$-glycoprotein I in the antiphospholipid syndrome. Autoimmun Rev 2018; 17: 1210-8. 
52 Pengo V, Denas G, Zoppellaro G, Jose SP, Hoxha A, Ruffatti A, Andreoli L, Tincani A, Cenci C, Prisco D, Fierro T, Gresele P, Cafolla A, De Micheli V, Ghirarduzzi A, Tosetto A, Falanga A, Martinelli I, Testa $S$, Barcellona $D$, et al. Rivaroxaban vs warfarin in high-risk patients with antiphospholipid syndrome. Blood 2018; 132: 1365-71.

53 Ordi-Ros J, Sáez-Comet L, Pérez-Conesa M, Vidal X, Riera-Mestre A, Castro-Salomó A, CuquetPedragosa J, Ortiz-Santamaria V, Mauri-Plana M, Solé C, Cortés-Hernández J. Rivaroxaban Versus Vitamin K Antagonist in Antiphospholipid Syndrome: A Randomized Noninferiority Trial. Ann Intern Med 2019; 171: 685-94.

54 Di Simone N, Meroni PL, de Papa N, Raschi E, Caliandro D, De Carolis CS, Khamashta MA, Atsumi T, Hughes GR, Balestrieri G, Tincani A, Casali P, Caruso A. Antiphospholipid antibodies affect trophoblast gonadotropin secretion and invasiveness by binding directly and through adhered beta2-glycoprotein I. Arthritis Rheum 2000; 43: 140-50.

55 Di Simone N, Castellani R, Caliandro D, Caruso A. Antiphospholid antibodies regulate the expression of trophoblast cell adhesion molecules. Fertil Steril 2002; 77: 805-11.

56 Di Simone N, Di Nicuolo F, D'Ippolito S, Castellani R, Tersigni C, Caruso A, Meroni P, Marana R. Antiphospholipid antibodies affect human endometrial angiogenesis. Biol Reprod 2010; 83: 212-9.

57 Raschi E, Testoni C, Bosisio D, Borghi MO, Koike T, Mantovani A, Meroni PL. Role of the MyD88 transduction signaling pathway in endothelial activation by antiphospholipid antibodies. Blood 2003; 101: 3495-500.

58 Katsuragawa H, Kanzaki H, Inoue T, Hirano T, Mori T, Rote NS. Monoclonal antibody against phosphatidylserine inhibits in vitro human trophoblastic hormone production and invasion. Biol Reprod 1997; 56: 50-8.

59 Salmon JE, de Groot PG. Pathogenic role of antiphospholipid antibodies. Lupus 2008; 17: 405-11.

60 Yamada M, Kawakami T, Takashima K, Nishioka Y, Nishibata Y, Masuda S, Yoshida S, Tomaru $\mathrm{U}$, Ishizu A. Establishment of a rat model of thrombosis induced by intravenous injection of anti-phosphatidylserine-prothrombin complex antibody. Rheumatology (Oxford) 2017; 56: 1013-8.

61 Vega-Ostertag M, Liu X, Kwan-Ki H, Chen P, Pierangeli S. A human monoclonal antiprothrombin antibody is thrombogenic in vivo and upregulates expression of tissue factor and E-selectin on endothelial cells. Br J Haematol 2006; 135: 214-9.

62 Haj-Yahia S, Haj-Yahja S, Sherer Y, Blank M, Kaetsu H, Smolinsky A, Shoenfeld Y. Antiprothrombin antibodies cause thrombosis in a novel qualitative ex-vivo animal model. Lupus 2003; 12: 364-9.

63 Arad A, Proulle V, Furie RA, Furie BC, Furie B. $\beta_{2}$-Glycoprotein-1 autoantibodies from patients with antiphospholipid syndrome are sufficient to potentiate arterial thrombus formation in a mouse model. Blood 2011; 117: 3453-9.

64 Kearon C, Parpia S, Spencer FA, Baglin T, Stevens SM, Bauer KA, Lentz SR, Kessler CM, Douketis JD, Moll S, Kaatz S, Schulman S, Connors JM, Ginsberg JS, Spadafora L, Bhagirath V, Liaw PC, Weitz JI, Julian JA. Antiphospholipid antibodies and recurrent thrombosis after a first unprovoked venous thromboembolism. Blood 2018; 131: 2151-60. 
65 Wahl D. "Antiphospholipids": the more, the worse? Blood 2018; 131: 2092-4.

66 Limper M, de Leeuw K, Lely AT, Westerink J, Teng YKO, Eikenboom J, Otter S, Jansen AJG, V D Ree M, Spierings J, Kruyt ND, van der Molen R, Middeldorp S, Leebeek FWG, Bijl M, Urbanus RT. Diagnosing and treating antiphospholipid syndrome: a consensus paper. Neth J Med 2019; 77: 98-108.

67 Tektonidou MG, Andreoli L, Limper M, Amoura Z, Cervera R, Costedoat-Chalumeau N, Cuadrado MJ, Dörner T, Ferrer-Oliveras R, Hambly K, Khamashta MA, King J, Marchiori F, Meroni PL, Mosca M, Pengo V, Raio L, Ruiz-Irastorza G, Shoenfeld Y, Stojanovich L, et al. EULAR recommendations for the management of antiphospholipid syndrome in adults. Ann Rheum Dis 2019; 78: 1296-304.

68 Erkan D, Lockshin MD. Non-criteria manifestations of antiphospholipid syndrome. Lupus 2010; 19: 424-7.

69 Aringer M, Costenbader K, Daikh D, Brinks R, Mosca M, Ramsey-Goldman R, Smolen JS, Wofsy D, Boumpas DT, Kamen DL, Jayne D, Cervera R, Costedoat-Chalumeau N, Diamond B, Gladman DD, Hahn B, Hiepe F, Jacobsen S, Khanna D, Lerstrøm K, et al. 2019 European League Against Rheumatism/American College of Rheumatology Classification Criteria for Systemic Lupus Erythematosus. Arthritis \& Rheumatology (Hoboken, NJ) 2019; 71: 1400-12.

70 Devreese KMJ. How to Interpret Antiphospholipid Laboratory Tests. Curr Rheumatol Rep 2020; 22: 38.

71 Dembitzer FR, Ledford Kraemer MR, Meijer P, Peerschke EIB. Lupus anticoagulant testing: performance and practices by north american clinical laboratories. Am J Clin Pathol 2010; 134: 764-73.

72 Harris EN, Gharavi AE, Boey ML, Patel BM, Mackworth-Young CG, Loizou S, Hughes GR. Anticardiolipin antibodies: detection by radioimmunoassay and association with thrombosis in systemic lupus erythematosus. Lancet 1983; 2: 1211-4.

73 Loizou S, McCrea JD, Rudge AC, Reynolds R, Boyle CC, Harris EN. Measurement of anticardiolipin antibodies by an enzyme-linked immunosorbent assay (ELISA): standardization and quantitation of results. Clin Exp Immunol 1985; 62: 738-45.

74 Devreese KM, Poncet A, Lindhoff-Last E, Musial J, de Moerloose P, Fontana P. A multicenter study to assess the reproducibility of antiphospholipid antibody results produced by an automated system. J Thromb Haemost 2017; 15: 91-5.

75 de Laat B, Derksen RHWM, van Lummel M, Pennings MTT, de Groot PG. Pathogenic antibeta2-glycoprotein I antibodies recognize domain I of beta2-glycoprotein I only after a conformational change. Blood 2006; 107: 1916-24.

76 Pelkmans L, Kelchtermans H, de Groot PG, Zuily S, Regnault V, Wahl D, Pengo V, de Laat B. Variability in exposure of epitope G40-R43 of domain i in commercial anti-beta2glycoprotein I lgG ELISAs. PLoS ONE 2013; 8: e71402.

77 Favaloro EJ, Wong RCW. Current clinical and laboratory practice for the investigation of the antiphospholipid syndrome: findings from the 2008 Australasian antiphospholipid antibody survey. Pathology 2009; 41: 666-75. 
78 Vanoverschelde L, Kelchtermans H, Musial J, de Laat B, Devreese KMJ. Influence of anticardiolipin and anti- $\beta 2$ glycoprotein I antibody cutoff values on antiphospholipid syndrome classification. Res Pract Thromb Haemost 2019; 3: 515-27.

79 Pengo V, Biasiolo A, Bison E, Chantarangkul V, Tripodi A, Italian Federation of Anticoagulation Clinics (FCSA). Antiphospholipid antibody ELISAs: survey on the performance of clinical laboratories assessed by using lyophilized affinity-purified IgG with anticardiolipin and antibeta2-Glycoprotein I activity. Thromb Res 2007; 120: 127-33.

80 Pierangeli SS, Favaloro EJ, Lakos G, Meroni PL, Tincani A, Wong RCW, Harris EN. Standards and reference materials for the anticardiolipin and anti- $\beta 2$ glycoprotein I assays: a report of recommendations from the APL Task Force at the 13th International Congress on Antiphospholipid Antibodies. Clin Chim Acta 2012; 413: 358-60.

81 Chayoua W, Kelchtermans H, Gris J-C, Moore GW, Musiał J, Wahl D, de Groot PG, de Laat B, Devreese KMJ. The (non-)sense of detecting anti-cardiolipin and anti- $\beta 2$ glycoprotein I IgM antibodies in the antiphospholipid syndrome. J Thromb Haemost 2020; 18: 169-79.

82 Pengo V, Bison E, Denas G, Jose SP, Zoppellaro G, Banzato A. Laboratory Diagnostics of Antiphospholipid Syndrome. Semin Thromb Hemost 2018; 44: 439-44.

83 Garcia D, Erkan D. Diagnosis and Management of the Antiphospholipid Syndrome. Longo DL, editor. New England Journal of Medicine 2018; 378: 2010-21.

84 Pengo V, Ruffatti A, Legnani C, Gresele P, Barcellona D, Erba N, Testa S, Marongiu F, Bison E, Denas G, Banzato A, Jose SP, lliceto S. Clinical course of high-risk patients diagnosed with antiphospholipid syndrome. Journal of Thrombosis and Haemostasis 2010; 8: 237-42.

85 Lakos G. Interference in antiphospholipid antibody assays. Semin Thromb Hemost 2012; 38: 353-9.

86 Arvieux J, Renaudineau Y, Mane I, Perraut R, Krilis SA, Youinou P. Distinguishing Features of Anti- $\beta 2$ Glycoprotein I Antibodies between Patients with Leprosy and the Antiphospholipid Syndrome. Thromb Haemost 2002; 87: 599-605.

87 Mustonen P, Lehtonen KV, Javela K, Puurunen M. Persistent antiphospholipid antibody $(\mathrm{aPL})$ in asymptomatic carriers as a risk factor for future thrombotic events: a nationwide prospective study. Lupus 2014; 23: 1468-76.

88 Pengo V, Ruffatti A, Legnani C, Testa S, Fierro T, Marongiu F, De Micheli V, Gresele P, Tonello M, Ghirarduzzi A, Bison E, Denas G, Banzato A, Padayattil Jose S, lliceto S. Incidence of a first thromboembolic event in asymptomatic carriers of high-risk antiphospholipid antibody profile: a multicenter prospective study. Blood 2011; 118: 4714-8.

89 Male C, Mitchell L, Julian J, Vegh P, Joshua P, Adams M, David M, Andrew ME. Acquired activated protein $C$ resistance is associated with lupus anticoagulants and thrombotic events in pediatric patients with systemic lupus erythematosus. Blood 2001; 97: 844-9.

90 Liestøl S, Sandset PM, Mowinckel M-C, Wisløff F. Activated protein C resistance determined with a thrombin generation-based test is associated with thrombotic events in patients with lupus anticoagulants. J Thromb Haemost 2007; 5: 2204-10. 
91 Devreese K, Peerlinck K, Hoylaerts MF. Thrombotic risk assessment in the antiphospholipid syndrome requires more than the quantification of lupus anticoagulants. Blood 2010; 115: 870-8.

92 Devreese KMJ. No more mixing tests required for integrated assay systems in the laboratory diagnosis of lupus anticoagulants? Journal of Thrombosis and Haemostasis 2010; 8: 1120-2.

93 Florin L, Desloovere M, Devreese KMJ. Evaluation of an automated algorithm for interpretation of lupus anticoagulant testing. Int J Lab Hematol 2019; 41: 412-7.

94 Moore GW. Current Controversies in Lupus Anticoagulant Detection. Antibodies (Basel) 2016; 5.

95 Schouwers SME, Delanghe JR, Devreese KMJ. Lupus Anticoagulant (LAC) testing in patients with inflammatory status: does C-reactive protein interfere with LAC test results? Thromb Res 2010; 125: 102-4.

96 Yelnik CM, Laskin CA, Porter TF, Branch DW, Buyon JP, Guerra MM, Lockshin MD, Petri M, Merrill JT, Sammaritano LR, Kim MY, Salmon JE. Lupus anticoagulant is the main predictor of adverse pregnancy outcomes in aPL-positive patients: validation of PROMISSE study results. Lupus Sci Med 2016; 3: e000131.

97 Lockshin MD, Kim M, Laskin CA, Guerra M, Branch DW, Merrill J, Petri M, Porter TF, Sammaritano L, Stephenson MD, Buyon J, Salmon JE. Prediction of adverse pregnancy outcome by the presence of lupus anticoagulant, but not anticardiolipin antibody, in patients with antiphospholipid antibodies. Arthritis Rheum 2012; 64: 2311-8.

98 Galli M, Luciani D, Bertolini G, Barbui T. Lupus anticoagulants are stronger risk factors for thrombosis than anticardiolipin antibodies in the antiphospholipid syndrome: a systematic review of the literature. Blood 2003; 101: 1827-32.

99 Pengo V, Tripodi A, Reber G, Rand JH, Ortel TL, Galli M, Groot PGD. Update of the guidelines for lupus anticoagulant detection. Journal of Thrombosis and Haemostasis 7: 1737-40.

100 Devreese KMJ, de Groot PG, De laat B, Erkan D, Favaloro EJ, Mackie I, Martinuzzo M, Ortel TL, Pengo V, Rand JH, Tripodi A, Wahl D, Cohen H. Guidance from the Scientific and Standardization Committee for lupus anticoagulant/antiphospholipid antibodies of the International Society on Thrombosis and Haemostasis. J Thromb Haemost. 2020; 18: 2828-39.

101 Niederdöckl J, Dempfle C-E, Schönherr H-R, Bartsch A, Miles G, Laggner A, Pathil A. Pointof-care PT and aPTT in patients with suspected deficiencies of coagulation factors. Int J Lab Hematol 2016; 38: 426-34.

102 Fenollar F, Mediannikov O. Emerging infectious diseases in Africa in the 21st century. New Microbes New Infect 2018; 26: S10-8.

103 Abdel-Wahab N, Talathi S, Lopez-Olivo MA, Suarez-Almazor ME. Risk of developing antiphospholipid antibodies following viral infection: a systematic review and metaanalysis. Lupus 2018; 27: 572-83.

104 de Mast Q, Molhoek JE, van der Ven AJ, Gray WK, de Groot PG, Jusabani A, Mugusi F, Urbanus RT, Walker RW. Antiphospholipid Antibodies and the Risk of Stroke in Urban and Rural Tanzania: A Community-Based Case-Control Study. Stroke 2016; 47: 2589-95. 
105 Verro P, Levine SR, Tietjen GE. Cerebrovascular Ischemic Events With High Positive Anticardiolipin Antibodies. Stroke 1998; 29: 2245-53.

106 Wang C-R, Liu M-F. Rituximab usage in systemic lupus erythematosus-associated antiphospholipid syndrome: A single-center experience. Seminars in Arthritis and Rheumatism 2016; 46: 102-8.

107 Levine SR, Brey RL, Tilley BC, Thompson JLP, Sacco RL, Sciacca RR, Murphy A, Lu Y, Costigan TM, Rhine C, Levin B, Triplett DA, Mohr JP, APASS Investigators. Antiphospholipid antibodies and subsequent thrombo-occlusive events in patients with ischemic stroke. JAMA 2004; 291: $576-84$. 

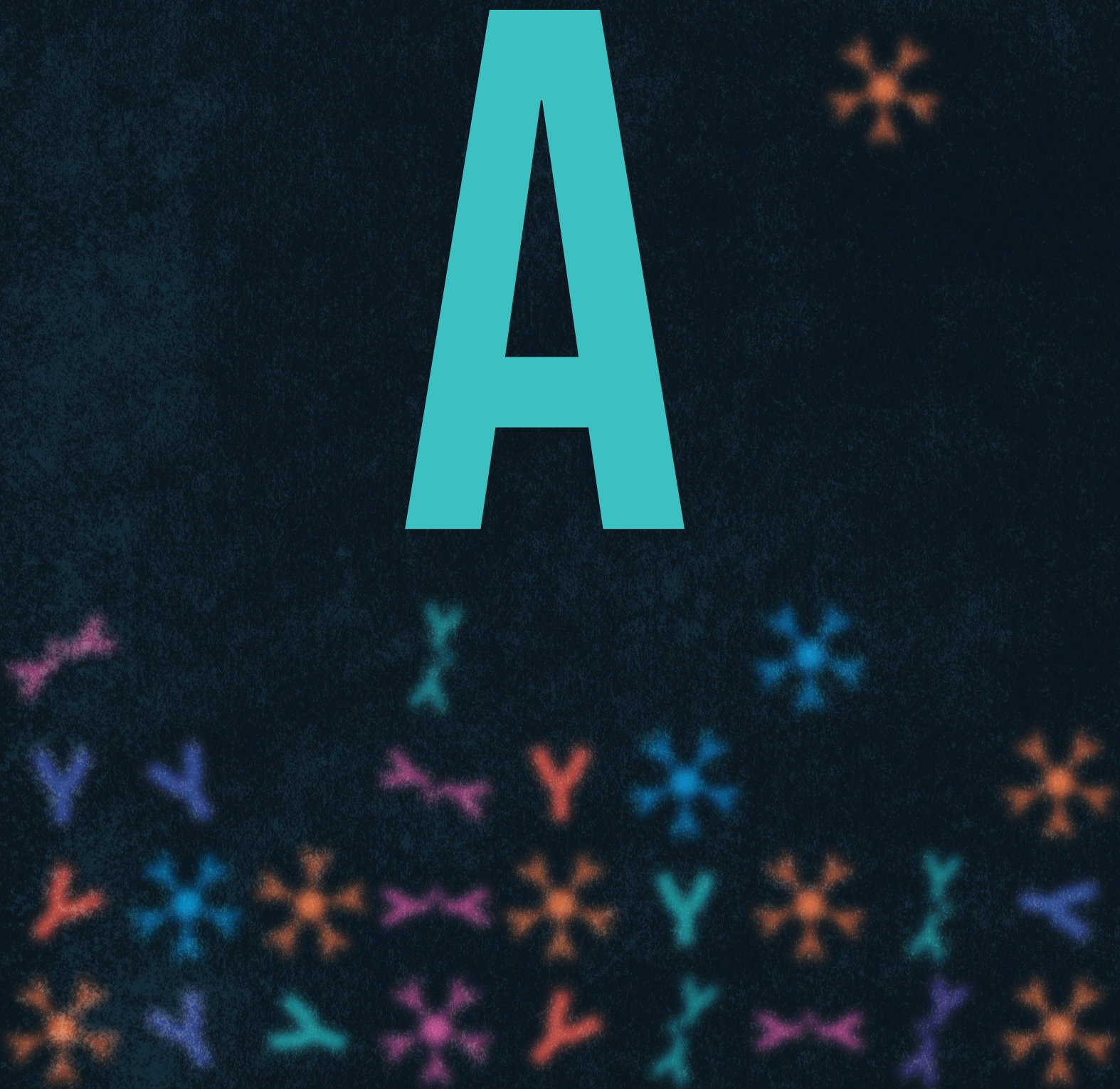


\section{Appendices}

Nederlandse samenvatting

Impact

Dankwoord

Curriculum Vitae

Publications

List of abbreviations 



\section{NEDERLANDSE SAMENVATTING}

Het antifosfolipiden syndroom (APS) is een auto-immuunziekte en wordt gekenmerkt door trombose en/of zwangerschapscomplicaties met de aanwezigheid van antifosfolipiden (aPL) antilichamen. Trombose en zwangerschapscomplicaties komen veelal voor zonder een indicatie voor APS. De diagnose APS is daarom voornamelijk afhankelijk van diagnostische testen. Laboratorium criteria voor de diagnose APS bestaan uit de detectie van; 1) lupus anticoagulans (LAC), 2) anti-cardiolipine (aCL) IgG/M antilichamen en 3) anti- $\beta 2$ glycoproteïne I (aß2GPI) IgG/M antilichamen. Dit proefschrift beoogt de optimalisatie van de diagnose en risicostratificatie van patiënten met APS. Hierbij is de klinische relevantie van verschillende immunologische- en stollingstesten binnen APS onderzocht.

In hoofdstuk 2 is aangetoond dat de detectie van aCL en aß2GPI antilichamen afhankelijk is van de immunologische test die gebruikt wordt. Desalniettemin is de associatie van deze antilichamen met trombose en zwangerschapsmorbiditeit vergelijkbaar tussen immunologische testen. De verkregen resultaten benadrukken dat bij het stellen van de diagnose APS, er rekening gehouden moet worden met de variatie die de immunologische testen teweegbrengen. De aanwezigheid van $\mathrm{LAC}, \mathrm{aCL}$ en aß2GPI antilichamen (triple positiviteit) in APS-patiënten is een hoog risicoprofiel voor recidief (terugkomende) trombose. In hoofdstuk 3 is aangetoond dat ook de identificatie van deze hoog-risico patiënten afhankelijk is van de immunologische test die gebruikt wordt. Daarnaast blijkt positiviteit voor aCL en aß2GPI lgG uitermate belangrijk te zijn voor de sterke associatie van triple positiviteit met trombose, terwijl positiviteit voor aCL en aß2GPI lgM maar een geringe bijdage leveren aan de associatie van triple positiviteit met trombose.

De diagnostische waarde van $\mathrm{aCL}$ en a $32 \mathrm{GPI}$ IgM antilichamen in APS staat al kort na de introductie van de herziene criteria voor het vastellen van APS ter discussie. Hoofdstuk 4 omschrijft de klinische relevantie van aCL en aß2GPI IgM binnen APS. De detectie van aCL en aß2GPI IgM antilichamen is overbodig bevonden voor het opsporen van trombotische APS indien er al getest wordt voor LAC, aCL IgG en aß2GPI IgG antilichamen. De detectie van aCL en aß2GPI IgM antilichamen was wel van belang bij het opsporen van obstetrische APS. Deze resultaten suggereren een andere strategie voor het testen van aPL antilichamen bij verdenking van trombotische en obstetrische APS.

Naast LAC, aCL IgG/M en a 32 GPI IgG/M antilichamen is ook voorgesteld om andere $\mathrm{aPL}$ antilichamen te includeren in de classificatie criteria van APS, waaronder aCL en aß2GPI 
$\lg \mathrm{A}$ antilichamen. In hoofdstuk $\mathbf{5}$ is de correlatie van aCL en a $2 \mathrm{GPI} \lg A$ antilichamen met trombose en zwangerschapscomplicaties bevestigd. Desalniettemin zijn patiënten met aCL en/of aß2GPI IgA antilichamen, maar negatief voor LAC, aCL IgG/M en/of aß2GPI lgG/M, zeldzaam. Hieruit kan geconcludeerd worden dat positiviteit voor $\mathrm{aCL}$ en aß2GPI IgA antilichamen geen toegevoegde waarde heeft naast de huidige laboratorium criteria voor APS.

Hoofdstuk 6 biedt relevante achtergrondinformatie over het belang van het testen van antilichamen die gericht zijn tegen het eerste domein van $\beta 2 \mathrm{GPI}$ (anti-DI). Daarbij werden de pathogeniciteit en de klinische significantie van anti-DI antilichamen onderzocht. In hoofdstuk 7 is aangetoond dat anti-DI antilichamen gecorreleerd zijn met trombose en zwangerschapscomplicaties, maar dat het meten van deze antilichamen geen toegevoegde waarde heeft naast de huidige laboratorium criteria voor de diagnose van APS.

Aggregatie van bloedplaatjes speelt een cruciale rol in het ontwikkelen van arteriële trombose. Toch is er maar weinig bekend over het effect van aPL antilichamen op plaatjesaggregatie. In hoofdstuk $\mathbf{8}$ is aangetoond dat de aanwezigheid van antiprotrombine antilichamen met LAC activiteit kan leiden tot aggregatie van bloedplaatjes via de FcyRIIA receptor. Vitamine $K$ antagonisten (VKAs) zijn antistollingsmiddelen die de productie van vitamine K-afhankelijke stollingsfactoren, waaronder protrombine, remmen. Het directe orale anticoagulans (DOAC) rivaroxaban is een directe remmer van geactiveerde stollingsfactor Xa. Klinisch onderzoek heeft aangetoond dat in vergelijking met het gebruik van VKAs, het gebruik van DOACs het risico kan verhogen op arteriële trombose in triple positieve APS patiënten. In hoofdstuk 8 is ook aangetoond dat het verlagen van de protrombine concentratie zorgt voor verminderde bloedplaatjes aggregatie. Daarentegen wordt plaatjes aggregatie door antiprotrombine antilichamen niet beïnvloed door rivaroxaban. Aggregatie van bloedplaatjes door antiprotrombine antilichamen en het effect van antistolling hierop, kan een mogelijke verklaring zijn voor het falen van DOAC-therapie in triple positieve APS patiënten.

In hoofdstuk 9 worden de belangrijkste bevindingen van dit proefschrift besproken in het licht van de huidige literatuur. Hierin wordt beargumenteerd wat de klinische relevantie is van aPL antilichamen die gemeten worden door middel van immunologische testen en hoe deze testen beter gestandaardiseerd kunnen worden. Daarnaast is beargumenteerd welke laboratoriumtesten nodig zijn bij het vaststellen van APS in een academisch ziekenhuis, een algemeen ziekenhuis, alsook een (afgelegen) ziekenhuis in ontwikkelingslanden met beperkte middelen. 


\section{IMPACT}

The antiphospholipid syndrome (APS) is a rare autoimmune disorder, characterized by thrombosis and/or pregnancy morbidity with the persistent presence of antiphospholipid (aPL) antibodies (1). Clinical manifestations of APS (thrombosis and pregnancy morbidity) occur frequently without any indication of APS (1). This makes the detection of aPL antibodies by laboratory assays crucial in the diagnosis of APS. Laboratory assays used for the diagnosis of APS include the detection of lupus anticoagulant (LAC), anti-cardiolipin ( $\mathrm{aCL}$ ) lgG/M antibodies and anti- $\beta 2$ glycoprotein I (aß2GPI) IgG/M antibodies (1). We aimed to optimize the diagnosis and risk stratification of patients with APS. The clinical relevance of several immunoassays and non-criteria aPL antibodies (e.g. aCL IgA, a 32 GPI IgA and anti-domain I $\beta 2$ GPI lgG) within APS was investigated.

\section{Key findings}

We found that the detection of $\mathrm{aCL}$ and $\mathrm{a} \beta 2 \mathrm{GPI} \mathrm{lgG} / \mathrm{M}$ antibodies differs between immunoassays without affecting the association with clinical manifestations of APS. In addition, the identification of high thrombotic risk triple-positive APS patients (i.e. LAC, $\mathrm{aCL}$ and $\mathrm{a} \beta 2 \mathrm{GPI}$ positive) is dependent on the $\mathrm{aCL}$ and $\mathrm{a} \beta 2 \mathrm{GPI}$ antibody detection assay used.

The role of aCL and a $32 \mathrm{GPI}$ IgM antibodies in thrombotic APS is debated by experts in the field, since conclusive data on the role of $\mathrm{aCL}$ and $\mathrm{a} \beta 2 \mathrm{GPI} \operatorname{lgM}$ within APS is lacking in current literature (2). Our data support the usage of two separate decision trees, depending on the clinical presentation. We have suggested to test $\mathrm{aCL}$ and $\mathrm{a} \beta 2 \mathrm{GPI}$ IgM in women suspected of obstetric APS, but not in patients suspected of thrombotic APS (Figure 1).

Although not included in the laboratory criteria for the diagnosis of APS, antiprothrombin antibodies are common in patients with APS (3). Antiprothrombin antibodies have shown to be correlated with arterial thrombosis, in which platelets play a key role. However, data on antiprothrombin antibodies and platelet activation are lacking. We found that antiprothrombin antibodies with LAC activity are able to induce platelet aggregation via the FcyRIIA receptor.

Recent studies have shown that therapy with direct oral anticoagulants (rivaroxaban) in patients with APS leads to a high incidence of arterial thrombosis compared with vitamin $\mathrm{K}$ antagonist (VKA) therapy $(4,5)$. We observed that decreased prothrombin 


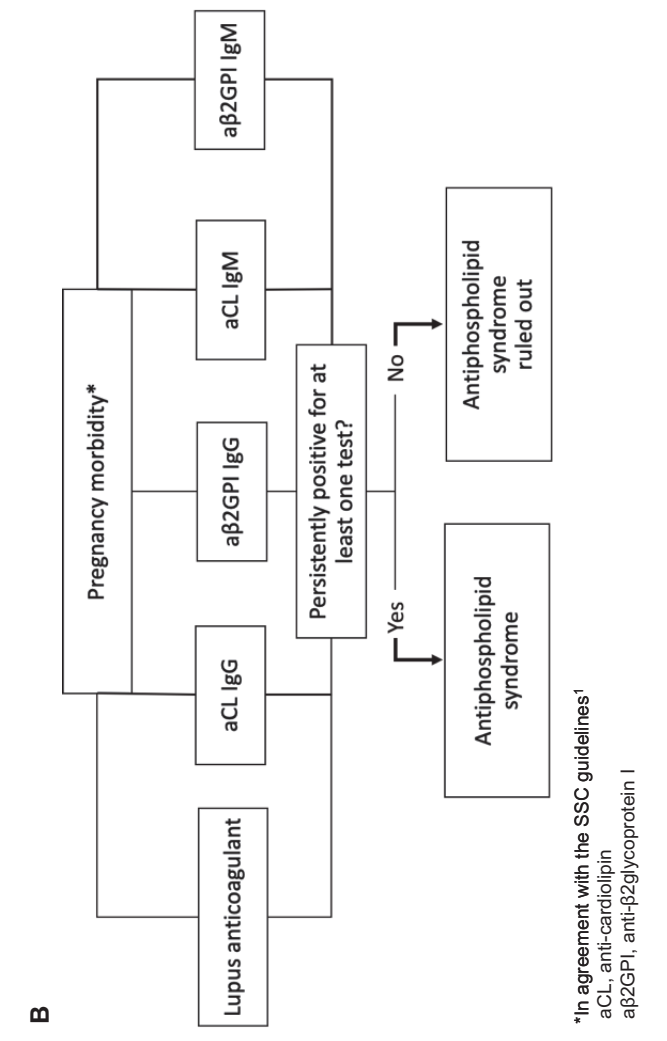

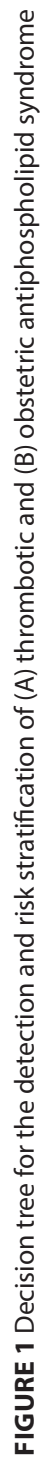


levels resulted in less antiprothrombin antibody-mediated platelet aggregation. We therefore hypothesize that the reduction in antiprothrombin levels by VKA attributes to the lower incidence of arterial thrombosis in patients treated with rivaroxaban.

\section{Diagnosis of APS should be independent of the immunoassay used to detect aPL antibodies}

We have shown that detection of aPL antibodies varies among immunoassays, which can affect the diagnosis of APS. Medical specialists should be aware of the low agreement between immunoassays and limit testing for aPL antibodies in patients with a significant probability of having APS, to avoid overdiagnosis $(1,6)$. Also, retesting of aPL antibodies in patients with definite APS in a different laboratory and with another immunoassay can result in dilemmas when unexpected $\mathrm{aPL}$ results are obtained. Negative aPL results will not support the diagnosis APS and lifelong anticoagulation therapy becomes debatable.

Manufacturers of immunoassays should make more effort in standardizing the detecting of aPL antibodies. Development of an international standard together with the efforts of scientists and medical specialists to provide new insights in the pathogenesis of APS may contribute to a better laboratory diagnosis of APS.

\section{Personalized aPL antibody testing}

We have proposed two separate decision trees for thrombosis versus pregnancy morbidity. Exclusion of IgM aPL antibody testing for the diagnosis of thrombotic APS could lead to less false positives. Moreover, risk stratification using IgM aPL antibodies was only found to be useful in thrombotic APS and not obstetric APS. Altogether, these results will lead to improved diagnosis of APS and consequent treatment of patients with APS.

\section{Detection of antiprothrombin antibodies that induce platelet aggregation enables DOAC use in patients with APS}

We identified a specific subgroup of antiprothrombin antibodies, able to induce platelet aggregation. We hypothesize that these antiprothrombin antibodies are responsible for the high incidence of arterial thrombosis in patients with APS receiving DOAC therapy. More data are needed to confirm this hypothesis. However, future studies should focus on a diagnostic assay to distinguish between antiprothrombin antibodies that are able to induce platelet aggregation and those that do not induce aggregation of platelets. In the absence of antiprothrombin antibodies that induce platelet aggregation, DOAC 
use might be feasible. Although not established in thrombotic APS due to the lack of definite evidence, the use of DOACs over VKAs has many advantageous, including no need for frequent laboratory monitoring, what can be a problem in $\operatorname{APS}(7,8)$.

\section{CONCLUSION}

The research presented in this thesis provides insight into the diagnostic performance of immunoassays detecting aPL antibodies. The immunoassays used in these studies are commercially available and often used in medical laboratories. Therefore, our findings can be directly related to current practice. Next, we have suggested different decision trees for the laboratory diagnosis of thrombotic and obstetric APS which should be further evaluated in well-designed large prospective multicenter studies. In addition, we provided the first steps of evidence towards DOAC use in APS patients which is a more practical and user-friendly alternative treatment. 


\section{REFERENCES}

1. Miyakis S, Lockshin MD, Atsumi T, et al. International consensus statement on an update of the classification criteria for definite antiphospholipid syndrome (APS). J Thromb Haemost 2006; 4: 295-306.

2. Kelchtermans $\mathrm{H}$, Pelkmans $\mathrm{L}$, Laat $B$ de, et al. lgG/lgM antiphospholipid antibodies present in the classification criteria for the antiphospholipid syndrome: a critical review of their association with thrombosis. Journal of Thrombosis and Haemostasis 2016; 14: 1530-48.

3. Chinnaraj $M$, Planer $W$, Pengo $V$, et al. Discovery and characterization of 2 novel subpopulations of aPS/PT antibodies in patients at high risk of thrombosis. Blood Adv 2019; 3: 1738-49.

4. Pengo V, Denas G, Zoppellaro G, et al. Rivaroxaban vs warfarin in high-risk patients with antiphospholipid syndrome. Blood 2018; 132: 1365-71.

5. Ordi-Ros J, Sáez-Comet L, Pérez-Conesa M, et al. Rivaroxaban Versus Vitamin K Antagonist in Antiphospholipid Syndrome: A Randomized Noninferiority Trial. Ann Intern Med 2019; 10: 685-94

6. Limper M, de Leeuw K, Lely AT, et al. Diagnosing and treating antiphospholipid syndrome: a consensus paper. Neth J Med 2019; 77: 98-108.

7. Zuily $\mathrm{S}$, Cohen $\mathrm{H}$, Isenberg $\mathrm{D}$, et al. Use of direct oral anticoagulants in patients with thrombotic antiphospholipid syndrome: Guidance from the Scientific and Standardization Committee of the International Society on Thrombosis and Haemostasis. J Thromb Haemost 2020; 18: 2126-37.

8. Cohen H, Efthymiou M, Devreese KMJ. Monitoring of anticoagulation in thrombotic antiphospholipid syndrome. J Thromb Haemost 2020; jth.15217. 



\section{DANKWOORD}

Mijn proefschrift was nooit tot stand gekomen zonder de hulp van anderen. Graag wil ik deze personen bedanken.

Allereerst wil ik mijn eerste promotor, Prof. Dr. Hugo ten Cate, bedanken dat u mijn promotor wilde zijn. Ook wil ik u bedanken voor alle hulp tijdens mijn promotie en met name bij het afronden van mijn proefschrift.

Tevens wil ik mijn tweede promotor, Prof. Dr. Katrien Devreese bedanken. Katrien, ik wil je ontzettend bedanken voor alle hulp en begeleiding vanaf het begin tot het einde van mijn promotie. Ondanks dat we op zo'n 160 kilometer van elkaar af werkten, voelde het alsof je om de hoek zat. Bedankt voor de reisjes die je maakte naar Maastricht en alle tijd die je in mijn proefschrift hebt gestoken.

Daarnaast wil ik mijn copromotor Dr. Bas de Laat bedanken voor de kans om te mogen promoveren. In 2012 begon ik aan mijn eerste stage bij Synapse, vier jaar later mocht ik beginnen aan mijn promotie. Ik kwam zenuwachtig binnen bij mijn sollicitatiegesprek om een promotieplek te bemachtigen en ging de deur uit met de keuze uit 3 promotieprojecten. Dankjewel voor je vertrouwen in mij. Je deur stond altijd open, of het nu om wetenschappelijk onderzoek ging of omdat ik mijn frustraties even kwijt moest. Bedankt voor de fijne samenwerking, je was een geweldige mentor.

I would also like to thank Prof. Dr. Yvonne Henskens, Prof. Dr. Chris Reutelingsperger, Prof. Dr. Erik Beckers, Prof. Dr. Stéphane Zuily, and Dr. Doruk Erkan for their assessment of my thesis.

Hilde, ik wil je ontzettend bedanken voor de begeleiding in de eerste twee jaar van mijn promotie. Je stond altijd voor me klaar en met jou als begeleidster hoefde ik me niet druk te maken om randzaken. Onze werktijden liepen niet per se synchroon, maar dat was voor jou geen probleem. Bedankt voor al je begrip, begeleiding en vertrouwen. Ik denk terug aan een mooie tijd.

Flip, bedankt dat je als emeritus professor nog elke week dat lange stuk naar het zuiden rijdt om je kennis en kunde te delen. Ook wil ik je bedanken voor de contacten die je voor mij legde en voor de feedback op al mijn manuscripten en presentaties. Marisa, ik wil je bedanken voor het nakijken van mijn stukken en de input die je hebt gegeven. Dankzij je (constante) motivatie ging het afronden van mijn proefschrift een stuk gemakkelijker en sneller. 
Met veel plezier heb ik als PhD student bij Synapse gewerkt en wil ik al mijn collega's bedanken voor de geweldige tijd. Dong-mei, thank you for the great collaboration we had in the multicenter study. Tessa, bedankt voor je hulp bij het zuiveren van $\beta 2 \mathrm{GPI}$. Dana, bedankt voor je hulp in het lab. Mark, Joke, Jasper, Cui, Erik, Yaqui, Adam, Veronica and Rob thank you for the nice talks during lunch and the positive work environment. Jun, thank you for the great time we had playing Ping Pong. Qiuting, Shengshi, Li, Siyu, Jinmi, and Rachel thank you for the nice talks and good luck finishing your PhD. Lisa, bedankt voor de gezelligheid tijdens de aio-cursussen, we gaan elkaar vast nog tegenkomen in de toekomst. Romy, bedankt voor de fijne samenwerking bij de APS studies. Cécile, dankjewel voor de gezelligheid tijdens de congressen. Caroline, bedankt voor alles wat je ooit voor me geregeld hebt. Trees, graag wil ik je bedanken voor alle hulp tijdens mijn promotie en bij het afronden van mijn proefschrift. Daarnaast wil ik alle stagiaires bedanken voor de fijne samenwerking.

I also had the pleasure to work with the Birmingham Platelet Group for six months in Birmingham (UK). Steve, I would like to thank you for the opportunity to work in your lab. I have learned a lot from you and your group. Pip, I could not wish for a better supervisor. Thank you for your help inside and outside the laboratory.

I would also like to thank all my co-authors for their contribution to my thesis. I could not have done it without you. Michael Luypaert, bedankt voor het meten van de antifosfolipiden antilichamen. Ik ben je eeuwig dankbaar, zonder jou was de multicenter studie niet zo'n succes geweest.

Altijd geïnteresseerd in mijn onderzoek en wetenschappelijke carrière en vooral trots. Je wilde er altijd alles van weten. Bedankt leef Patty. Dankzij jou heb ik geleerd waarom het belangrijk is om even stil te staan bij een mijlpaal.

Mijn grote en altijd gezellige familie wil ik natuurlijk ook bedanken. Met name mijn broers en zusje; Mo, Youssra, Soufiane en Jonayde. Bedankt voor jullie steun en interesse in mijn promotietraject, zonder jullie hulp was het niet gelukt. Hopelijk zal iemand van jullie ook promoveren, anders kan ik nog stiekem hopen dat Liyana, Lyam of Souhail hun oom zal volgen.

Lieve mama en papa, het was soms lastig om mijn onderzoek te begrijpen en wat een $\mathrm{PhD}$ nu precies is. Toch zag ik hoe trots jullie waren als ik een artikel gepubliceerd had of terugkwam van een congres. Hopelijk kan ik jullie in de toekomst nog trotser maken. 


\section{CURRICULUM VITAE}

Walid Chayouâ was born on 14 July 1993 in Heerlen, The Netherlands. In 2005 he started secondary school at Sintermeertencollege in Heerlen and received his HAVO degree in 2010 with the specializations Nature \& Health and Nature \& Technology. Subsequently, he studied Biology and Medical Laboratory Research at Zuyd university of Applied Sciences in Heerlen. After earning his bachelor's degree, Walid enrolled in the Biomedical Sciences master program at Maastricht University in 2014. He performed his master internship at the Department of Biochemistry at Maastricht University, where he studied the protective effect of aspirin and rivaroxaban upon endothelial denudation of the mouse carotid artery. After successfully completing his internship, he obtained his master's degree in 2016. In the same year, Walid started his PhD research at Synapse Research Institute, affiliated to Maastricht University, under the supervision of Prof. Dr. H. ten Cate, Prof. Dr. K.M.J. Devreese, Prof. Dr. P.G. de Groot and Dr. B. de Laat. During his PhD, Walid investigated the clinical importance of detecting antiphospholipid antibodies by immunoassays in the antiphospholipid syndrome. In 2019, he received the Harry Struiker-Boudier Award for Talented Academics (HS-BAFTA) fellowship to investigate the role of antiprothrombin antibodies in platelet activation at the University of Birmingham (UK). As a PhD student, he presented his research at various international conferences. After obtaining his PhD degree he will start his resident training in clinical chemistry at the Medisch Spectrum Twente (MST) in Enschede, The Netherlands. 



\section{PUBLICATIONS}

\section{Scientific publications in this thesis}

1. Kelchtermans H, Chayoua W, de Laat B. The Significance of Antibodies Against Domain I of Beta-2 Glycoprotein I in Antiphospholipid Syndrome. Seminars in thrombosis and hemostasis (2018) 44: 458-65.

2. Chayoua W, Kelchtermans H, Moore GW, Musial J, Wahl D, de Laat B, Devreese KMJ. Identification of high thrombotic risk triple-positive antiphospholipid syndrome patients is dependent on anti-cardiolipin and anti- $\beta 2$ glycoprotein I antibody detection assays. Journal of Thrombosis and Haemostasis (2018) 16: 2016-23.

3. Chayoua W, Kelchtermans H, Moore GW, Gris J-C, Musial J, Wahl D, Zuily S, Gianniello F, Fontana P, Remijn J, Urbanus RT, de Laat B, Devreese KMJ. Detection of anti-cardiolipin and anti- $\beta 2$ glycoprotein I antibodies differsbetween platforms without influence on association with clinical symptoms. Thrombosis and Haemostasis (2019) 119: 797-806.

4. Chayoua W, Kelchtermans H, Gris J-C, Moore GW, Musial J, Wahl D, de Groot PG, de Laat B, Devreese KMJ. The (non-)sense of detecting anti-cardiolipin and anti- $\beta 2$ glycoprotein I lgM antibodies in the antiphospholipid syndrome. Journal of Thrombosis and Haemostasis (2020) 18:169-79.

5. Yin D, Chayoua W, Kelchtermans H, de Groot PG, Moore GW, Gris J-C, Zuily S, Musial J, de Laat $B$, Devreese KMJ. Detection of anti-domain I antibodies by chemiluminescence enables the identification of high-risk antiphospholipid syndrome patients: A multicenter multiplatform study. Journal of Thrombosis and Haemostasis (2020) 18: 463-78.

6. Chayoua W, Yin D, Kelchtermans H, Moore GW, Gris J-C, Musial J, Zuily S, ten Cate H, de Laat B, Devreese KMJ. Is there an additional value in detecting anti-cardiolipin and a 32 glycoprotein I IgA antibodies in the Antiphospholipid Syndrome? Thrombosis and Haemostasis (2020) 11: 1557-68.

7. Chayoua W, Nicolson PLR, Meijers JCM, Kardeby C, Garcia-Quintanilla L, Devreese KMJ, de Laat B, Watson SP, de Groot PG. Antiprothrombin antibodies induce platelet activation: a possible explanation for anti-FXa therapy failure in patients with antiphospholipid syndrome? Submitted

\section{Other Publications}

1. Spronk HMH, Padro T, Siland JE, Prochaska JH, Winters J, van der Wal AC, Posthuma JJ, Lowe G, d'Alessandro E, Wenzel P, Coenen DM, Reitsma PH, Ruf W, van Gorp RH, Koenen RR, Vajen T, Alshaikh NA, Wolberg AS, Macrae FL, Asquith N, Heemskerk J, Heinzmann A, Moorlag M, Mackman N, van der Meijden P, Meijers JCM, Heestermans M, Renné T, Dólleman S, Chayouâ W, Ariëns RAS, Baaten CC, Nagy M, Kuliopulos A, Posma JJ, Harrison P, Vries MJ, Crijns HJGM, Dudink EAMP, Buller HR, Henskens YMC, Själander A, Zwaveling $S$, Erküner O, Eikelboom JW, Gulpen A, Peeters FECM, Douxfils J, Olie RH, Baglin T, Leader A, Schotten U, Scaf B, van 
Beusekom HMM, Mosnier LO, van der Vorm L, Declerck P, Visser M, Dippel DWJ, Strijbis VJ, Pertiwi K, ten Cate-Hoek AJ and ten Cate H. Atherothrombosis and thromboembolism: position paper from the second Maastricht Consensus Conference on Thrombosis. Thrombosis and Haemostasis. (2018) 118: 229-250.

2. Chayouâ W, Yin D, de Groot P, Zuily S, Wahl D, de Laat B, Kelchtermans H. Brief report on the 11 th Meeting of the European Forum on Antiphospholipid Antibodies. Current rheumatology reports (2019) 21:1-6.

3. van der Vorm LN, Li L, Huskens D, Chayouâ W, Kelchtermans H, de Groot PG, Roest M, Remijn JA, de Laat B. Analytical characterization and reference interval of an enzyme-linked immunosorbent assay for active von Willebrand factor. PLOS ONE (2019) 14(2):e021196.

4. Mastenbroek TG, Karel MFA, Nagy M, Chayoua W, Korsten EIJ, Coenen DM, Debets J, Konings J, Brouns AE, Leenders PJA, van Essen H, van Oerle R, Heitmeier S, Spronk HM, Kuijpers MJE, Cosemans JMEM. Vascular protective effect of aspirin and rivaroxaban upon endothelial denudation of the mouse carotid artery. Scientific Reports (2020) 1: 19360.

\section{Oral presentations}

1. Chayoua W, Multicenter study on solid phase assays: role of IgG and IgM antiphosphatidylserine/prothrombin (aPS/PT) antibodies in APS. The Scientific and Standardization Committee (SSC) 2020 Virtual Congress (June 2020).

2. Chayoua W, The Role of IgM in APS. International Congress on Antiphospholipid antibodies. Manchester, UK (September 2019).

3. Chayoua W, Do the role of isotypes and antibody profile of antiphospholipid antibodies differ for thrombosis and pregnancy morbidity? SSC, Melbourne, Australia (July 2019).

4. Chayoua W, Multicenter study on solid phase assays: role of IgA antiphospholipid antibodies in APS. SSC, Melbourne, Australia (July 2019).

5. Chayoua W, The Added Value of Anti-cardiolipin and Anti-b2glycoprotein I IgM Antibodies in the Antiphospholipid Syndrome, a European multicenter study. International Society for Laboratory Hematology (ISLH), Vancouver, Canada (May 2019).

6. Chayoua W, The Added Value of Anti-cardiolipin and Anti-b2glycoprotein I lgM Antibodies in the Antiphospholipid Syndrome, a European multicenter study. Dutch Society on Thrombosis and Haemostasis (NVTH), Koudekerke, The Netherlands (April 2019).

7. Chayoua W, Is there an added value of IgM: Results from a multicenter study. European Forum on Antiphospholipid Antibodies, Maastricht, The Netherlands (September 2018).

8. Chayoua W, Role of IgM in APS: The Solid Phase Assay Multicenter Study. SSC, Dublin, Ireland (July 2018).

9. Chayoua W, The identification of high risk APS patients for thrombosis with triple antiphospholipid antibody positivity is platform dependent. American Society of Hematology (ASH), Atlanta, USA (December 2017).

10. Chayoua W, First Results out of the Multicenter Study on the Role of IgM in APS. SSC, Berlin, Germany (July 2017). 
11. Chayoua W, A simple method to discriminate between anti-prothrombin and anti- $\beta 2$ glycoprotein I antibody induced activated protein C (APC) resistance. European forum on antiphospholipid antibodies, Nancy, France (April 2017).

\section{Awards}

1. The Harry Struiker-Boudier Award for Talented Academics (HS-BAFTA) fellowship, CARIM (2019).

2. Award for Scientific Excellence, NVTH (2019).

3. Trainee Travel award, ISLH (2019).

4. American Society of hematology (ASH) abstract achievement award (2018).

5. American Society of hematology (ASH) abstract achievement award (2017). 



\section{LIST OF ABBREVIATIONS}

\begin{tabular}{|c|c|}
\hline ABS & adult bovine serum \\
\hline $\mathrm{aCL}$ & anti-cardiolipin \\
\hline AID & autoimmune disease \\
\hline APC & activated protein $C$ \\
\hline aPL & antiphospholipid antibodies \\
\hline APS & antiphospholipid syndrome \\
\hline aPS/PT & anti-phosphatidylserine/prothrombin \\
\hline aPT & anti-prothrombin \\
\hline aPTT & activated partial thromboplastic time \\
\hline Arg & arginine \\
\hline AT & arterial thrombosis \\
\hline AU & arbitrary unit \\
\hline$a \beta 2 G P I$ & anti- $\beta 2$ glycoprotein I \\
\hline$\beta 2 \mathrm{GPI}$ & $\beta 2$ glycoprotein I \\
\hline BSA & bovine serum albumin \\
\hline CCP & complement control protein \\
\hline $\mathrm{Cl}$ & confidence interval \\
\hline CIA & chemiluminescence immunoassay \\
\hline CL & cardiolipin \\
\hline CLEC-2 & C-type lectin-like receptor 2 \\
\hline CRP & C-reactive protein \\
\hline DI & domain I \\
\hline DOAC & direct oral anticoagulants \\
\hline dRVVT & dilute Russell's viper venom time \\
\hline DV & domain V \\
\hline ECAT & external quality control of diagnostic assays and tests \\
\hline ECT & Ecarin clotting time \\
\hline ELISA & enzyme-linked immunosorbent assay \\
\hline EULAR & European league against rheumatism \\
\hline $\mathbf{F}$ & (coagulation) factor \\
\hline FBS & fetal bovine serum \\
\hline Gly & glycine \\
\hline
\end{tabular}


GP

HIT

Ig

ISTH

ITAM

LAC/LA

LDA

LMWH

LOD

LTA

mAb

NFKB

NPV

OD

OR

PAPS

PBS

PL

POC

PPV

PRP

PT

ROC

SAPS

SD

SLE

SSC

TBS

TIA

TLR4

TMB

VDRL

VKA

VT glycoprotein

heparin induced thrombocytopenia

Immunoglobulin

international society on thrombosis and haemostasis

immunoreceptor tyrosine-based activation motif

lupus anticoagulant

low-dose aspirin

low-molecular-weight heparin

lower limit of detection

light transmission aggregometry

monoclonal antibody

nuclear factor kappa B

negative predictive value

optical density

odds ratio

primary antiphospholipid syndrome

phosphate buffered saline

phospholipid

point-of-care

positive predictive value

platelet-rich plasma

prothrombin time

receiver operating characteristic

secondary antiphospholipid syndrome

standard deviation

systemic lupus erythematosus

scientific and standardization committee

tris-buffered saline

transient ischemic attack

toll-like receptor 4

3,3',5,5'-tetramethylbenzidine

venereal disease research laboratory

vitamin K-antagonists

venous thrombosis 

(2)

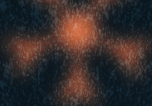

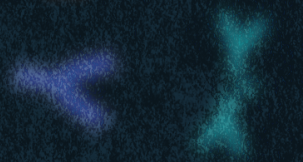

(3)

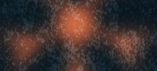
a.s.

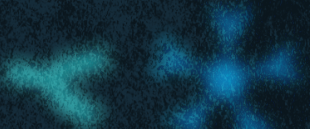
(5)

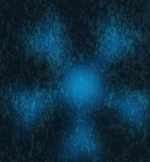
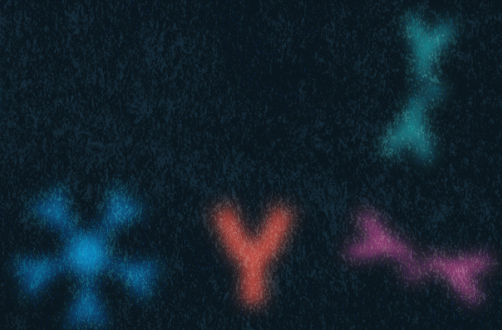

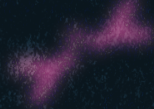

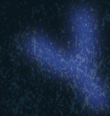

4.

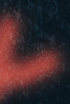

S.

(1).

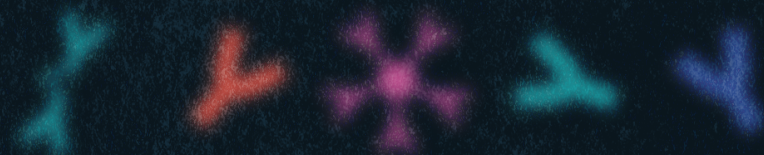

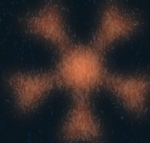

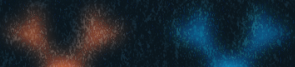

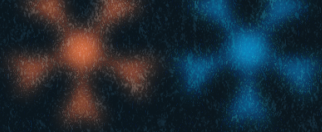

1.20

13

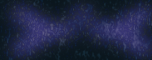

(2.)

(2).

1.

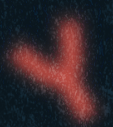

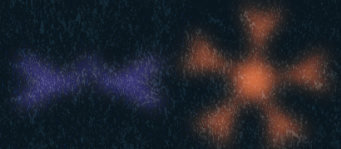

(2)

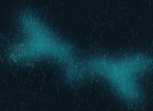

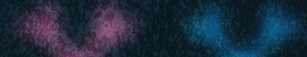

$\sin x+2 x$

(a) +2

10.

(2)

4.

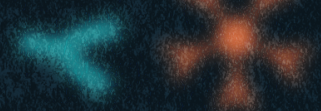

19.203

1.

(5)

(2.20 (x)

$\log (x)=$

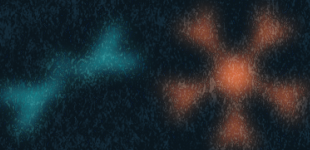

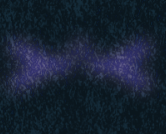

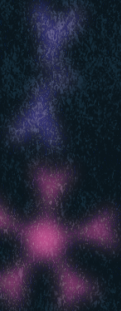

$x+x_{x \rightarrow 3}$

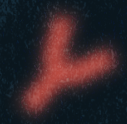

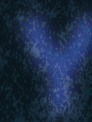

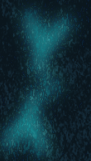

(2) $+2=$

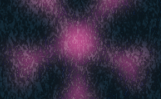

(2)

$\ln (x)=0$

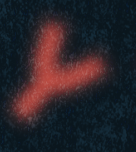

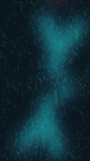

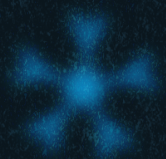

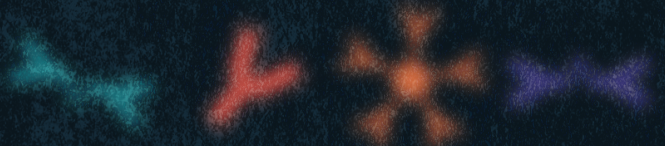

20

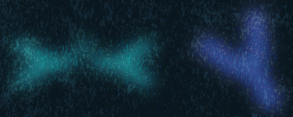

(4)

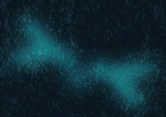

3)

(2)

$2+x^{2}+2$

$(-2)^{2}+x^{2}$

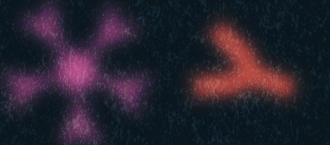

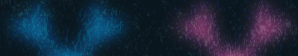
(2) 20. 